Portland State University

PDXScholar

Spring 6-4-2013

\title{
Developing the Instructional Leadership Skills of High School Principals in Tanzania: A Problem- Based Learning Approach
}

Peter N. Siamoo

Portland State University

Follow this and additional works at: https://pdxscholar.library.pdx.edu/open_access_etds

Part of the Educational Assessment, Evaluation, and Research Commons, Educational Leadership Commons, and the Elementary and Middle and Secondary Education Administration Commons Let us know how access to this document benefits you.

\section{Recommended Citation}

Siamoo, Peter N., "Developing the Instructional Leadership Skills of High School Principals in Tanzania: A Problem-Based Learning Approach" (2013). Dissertations and Theses. Paper 984.

https://doi.org/10.15760/etd.984

This Dissertation is brought to you for free and open access. It has been accepted for inclusion in Dissertations and Theses by an authorized administrator of PDXScholar. Please contact us if we can make this document more accessible: pdxscholar@pdx.edu. 
Developing the Instructional Leadership Skills of High School Principals in Tanzania:

A Problem-Based Learning Approach

by

Peter N. Siamoo

A dissertation submitted in partial fulfillment of the requirements for the degree of

\section{Doctor of Education}

in

Educational Leadership: Administration

Dissertation Committee:

Tom Chenoweth, Chair

Samuel Henry

Laurie R. Kash

Tucker Childs

Portland State University

2013 
(C) 2013 Peter N. Siamoo 


\begin{abstract}
Underachievement among secondary students in Tanzania is tragic: the
\end{abstract} failure rate on the national exams after the fourth year is between 65 to 100 percent (Mushi, 2011). The literature affirms that student learning is primarily improved by enhancing quality classroom instruction while the second most impactful strategy is consistent school leadership to ensure that effective practices are utilized in the classroom (Blase \& Blase, 2004; Chenoweth \& Everhart, 2002; Fink \& Markholt, 2011; Leithwood, Louis, Anderson, \& Wahlstrom, 2004; Leithwood, Harris, \& Strauss, 2010; Marzano, Waters, \& McNulty, 2005). Despite the research, the researcher's pilot study revealed that there is currently little or no oversight of classroom instruction in most Tanzanian secondary schools. This paradox yielded two research questions: 1. Can Tanzanian schools leaders improve the quality of classroom instruction in order to enhance student learning and performance by employing systematic, fair, and culturally relevant teacher evaluation techniques? 2. Are the teacher evaluation tools developed for American school systems suitable to serve the Tanzanian school system or must they be adapted into the Tanzanian cultural context?

Using a Problem-Based Learning [PBL] method, the researcher field-tested and refined The Curriculum for Training Secondary School Leaders, and a workshop in which it was taught. The workshop and its curriculum provided instruction in Evaluation and Supervision of Classroom Instruction (ESCI) to Tanzanian Head Masters and Mistresses (HMs), or as commonly referred to as principals in America, in an effort to develop their pedagogical leadership skills. During the workshop, HMs refined the 
American-designed evaluation tools to make them culturally relevant to a Tanzanian context. After attending the six-day intensive ESCI workshop, participants indicated in surveys that they felt capable of providing support and coaching to their teachers and capable of assisting teachers in their efforts to improve their pedagogical skills. The researcher provided additional workshops for teachers and HMs at their school sites to support educators in the implementation of ESCI. Qualitative research demonstrated teachers also had favorable post-workshop reactions to ESCI. Though the implementation of the product and training will be further assessed in 2014, the initial qualitative results from post-workshop surveys strongly confirmed that HMs developed confidence, skill, and competence in employing ESCI, thus increasing the likelihood that HMs would employ ESCI in their own schools in the year to come. 


\section{Dedication}

I would like to dedicate my dissertation work, first and foremost to my father Michael Siamoo, the hero of my life. Dad, I wish you were still with us to witness the maturity of what you planted long ago: passion, love, courage, hard work, and commitment to learning and serving! I believe even where you are with the Lord, you are smiling from above and are proud of what your youngest son has become. It is exactly what you wanted, although I am not sure if you ever dreamed that I would get that far as being a Doctor! Yes dad, I made it, I will do more than this, and I want to deeply thank you. With you, this work is dedicated also to my mother Mary Siamoo and my family, whom I truly love. Second, I want to dedicate this work to all the secondary school students of Tanzania, particularly those who have been failed in the current school system. Their pain was my driving force to do this work. To you I will advise; don't waste your time complaining. Be creative and look for alternative ways to make your life worth living.

I also dedicate this work to all school leaders, and in particular, to the current Headmasters and Headmistresses of the Catholic Diocese of Moshi, as well as to all private and public secondary schools in general, all of whom work so hard to make schooling possible despite the lack of adequate funds to run the schools. The stories of their struggles assured me that this work is a worthy endeavor despite its challenges, and its value is priceless because quality education is priceless. I also dedicate it to the teachers who work tirelessly each day to provide a quality education for all students they are privileged to serve. This work was done with you in mind, to equip your leaders who 
will support, coach, and help you to improve your pedagogical skills and become even better quality educators. I have learned through experience that a quality teacher is like a good book in the library. It is always in the hands of a reader. Please, strive to be one for we truly need you. The future of our country and our world is in your classrooms. From the poorest of countries to the richest of nations, education is the key to moving forward in any society. My assumption is that the value of your work is well reflected in the two famous quotes of the former Southern African President, Nelson Mandela, who said:

Education is the most powerful weapon which you can use to change the world. Education is the great engine of personal development. It is through education that the daughter of a peasant can become a doctor, that a son of a mineworker can become the head of the mine, that a child of farm workers can become the president of a nation.

This dissertation is also dedicated to my former students, who helped me to realize my ability as a passionate, quality teacher. Their appreciation back then and now, clearly tells me that I made a positive difference in their lives and that is what I want every educator to do. Lastly, it is to you my nephews and nieces. I have set a high bar for you. With good education, nothing can stand between you and what you want to become. The great human virtues of compassion, love, courage, hard work, and commitment to learning and serving, we all learned from your grandfather Michael Siamoo. Allow them to define you. The words of Steve Jobs sum it up well for you here: "Stay Hungry. Stay Foolish." The rising school expense is not an excuse for you not to have quality education. To you and in fact to all who will ever read this work, I challenge you with the words of Derek Bok: "If you think education is expensive, try ignorance!" If I made it this far, you can! I love you all. 


\section{Acknowledgments}

I owe an immense debt of gratitude to God, who has blessed me so profoundly that my life has been like a series of wonderful movie trailers! God has orchestrated my life path and put in my way incredible people at the right time, who have made my life both enjoyable and interesting. I would like to thank my parents, Michael and Mary Siamoo, for instilling in me the love of God and people, the love of education, hard work, and always to be ready to serve and help. They taught the secret of greatness. As my father used to say, "Greatness is not in what you gain, but in what you give. Always be part of a solution, otherwise you are part of the problem!" They taught me to have faith in God and in myself. This unique strength in me was recognized early on by my peers that in every stage of my education, from grade school to college I was always elected a leader. I now realize it was the product of what my parents instilled in me. I want also to thank my great aunt Benedicta Siamoo who just turned 107 on March 2012, for her ceaseless prayers. Thanks to my siblings: Dominick, Simon, Benedict, Fr. Patrick and Gerard, along with their wives and children. It has not been easy for me to be away from my family for such a long time. And yet, they were always there to pray and encourage me to move on!

I want to thank Mr. Richard Jusseaume, the president of Walsh University, Canton, Ohio. This man inspired me as a leader by his courage and boldness to face hard situations. He believed in me and made me make history at that university, being the first to do three Master degrees in Education, Theology and Clinical Counseling in less than four years. He was the main reason I was able to do it. I am also thankful to staff and the 
community of St. Pius X Catholic Church in Portland for their spiritual and material support. Thanks to Tom English for reading the first draft and for his suggestions. I am sincerely grateful to the late Right Rev. Amedeus Msarikie, the former bishop of Moshi for seeing my potential and giving me a chance to broadly and widely explore the world of education. I am profoundly grateful to my former teacher and now my current bishop, Right Rev. Isaac Amani for believing in me. He is my role model of a caring teacher and an inspirational leader. I have benefited greatly from his high standards of leadership, expectations, and accountability. Bishop Amani’s high quality leadership style and his dedication to professionalism have not only inspired, but also challenged me, to always strike higher and never be content with mediocrity. He has been incredibly supportive and patient with me as I continue to pursue my thirst for education. I am deeply grateful to Tom Chenoweth, $\mathrm{PhD}$, my professor and a great advisor for his tireless support, challenge, corrections and providing solutions whenever I felt as though I were stuck. He is truly a role model of a passionate educator and a resourceful leader. His sea of knowledge and experience topped with his passion for education is inexhaustible. His trip to Tanzania in 2011 made him "a kind of insider of my work" and so all the more a resource for me. His readiness to help and answer questions was instrumental in making this work possible. Dr. Chenoweth taught me the beauty of Problem-Based Learning and the Research and Development process, as a practical way to solving the current education problem in Tanzania. I would like also to thank my committee members, Dr. Samuel Henry, Dr. Laurie Kash, and Dr. Tucker Childs for their readiness to help me, change their schedules to meet my needs and their excellent 
suggestions and thought-provoking questions. I have learned from their deep knowledge and experience, from their work and their influence that have shaped this dissertation. Special thanks to Dr. Laurie Kash for taking time to edit this work and for her recommendations that shaped this work and added its quality. She joined my dissertation committee at the last minutes, but she was incredibly resourceful and helpful.

My sincere thanks to my classmate and best friend, and the superintendent of Moshi Catholic schools Fr. William Ruwaichi. His support and cooperation helped to ease my way and made this study possible. Thanks to all the 24 school leaders who participated in the main field testing of the Performance-Based Learning module. I learned a lot from their commitment, experience and desire to learn.

I no longer believe in coincidence, rather I believe in providence! Being in the cohort of such dedicated, wonderful educators and seasoned administrators was providential and a blessing to me. I had the pleasure to be part of such a fine team of my colleagues without whom I cannot imagine this work would be possible. Their support, encouragement, challenge and going the extra mile to make sure we are all on board to meet our deadlines were priceless. So, I am sincerely thankful to my cohort members: Brian Sien, Carol Campbell, Dan Huld, Paul Coakley, and Teri Tilley. If you have never worked with fine individuals who are dedicated, inspiring, and energizing with such great positive attitude, you need to meet these folks! Being the only international student in the cohort, they reached out to meet my needs and made me feel quite at home. They made me love and look forward to a pro-seminar class meeting. I could not ask for any better team to work with, and I will surely miss them! 
Table of Contents

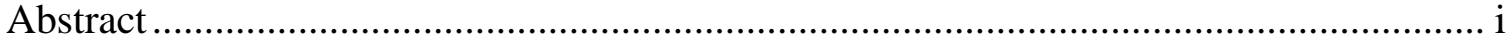

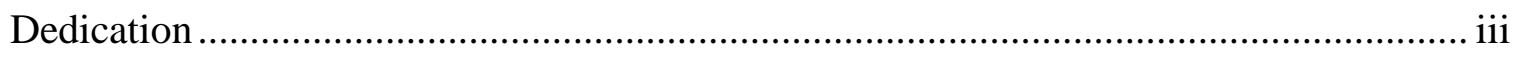

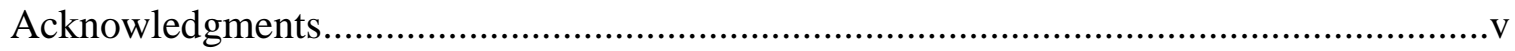

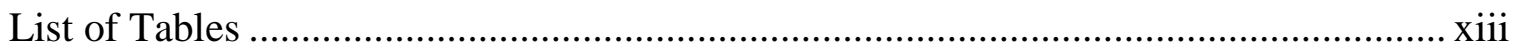

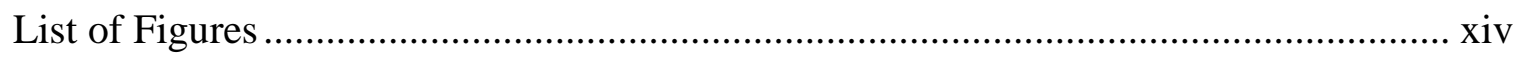

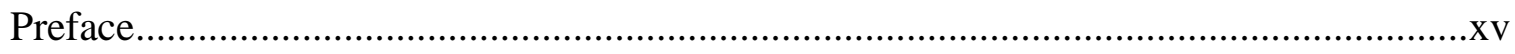

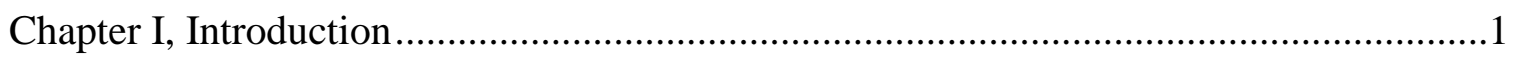

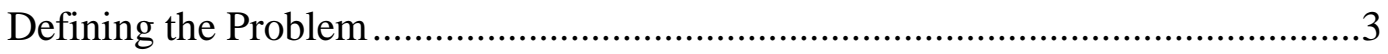

Tanzania: Location and the History of the Land …......................................

The Structure of Tanzania School System .................................................

The Problem Statement, Its Relevance, and Attempted Solutions ......................11

Rationale for Studying the Problem........................................................... 15

Research Design and Methodology ......................................................... 18

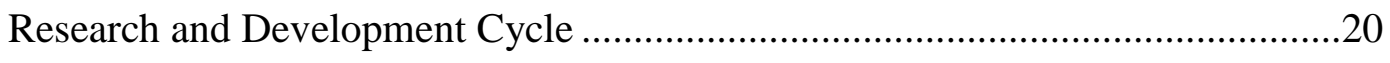

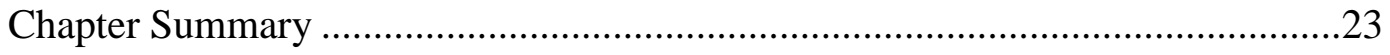

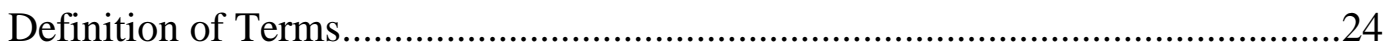

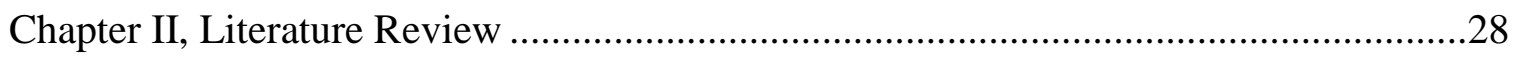

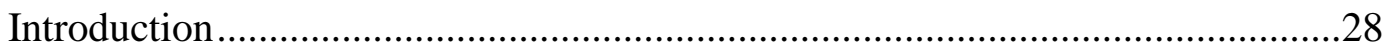

A Brief History of Education in Tanzania; Evaluation and Supervision ...............28 Pre-Colonial Education: Up to 1870s

Early Colonial Period: 1880-1918 
Later Colonial Period-Trusteeship Period: 1946-1961

Post Independence: 1961 to Present

Current Situation of Student Achievement: The Study Problem

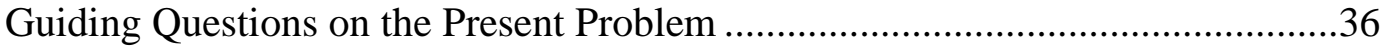

Quality Teaching Matters Most for Student Achievement ..................................37

Lacking Leadership skills for Tanzanian School Reform

Attempted Solutions and Claims for a New Approach

Standardized Curriculum for All Schools

Mandated Teacher Training Programs in Colleges

The Student-Centered Pedagogical Policy

Attempted ESCI: Why it Failed and What it Should Be

The New Approach: PBL Module for Instructional Leadership

ESCI: The Leadership Tool for Quality Teaching and Learning

Clinical Supervision

Theory and Practices: Transformational and Instructional Leadership Models

Chapter Summary

Chapter III, Research Design and Methodology........................................................59

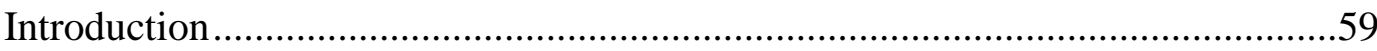

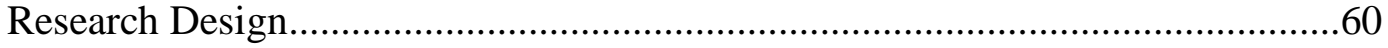

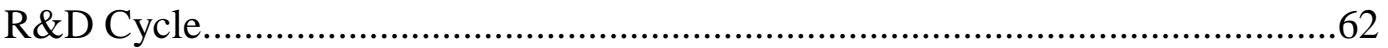

Preliminary Work: Research and Information Gathering

Planning: Objectives, Learning Activities, and Small Scale Testing

Preliminary Program/Product Development

Preliminary Field Test

Main Program/Product Revision

Main Field Test

Operational Product Revision

Action Plan and Timeline

Research Questions: Primary and Secondary

Data Collection

Data Analysis

Ethical Guidance: Bias and Position of Power 


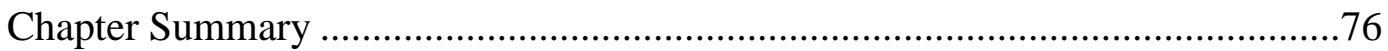

Chapter IV, PBL Research Study: Analysis and Findings ............................................78

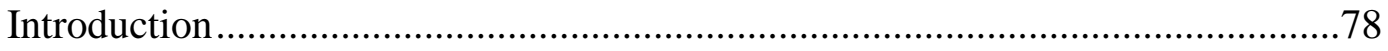

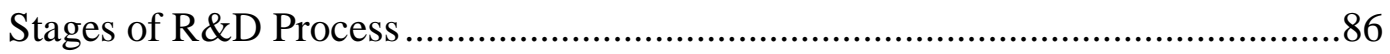

Step 1: Research and Information Collection

Step 2: Planning Objectives, Learning Activities, and Small-Scale Testing

Step 3: Developing Preliminary Form of the Product

Step 4: Preliminary Field Testing

Step 5: Main Product Revision

Reflective Knowledge From Step 5

Step 6: Main Field Testing

The Relevancy of Adapting the Tool

Findings: The Changes Made to Make Danielson's Tool Culturally Relevant

Demonstration of the Findings

Suggested Solutions: Danielson Teacher Evaluation Model

Step 7: Operation Product Revision

Research Questions .136

Evaluation of the PBL Module Effectiveness: The Analysis of Words 136

Knowledge or Skills

Participants' Competence and Confidence

Motivation

Conviction

Participants' Expectations: Were They Met or Not?

The PBL Module and Leadership Improvement

Implications of Training Outcomes

Participants' Self Awareness

Exercise of Leadership During the Study

School Visits: Teachers' Short Seminar

Overall Personal Experience of the Process .158

PBL and Its Benefits

Conclusion 162 
Chapter V, The Future of PBL Module and Recommendations 165

Introduction

Future Implications of the PBL Curriculum

167

R\&D Steps 8 \& 9: Operational Field Testing and Final Product Revision

Step 10: Dissemination and Implementation

Use PBL Module to Train HMs of Other School Districts

Use PBL Module to Train Teachers on ESCI

PBL Module and Annual Leadership Professional Development

University Curriculum for Future HM Training

Creating Leadership Collaboration and Support

Setting High Leadership Standards and Expectations

Recommendations to School Leaders and Researchers

To Build HMs' Instructional Leadership Capacity

Using PBL Module Procedure and Its Intended Outcome

Conclusions

PBL Module Can Improve Instructional Leadership of HMs

PBL Module Can Make HMs Academic Reform Agents

Self-Awareness, Leadership Responsibility, and Commitment

Resources and Collaboration Among the Participants

Knowledge, Confidence, Competence, and Motivation for Doing ESCI

References

Appendices

A National Exam Results of Moshi

B PBL Curriculum

C Pilot Survey Questionnaire

D Pilot Survey Letter to the HMs

E Invitation Letter for the HMs to Participate in the Study

F A Letter to the Superintendent.

G Workshop Protocol 


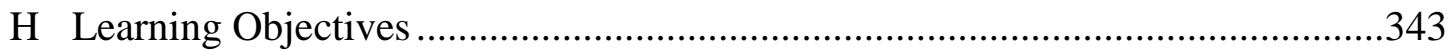

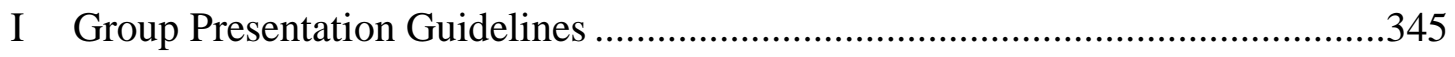

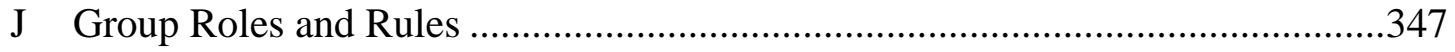

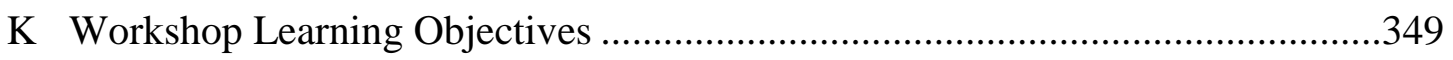

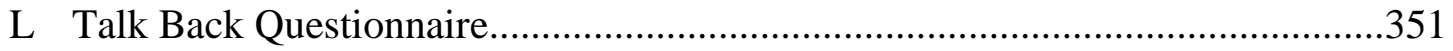

M Danielson Adaptation Process Guidelines .............................................................353

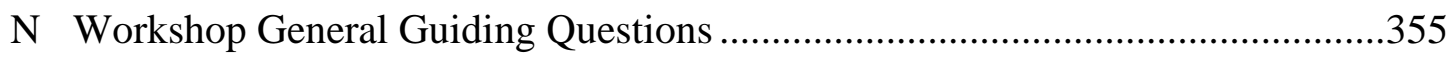

O Course Overview: Purpose of the Workshop......................................................357

P Brainstorming Questions: Prior Knowledge and Anticipation ..............................359

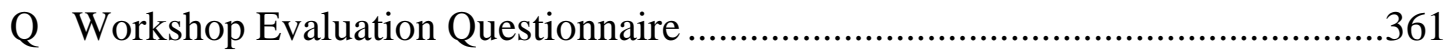

R Participants' Expectations and Their Fulfillment: Assessment ............................365

S Evaluation of Content and Presenters ..................................................................371

T Adapted Danielson Evaluation Rubric..............................................................373

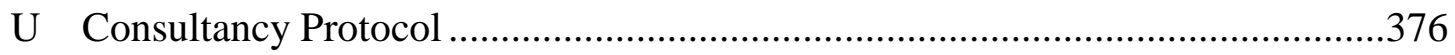

V Formative Assessment: Filled Form Sample .......................................................378

W A Completed Sample of the Workshop Evaluation Form ...................................380

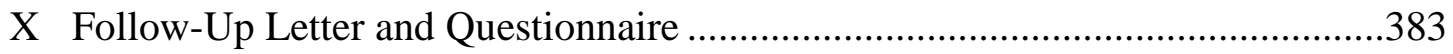

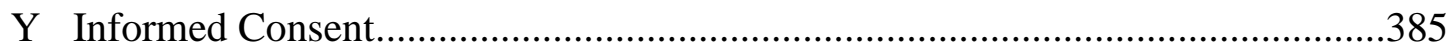

Z Pictures of the Workshop Hall Group and Retreat House ....................................387 
$\begin{array}{lll}\text { Table } & \text { List of Tables } & \text { Page }\end{array}$

1 Different Kinds of Secondary Schools in Tanzania ......................................10

2 Moshi Catholic School Leadership Challenges as Expression of 2011 Pilot

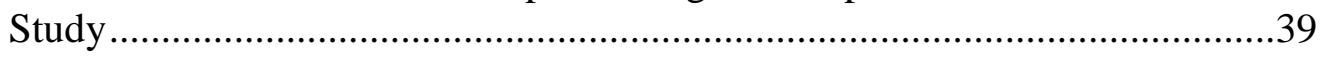

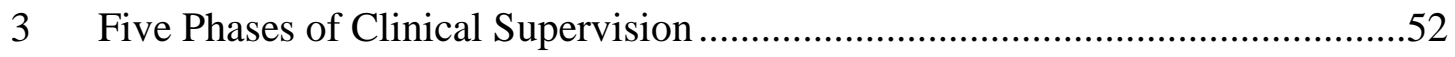

4 The 4-I's of Transformational Leadership and ESCI ....................................54

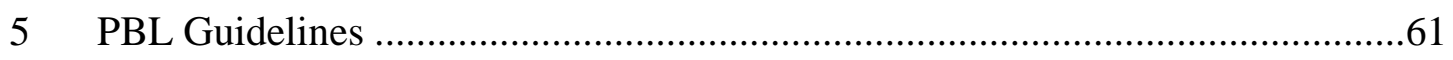

6 The Workshop Schedule, Group Activities, and Course Objectives..................91

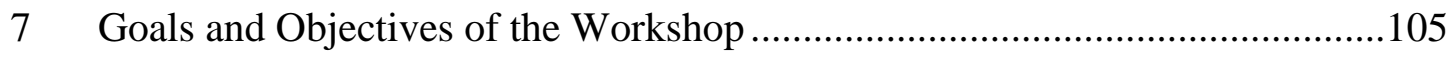

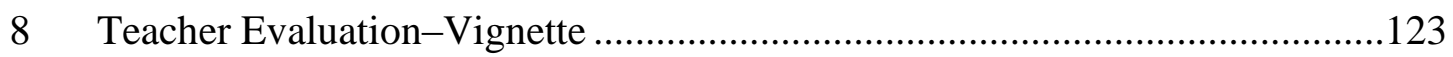

9 Pre-Workshop Self-Assessment on Knowledge/Skills to Conduct ESCI .........137

10 Post-Workshop Self-Assessment on Knowledge/Skills to Conduct ESCI........138

11 Pre-Workshop Levels of Competence and Confidence ...............................140

12 Post-Workshop Levels of Competence and Confidence ................................141

13 Pre-Workshop Levels of Motivation to Conduct ESCI.................................142

14 Post-Workshop Levels of Motivation to Conduct ESCI ................................143

15 Participant Pre- and Post-Workshop Expectations .......................................146 


\section{List of Figures}

Figure

1 School Leadership Operation to Improve Student Achievement .........................5

2 Conceptual Framework of Leadership and Teacher Interaction .......................18

$3 \quad$ Vision of Leadership for Student Achievement ...........................................47

4 A Conceptual Representation of ESCI and student achievement .....................50

$5 \quad$ The Marshall's Teaching Domains and Two Leadership Models.......................57

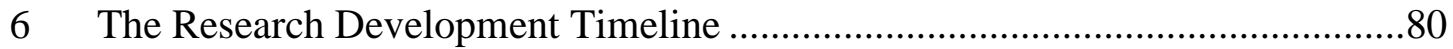


Preface

\section{A New Headmaster's Personal Story: What to Do About Improving Student Learning}

When I met Edwin, he was new in his role as a secondary/high school

headmaster/principal of Amka Secondary School. The following is a true story of Edwin

that gives an account of his experience as he wrote it himself:

I was the assistant headmaster, or second master, of Osale secondary school for four years. I had a full class load. I was teaching History and Civics in three different classes, and I also enjoyed sharing administrative duties as I assisted my headmaster, Mr. Busara. I felt honored to work with him because of his rising reputation as a school leader. Mr. Busara came to Osale Secondary school when the school could be compared to a "day care center," where boys and girls came after primary education and spent their four years there growing up with no hope of academic advancement and brighter future. The school is complex and coeducational, combining commuting and boarding for boys and girls with an enrollment of 490 students. In the 1980s and 1990s the school achievement was among the lowest 50 of 2,428 schools nationally when Mr. Busara was appointed headmaster. He had six years of teaching experience and looks very young. After four years under his leadership, the school turned around. Osale was among the top 160 of 3,108 schools in the country. This was huge improvement. Some of the things he did were leading by example: he was never late without a serious reason, and whenever he had one, he communicated it to the staff. He was physically present in school, very supportive, although a bit tough and authoritative on the staff. The academic improvement made every teacher proud to be there. In response to this, student achievement improvement and enrollment increased to its full capacity, which in turn stabilized the school financially. Although I was playing a secondary and supportive role, I enjoyed being part of this change.

Before I knew it, I received a letter from the Director of Education of the Catholic Diocese of Moshi, appointing me as a new Headmaster of Amka Secondary School. This process of teacher promotion into leadership roles was typical. While to my colleagues this promotion was something to celebrate, to me it was the most challenging and somewhat scary thing I ever imagined. I had ambivalent feelings and thoughts: On one hand, I felt honored to be trusted with this task; I thought it was a good opportunity to serve by shaping the future of Tanzania's youth. I would be the man with the final say in the building including being accountable to the school board, the Director of Education of Moshi Diocese and the Ministry of Education. On the other hand, I felt I was not ready for such a 
daunting task. I wondered, "Does any teacher ever become ready to be a leader without any prior training for their new leadership roles?" Like the rest of the headmasters, I did not have formal training for school leadership other than the few classes I took in college. Since almost all the headmasters I know, including Mr. Busara, had the same, I took courage and signed the letter of acceptance. I was given only three weeks to pack my belongings and move to my new school. My wife and my son remained in my former school since she was also teaching there. We decided that we would process her transfer later after we got settled. I was absolutely shocked when I first came to Amka Secondary School and toured the school. I knew the school only externally, with sky blue and brown classrooms. Getting in, I could not believe what I was watching. I regretted signing the letter of acceptance. I did not know what I was getting into. For the last four years, the school had a failure rate of over $80 \%$. The student population had dropped from 380 to 122 in the last three years. The reason was clear: parents did not want to pay to send their children to a school where they were almost certain the school would shatter their life dreams. The drop of student enrollment left the school with severe financial problems. Student living conditions were horrible. They had water rationing, they did not have a suitable latrine, and the roofs of some dorm rooms were leaking. This is hard especially for students in a boarding coeducation school like Amka. I don't know how parents who brought their Form One students [freshmen] dared to leave their children in this kind of environment. I wondered if I should quit before I had even begun the job. But the position I had at Osale had already been filled. I tried to consult some well-known headmasters and headmistresses, asking about where to begin. The common response was: "You have to figure it out and use your own wits!"

My hope came from the teachers and students. Talking to them, I found the students' spirits were still very high; they were hard working and loved to learn. They were very cooperative, disciplined, and obedient. They were convinced they could change the history and their "failure school" reputation. Teachers worked hard. They never missed their lessons, they were on time, and they seemed enthusiastic and optimistic. Some spent unpaid overtime in order to offer extra help to their students. They were aware of their instructional struggles as they tried to implement the new "learner-centered pedagogical approach" of the Ministry of Education. I thought, "If students are committed to learn, and teachers are working hard, why is student achievement so low? How can I help them?" I knew one thing teachers were struggling with across the district was how to implement the new constructivist pedagogical model also known as "studentcentered pedagogy." I did not know how to help them with their struggle since this teaching model was new to everybody. My question of why this level of hard work and optimism was not reflected in student achievement, as measured by the national exams, had not been answered yet. I was sure something must be wrong somewhere. I knew teachers, students, parents, and the school board were looking up to me, hoping I would have something to offer to improve student 
achievement. I spent many sleepless nights wondering, among many factors, what influences student achievement most? I really needed some help!

Recalling my experience as a vice Head Master (HM) and what Mr. Busara did at Osale, I remembered two things: one was the evaluation of classroom instruction. Busara tended to visit teachers when they were teaching, especially those whose students were not doing well on the national exams. Often, he did not talk to them after his visit, which made teachers nervous wondering, "What is he after in my class, playing 'gotcha'?" Sometimes he would point out a few areas for improvement like poor classroom management or a lack of clear focus in the lesson. He would charge the teacher to correct those things or else they would face the consequence! This was a top-down model, authoritative, and somewhat threatening. Teachers, including me, hated it. I thought it was humiliating and did not give teachers room to improve and grow professionally.

The second thing I remember was his policy of rewarding teachers for every " $\mathrm{A}$ " students made in their subjects on the national exam. This created competition among teachers at the expense of collaboration. The worst part of this system was that teachers paid more attention and spent more time helping potential " $\mathrm{A}$ " students at the expense of struggling students. Despite these flaws, I would like to imitate this approach since it increased the school's performance. However, I am afraid that the top-down style will set my teachers off, and I need their cooperation. I cannot afford to lose their support under the current school structure. I also do not have money to run the school for this semester, let alone give incentives to the high-performing teachers. I know if I could help improve teaching and learning, my students would do better on their national tests. Is there any other way of improving classroom instruction and learning in order to increase student achievement?

While the school board and my boss, the Diocesan Director of Education, had promised me support, the task they entrusted to me was enormous. The school board was fund raising to improve the students' living conditions and the school environment. Their effort was supported by a group of American visitors including Dr. Tom Chenoweth from Portland State University, whose donations helped to renovate the boys' dormitory. The Director of Education of the Moshi Diocese agreed to give the school a loan in order to ensure the school could remain open for the remainder of the semester. Everyone was looking at me to see what I would do to reform and resurrect the academic life and achievement of our students and rescue this sinking ship-Amka! Can anyone help?

Edwin is one of many school leaders who sees the need to improve student achievement, but he does not know how. He is determined to make a change. He has passion for his job, and wants to do the right thing. He wants his students to thrive, and 
he also knows his limitations. He is longing for help. His quest to improve student achievement is real. He just needs some help determining how leaders can learn in order to realize their goal of improving student learning and achievement.

The story highlights the main problem of Amka Secondary School. Student underachievement on the national exams is an indication of the main problem. The Headmaster knows the problem. His narration indicates that he also knows that the problem is caused by the inadequate teaching methods of his teachers. Teachers have a strong work ethic shown by how hard they work, some spending unpaid overtime to help their students. But the outcome of their work is not proportional to their effort; they seem to be helpless as they do not know what to do.

The HM understands that his teachers are struggling and are longing for help, but he similarly does not know how to help them. Students and their parents are hopeful that the HM will lead the changes needed to turn things around for student learning and success. They all have the same goal: to improve student learning. I sought to find how school leaders like this can learn how to improve student learning and achievement.

My goal was to create a Problem-Based Learning training module or curriculum that would educate the Headmasters/Headmistresses (HMs) on how to help their teachers to improve their pedagogical skills. Knowing that the Tanzanian HMs are promoted to a school leadership position from a teaching career without undergoing any further leadership training, their good intentions and hard work are not enough to influence the needed reform to improve student quality learning. Leadership skills are also needed; 
new HMs need to learn how to coach, support, and help their teachers. They need to identify the necessary tools and employ them in the classroom.

I was also strongly convinced that for the HMs to be successful as reform leaders, they had to know how to rally their staffs to form a vision and mission in their schools, inspire the staff to commit to working to achieve the common school goal of improving student learning. This kind of leadership calls for HMs to learn the Transformational Leadership skills that are necessary to influence their staffs to have new thinking and strategies (J. R. Blase \& Blase, 2004). This is achieved more effectively through Transformational Leadership than more traditional means because it emphasizes the interpersonal relationships between teachers and leaders and helps them to execute a shared vision.

Mr. Busara the HM of Osale, himself a visionary of sorts, deserves some credit for attempting to use ESCI even if the process was not that successful. Much can be learned from his attempt. First, ESCI works; as Busara commented, "I know it is not popular but it works." There was a substantial improvement in student performance in his school even there was a sacrifice of morale. Due to poor staff morale, student achievement is likely to be short lived, therefore, there is a better way of doing ESCI than Busara did. Using the authoritative top-down model made the process distasteful and so disliked by the teachers and unattractive to other HMs like Mr. Edwin, who would like to try it. His inconsistency in giving feedback made his ESCI ineffective and unpredictable (Marshall, 2003), enemies to teacher satisfaction and security. 
Mr. Edwin, like many others, cares for his students and hopes to do something that would help his teachers and students raise the academic standard of his school. As an educational leader, he is responsible for managing policies, regulations, and procedures to ensure that all students are provided a safe learning environment that meets both the ministry and diocesan standards. Leaders in the Catholic schools have an even stronger moral obligation inherent in their faith as taught by the Bible and the social teaching of the Catholic Church, in which education is termed as one of the inalienable rights of every human (Flannery, 1999). It is my belief that it is the responsibility of every HM is to guarantee that every student is given access to quality learning that will establish a solid foundation for a future as a good citizen. This responsibility is also extended to teachers, regardless of their belief or faith tradition. Doing nothing is not an option while the students' basic right of education is violated. 


\section{CHAPTER I}

\section{INTRODUCTION}

The true story of Edwin as a secondary school Headmaster facing overwhelming leadership challenges, represents the challenge of school leaders in Tanzania. More than half of secondary school students fail the national exam given at the end of the fourth year. Headmasters are aware of the problem; however, like Edwin, they do not know what to do. Parallel to this, school leaders do not normally evaluate and supervise teachers with a goal of helping them to improve the quality of their teaching. In this chapter, I explain why it is crucial for HMs to evaluate and supervise classroom instruction and demonstrate its relationship with quality teaching and learning.

Generally, Headmasters/Headmistresses (HMs) and their teachers are frustrated with their schools' performances. The parents and students who are failed by the current school system are equally discontent. HMs reportedly have made attempts to solve the problem by implementing policies from the Ministry of Education. No single policy has proven effective, however, adding to their frustration and suggesting that something new is needed. This study presents that something new: it provides a new way of looking at and addresses the problem of student performance. This chapter briefly highlights the attempts made not only by some HMs but also by the Ministry of Education of Tanzania to solve this problem without much success. The full account of these attempts are given in chapter 2. Before ending this chapter with definitions of key terms and a chapter summary, I briefly explain the research design and methodology of this dissertation, 
which is an implementation of the Curriculum for Instructional Leadership Training for High School Principals of Tanzania through a Problem-Based Learning (PBL) approach. The detailed analysis of the research methodology is explored in chapter 3. Analysis of qualitative data is described in chapter 4 , and the future of this research is discussed in chapter 5 .

After conducting research in the literature about the problems of student achievement, I posed questions in surveys and interviews to HMs in a pilot study in 2011 to determine what they perceived were the issues surrounding student achievement (see Appendix C). After reviewing their responses, I returned to the literature to develop curriculum to inform the instructional leadership practice of the HMs. After practice field testing the curriculum guide, I returned to Tanzania in 2012 to field test the curriculum, and conducted a 6-day workshop with 24 HMs of the Moshi Diocese Secondary Schools or their representatives. In the workshop, HMs learned instructional leadership skills related to improving the quality of teaching and learning through teacher evaluation and supervision, thus implementing through role play during field testing the PBL Training Module I had created. The PBL Module adapted Danielson's (2007) rubrics of teacher evaluation framework. Other evaluation tools such as clinical supervision, mini evaluation, and informal "Walk Through" evaluation were briefly explored (Acheson \& Gall, 2003; Danielson, 2007; Downey et al., 2009; Marshall, 2009).

In the process of adapting Danielson's (2007) evaluation tool, the participants adapted it to their own school environments. They learned how to conduct teacher evaluation and communicate feedback. I believe this was a big step toward solving the 
problem of student learning and achievement. This is the core of this study. Moreover, Mwenge University College of Education in Moshi, Tanzania, has created a school leadership preparation program as of September 2011. The intent is to provide future school leaders with formal leadership training so that they can deal with current education challenges. This study was done with the assumption that it would benefit the Tanzanian Universities education program like Mwenge by becoming part of the curriculum, as it was asserted by the Dean of Graduate Program of Education Leadership of Mwenge (J. Okot, personal communication, July 20, 2012).

\section{Defining the Problem}

Edwin's story represents many similar stories. The main problem of education in Tanzania is student underachievement. The literature suggests that quality instruction is a main factor that influences quality learning and performance (J. Blase \& Blase, 2001; Marshall, 2009; Leithwood, Harris, \& Strauss, 2010). Therefore, to end the problem of student underachievement in Tanzania, quality classroom instruction must be instituted with fidelity. Quality teachers are created through learning, support, and coaching (Acheson \& Gall, 2003; Danielson, 2007; Fink \& Markholt, 2011; Marzano, Frontier, \& Livingston, 2011). It is the responsibility of school leaders to help teachers in their professional growth. If the problem of student underachievement is to be resolved, one has to begin with the school leaders. My contention is that school leaders must be equipped with the necessary instructional leadership skills in order to help their teachers improve their pedagogical skills. With the development of collective visions for improved student achievement and the collaborative strategies of transformational 
leadership, the literature suggests that this is likely to lead to teachers improving instruction as measured by Evaluation and Supervision of Classroom Instruction (ESCI) and improved student performance as measured by greater success. This dissertation was planned to address this problem by testing the effectiveness of Instructional Leadership Training Module through the PBL model. I developed the tool and facilitated its field testing through role play in Moshi, Tanzania. Participant feedback from field testing suggests that this may be a big step in the direction of solving this lifelong problem.

From Mr. Edwin's case story, I can identify three points that support my research plan. First, Mr. Edwin, among other things, needs an instructional leadership approach to exercise his leadership because his main challenge was how to improve teaching and learning. This approach will help him focus on improving the quality of instruction by using research-based methods like the ESCI, which will help teachers grow professionally (Acheson \& Gall, 2003; Fink \& Markholt, 2011; Marzano et al., 2011). Educational leadership scholars like Leithwood, Jantzi, and Steinbach (1999), Bass and Avolio (1994), and Marzano, Waters, and McNulty (2005) suggest that he also needs to use a transformational leadership approach because it will help him develop collaboration with his teachers and inspire them to work toward the common goal. He will also need to employ transformational leadership in order to create a vision of his school and communicate it as he works with his teachers to realize the goal of his school: improving teaching and learning. By collaborating with teachers and caring for them, he will allow for teachers' personal growth, and thus prompt their commitment to the school's organization (Bass \& Avolio, 1994; Bolman \& Deal, 2003). Figure 1 shows the 
relationship of these elements of School Leadership Operation, which I proposed the Tanzanian HMs to adopt in their role of school reform to improve student learning and performance.

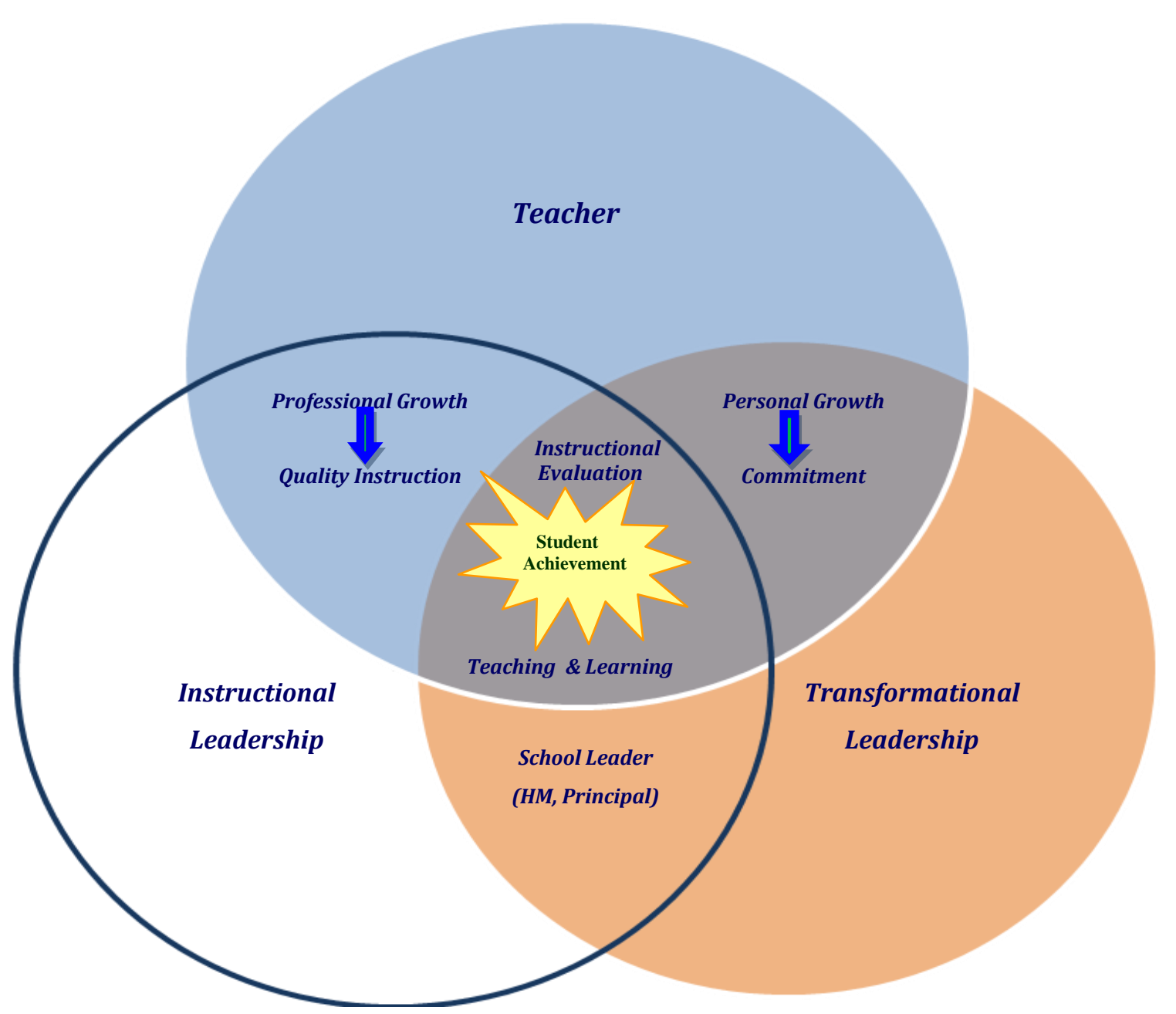

Figure 1. School leadership operation to improve student achievement. Source: J. R. Blase and Blase (2004) and Bass and Riggio (2006).

Since primary school, I have personally known the importance of a highperforming school. This awareness caused a fight between my parents and me regarding which secondary school I should attend. They wanted me to attend a commute school (a school to which students travel daily rather than one at which they board) that had a 
record of student failure. Whenever the results of the national exams were publicly published, I would hear people's comments like, “Teachers in this school don't teach anything; look at the results!' I knew then, though vaguely, that student achievement is associated with teaching-based on the assumption that test scores measure quality teaching and learning. Since there was no school bus, I did not like the idea of walking about up to 12 kilometers to and from school every day. My parents did not seem to know any better. My mother was illiterate, and my father was forced to drop out of school in second grade (Standard Two) with no chance of returning. Because he loved and valued education, he insisted that I commute. As a result of refusing to attend the commuter school, I lost one school year between primary school and secondary school. However, it paid off. I managed to get into one of the most competitive boarding secondary schools in the country, St. James Seminary. Later, I became a teacher at this school for approximately four years. This was the best thing that ever happened to me. I am a lifelong learner because of the solid foundation this school gave me. This is what I want all Tanzanian students to have. I love learning, and now I know what it is like to be "a professional student" after being in the education system both as a teacher and student for more than 20 years.

I grew up in a poor family, yet our parents worked very hard and made us feel like we were royal children. Looking back at what my family had to endure to put my five siblings and me through secondary school fuels my passion to help HMs, teachers, and students to do better. I remember when I was Form Three (Junior High), there was a drought so severe we did not harvest our crops. To keep me in school, my parents had to 
sell the only family cow. When I think of students being failed by our school system, I am reminded of sacrifices as fundamental as those of my parents, and I am driven to deliver excellent educational opportunities to the students I serve.

When I came to America and discovered that a teacher's classroom instruction was evaluated regularly in a collaborative fashion, I was relieved to know that teacher evaluation can be done without intimidating or threatening the teacher. Teachers even take the lead in clinical supervision (Goldhammer, 1969). My next question was, Can I use, or adapt for use, the American instructional evaluation model in the Tanzanian school system?

This study was done to try to answer some key challenging questions in education: How can secondary schools improve student learning and achievement? Since evaluation has been used by school leaders to support and help teachers improve their pedagogical skills, can we develop a culturally sensitive instructional evaluation tool to help HMs improve instruction in their schools? Since HMs who have tried using evaluation tools faced resistance, what are the leadership theories and skills needed to help Tanzanian HMs conduct classroom evaluations with little to no teacher resistance and with positive results? How can we shape knowledgeable, competent, confident, and committed leaders who will improve the quality of teaching and learning in their schools? I believe the best place to start in finding answers to these questions is to train the HMs on instructional leadership skills that are directly related to improving the quality of teaching and learning. 
This study was the implementation of a PBL module that trained HMs in Moshi Diocese Secondary Schools to evaluate teachers effectively. The initial plan was to conduct field testing of the leadership-training curriculum. The teachers' input was used to adapt and acculturate Danielson's evaluation tools, making them appropriate for a classroom instructional evaluation tool for the secondary schools of Tanzania. In the course of field testing role plays, vignettes, and other training, leaders learned how their role in facilitating teaching and learning is related to classroom evaluation. In doing so, they explored the relationship between the evaluation of classroom instruction, instructional and transformational leadership, and the improvement of teachers' instructional skills. The intention was not only to help the HMs know about teacher evaluation, but also to have courage and willingness to use it. The participants assessed themselves before and after the training to find out if the training module managed to give them skills, confidence, and competence. These elements were used to measure the effectiveness of the delivery of module through qualitative research consisting of pre- and post-training surveys and daily end-of-day feedback.

Tanzania: Location and the History of the Land

The United Republic of Tanzania includes the Indian Ocean islands of Pemba and Zanzibar and the mainland territory formerly known as Tanganyika. It is located in East Africa and borders Kenya to the north, Rwanda, Burundi, and the Democratic Republic of Congo to the west, and Zambia, Malawi, and Mozambique to the south and India Ocean to the east. The total population of Tanzania is estimated at 43.7 million (World Bank Group, 2012). There are more than 120 ethnic groups, each with its own language 
or dialect. Indigenous Tanzanians make up $99 \%$ of the population. Other ethnic groups include Asians, Europeans, and Arabs. Kiswahili is the official, universally spoken language in Tanzania. English, also an official language, is the language of commerce and instruction for secondary and college education. Religious beliefs are fairly evenly divided between Muslim, Christian, and traditional.

In 1946 Tanganyika became a United Nations trust territory under British authorities. Tanganyika won its independence peacefully in 1961 (Nyerere, 1967). Zanzibar received its independence 2 years later and then joined the mainland of Tanganyika in 1964 to form the United Republic of Tanzania. Tanzania held its first multiparty elections in November 1995. The country maintains a good record of political stability. Elections are held every 5 years.

\section{The Structure of the Tanzanian School System}

Since the focus of this study is on Tanzanian secondary school leadership, I want to present the Tanzania education system, as it might be unfamiliar to some readers. Tanzania's formal education system is similar to the British system of a 2-7-(4-2)-3+ structure. The first 2 years are pre-primary education, or kindergarten, and are followed by 7 years of primary education (grade school and middle school). Because primary education is free and mandatory, the enrollment rate is high. For example, from 2000 to 2010 primary education enrollment has been nearly 96\% (United Republic of Tanzania, Ministry of Education and Vocational Training, 2011). Students take the national exam after their seventh year, and those who pass transition to secondary school for 4 years of 
Ordinary Level secondary education (O-Level). There are different kinds of secondary schools in Tanzania (see Table 1).

Table 1

Different Kinds of Secondary Schools in Tanzania

\begin{tabular}{|l|l||}
\hline Living Arrangement & Explanation \\
\hline Boarding & Student lives in the dorms or hostels within the schools \\
\hline Commuting & Student lives at home and come school \\
\hline Boarding / Commuting & Some students lives on campus and some live at home \\
\hline \hline Gender & Females Only \\
\hline Girls' School & Males Only \\
\hline Boys' School & Both Males and Females \\
\hline Co-educational School & $\begin{array}{l}\text { Owned, funded and run by the government. Schools are open for all students } \\
\text { of all faiths. Most of them are boarding schools. }\end{array}$ \\
\hline Affiliation & $\begin{array}{l}\text { Public commuter schools which are established to serve specific } \\
\text { demographic communities }\end{array}$ \\
\hline Public Schools & $\begin{array}{l}\text { Schools are owned and run by religious organizations like the Catholic } \\
\text { church, Lutheran church, Islamic organization or mosque etc. }\end{array}$ \\
\hline Community Schools to be future \\
\hline Private Religious & $\begin{array}{l}\text { Religious private schools restricted to those students who want to } \\
\text { leaders of those organizations. }\end{array}$ \\
\hline Seminaries & Schools are owned and run by some organizations like parents'. \\
\hline Private Nonreligious
\end{tabular}

Note: All secondary schools, private and public, are open for all diverse students except seminaries which accommodate only students of specific faith tradition and gender. Students in the seminary schools are potential leaders of that faith tradition.

Students take another national exam at the end of their fourth year, and those who pass are admitted to the Advanced Level (A-Level) secondary education for 2 more years, making a total of 6 years of secondary (high) school education. The average number of students who pass the national exam and transition from O-Level to A-Level is less than 50\%. For example in 2011, from the 24 Catholic secondary schools of Moshi Diocese, only 45\% of students passed (United Republic of Tanzania, Ministry of 
Education, 2011). D. Mushi (2010) identified that the failure rate is higher in the public schools. Students do another national exam at the end of their sixth year, and those who pass are eligible to join colleges or universities for approximately three years or more (United Republic of Tanzania, Ministry of Education and Vocational Training, 2011)

There is a direct correlation between Tanzania's national curriculum and the National Examination Council of Tanzania (NECTA) exam and therefore a certain transparency regarding what will be assessed. For example, if the national curriculum is followed with fidelity and delivered with skill, students are likely to score well on the NECTA. Because the population of Tanzania is $99 \%$ indigenous Tanzanians, the homogenous nature of the population would suggest that race is not a factor in the norm referencing of the NECTA exam.

\section{The Problem Statement, Its Relevance, and Attempted Solutions}

Looking at the current student performance in Tanzanian secondary schools, most educators agree that there is a serious problem in student achievement. Appendix A shows the 2011 national examination results of the Moshi Catholic schools after the fourth year. Some schools are doing well with a failure rate of $0 \%$. Some fare much worse with a failure rate of $100 \%$, such as Kisomachi and Lombeta. The average pass rate of those schools for 2011 was $44.8 \%$. Appendix A shows that this problem is a national wide problem. This problem is serious and its remedy urgent since students who failed will probably not have a second chance; those students who pass are promoted to the higher level of secondary education, and those who fail drop out. Since quality classroom instruction is a number one factor influencing student achievement, the current 
underachievement implies a lack of quality instruction on a grand scale. All of the 21 HMs who participated in my pilot study agree with this assessment.

In my 2011 pilot study, all of the participants revealed they want to improve classroom teaching but did not know what the best approach was. They were concerned with classroom instruction, especially with the teachers whose students always do poorly on the national exams. Due to the shortage of teachers in the country, firing is not a solution (Education Sector Development Committee, 2008; Independent Evaluation Group, 2010): some HMs have tried firing teachers, only to end up hiring a worse teacher than they had or, in some cases, rehiring the same teachers (W. Ruwaichi, personal communication, July 13, 2011). The solution is for school leaders to help the current teachers become instructional experts. But as Fink and Markholt (2011) asserted, "It takes expertise to make expertise" (p. 5). Because they do not have any formal leadership training prior to assuming their leadership roles, school leaders are not experts either, and they are aware of their deficiencies. This implies that leaders must learn to be instructional experts before they are able help teachers improve their instructional skills.

As the story of Mr. Edwin reveals, the HMs who tried to evaluate classroom instruction as a way to improve achievement faced resistance from teachers. Because teachers dislike the process of teacher evaluation, other school leaders (particularly new HMs) are typically afraid of the practice. After all, the teacher evaluation of classroom instruction is only recommended policy; it is not a mandatory leadership practice (W. Ruwaichi, personal communication, August 13, 2011). From our story, Mr. Edwin, like his teachers, disliked this approach because it was it was done in an unprofessional manner. It was top-down, authoritative, condescending, and threatening. Here I will argue 
that those who practice this type of classroom evaluation are lacking the needed teacher evaluation skills. I propose that HMs learn how to use both instructional and transformation leadership skills as a basis for conducting teacher evaluations. The instructional and transformational theories provide essential information for the HMs as they conduct teacher evaluation in a more collaborative, supportive, and teacher-centered fashion.

However, knowing that often HMs are just classroom teachers who were promoted to a leadership position, we cannot blame them much for lacking key leadership skills. Basically the HMs were good teachers, passionate, enthusiastic, and successful in their teaching careers, demonstrating some leadership abilities; that is why they were promoted to leadership positions (W. Ruwaichi, personal communication, August 13, 2011). Comparing Tanzanian to U.S. school leadership standards, I found HMs to be deficient in leadership skills due to minimal training; HMs do not undergo any formal leadership training other than what they learn in their teacher education programs. Even experienced HMs shared in surveys from my 2011 pilot study that they felt unprepared to face leadership challenges, especially when they were abruptly transferred to a new school with challenges that were different from what they faced in their original school environment (W. Ruwaichi, personal communication, August 13, 2011).

Several attempts have been made to improve achievement with little to no success. From Tanzanian Independence in 1961 to today, policies have been initiated to promote the quality of education: The Arusha Declaration of 1967, the Musoma Declaration Education Act 1968, The Education Reform Act 1998, The Tanzania Development Vision 2005, and Student-Centered Learning Policy of 2005 (Tanzania 
Planning Commission, n.d.). These policies have the intention of improving education as measured by student achievement and have been successful in increasing the number of students in secondary school, but, researchers suggest, not necessarily the quality of education (Nguni, 2005; Nyerere, 1967; Thomas \& Vavrus, 2009). There are some improvements, such as decreasing student dropouts, increasing inclusion of female students in secondary and tertiary education, encouraging female students to return to school after pregnancy, and increasing the number of secondary school graduates. The improvement of student learning and achievement still remains a problem.

One of the possible reasons given as to why this problem is prevalent, despite the attempted solutions, Nguni (2005) pointed out, is the lack of quality teachers and the rapid increase of secondary schools. Student enrollment grew from 289,699 students in 2001 to $1,789,457$ students in 2011, a $617.6 \%$ increase (United Republic of Tanzania, Ministry of Education and Vocational Training, 2011). There was no equivalent effort to add qualified teachers for this rapidly increased student population. The lack of qualified teachers has led to the lack of quality classroom instruction. This could explain student underachievement in recent years though it does not fully explain the decades of this trend.

Another attempt to address student underachievement was made by the Ministry of Education of Tanzania. Aimed at improving classroom instruction, the Ministry tried to change the policy of pedagogy from a teacher-centered to a student-centered, or constructivist teaching model. Research shows that the constructivist teaching model has the potential to engage students, increase their learning interests, and therefore raise their achievement more than the traditional teaching model (Ernest, 1994; Fosnot, 2005). 
However, there are no noticeable benefits of this policy yet. School leaders received no training and consequently were unable to coach and support teachers to implement the policy. As a result, teachers did not implement the policy. This fact supports my proposal to improve quality teaching and learning for student achievement by focusing on improving school leadership.

From my 2011 pilot study, and from the story of Mr. Edwin, I identified another problem of negative perception of instructional evaluation. The teachers disliked classroom evaluation because it was too authoritative and threatening and was traditionally done with student teachers only and ended when they graduated. When it was done with experienced teachers without any clarification, it sent a message that the teachers might be under-qualified (F. Furaha, personal communication, July 18, 2011). Because of this, teacher evaluation was not done, and so teachers were left to improve their instructional skills through trial and error or seldom offered professional development workshops (W. Ruwaichi, personal communication, August 13, 2011). Once HMs learn how to appropriately and effectively use ESCI, the teachers will see it for what it is: a supportive tool for their classroom instructional improvement, personal growth, and professional development (Danielson, 2007; Fink \& Markholt, 2011; Marzano et al., 2011).

\section{Rationale for Studying the Problem}

Why does it matter? In 1948, the General Assembly of the United Nations declared that education is a basic human right of every child. In Tanzania, secondary school education appears to be a privilege of the few and not a basic human eright of every child. Statistics show that the secondary school freshmen enrollment rate for 2011 
was only $21.3 \%$ of those graduating from grade school, the highest rate ever achieved (United Republic of Tanzania, Ministry of Education and Vocational Training, 2011). Though the goal of high school education in Tanzania is "to prepare students for tertiary and higher education and for work and service to the community" (Nyerere, 1964, p. 62), it is evident from scores on the national exams, which includes measures of workplace readiness, that this goal is not being met since almost half of the students drop out of the education system after 4 years of secondary education (United Republic of Tanzania, Ministry of Education and Culture, 2007). This, in turn, limits the number of tertiary students and skilled workers entering the workforce.

Given that Tanzania is one of the poorest countries in the world, with an annual Gross Domestic Product (GDP) per capita of $\$ 509$, and that education is said to be the antidote of poverty (UNESCO, 2009; Nyerere, 1969), what is taught in classrooms has to be solid in order to prepare students for $21^{\text {st }}$ century challenges and to change the economic future of Tanzania and its students. In the national development strategic plan, the Government of Tanzania (n.d.) indicated that their intention was to establish a resilient and competitive economy through strong and sound education of their students. If Tanzania is to develop as a competitive nation in the increasingly global knowledge economy, it must create citizens that are able to think critically and innovatively (Thomas \& Vavrus, 2009).

The majority of students are in school at some cost to their families' livelihood. The majority of families in Tanzania cannot afford private schools, and there is limited room in public schools. Because of this fact, most families have to sacrifice in order to support even just one child enrolled through secondary school. Failure of a student in this 
case has a profoundly negative effect on the entire family's income and status. Because of this, quality instruction to ensure learning and achievement is of pressing importance for both students and their families.

The Government of Tanzania, sensing parent and educator frustration with student failure, created a task force to explore the state of educational leadership in the country, hoping to improve student learning and achievement. The Task Force Report suggests that the ministry of education should improve the training capacity of the Department of Educational Planning and Administration of Dar es Salaam University in order to introduce an education management program. This program produces a very limited number of graduate educational leaders who mostly work in high positions of educational organizations. They normally do not work as HMs (Nguni, 2005). To the best of my knowledge, there is no plan for reforming, developing, or even challenging our current principals other than occasional professional development workshops.

Furthermore, HMs admit these workshops do not really address school changes in student learning (P. Osoki \& F. Furaha, personal communication, July 18, 2011).

I strongly believe using ESCI to improve instruction is best because it is safe for both HMs and teachers seeking to secure their jobs. One reason is that it does not threaten HMs with termination because of their deficiency in instructional leadership skills. Secondly, it does not threaten teachers with termination because of deficient classroom instruction as measured by student achievement. Thirdly, it does not impose on the HMs and teachers an instructional evaluation tool that might lack cultural relevance. Instead, it respects the culture and customs of Tanzania by allowing HMs to help develop their own instructional practices. It honors their leadership and models a style of collaboration with 
their teachers. It understands the complexity of teaching and honors the uniqueness of teachers, helping them build from where they are, using the resources available to them to improve their pedagogical skills. It is directly linked to student achievement. Figure 2 shows the vision of this approach in which leadership practice is linked to quality teaching and student achievement.

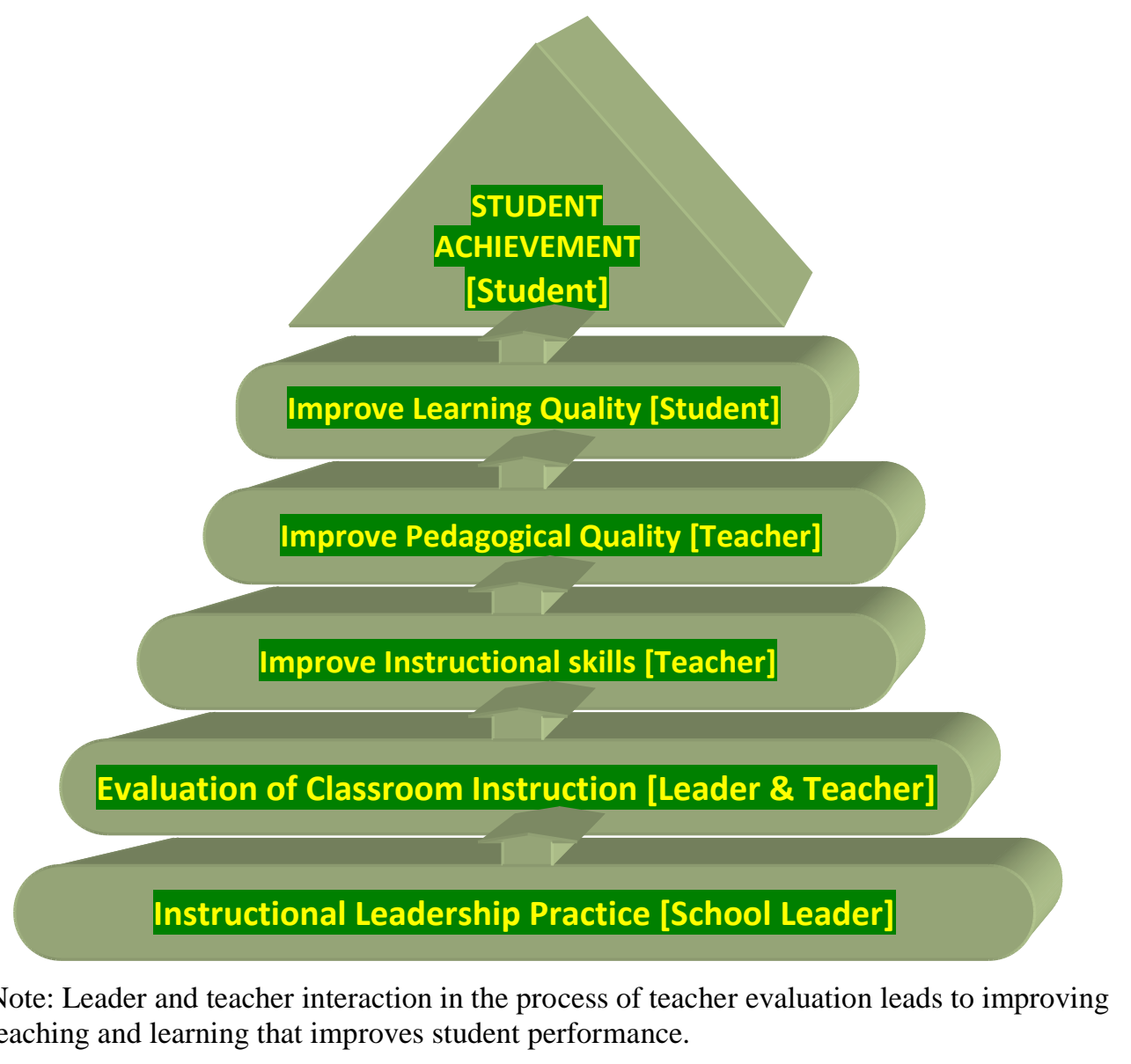

Figure 2. Conceptual framework of leadership and teacher interaction.

\section{Research Design and Methodology}

The intention of this dissertation is to field test the PBL module to see if it will be able to help Tanzanian high school principals learn and practice a powerful tool of 
instructional leadership: teacher evaluation (J. R. Blase \& Blase, 2004; Danielson, 2007; Fink \& Markholt, 2011). This study provides a solution by improving the quality of classroom teaching and learning. This was accomplished by coaching and supporting teachers in improving instructional practices (Danielson, 2007; Marzano et al., 2011)

This research was grounded in the PBL model (Bridges \& Hallinger, 1992). This research addressed the current existing problem of student underachievement by implementing the PBL approach. The participants of the study implemented the field testing of the PBL curriculum on teacher evaluation by using Danielson's (2007) evaluation tool. They briefly learned about other evaluation models like mini-evaluation and walk-through models (Marshall, 2009; Marzano et al., 2011). Danielson's model was chosen because it is one of the most exhaustive, extensive, and thorough. In this PBL approach, Bridges and Hallinger (1992) identified the characteristics of PBL instructional strategies, which were reflected in this research:

- The starting point for learning is a problem-student underachievement

- The same problem is what participants face-Participants are HMs who are currently facing that problem in their respective schools.

- Knowledge gained is organized around the problem-The HMs learned how to effectively conduct ESCI with a view toward helping teachers solve the problem.

- Participants assume responsibilities for their own learning in the research process-Participants will build their knowledge by attending a workshop and practice evaluation and supervision through role presentations and role-playing. Role-playing is important because it gives the participants a controlled environment to practice what they will later on do in their respective schools.

- Most learning occurs in small groups-For the six days of the workshop, participants will participate in two to three sessions of group discussion per day (pp. 5-6). 
This study took place in Moshi Catholic School District-Tanzania with 24 participants. Of these, 21 were HMs, 2 were vice HMs and 1 was an academic dean. The superintendent of Moshi Catholic school district was in full support of this project as he affirmed, "Leadership training and a tool for teaching evaluation is much needed; we can not wait to see it developed and used in our schools" (W. Ruwaichi, personal communication, August 13, 2011).

\section{Research and Development Cycle}

Gall, Gall, and Borg (2006) identified 10 steps of PBL in the research and development cycle. This study utilizes steps one to seven only. These steps follow.

Step One-Research and Information Gathering: I did this through a review of the literature on school leadership and reform, factors affecting school leadership, factors affecting student learning and achievement, and the relationship of school leadership, teaching, and learning. In 2011, I also conducted a pilot survey with $21 \mathrm{HMs}$ of Moshi to evaluate the problem of student achievement as it is experienced by the practitioners in the field. I conducted phone email and/or Skype interviews. From these I was able to determine the topic of my study.

Step Two-Planning and Preparation: I chose to use Moshi Catholic School HMs because I had access to these schools and the support of the superintendent of Moshi. I went to Tanzania in the summer of 2012 to implement the PBL Training Module through the workshop in which the participants field tested the PBL module through role plays and other training. Data were collected in different ways including observation, pre- and post-assessments, formative assessments after every session, talk back assessments at the 
end of every day, and verbal and written comments of the participants. The data were used to refine the curriculum.

Step Three-Preliminary Program/Product Development: I collected the resources for training the HMs in the 6-day workshop on July 23-28, 2012. I had a structured curriculum with training materials for every session, formative evaluation forms, vignettes for group discussion and other resources for them to read (e.g., book sections, journal articles, and videos).

Step Four-Preliminary Field Test: Five HMs had been asked to be the leaders of the small groups during the workshop. Only four were needed, as there were only four groups. They met for 2 days one week prior to the PBL training workshop. They conducted a preliminary field test of the Module through group discussions and role play.

Step Five-Product Revision: The feedback given in Step Four was used to make revisions as needed to revise the training module. Participants processed the cultural elements and make any necessary modifications, bringing their findings to the PBL Training Module. The revised version of the PBL Training Module was given to the workshop participants for the main field test.

Step Six-Main Field Test: HMs participated in the training and role playing in order to effectively conduct ESCI in their respective schools. For 6 days, HMs were engaged in learning activities like role play, as the PBL training curriculum suggests. In the course of training, they adapted Danielson's (2007) evaluation tool and acculturated it to fit the Tanzanian school system and culture. After the workshop, they used the adapted Danielson's tool to conduct ESCI in their schools. In the first month, I visited them for 
observation, coaching, and support. They also continued to conduct evaluations and write their findings and suggestions for 4 more months. This information was used to revise and refine the product.

Step Seven-Operational Product Revision: At this final stage of my study, the findings collected during Step Six were used to revise the product, making it ready for use by the rest of the HMs in Moshi District.

Since the study was looking at the quality school leadership and the quality teaching and learning, specifically leadership methods involving relationships between participants, I employed qualitative research methods to measure results. It was also a case study because it dealt with one group of school leaders who field tested the PBL module to measure its effectiveness in training practitioners to make them instructional leaders who can use Danielson's tool to implement teacher evaluation (Creswell, 2007). The 24 participants in the 2012 field test implemented the PBL Training Module through vignette and role play and learned through group interaction and practice how to employ the evaluation tool in preparation for implementing ESCI in their own schools in the following school year. The entire process was conducted through the implementation of PBL learning of research model (Bridges \& Hallinger, 1992). In the end we had not only the final product (i.e., the PBL Training Module for Tanzanian High School Principals), but we had also the teacher evaluation or ESCI tool, which is culturally sensitive to Tanzania secondary schools. 


\section{Chapter Summary}

With the growing demand for an increasingly knowledge-based labor market, we can no longer be content with 4 years of secondary education for Tanzanian students. With the sacrifice families are making to keep their children in secondary education, failure to educate their children in our schools is not an option. We, as educators and leaders, have a moral obligation to act and ensure quality instruction that will raise student achievement as measure by national exams.

It is time for all HMs, including both new ones and those nearing retirement, to exercise their leadership roles in a new fashion that ensures the attainment of the school's number one goal: student quality learning and achievement (DuFour, 2010; Fullan, 2005; Leithwood, Louis, Anderson, and Wahlstrom, 2004). It is time to learn and employ instructional leadership that will focus on improving the quality of instruction through teacher evaluation, as well as transformational leadership that will ensure collaboration and provide care and support for individual teachers. The combination of instructional and transformational leadership models is crucial to end the negative attitudes of teachers toward classroom evaluation and to earn their cooperation in the process. The aim of this dissertation was to implement a research-based classroom evaluation and supervision tool in the Tanzania secondary school system. Using a PBL Training Module, the participants adapted evaluation and supervision tools; the process made these tools culturally responsive and sensitive to the current needs of HMs. Hopefully, a new approach, grounded in instructional and transformational leadership, will replace the current topdown authoritative evaluation model throughout Tanzania. 


\section{Definition of Terms}

The Arusha Declaration: Tanzania's most prominent political statement that promoted the Policy of African Socialism, "Ujamaa" or brotherhood, and Self-Reliance (Nyerere, 1967). Education was defined as a means of achieving self-reliance.

Division: A national pass mark or grade level in Tanzanian tests grading system, which shows how well the student passed the national test out of seven disciplines or subjects. There are only five Divisions written in Roman numbers, namely I, II, III, IV and 0 . The lower the number, except zero, the better the grade. For example a student who has seven A's will be in Division I, while a student who has two A's, three B's and two C's will be in Division II. For the sake of simplicity, Division I, II, III and IV can be compared to score or grade average of A, B, C, and D.

Effective School Leadership: Having the ability to influence student achievement (Chenoweth \& Everhart, 2002; Fullan, 2001). For the sake of simplicity, in this paper I will use school leadership, principal, and HM interchangeably.

Form Four: The fourth year of secondary school, which marks the end of the first part of secondary (high) school, equivalent to eleventh grade in the U.S. There is a national test after the fourth year that determines whether or not the candidate will be admitted to the 2 years of the second part of secondary education.

Headmaster/Headmistress [HM] or Headmasters/Headmistresses [HMs]: The title given to the male/female head of the secondary school, respectfully. It is the same as the high school principal in the U.S. 
Instructional Leadership: The most popular definition of a school leader of the $21^{\text {st }}$ century with the following roles: as a resource provider to ensure the teachers have teaching materials, facilities, and the budget necessary to adequately perform their duties; as an instructional resource the HM actively supports day to day teaching activities and models the desired behavior; and as a communicator the HM must have a clear goal of the school and articulate those goals to the staff while maintaining a physical presence (Leithwood et al., 1999; Marzano et al., 2005).

Leadership: Leadership is perceived to be important to the effective functioning of any organization and of any school in particular. Leadership, according to Roueche, Baker, and Rose (1989) is defined as "the ability of one with power and authority to influence and direct others toward a common destination" (p. 210). Day and Leithwood (2007) have a more comprehensive definition of school leadership by explaining the principal leadership roles including

building vision and setting direction... understanding and developing people by providing support to the staff, offer intellectual stimulation, promote reflection and modeling desired values and practices...designing the organization by building and sustaining the collaborative culture... and managing the teaching and learning programs. (pp. 6-7)

Problem-Based Learning: An instructional strategy that organizes knowledge around administrative problems rather than the disciplines. This model of research is based on the works of (Bridges \& Hallinger, 1992). There are two major versions of PBL, namely Problem-Stimulated and Student-Centered learning. The research is done by testing how a research product works in the field. 
Consultancy Protocol: A Consultancy is a structured process for helping an individual or a team thinks more expansively about a particular, concrete dilemma. Outside perspective is critical to this protocol working effectively; therefore, some of the participants in the group must be people who do not share the presenter's specific dilemma at that time. When putting together a Consultancy group, be sure to include people with differing perspectives.

Research and Development (R\&D) Cycle: This is a program development model used to translate research findings into educational programs or products ready for use in the field. It is based on the work of (Gall et al., 2006). The purpose of the R\&D cycle is to translate the basic applied educational research into an applicable form in the field program. The cycle begins with designing, developing, and testing of the product. Then the product is implemented, study its efficacy and improve it. It is synthesized and theorized, then explored, hypothesized, and clarified before it is tested again.

Student-Centered Learning: An approach to education focusing on the needs of the students. The emphasis is on connecting teaching with previous knowledge and the students' experience, in which students actively participate in forming their knowledge (Weimer, 2002). This approach leads to a more constructivist teaching approach as opposed to the traditional lecturing method.

Student Achievement: In this study student achievement means the ability of a student to meet the goal of education namely "Consolidate and broaden the scope of ideas, knowledge, skills, and concepts already acquired at primary education level...prepare students for tertiary, higher, vocational, technical, and professional 
education and training...prepare students for the world of work" (United Republic of Tanzania, Ministry of Education and Culture, 2000, p. 2). Included in this category are those students with Division I, II and III only. Those with Divisions IV \& 0 are not included since those divisions do not qualify students for higher education.

Transformational Leadership: In education, this is a model of leadership in which the educational leader (HM) focuses on caring for and attending to the needs of the individual staff members for their personal growth; helps them to think of old problems in new ways; communicates expectations and models good behavior. The leader engages with followers, focused on higher order intrinsic needs, and raised consciousness about the significance of specific outcomes and new ways in which those outcomes might be achieved (Leithwood, Begley, \& Cousins, 1994; Marzano et al., 2005).

Ujamaa: Ujamaa comes from the Swahili word for extended family or familyhood. It was a political and economic model of African socialism. Its main assumption is that a person is defined through the people or community. It is a modified socialist system in that all the major means of production were nationalized, while individuals could own personal properties. 
CHAPTER II

\section{LITERATURE REVIEW}

\section{Introduction}

This chapter explores the problem of low student achievement in Tanzanian secondary schools from the perspective of literature I reviewed, and generates research questions for this study. It presents the historical development of instructional evaluation in Tanzania from the pre-colonial era to the present to illuminate the historical roots of the problem of student achievement. Since student achievement is a long-term problem, the Government of Tanzania and additional educational organizations have attempted to solve it in different ways with little to no success. These attempts are explored along with a new proposal to use a culturally sensitive ESCI tool to improve the quality of instruction. For decades, ESCI has been used as an administrative tool for improving the instructional skills of teachers and the quality of education (Marzano et al., 2011). Two leadership theories, instructional and transformational, are discussed because they support teacher evaluation.

\section{A Brief History of Education in Tanzania: Evaluation and Supervision}

The evaluation and supervision of teaching in Tanzanian communities was practiced in some fashion prior to the introduction of formal or western education.

\section{Pre-Colonial Education: Up to the 1870s}

Prior to the introduction of formal education in Tanzania in the 1860s and 1870s by the Arabs, Portuguese, German, and British, the native Tanzanians had only informal 
traditional education. It was practical, imparting life skills and family and tribal values. It focused on creating "good citizens" and was based on age and gender groups (Nyerere, 1967). Informal education was done in the family and tribal settings and so it was restricted to the family, clan or tribal members. This was to keep the family, clan, or tribal secrets from being exposed to nonmembers. At times, instruction included ceremonies. A coming-of-age training, for example, offered survival skills to the individual at a critical stage in one's life, making the transitional period from boyhood to adulthood more comfortable by unveiling the mysteries of the unknown. P. A. K. Mushi (2009) reported that children were basically taught the "do's and don'ts;" teens and young adults were taught some family and tribal values, taboos and secrets, how to date, how to take care of the family and be a responsible member of the community. After this informal education they were ceremonially initiated into full membership of the community with its rights and responsibilities. Family or tribal elders were the educators. For example, my maternal uncle was one of the instructors. Every cohort had at least two instructors to ensure adequate and thorough coverage of the topics (Mazonde, 2007).

The instructors/elders had full autonomy and authority over the curriculum and instructional style. There was no supervision or evaluation except at the period of their recruitment. The new instructors would first participate in the teaching sessions as observers for about a year. Then they would begin teaching while being observed, guided and corrected by the senior instructors for about two years. After this period, they were regarded as qualified instructors and so operated with no supervision or interferences. The only time the head of the clan or the tribal chief would intervene with the teaching 
process, either in person or by proxy, was if it was proven that the instruction of a particular cohort resulted in unacceptable behaviors like domestic violence in beating their wives, neglecting their families, or failing to sustain their families due to laziness. With this knowledge, the instructors would lose their teaching status with no recourse possible (Mazonde, 2007). This form of education continued even after the introduction of formal education. As a secondary school student, at age 16, I was a recipient of this form of education when my rite of passage was marked by my official transition into adulthood. The rite included circumcision followed by a long time of care and rest. I was separated from the rest of the family and friends except my cohorts for a month, receiving instructions on how to behave as a responsible man in my Chagga tribe and my family. The instruction imparted knowledge and skills on how to deal with enemies, how to handle women, dating, sustaining a successful marriage, caring for children, and how to protect the community. In short, they taught us the practical social skills necessary for successful life.

\section{Early Colonial Period: 1880-1918}

Although Tanzania (then called Tanganyika) had been a German colony from 1840s, formal education, also referred to as "Western Education," was not introduced in the country until 1860s and 1870s. And even when it was introduced by the first missionaries, it was not really enforced until 1893 when Tanzania had its first public school (Tanzania Education Network, 2007a). Before 1893, the schools were all parochial ones with religious instruction as a mandatory part of the curriculum. As in the U.S., clergy were the heads of the schools, instructional supervisors of curriculum and 
teaching because they were among the most learned in the local communities (Marzano et al., 2011). At the 1884-1885 Berlin conference, which settled the European scramble for Africa, German rule over Tanzania was recognized by the European superpowers (deBlij \& Muller, 2007). Formal education was then enforced by German rule. However, both public or government and parochial or private schools virtually collapsed with the First World War (WW-I). This war also ended German rule in Tanzania.

The German approach to education in Tanzania was limited to a few colonial civil servants. Rodney (1981), in his book How Europe Underdeveloped Africa, observed that the Africans, predominantly male, who were given a privilege of minimal education were extremely few. German education to a greater part taught natives to despise their own culture, and separate them from those who had no western education as they counted themselves as of the higher class (P. A. K. Mushi, 2009). Since only a few received the education (i.e., only those who were needed to assist their colonial masters with simple duties), its effect after Germany left Tanzania was minimal.

\section{Later Colonial Period-Trusteeship Period: 1946-1961}

Following WWI, the League of Nations placed Tanganyika under British rule in 1919, and in 1946 Tanganyika became a United Nations Trust Territory under British Administration. At this time, missionaries and government education approaches harmonized, and the number of public, religious, or racially based schools increased (Rodney, 1981). It is important to note here that during this period there were racially based schools for white children of colonial masters only, or for Asian business people, or for black Tanzanian children. ESCI in all schools was done by whites only, as P. A. K. 
Mushi (2009) asserted, "to enforce the aim of education which was realizing colonial needs and interests" (p. 4). As mentioned before, the religious schools had the clergy as their supervisors. As Clergymen were considered a logical fit since they became the heads of school as well as the heads of their congregations (Tracy, 1995). To this I will add clergymen were also a good fit to represent the colonial whites and their western and cultural interests in the education system. ESCI focused more on the teacher's behavior than on pedagogical skills. It extended beyond the school boundaries to the family and community life of the teacher. The instructional observation and feedback not only addressed the quality of instruction but also the cultural adaptation in which some of the African teachers had to "act white" in things like attire. For example males had to wear a tie in class and shiny, black shoes so as to fit into the category of quality teachers (P. A. K. Mushi, 2009). There is no evidence this helped to improve achievement because it did not focus on the teaching skills and quality of instruction.

\section{Post-Independence: 1961 to Present}

When Tanzania became independent on December $9,1961,85 \%$ of the population did not know how to read or write (P. A. K. Mushi, 2009). The new government was committed to building an orderly and just nation, so the racially based school system was abolished. These schools were introduced during the colonial era in which African children attended their school; Indians who were mostly traders and store owners had their schools; and the children of white colonial masters, whether German or British, had their schools. Normally they were not allowed to mix. The focus of education shifted from preparing colonial civil servants, to producing skilled manpower for social 
and economic sectors of the post independent state. With the Arusha declaration of 1967 in which Tanzania officially adopted African socialism or Ujamaa, all private schools were nationalized and private schools, including religious ones, were no longer permitted.

Teacher evaluation was reinforced not only to ensure the quality of education, but also to ensure that Tanzania's education system fostered and encouraged the prescribed national educational goals at all levels. As the first President of Tanzania, Julius Kambarage Nyerere (1967) declared, "education must prepare our young people to play a dynamic and constructive part in the development of a society... and help our pupils to accept the kind of values appropriate to our kind of future, not those of our colonial past" (p. 52). Since the emphasis of teaching and evaluation were now placed on the "why" and not on the "how" of instruction, classroom instruction had to ensure three key learning objectives were imparted to students. Nyerere described them as

(1) an enquiring mind; the ability to learn from what others do; (2) informed decision making to reject or adapt it to their own needs; and (3) a basic confidence in their own position as free and equal members of the society, a person who values others and values them for what they do and not for what they obtain. (p. 53)

With the establishment of the Ministry of Education in 1970s, private schools were once again allowed. The ministry took the mandate of issuing a national curriculum for all primary and secondary schools and teachers' training colleges with standardized instructional skills. To improve education, different departments within the ministry of education were created. These included education sector development in 1997, the primary education development plan, in 2001 and the secondary school development plan was developed in 2003. However, even with these new development plans, ESCI was no 
longer enforced, but was, and still is limited to student teachers only. The current failure rate of students indicates that more work needs to be done to improve the quality of classroom instruction. If ESCI is done for student teachers in an attempt to make them skilled teachers, why not continue doing ESCI and help professional teachers improve their instructional skills? Learning from this, I proposed the use of ESCI as a means of improving teaching and learning.

From independence to today, several policies have been instituted and relevant organizations have been created. For example the Tanzania Institute of Education, which is an organization under the Ministry of Education and Vocational Training, is charged with the responsibility of ensuring the quality of education in Tanzania at the preschool, primary, secondary, and teacher-training levels. Other organizations were established through enactment of the Education Improvement Act No. 13 of 1963 (Tanzania Institute of Education, 2011). The goal of improving the quality of education was included in the Arusha declaration of 1967, the Musoma declaration Education Act 1968, the Education Reform Act 1998, the Vision of Tanzanian Development of 2005 and the Student Centered Learning policy of 2005. They had, among other things, the intention of improving education as measured by student achievement. These policies were successful in increasing the number of students in secondary schools, but not the quality of education (Nguni, 2005; Nyerere, 1967; Thomas \& Vavrus, 2009). This suggests that some more initiatives are needed in order to improve the quality of education. The Ministry of Education has attempted to initiate reform by passing new policies of education development and reform (Tanzania Education Network, 2007b). There have 
been some signs of improvement: a decrease in student dropouts, an increase in the number of female students, female students returning to school after pregnancy interruption, and a slight increase in the number of students who graduate from high school.

\section{Current Situation of Student Achievement: The Study Problem}

Although the 2011 National Form Four exam results in Tanzania indicate girls have captured the lead in the academic performance, the general failure rate of student population as a whole is higher than it was in 2009 (Nkolimwa, 2011). Female students did not have an equal chance of getting secondary education from colonial times up to the late 1990s. However, the gap between male and female students is progressively narrowing (D. Mushi, 2011). Statistics also show that from the time of independence (1961) to today, there has been some improvement in student achievement, although still more than half of those who graduate from secondary schools do not qualify for higher education (United Republic of Tanzania, Ministry of Education and Vocational Training, 2011). For example, of the 2,285 students of Moshi Catholic schools who took the national exam after their fourth year of secondary education in 2011, only 1,007 (44\%) scored Division I-III (passed) while 1,278 (56\%) scored Division IV_0 (failed). This continues to limit the number of students in higher education and the professional work force.

When it comes to student achievement, this study uses a slightly different standard than NECTA. The NECTA pass mark standard includes Division IV, despite the fact that a student in Division IV does not qualify for higher education, but rather a 
vocational school. In this study, therefore, only Divisions I, II and III are counted in the pass mark, while those with Divisions IV and 0 are failures. This reorganization makes the data presented in this study slightly different from those found in the Tanzanian national statistics reports. That being said, the 2011 national exam results show that $40 \%$ of the public school students passed, and about $44 \%$ of the private Catholic school students passed (Nkolimwa, 2011). This means that the overall failure rate is about 56 to $60 \%$. Some high schools even have a $100 \%$ failure rate. This is the problem this research is trying to address.

\section{Guiding Questions on the Present Problem}

The literature I used to address the problem of student achievement in Tanzania is predominantly American and generally addresses the problem in many layers including the students' cultural contexts, curriculum development, and pedagogical approaches. First, the current situation calls for the attention of school leadership to facilitate reform to improve quality instruction for quality learning. Secondly, both the leadership and teachers have to look for a way or a tool to improve teaching since it is a necessary factor for achievement. Lastly, they need to figure out how to sustain quality classroom instruction. I have used both the literature and my life experience in both Tanzania and America to address these two research questions by creating a teaching module that will train school leaders to improve their instructional skills. The primary question is: Can the PBL module help Tanzanian HMs improve their instructional skills so as to improve teaching and learning? This question arose from considering the literature confirming that leadership had a big influence on quality teaching and learning (J. R. Blase \& Blase, 
2004; Leithwood et al., 2004). The second question also came from the literature that claims that ESCI is one of the best instructional leadership tools for improving learning and teaching. The research question is: Can the evaluation tool that was created for American schools be culturally relevant (or be adapted to be culturally relevant) for Tanzanian school systems and culture?

Although I have never been a school principal or a HM, I have always believed leadership is responsible for bringing about positive change in schools. The literature on school leadership, reform and change, insists that performance and achievement improvement is the primary duty of leadership (DuFour, 2010; Fullan, 2001, 2005; Leithwood et al., 1999; Leithwood et al., 2010; Marzano et al., 2005). As a secondary school teacher, I used to see my HM receiving letters, cards, phone calls, notes and even gifts, congratulating him for the best student performance right after national exam results were published, despite the fact that he never taught a single class. My argument is: if he can receive congratulations, it is logical to say he should also take some primary responsibility for the students' failures and initiate needed school reform to improve learning and performance.

\section{Quality Teaching Matters Most for Student Achievement}

Educators know that quality teaching is a result of professional growth.

Professional growth comes from continued learning and practice. School leaders need to ensure a continued improvement of teachers' pedagogical skills for teachers' professional and personal growth. All 21 school leaders of the Moshi Diocese Catholic high schools who volunteered to participate in my 2011 pilot survey agreed that schools need some 
sort of reform to improve student achievement. In that study, 24 principals were asked to express their leadership challenges that contribute to student underachievement. Twentyone of 24 responded. Their responses are in three the categories as presented in Table 2. It shows that instructional challenges have the highest frequency; implying that the HMs are not content with the current student performance on the NECTA exams. This suggests they see the need for improving classroom instruction for student learning and achievement. Equally important is not only to improve quality instruction for quality learning and high achievement, but also to sustain it, to create what Muhammad (2010) called "a culture of success." Few of the schools surveyed had this culture of success with high achievement rates every year. They are among the best 10 schools in the country (D. Mushi, 2010).

\section{Lacking Leadership Skills for Tanzanian School Reform}

Because school principals or HMs receive no formal leadership training prior to assuming their leadership roles and are typically appointed to the school principalship after demonstrating some success in teaching and some leadership skills, these leaders end up serving in a managerial rather than an instructional leadership role. When I asked them about their strategies to improve student achievement, they mentioned a variety of things. For instance, they need more funds, conflict management, and improvement in classroom instruction (P. Osoki \& F. Furaha, personal communication, July 18, 2011). Furthermore, the Moshi superintendent reported to me, "the HMs mean well and some are working very hard to improve performance, only they do not know how" (W. Ruwaichi, personal communication, August 13, 2011). All of the HMs agreed that 
schools need some sort of reform. Current HMs can improve their learning through special training programs and become effective leaders capable of influencing student achievement.

Table 2

Moshi Catholic School Leadership Challenges as Expressed in a 2011 Pilot Study

\begin{tabular}{|l|l|c|}
\hline Challenge Category & Explanation & Out of 21 \\
\hline A: Finance & Finance: Fund raising and financial management & 20 \\
\hline \multirow{4}{*}{$\begin{array}{l}\text { B: Instructional } \\
\text { challenges }\end{array}$} & School master plan/ Vision/ goals and strategies & 19 \\
\cline { 2 - 3 } & Improving Student Achievement & $\mathbf{2 1}$ \\
\cline { 2 - 3 } & Creating and maintaining school culture of success & 20 \\
\cline { 2 - 3 } & Student/class behavior management & 12 \\
\cline { 2 - 3 } & Teacher's ethical responsibility/accountability & 15 \\
\cline { 2 - 3 } & Education management and evaluation & 7 \\
\cline { 2 - 3 } & Being knowledgable on Instructional Leadership skills & 18 \\
\hline & Conflict resolution & 5 \\
\cline { 2 - 3 } & Guidance and counseling & 6 \\
\cline { 2 - 3 } & Meetings management & 5 \\
\cline { 2 - 3 } & Parents involvements in school matters & 7 \\
\cline { 2 - 3 } & Legislation and Policy & 5 \\
\hline
\end{tabular}

Note: The table shows that improving student achievement is a number challenge of HMs of Moshi because it has a highest frequency of 21 followed by finance and creating and maintaining school culture of success.

\section{Attempted Solutions and Claims for a New Approach}

Systemic pedagogical improvement requires strategizing and organized

implementation, but this path has not been tread thus far in Tanzanian schools. Typically, when no one seems to know the right way to do it, several attempts might be made in the form of trial and error rather than from clear policy or research based professional development opportunities. In 2006, the Tanzanian government took the initiative to 
identify the most prevalent challenges to education in the country. The Education Sector Development Program gave some suggestions as to what the secondary schools need to do in order to improve student achievement. Among them were: improving the skills of untrained and under-qualified teachers, procuring appropriate teaching and learning skills, and assisting new teachers by fitting their in-service training to new curriculum demands through supervision and mentorship during teaching practice and probation (Tanzania Education Network, 2007b). I both agree and disagree with this proposal. While I agree that it is a solution to the problem, I also disagree that supervision and mentorship should not end in college with student teachers. Teachers' support, evaluation, and supervision should continue throughout their teaching careers. Another problem with the Education Sector Development Program proposal is that school leaders were not prepared to carry out these tasks (I. Amani, personal communication, May 15, 2011; Thomas \& Vavrus, 2009), which ensures the continuation of low-quality classroom instruction and student underachievement.

\section{Standardized Curriculum for All Schools}

Because of the disparities in student achievement between schools from the early 1970s, the Ministry of Education created and enforced the use of one standardized curriculum nationwide for both primary and secondary schools. The syllabi articulate the topics to be covered at every level, i.e., the teaching materials to be used, the goals and objectives of the subject, and how students are assessed. The teacher's job is to use the syllabi and adopt the template, making adjustments to fit the classroom environment. 
This ensures that the same content is learned by all the students in the country regardless of where their school is located.

Students are also measured by the same test nationwide after their seventh year. Other national tests are conducted at the end of the second year, at the end of the fourth year, and the last test at the end of the sixth year. While this approach assures uniformity of what students learn, it does not assure the quality of what they learn. As Appendix A indicates, the results are highly disparate; one might wonder why. If students are learning the same materials and are taking the same tests throughout the country, why do some schools have the achievement rate of $100 \%$ and others $0 \%$ ? This implies that having a standardized curriculum does not necessarily improve student learning and achievement. I agree that standardized curriculum helps all students to have the same learning materials regardless of their location and social economic background. A standardized curriculum also holds teachers accountable to cover the same content nationwide. However, classroom evaluation, which is necessary to ensure that quality teaching is taking place, has never being given its due emphasis. Unless quality instruction is ensured, students will continue to suffer. It also may mean that reforms are not being implemented with fidelity.

\section{Mandated Teacher Training Programs in Colleges}

One of the factors responsible for lowered student achievement is the lack of quality teachers. While there has been an increase in the number of secondary schools and student enrollment, there had been a disproportional increase in the number of qualified teachers. Although the number of secondary schools and student enrollment has 
grown dramatically, the problem of low student performance remains because the number of effective teachers is not keeping pace with the number of enrolled students.

To solve this problem, the Government of Tanzania through the Tanzania Commission for Universities issued a law that all colleges and universities, except schools of medicine, should have a teacher-training program. The fruit of this law is yet to be seen. Though this may sound like an effective stopgap measure, in reality, alone, it is simply not sufficient because there are a limited number of students who are eligible for a college education due to poor achievement in their secondary schools at the current time. With current graduation rates so low, it will take a long time before we see the effect of increased numbers of students in teacher education programs, further justifying my claim that the best approach to improving student achievement is to support and help our current teachers to improve their pedagogical skills through classroom instructional evaluation. Perhaps then, we will see increased numbers of students emerging from secondary schools to the university system where they can enter the teacher preparation programs.

In fact, underachieving students are not only in the new public community schools, but also in old schools, both private and public. It is a common problem across the country (D. Mushi, 2011). Quality education is suggested to be the remedy. But quality teaching needs quality leadership for its implementation as Oduro, Dachi, and Fertig (2008) suggested,

Achieving quality in education has increasingly become crucial in strategic improvement plans of developing countries. While the concept of quality and its priority indicators may differ from country to country, it is commonly considered as a determining factor in facilitating the implementation of education for all 
initiatives...At the centre of strategies for accelerating the achievement of quality education is effective leadership at all levels of the school system. (p. 1)

\section{The Student-Centered Pedagogical Policy}

In 2005, the Ministry of Education made another attempt to improve student learning and achievement by issuing a new policy that changed the pedagogical instruction from teacher- centered [the traditional lecturing method-“"The drill and kill" model] to learner-centered [constructivist model], with the hope that this research-based constructivist model of teaching will engage the students more, increase their learning interests, and thereby raise achievement. Thomas and Vavrus (2009) reported that the policy has not been effectively implemented because there are no opportunities for coaching and following up with the relatively few teachers trained in the constructivist model. Consequently, there is a gap between the policy and its implementation. The new policy has actually perpetuated the problem with the same, if not higher, failure rates. This leads to the conclusion that without effective instructional leadership at the school level, the policy might not be implemented.

While the research supports the use of a collaborative, constructivist teaching model to promote powerful learning and active student participation in the learning process (Leithwood, Mascall, \& Strauss, 2009; Quinn, 2002), it also questions the tendency of the legislature to leave school leaders out of the policy development and implementation process. The failure of the new policy proves the claim that successful school reform is possible only when leadership is actively involved (Chenoweth \& Everhart, 2002; Cunningham \& Cordeiro, 2000; Fullan, 2001; Senge, 1990). This is so because school leaders are the implementers or the primary overseers of policy 
implementation. Yet without the active support and coaching of school leaders, there has been little improvement if any (Glickman, 2002; Ross, 1992). That is why my study is focused on school leaders and not on classroom teachers. As it is, teachers are only successful when they are supported and helped to be the best in their profession, which is the responsibility of school leaders. "The principal's most important job is getting good teaching in every classroom" (Marshall, 2009, p. xvi). I am calling for the HMs to do this by working with and helping teachers improve their instructional skills. Quality instruction translates to student learning and achievement (Marshall, 2009). I believe that true school reform through instructional leadership and ESCI is the most effective way to improve learning.

\section{Attempted ESCI: Why it Failed and What it Should Be}

How about those few HMs who attempted classroom evaluation but got discouraged because their teachers abhorred it? Based on what I know from the $21 \mathrm{HMs}$ who participated in my pilot study and the story of Edwin, likely their administration of ESCI was deficient. They were using a defective model, and as one of the ESCI authorities succinctly put it, "The boss inspects and the workers shape up-or ship out" (Marshall, 2009, p. 19). Using authority and threats is not a good way of inviting teachers to improve their pedagogical skills and grow professionally.

That is why I advocate for the leadership praxes that will utilize both instructional and transformational leadership theories in conducting classroom evaluations. Leaders will need to develop their communication style by providing feedback with an assurance of support and interest in every teacher's personal and professional growth. An 
instructional leadership model is needed since it prioritizes teaching and learning as the primary duty of the HM. The HM's duties call for this model to be realized by ensuring the supply of teaching materials, protecting the curriculum and instructional time, and supporting teachers' instructional development so that they can be the best in their profession (Marzano et al., 2005). With the instructional leadership model, the school and community resources are utilized primarily for teaching and learning rather than myriad disparate concerns like capital projects, community meetings, and farm works.

Instructional leadership changes are best executed through transformational leadership, which calls for collaboration in designing the school's vision and mission, as well as caring for the individual teacher's personal needs. The leaders focus their attention in building relationships that are necessary for staff loyalty and productivity (J. R. Blase \& Blase, 2004). The transformational models call for the leader to set high expectations and lead by example. They also help their staff to think "outside the box" and inspire them to be the best they can be. Bolman and Deal (2003) asserted that this kind of leadership approach ensures teachers' commitment and productivity. Classroom evaluation done with this kind of leadership mentality communicates the right message to the teacher from the HM (Leithwood \& Mascall, 2008). In my imagination, this is the kind of message the HMs will be communicating to their teachers:

Something precious to us, namely, our students' achievement, is at stake here. As educators we have moral obligation to do something. It is not about me (HM), it is all about our students, and it is about your profession; it is about you. I want you to be successful, to grow, to shine, to reach your professional potential, and I am committed to support and help you. When you do well as a teacher, students also perform well. I believe in you, and we can do this: to improve student achievement by improving the quality of classroom instruction. I just want to help you to be the best teacher you can be, one who will cause our students achieve to 
the best of their potential. We are in this together. Let us do the work, and don't hesitate to ask for my help!

This kind of approach, like any change process, demands HMs change their perspective on how ESCI is and should be done (Chenoweth \& Everhart, 2002). It invites collaboration and commitment. It does not force or push, but appeals to the teachers' professional and personal conscience. Here I agree with Fullan (2001) who emphasized leaders must lead with a moral purpose, intentionally aimed at making a positive difference.

I would also argue from the story of Mr. Edwin, that lack of consistency in communicating feedback raises the suspicion of teachers about the intentions of HM's classroom observations. Marshall (2009) shared the same negative experience in his first year of teaching where his supervisor was critical and did not give ESCI feedback consistently. If the HMs cannot communicate ESCI feedback to their teachers in a timely manner, they should not conduct ESCI because the outcome is not likely to be improved teacher practice. Teachers must share in a post-observation conference quickly so that the information is fresh and the redirection is relevant and timely. Knowing that some HMs tried to conduct evaluations with little knowledge of how it is properly done (P. Osoki, personal communication, July 18, 2011), I praise those HMs who at least tried. Figure 3 represents what I envision to be the application of leadership theories and practice in improving teachers' pedagogical skills, instruction, student learning, and achievement.

This section has highlighted the various attempts made to improve student learning and achievement and the reasons why these attempts were met with little to no success. In the course of showing why these attempts were not successful, I have touched 
on some of the suggestions I am proposing as a new approach to improving academics. The administration of ESCI with a teacher-HM collaborative relationship will make a difference in student achievement.

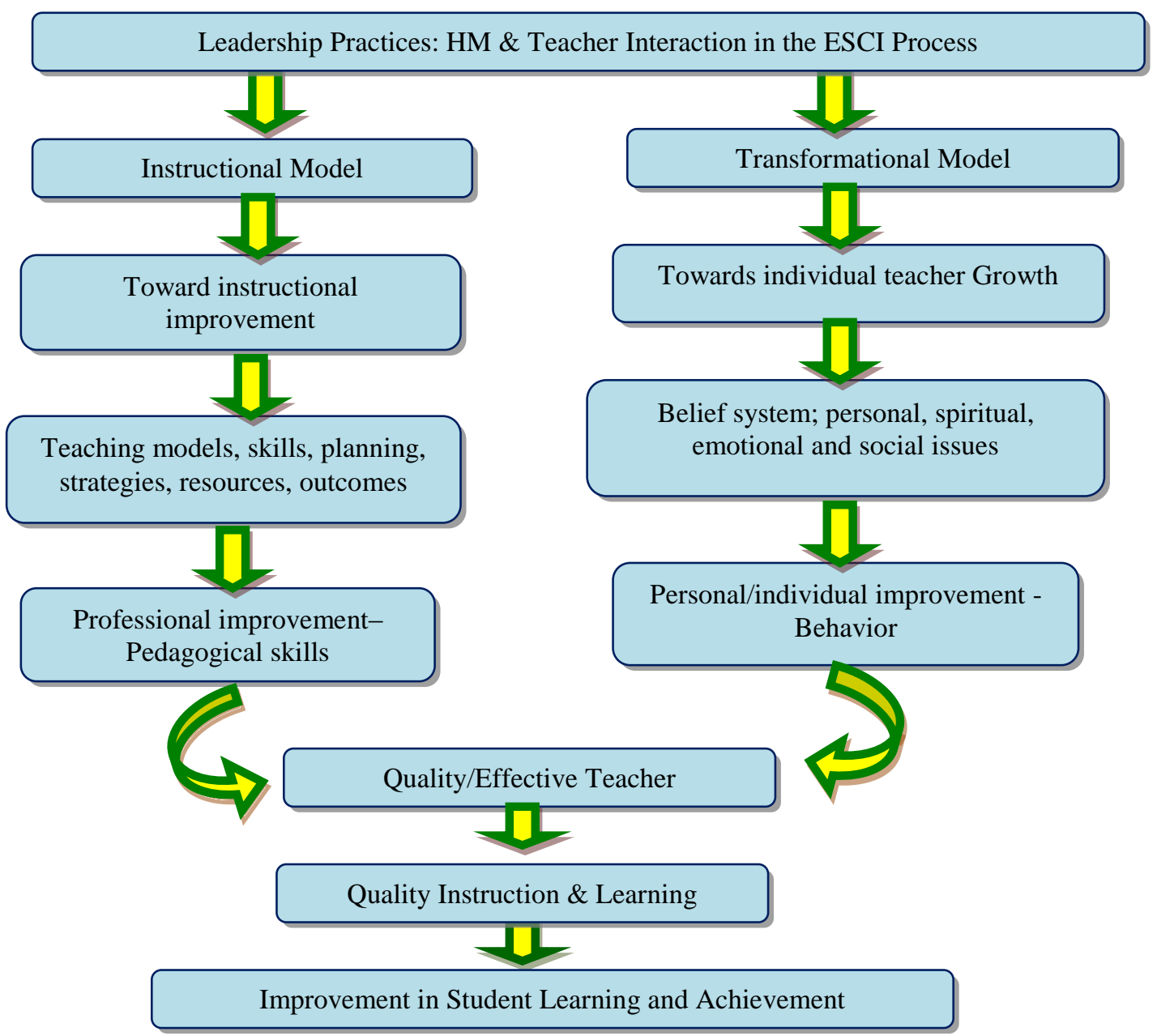

Figure 3. Vision of leadership for student achievement. Source: J. R. Blase and Blase (2004) and Bass and Riggio (2006).

\section{The New Approach: PBL Module for Instructional Leadership}

After identifying the multi-layered problem of student achievement, caused by a lack of quality classroom instruction and leadership's inability to influence the 
improvement of teachers' pedagogical skills, I am proposing the use of the PBL Training Module to help school leaders acquire the necessary instructional skills that enhance quality teaching and learning.

The training will introduce ESCI as the best leadership tool for instructional improvement (Danielson, 2004; Fink \& Markholt, 2011; Marshall, 2009).

HMs will need to learn how to properly and effectively administer ESCI, as well as take part in the process of adopting and developing it. This hopefully will answer my last study question: What is the best instructional leadership tool Tanzanian secondary school leaders can use to improve instruction in their schools?

\section{ESCI: The Leadership Tool for Quality Teaching and Learning}

The literature confirms that school's primary business is about teaching and learning (Bolman \& Deal, 2003). This implies that the school leader's primary responsibility is to ensure effective teaching and learning (J. R. Blase \& Blase, 2004; Daresh, 2002; Fink \& Markholt, 2011). Fullan (2001) supported this view by stating this kind of reform is not to be ignored but to be led. It is the responsibility of HMs to use ESCI to change the situation as part of education reform.

For decades now, ESCI has been used as a means of improving classroom instruction. Marzano et al. (2011) asserted that the sole purpose of instructional evaluation and supervision "should be the enhancement of teachers' pedagogical skills, with the ultimate goal of enhancing student achievement" (p. 2). Instructional improvement must be accomplished primarily by the teachers who actually do the classroom instruction. If the HMs hope to be of any value in improving instruction and 
student achievement, they must cooperate, support, and help those teachers be the best in their job. The HMs have to ensure that their teachers are becoming experts in their profession. This demands the HM to display, not only instructional leadership but also transformational leadership. Leithwood et al. (1999) asserted that "this form of leadership assumes that the central focus of leadership ought to be the commitment and capacities of organizational members-in this case, teachers" (p. 9).

However, the HMs who participated in my pilot study revealed they do not really know how to conduct ESCI in a transformational context or any other. At best, they have the experience of being evaluated when they were student teachers. Those who intuitively knew what ESCI can offer and tried to use it in their schools had little success. Of the 21 HMs in my pilot study, only four HMs attempted ESCI in the first two years of their leadership, and only one of them was still practicing it. Despite using a top-down authoritative model, which made teachers resent the practice, the student achievement of the HM who was still using it improved remarkably. The HM believes that this change was largely determined by the use of ESCI (P. Osoki, personal communication, July 18, 2011). Because of criticism, most of the HMs could not defend ESCI and quit using it (W. Ruwaichi, personal communication, August 13, 2011). Moreover, using the ESCI models like the ones of Danielson (2007), Marzano et al. (2011), Marshall (2009) and Fink and Markholt (2011) which prove suitable to the American school system and culture, might run the risks of being culturally unsuitable for Tanzanian schools. This might cause resistance and fail to produce the intended outcome. This is why I believe, if the HMs are equipped with instructional leadership skills and use the right ESCI tool, 
they are more likely to reform classroom teaching and student achievement. Figure 4 demonstrates the connection between ESCI and student achievement (Marshall, 2009). I concur with this view in which the process of improvement begins with the ESCI. This creates collaboration between the teacher and the HM and highlights the importance of quality instruction for student learning. Since ESCI is a way of coaching teachers to improve their teaching skills, it is expected to improve their quality as teachers, who, with quality instructions, will make quality learning for students. Quality learning produces good achievement.

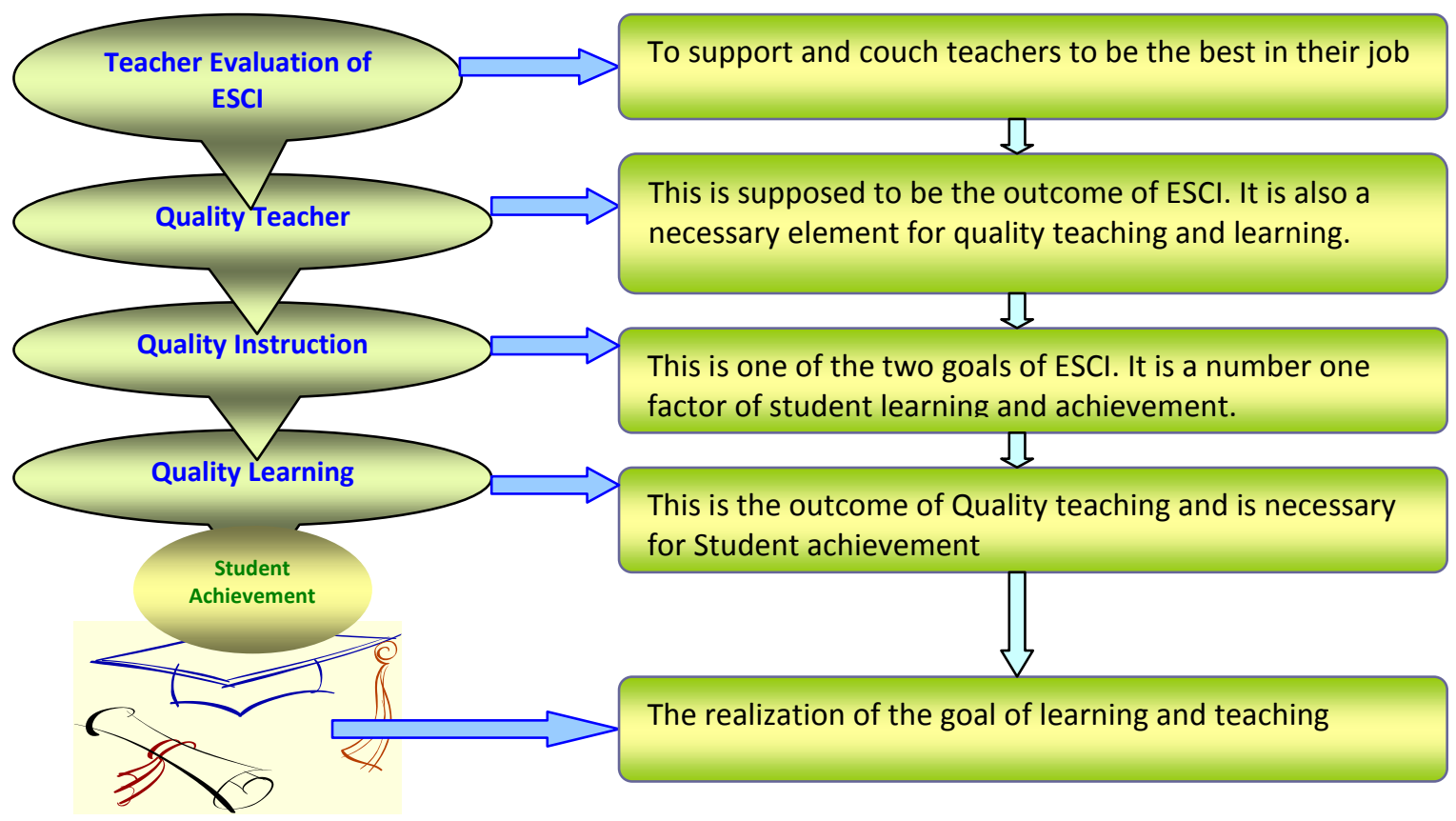

Figure 4. A conceptual representation of ESCI and student achievement. Source: Leithwood et al. (2004).

That is why this study is focused on teaching HMs how to conduct ESCI by adapting Charlotte Danielson's teaching model. This model or framework has four teaching domains, which are: planning and preparation, classroom environment, 
instruction and professional responsibilities. The model demands the teacher to be evaluated and rated in the four different standards of unsatisfactory, basic, proficiency and exceptional (Danielson, 2007). I chose to begin with this model over others because in its approach to the art and science of teaching, it is expansive, thorough, and robust. Its detailed rubrics articulate what the teacher is expected to demonstrate in quality teaching.

Having rubrics also helps HMs by having something handy to follow; also, teachers can participate in their own assessment as in the practice of clinical supervision and even make their own self-assessments. However, this does not mean that HMs cannot use other ESCI suitable models that would support teacher evaluation. In fact, I would encourage the Diocese or the District to develop a professional development program for HMs to learn these models. They can also be taught at Mwenge University in the Graduate Program of Educational Leadership, which began in 2012. HMs can adapt Marshall's "mini-observation" or Downey’s "walk-through" model, which can save HMs' time while maintaining their involvement in classroom instruction (Downey, Steffy, English, Frase, \& Poston, 2004; Fink \& Markholt, 2011; Marshall, 2009; Marzano et al., 2011).

\section{Clinical Supervision}

As the HMs master the evaluation practice over time, they can also apply clinical supervision. Clinical supervision became popular after Goldhammer's book, Clinical Supervision: Special Methods for the Supervision of Teachers, was published in 1969. This approach includes five phases as summarized in Table 3. 
Table 3

Five Phases of Clinical Supervision

\begin{tabular}{|l|l|}
\hline $\begin{array}{l}\text { Phase 1: Pre- } \\
\text { observation } \\
\text { Conference }\end{array}$ & $\begin{array}{l}\text { This phase was designed to provide a conceptual framework for observation. During } \\
\text { this phase, the teacher and supervisor planned the specifics of the observation }\end{array}$ \\
\hline $\begin{array}{l}\text { Phase 2: } \\
\text { Classroom } \\
\text { Observation }\end{array}$ & $\begin{array}{l}\text { During this phase, the supervisor observed the teacher using the framework } \\
\text { articulated in phase 1. }\end{array}$ \\
\hline $\begin{array}{l}\text { Phase } 3 \\
\text { Analysis }\end{array}$ & $\begin{array}{l}\text { Date from the observation was organized by the supervisor with the intent of helping } \\
\text { teachers participate in developing evaluations of their own teaching }\end{array}$ \\
\hline $\begin{array}{l}\text { Phase } 4 \\
\text { Supervision } \\
\text { Conference }\end{array}$ & $\begin{array}{l}\text { The teacher and the supervisor engaged in a dialogue about the date, the place and the } \\
\text { time of conference. The teacher asked to reflect upon and explain his or her } \\
\text { professional practice. This stage also could include providing didactic assistance to } \\
\text { the teacher. }\end{array}$ \\
\hline $\begin{array}{l}\text { Phase 5 } \\
\text { Analysis of the } \\
\text { Analysis }\end{array}$ & $\begin{array}{l}\text { The supervisor's practice was examined with the entire rigor and for basically the } \\
\text { same purpose that teacher's professional behavior was analyzed heretofore. }\end{array}$ \\
\hline
\end{tabular}

Note: Clinical supervision is done in dialogue between the teacher and HM in which the teacher leads the conversation (Goldhammer, 1969).

The research studies reported after 1970 indicate clinical supervision is effective in improving teaching. Attention is focused on the nine characteristics associated with gains in student academic achievement:

1. clarity,

2. variety in use of materials and methods,

3. enthusiasm,

4. task-oriented, businesslike approach to instruction,

5. avoidance of harsh criticism,

6. indirect teaching style,

7. emphasis on teaching content covered on the criterion achievement test, 
8. use of structuring statements that provide an overview for what is about to happen or has happened, and,

9. use of questions at multiple cognitive levels (Acheson \& Gall, 2003, p. 59).

There are some advantages to doing clinical supervision, despite the fact that it takes more time because of the number of conferences involved. The pre-observation conference helps both the teacher and HM to understand what is being evaluated and what is expected of the teacher. The teacher can ask questions to clear the doubts and build confidence. The supervision conference highlights the strength and growing edges of the teacher in those particular elements that were evaluated. The entire process demands collaboration with the sense of common purpose-creating quality learning and teaching for students (Anderson, 2001). As Acheson and Gall (2003) observed, the teachers take the charge and lead the conferences, determine what they want to be evaluated on, and articulate the outcome.

\section{Theories and Practice: Transformational and Instructional Leadership Models}

I propose to focus on the two leadership theories of instructional and transformational leadership because of their connection to ESCI and effective administration. The most suitable leadership models for understanding principal behavior show these two conceptual models as most helpful (Hallinger, 2003). Moreover, transformational leadership is suitable for the implementation of school reform and is effective because it influences the HM's behavior and helps the staff to want to commit to improving their teaching even more than they have been doing (Bass \& Avolio 1994). It aspires to accomplish the bigger goal of the organization, which in my case is improving teaching and learning for higher student achievement. Bass and Avolio 
introduced the 4-I's: Individual care, Intellectual stimulation, Inspirational motivation, and Idealized influence. Table 4 presents a summary of the 4-I's and their influence on the ESCI. It gives the HMs the skills they need most as they engage their teachers to improve the quality of their instruction. This model corrects the top-down authoritative way of conducting ESCI. It helps a HM to exercise high quality leadership as a person who cares about the staff, has vision and motivation, holds others responsible, and respects their input, while leading by example.

Table 4

The 4-I's of Transformational Leadership and ESCI

\begin{tabular}{|l|l|}
\hline \multicolumn{1}{|c|}{ The 4-I's of Transformation Leadership } & Impact on Leaders' behavior-ESCI \\
\hline $\begin{array}{l}\text { 1. Individual Consideration: Taking care to attend } \\
\text { the individual needs of the staff, give personal } \\
\text { attention to each, especially the left outs, show that } \\
\text { you care to make them care }\end{array}$ & $\begin{array}{l}\text { HM fosters cooperation between the HM and } \\
\text { teachers; care and commitment of teachers, be } \\
\text { kind, thoughtful, caring and yet tough and hold } \\
\text { them accountable to meet the goals-achievement }\end{array}$ \\
\hline $\begin{array}{l}\text { 2. Intellectual stimulation: Help the staff to think of } \\
\text { the past problems with new ways: Problems provide } \\
\text { windows of improvement show them their strengths, } \\
\text { challenge them to get to the next step }\end{array}$ & $\begin{array}{l}\text { HM challenges teachers to be creative, } \\
\text { constantly improving their pedagogical skills, } \\
\text { comminicate feedbacks times, show what is }\end{array}$ \\
\hline $\begin{array}{l}\text { 3. Inspirational motivation: Present powerful \& } \\
\text { dynamic presence, in communicating high } \\
\text { expectations of the staff (of teaching, learning, } \\
\text { achievement) }\end{array}$ & $\begin{array}{l}\text { HM sets high standards, set goals, mission and } \\
\text { vision, a symbol of success, acknowledge and } \\
\text { celebrate success to encourage the staff }\end{array}$ \\
\hline $\begin{array}{l}\text { 4. Idealized influence: Become a model to your } \\
\text { staff through passion, commitment, accomplishments } \\
\text { and demonstrated character-live what you say, be } \\
\text { role model, supportive, a symbol of assurance and } \\
\text { success. }\end{array}$ & $\begin{array}{l}\text { HM's passion and compassion demonstrates } \\
\text { hope, keep their spirits up, and provide } \\
\text { assurance of what they can do by doing your } \\
\text { best. Show by action and always that quality } \\
\text { learning matters, do not settle for less. }\end{array}$ \\
\hline
\end{tabular}

Note: Transformation leadership calls leaders to create a personal relationship with the staff, inspire, to demonstrate leadership by example. Adapted from Bass and Avolio (1994, p. 3).

The instructional leadership model, on the other hand, has been the most popular

style in education for more than three decades (Marzano et al., 2011). It directs the HM's 
full attention to teaching and learning. According to Smith and Andrews (1989) there are four tasks for a leader: providing instructional materials; supporting instructional activities and programs; communicating clear goals for the school; and being the provider of a visible presence by engaging in frequent classroom observations as well as being highly accessible to faculty and staff. Here I will add that the administration of ESCI reinforces this last role of visible presence for staff and students, classroom observation and support of teachers and staff in their daily duties of teaching learning.

Instructional leadership demands the HM unleash what it takes for quality teaching and learning to occur. If quality classroom instruction and school leadership are the two leading factors influencing student learning and achievement, as literature suggests, then, with failure rates of $50-100 \%$, either one or both are inadequate in Tanzania. Moreover, schools are unique organizations whose primary business is student learning. If quality learning is not taking place for all students to learn, it is worthy to ask, what are HMs doing? Since classroom instruction is what actualizes learning, it is logical that school leadership should ensure the best instructional practices in their schools. Therefore, school principals must be instructional leaders.

In this way, principals who are in charge of student learning should also be in charge of classroom instruction. Since teaching is done by teachers, the only way the HM can be in charge is to be well versed on what is going on in the classroom. This is where ESCI becomes mandatory for instructional leaders. Effective and quality instruction demands the availability of the necessary instructional materials, a safe learning 
environment, qualified teachers, and the support of teachers by the leadership through instructional evaluation and supervision with constructive feedback and staff development programs (J. R. Blase \& Blase, 2004). These are the duties of instructional leaders. I will also add that this explains the importance of leadership in improving student learning and achievement.

The two leadership models are complementary, not contradictory. Successful ESCI requires specific leadership qualities, including transformational and instructional leadership models. I agree with the view that "instructional leadership is not the only role of the school principal" (Cuban, 1988, p. 58). Both models define a shared mission and develop a common language for addressing academic challenges. For example, through classroom evaluation and supervision [instructional lens] the HM will identify the areas where a teacher needs to make improvement and will determine the professional program that will actualize this improvement in view of the teacher's personal growth and fulfillment [Transformational model]. Figure 5, which is a combination of Marshall's Evaluation Model with Instructional and Transformational leadership models, shows how ESCI is affected by these two leadership theories. It created a situation whereby teachers enter into the cycle of continuous growth and improvement of their pedagogical skills. 


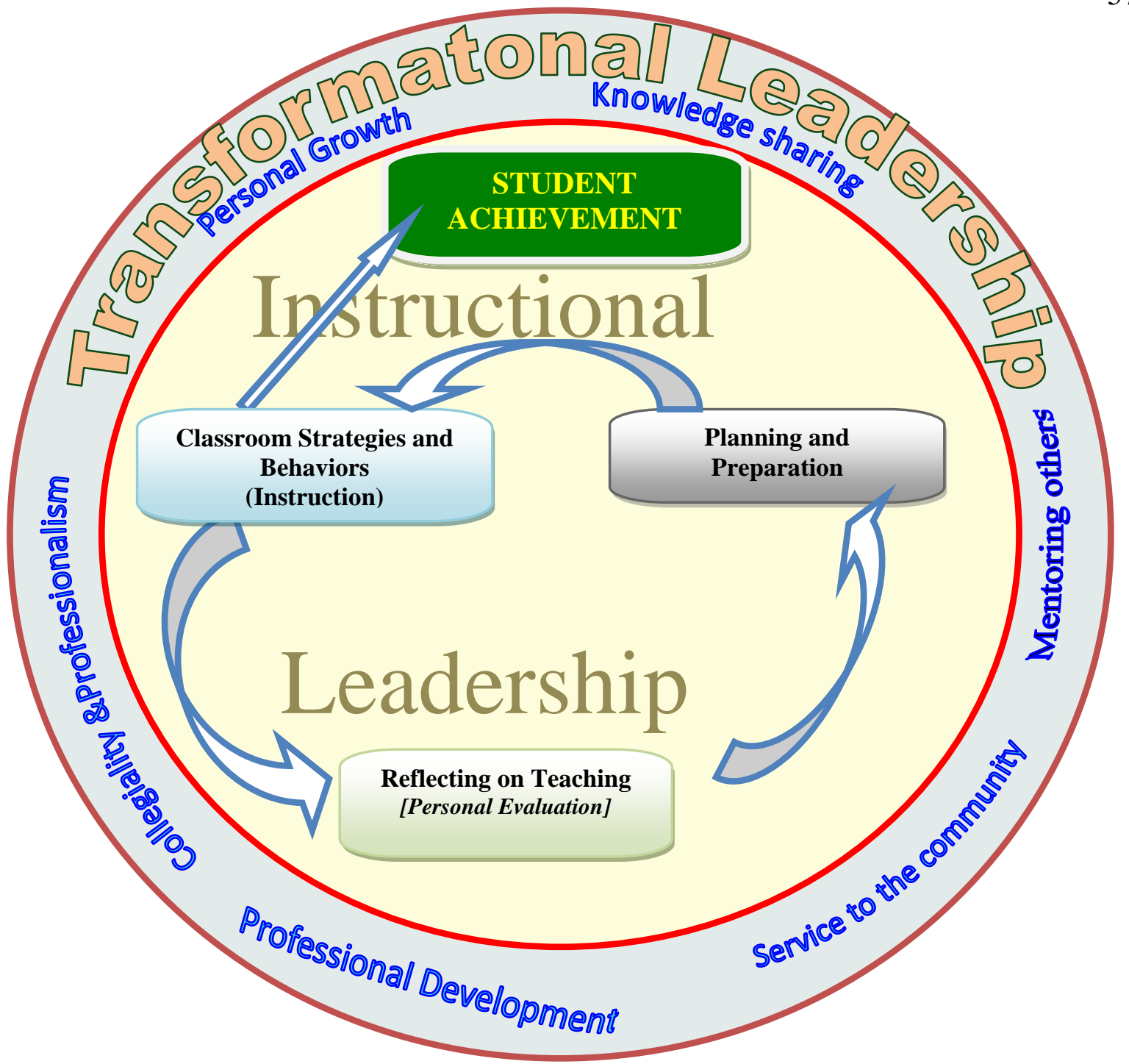

Note: The outer ring represents transformation the elements of transformation leadership while the inner ring represents the elements of instructional leadership. In the teaching process, planning and preparation determines classroom strategies and behavior (instructions). After teaching the teacher makes a reflection on the lesson and makes some changes if needed while doing the lesson plans for the next class. Student achievement is directly impacted by what happens in class, namely instruction. Transformational leadership creates a good environment for the effective instructional leadership (Marshall, 2009).

Figure 5. The Marshall's teaching domains and the two leadership models.

\section{Chapter Summary}

This chapter pointed out the current educational problem of secondary schools in

Tanzania: low student achievement. This problem is perpetuated by several factors 
including deficient leadership and a lack of effective teacher evaluation or ESCI strategies. Research shows that ESCI has been effective in developed countries like the United States for more than three decades. It is time for Tanzanian HMs to learn it, adapt it, and employ it in their leadership roles. This study, which utilizes the implementation of PBL, is designed to achieve just that. Another factor is the top-down model of administration at both the government and ministry levels, and by the HMs who attempted ESCI. The literature shows that the top-down leadership does not suit education institutions because of the teachers' autonomy in their profession (Bolman \& Deal, 2011; Deal, 1994). There is a direct link between student achievement and the quality of classroom instruction as well as a link between school leadership, teacher's performance, and student achievement. To end the cycle of student failure, I joined other education leaders and scholars and called for all HMs to participate in the implementation and field testing of the PBL training module. In doing so, the HMs learned how to effectively administer ESCI with a view toward improving teachers' pedagogical skills. It is anticipated this will improve teaching and learning, and research to this end will be conducted in 2014. To improve the quality of school leadership necessary for teaching and learning, instructional and transformation leadership models are called for as they offer the most helpful conceptual frameworks, and they are particularly suitable to ESCI (Marzano et al., 2005). In the next chapter, I explore how, through a PBL training module, I worked with Moshi Catholic school district leaders to address the problems of poor student achievement through effective ESCI. 


\section{CHAPTER III \\ RESEARCH DESIGN AND METHODOLOGY \\ Introduction}

This study used a PBL research model (Bridges \& Hallinger, 1995) to address a current, real problem of student achievement in the secondary schools of Tanzania by equipping high school leaders with instructional leadership skills. The study addressed the practice of leadership toward improving the quality of classroom teaching and learning. This was done by assisting HMs to conduct ESCI, while concomitantly improving their own instructional and transformation leadership skills. Literature shows that school leadership is best exercised when these two leadership models are employed (Leithwood et al., 2010). This chapter explores the research design which is theoretically and practically grounded in PBL (Bridges \& Hallinger, 1995) and the Research and Development (R\&D) model (Gall \& Borg, 1989). The chapter explains how data were collected from a 6-day professional development workshop for secondary school leaders to help them learn instructional leadership skills related to teaching and learning, and adapt classroom evaluation frameworks. Data were gathered from the following sources: from the observation of HMs engaging in the workshop; from small group discussions; role play; and presentations and formative assessment or evaluation after every session and at the end of every day.

Additional data were gathered from observing the HMs conducting ESCI with their teachers in their respective schools. The aim is to determine how effective the 
Instructional Leadership training was by making the HMs effectively conduct ESCI, and if, after learning how to conduct ESCI, determine whether or not the school leaders saw the benefits therein, and were willing to continue carrying out ESCI in the future. The data revealed the levels of their skills, competence, and confidence based on their selfassessment. The aim was to improve their instructional leadership skills so that they could help their teachers improve their pedagogical skills, thus improving the quality of teaching and learning. This was evaluated by pre- and post-self assessment of the participants.

\section{Research Design}

Thirty-one secondary school leaders from Moshi Catholic Diocese School District were invited to attend a 6-day professional development workshop in Moshi, Tanzania in July 2012. Each day had three sessions. The activities of the workshop included: lectures, small group discussions and presentations, larger cohort group discussions and presentations, individual work and role play. The course objectives of every session, as will be explored in detail in chapter 4, included: measuring what the participants knew before attending the workshop; encouraging participants acquire skills, confidence, competence, conviction, and motivation about ESCI; and helping them to identify their leadership challenges and solutions. Every session ended with formative assessment in which participants stated what they knew before the session, what they learned from the sessions in relations to their leadership tasks and what they wanted to know more about the same subject. At the end of each day, except the sixth day, participants completed a 
"talk back" form in which they identified what they wanted to keep or change for the following day.

The participants were HMs or their assistants when the HM was not able to attend. This study bears the PBL research characteristics as formulated by Bridges and Hallinger (1995). Table 5 articulates those characteristics as they applied in this study.

\section{Table 5}

\section{PBL Guidelines}

\begin{tabular}{|l|l|}
\hline PBL Characteristics & Their Application to the Study \\
\hline $\begin{array}{l}\text { 1. The starting point for } \\
\text { learning is a problem }\end{array}$ & $\begin{array}{l}\text { The problem of student underachievement in Tanzanian secondary schools } \\
\text { was the starting point }\end{array}$ \\
\hline $\begin{array}{l}\text { 2. The same problem is } \\
\text { what participants will face }\end{array}$ & $\begin{array}{l}\text { HMs of Moshi and Tanzania at large are currently facing the same } \\
\text { problem. }\end{array}$ \\
\hline $\begin{array}{l}\text { 3. Knowledge gained is } \\
\text { organized around the } \\
\text { problem }\end{array}$ & $\begin{array}{l}\text { HMs participating adapted the Danielson's evaluation tool and made it a } \\
\text { culturally sensitive tool for teacher evaluation in Tanzania; they learned } \\
\text { how to conduct classroom instruction evaluation, and applied the tool in } \\
\text { their respective schools. }\end{array}$ \\
\hline $\begin{array}{l}\text { 4. Participants assume } \\
\text { responsibility for their } \\
\text { own learning }\end{array}$ & $\begin{array}{l}\text { During the 6-day workshop participants actively participated in a variety } \\
\text { of activities including; small group discussions, presentations, role } \\
\text { playing, providing effective feedback and contributing to the development } \\
\text { of a culturally appropriate evaluation instrument. Then, HMs used the } \\
\text { product to conduct evaluations in their respective high schools. HMs } \\
\text { provided written and verbal feedback about the effectiveness of the tool. }\end{array}$ \\
\hline $\begin{array}{l}\text { 5. Most of the learning } \\
\text { occurs in small groups }\end{array}$ & $\begin{array}{l}\text { During the 6-day workshop HMs participated in numerous small group } \\
\text { discussions, writing activities, role plays and small group presentations. }\end{array}$ \\
\hline
\end{tabular}

Note: The five requirements for a study to be a PBL research fits perfectly my study. This was adapted from Bridges and Hallinger (1995, pp. 5-6).

The 31 participants who attended the 6-day workshop to implement the Instructional Leadership Training Module also learned about ESCI and they adapted Danielson's evaluation tool (Danielson, 2007). They learned its use through small groups and role play. They removed any elements that were incompatible with their education 
system and culture. At the end of the workshop, we came up with the product, a culturally appropriate evaluation tool for instructional evaluation. Then they used the product to implement ESCI in their respective schools. I visited some of them to see how they were doing and to get their comments on what went well and what might need some adjustment. My intention was to observe their readiness to use the tools, and their skill, confidence, and competence, and motivation toward doing so. That would measure whether or not the training module was effective. The evaluation was done through preand post-workshop self-assessment of the participants.

\section{R\&D Cycle}

Bridges and Hallinger (1995) adapted the work of Gall (2006) to fit PBL and identified 10 steps in the R\&D cycle. Seven of these were utilized by this study as explored below.

\section{Preliminary Work: Research and Information Gathering}

Because of the problem of student underachievement, it is paramount that secondary school leaders be recruited who can exercise the kind of leadership that will improve classroom teaching and learning. Since HMs generally do not perform ESCI, teachers do not get the support and coaching they need to improve their pedagogical skills, which translates into quality teaching and learning. To address this problem, I conducted a pilot study in 2011 to determine the viability of this project. I also developed the Instructional Leadership Training Module or Curriculum.

My primary investigation and the pilot study, conducted with the superintendent of schools and some of his HMs, clearly indicated that the structure of the education 
system in Moshi is sophisticated and advanced enough to predict with reasonable probability that a successful product could be built; namely, the PBL instructional leadership training module or curriculum. The Moshi Catholic school principals seem to be suitable participants because of their knowledge and leadership experience. I had the full support of Rev. William Ruwaichi, the superintendent of the Catholic school district, and the endorsement of Right Reverend Isaac Amani, the Bishop of Moshi and the CEO of the Catholic schools. The Education Department of Moshi Diocese is willing to subsidize the cost of accommodations for the participants (the HMs) for the six days of residency during the workshop. The 31 schools that were invited to participate in this study unequivocally responded positively. However, seven schools out of 31 chose not to participate in the workshop. I also had the support of the Department of Education of Mwenge University who had the plan to assist with the workshop.

My preparations for the event included a review of the literature on the following major topics:

- school leadership and reform (J. R. Blase \& Blase, 2004; Chenoweth \& Everhart, 2002; Fullan, 2001, 2005, 2008);

- factors affecting school leadership ( Bass \& Avolio, 1994; Burns, 1978; Howell \& Costley, 2006; Marzano et al., 2005; Senge, 1990; Yukl, 2001);

- school leadership factors affecting student learning and achievement (Leithwood \& Jantzi, 1999; Leithwood et al., 2004; Leithwood \& Riehl, 2003);

- the relationship between school leadership, teaching and learning (DuFour, 2010; Muhammad, 2009; Ott, 1996; Tucker \& Stronge, 2005);

- different models of ESCI and their impact on pedagogical improvement including the role of the principal in improving quality teaching and learning, and student performance (Bass \& Riggio, 2006; Danielson, 2007; Fink \& 
Markholt, 2011; Leithwood et al., 1999; Marshall, 2009; Marzano et al., 2011);

- $\quad$ and the implementation of PBL and its development cycle (Bridges \& Hallinger, 1992; 1995; Gall \& Borg, 1989; Hallinger \& Murphy, 1987).

I also conducted a pilot study in 2011 to determine the real problem facing

Tanzanian high schools and the main challenges of the HMs (see Table 2). The finding of the pilot study determined the specific topic of this dissertation. I conducted some interviews over the phone and via email or Skype. From the responses it was clear to me that student underachievement was the main problem, and HMs did not know what to do to change the situation. In addition, I examined some statistics of the Tanzanian national exams results of 2009 to 2011 at the Ministry of Education official website in order to determine the student performance. Bridges and Hallinger (1995) support my approach as they asserted, "The student may conduct 'small-scale research,' such as observations in schools, and interviews with practitioners and researchers who are knowledgeable about the problem" (p. 120). My findings justified the claim of the HMs, that student underachievement is a real problem.

The new approach to teacher evaluation was implemented within five months. During the 6-day workshop, the instrument was developed and readied for a field test. The HMs took the instrument with them and began using it. Their comments, feedback, and my observation assisted in the revision of the instrument.

\section{Planning: Objectives, Learning Activities, and Small Scale Testing}

I used Moshi Catholic School HMs because of their accessibility, and also because of the support I had from the HMs and their superintendent. The fact that all 31 HMs agreed to participate in this study and devote their time, day and night, for six days 
at Longuo Retreat Center-Moshi, is clear proof that they were determined to learn and make a difference in their schools. Each day I conducted three sessions, two in the morning and one in the afternoon. Each session had small group discussion and presentation of findings to the main cohort. Nights were used for social gatherings, informal discussion to process what happened during the day, and the viewing of educational leadership or similarly related movies. There was a break in the afternoon and evening for the participants to do their personal business or to catch up with their personal readings. They used the adapted format of consultancy protocol to guide them in the group discussion. A generic consultancy protocol was provided in their training kit.

Consultancy Protocol is a problem-solving process in which the leaders collect data to better understand a problem and postulate possible solutions. In framing and reframing the issue through comprehensive query and gathering input from others, it is more likely that the school leader will collect all the relevant data and then be able to formulate a plan of action that will engender support. This process also indicates the use of a collaborative role playing format based on consultancy protocol to develop their skills at in-depth problem solving and enhance the quality of their decisions through peer input.

During the sessions, participants attended lectures to learn how to conduct ESCI, using the general approach of Fink and Markholt (2011). The purpose of this approach was to equip the principals with the knowledge of what makes great instruction. They also learned the teaching skills so that they could be able to identify the presence or absence of the necessary elements of quality instruction of any academic discipline at any 
grade level. Then they used the available tools of ESCI, specifically the rubrics of Danielson (2007). They gave their feedback on what worked and what did not work with their own particular school's cultural system. The participants evaluated the content of the lectures and their relevancy through formative assessment.

\section{Preliminary Program/Product Development}

I collected the resources for training the HMs in the 6-day workshop on ESCI from July 23-28, 2012. I organized a training kit for every participant with materials for every session, formative evaluation forms, vignettes for group discussion, and other resources for them to read, discuss and about which to make comments. One of the objectives of the training was the adaptation of Danielson's (2007) ESCI tool. Through their small group discussions, the participants had an opportunity to identify any culturally inappropriate elements in the rubrics. The small groups then brought their findings to the main group or workshop cohort in the form of a presentation. The discussion in the main group led to accepting or modifying the information and adapting it as part of the new instrument. Participants used this process to eliminate or add any element, thus creating an instrument and tool that will be culturally appropriate, thereby enhancing the ESCI. This tool was the byproduct of the PBL module, a veritable "hands on" of the training module. It was also the first instructional leadership product created by the local school leaders as opposed to the rest that were created by the legislatures. Before departure, the final adapted copy was made available for them so that the participants could walk out with the revised instrument on the last day.

\section{Preliminary Field Test}


The training module preliminary test took place a week prior to the workshop. For one day I met with five HMs who were also the leaders of the small groups during the workshop. I went through the abstract, goals, and objectives of training, guiding questions, and in brief, the entire contents of the workshop with them, and explained what was expected of the participants. They gave their feedback, which helped to modify the curriculum and training activities. They were introduced to Danielson's evaluation tool and used it through role play. During the role play, one of them taught a lesson, [playing the teacher's role] one played the HM role and the rest in the group played the students. This was a preliminary field testing of the training module. "The purpose of preliminary field test is to obtain an initial qualitative evaluation of the new educational product" (Gall \& Borg, 1989, p. 170). They were asked to write and report their personal feelings on what was easy or difficult, where they felt confident and competent, or where they felt doubtful. They were asked to point out what elements they feel the needed to know more about, or felt unsure about how to employ. These observations were recorded and addressed in the cohort group during the workshop. The reported elements were used to refine the training module. These five HMs identified what they thought would work well with the remaining HMs, as well as what they believed might not work as well, and why. They were also asked to provide an alternative solution for what they believe would not work. The information gathered from these five HMs, plus my observations and my peers' observation reports, are part of my data collection.

\section{Main Program/Product Revision}


The revisions necessary were based on the data gathered from the preliminary field test of the training module. Additional revisions of the training module occurred as they were determined throughout the sessions. The formative assessment, or the talk back, given by each participant after every session and at the end of each day helped modify the training curriculum and activities for the module. The outcome of one of the workshops' learning objectives accomplished through workshop activities and curriculum were the findings generated from the preliminary field test. These were used to modify the evaluation tool. Participants processed the cultural element in their small groups and made any necessary modifications, bringing their findings to the main group though presentations, thus guiding modification of the tool. Modifying the tool included, but was not limited to, eliminating some elements from the Danielson's rubrics that are found to be culturally incompatible with Tanzanian school culture. Participants were encouraged to add any useful elements, making the tool more effective in improving classroom teaching and learning. Other suggestions were considered that may also help school leaders to more effectively administer ESCI. The revised version of the evaluation tool was now ready for a main field test in their schools.

\section{Main Field Test}

The workshop curriculum and activities served as the main field test. As mentioned above, the revisions of the module sections were made as the training continued. The feedback given in every session and each day set the direction of the training, and we continued to adjust the training schedule and procedure to improve its effectiveness. Participants, after learning how to conduct ESCI by using the evaluation 
and supervision rubrics, tried it out in their small groups and in the main group through role play with their peers. I observed and assisted them where needed. One of the evenings was also dedicated to role play so as to give every participant an opportunity to practice, with the hope that this experience would increase HM competence and confidence as they planned to implement teacher evaluation in their schools. Once again, the consultancy protocol was used to help them process their practice. Since at this point we had an amended evaluation tool, one teaching vignette was used by every participant to work through the teacher-evaluation process. HMs further evaluated the tool to determine if there are any culturally incompatible elements remaining in the Danielson rubrics. Participant feedback in the form of a formative-evaluation procedure was encouraged in which they were asked to identity what was different in performing the evaluation alone as opposed to doing so in the group with peers.

The revised version of the Danielson's (2007) rubrics was given to every participant as the trial or official evaluation instrument they used for ESCI in their schools. As a follow-up activity after training, they were asked to sign a letter of consent for me to visit and observe them as they conducted ESCI in their respective schools. They were subsequently asked to give their feedback in the form of formative assessment using the same format: what worked well and why? What did not go so well and why? What are your alternative suggestions? This information served as qualitative evidence of whether the training was effective or not and provided me with data needed to further modify the training module as well as modify the evaluation instrument. As mentioned 
earlier, the teacher evaluation instrument or tool is the outcome of the training curriculum and activities.

\section{Operational Product Revision}

At this final stage, the training module was ready for use since revisions were done on a daily basis. However, I made the final revision of the training module using the data collected in follow-up activities, since HMs had been practicing ESCI in their schools. I made any needed revisions of the adopted evaluation rubrics based on the data collected in the schools. Assuming that the product or the PBL training module proved to be efficacious, I used the findings collected at Stage 6 to make a final revision of the product, making it ready for use by the rest of the school leadership of Moshi schools in particular and in Tanzania in general. This final product can be adopted in the curriculum of the educational leadership graduate program at Mwenge University College of Education in Moshi, as well as in other Catholic and non-Catholic universities in Tanzania with school leadership programs. The participants' training products and materials formed a handbook and resource kit (videos, articles, books, paper, pens, etc.) for training Tanzanian school leaders on how to improve the quality of classroom instruction to enhance quality teaching, student learning, and achievement.

\section{Action Plan and Timeline}

The workshop began July 23-28, 2012at Longuo Retreat Center of Moshi Catholic Diocese. I visited their schools to conduct a short seminar with the teachers to assist the HMs implementing ESCI. For one month I was available for support, coaching, and to receive their feedback. I have continued to be available via email and Skype for 
those who continue to need my support. I asked the office of the superintended to dedicate some time for a follow-up and support as the HMs began to implement ESCI. I believe that after one to two semesters, the HMs would be able to tell if ESCI was helpful in their instructional leadership or not.

\section{Research Questions: Primary and Secondary}

The primary and secondary questions are grounded in the body of research literature for improving student learning and achievement. As shown in chapter 2 , the literature affirms that student learning is primarily improved by improving the quality classroom instruction. The literature also answers some preliminary questions, which helped me to come to my research questions. For example, my first question was: How can Tanzanian schools leaders improve the quality of classroom instruction so as to enhance student learning and performance?

This question did not qualify to be my research question because it is too general and wide. However, it helped to narrow my literature review. The suggested answer was for the HMs to use instructional leadership and focus on teaching and learning. I even ask sub-questions like, what are the underpinning leadership theories that reinforce best school leadership practice? This question led me to learning of instructional and transformation leadership models.

The literature also affirms that teacher evaluation or ESCI is the best way to support and help teachers improve their pedagogical skills and their classroom instructional performances. The pilot study had established that generally HMs do not conduct teacher evaluation in Tanzania. If they are to begin doing ESCI they have to 
learn first, and they have to use an evaluation tool. But the available teacher evaluation tools were developed for American schools system and culture. This raised the second question: Can the evaluation tools developed for American school system be suitable to serve the Tanzanian school system or do they need to be adapted into the Tanzanian system? I want to discover whether the ESCI tools that were developed for American (Western) school system are directly applicable to the Tanzanian school system, if Danielson's evaluation and supervision rubrics are culturally compatible with Tanzanian school culture, or are there some culturally incompatible elements that need to be pruned before they can be used in Tanzania.

The research study questions also come from the fact that Tanzanian Secondary School HMs assume the role of leadership straight from their teaching careers without having any formal training in school leadership. This might make it difficult for them to conduct ESCI since they are unfamiliar with the process. As the Moshi HMs affirmed, most of them have only one single experience of ESCI-year before when they were evaluated as student teachers.

With this knowledge in mind, it was clear to me that the HMs needed to develop some instructional leadership skills, particularly with regard to teacher evaluation. I therefore created a PBL curriculum or module for this training to address the primary and secondary research questions.

\section{Data Collection}

The 6-day professional development workshop constituted the main ground for data gathering. The workshop group activities and individual participation were set in 
such a way that they were constantly a source of data. Among the activities in which the participants engaged actively:

- Attending lectures to learn basic instruction skills such as the characteristics of the instructional leadership and transformational leadership, the characteristics of quality instructions, different evaluation models including formal evaluation (Danielson, 2007; Marzano, et al., 2011); Clinical evaluation (Goldhammer, 1969); mini-evaluation (Marshall, 2009); and informal evaluation or "walk through" (Acheson \& Gall, 2003). This took the lecture format.

Data were collected from formative assessment participants made at the end of every session, talk back assessment which participant gave at the end of each day, their comments and questions, my observation of group activities and individual participation and reactions, and any other relevant information given by the participants or invited guests.

- Before learning about the science and art of ESCI participants, completed their pre-training self-evaluation form. This measured their skills, confidence, competence, conviction, and motivation before they were trained on how to conduct ESCI. This was later compared with post-evaluation of the same elements to see if the training changed their personal assessments.

- Participants used vignettes to conduct two teacher evaluations. One was done before learning about Danielson's (2007) teaching framework and evaluation tool and the second was done after adapting Danielson's rubrics. The comparison was made to see if using adapted Danielson tool made any difference in the way the participants did the evaluation.

- After learning the goals and objectives of the workshop, but before they engaged in training, participants were asked to express what they expected to learn or accomplish with this training. Their expectation was compared with their assessment at the end of training in which they expressed if their expectations were met or not.

Journal writing, video and visual recording were used to collect data after getting written consent from the participants.

With the consent of the participants, I recorded their presentations and their role plays in the cohort or main group. I am aware that this can be threatening to them since it is early in their acquisition of these new skills. Therefore, recording depended on their 
comfort level and wiliness to do participate. Another source of data was from optional school visitations and teacher workshops. Teachers' participation, comments, questions, and formative assessment at the end of their seminar will be taken as a source of data.

\section{Data Analysis}

Comparative and descriptive data analysis will be done to determine the effectiveness of the curriculum and learning activities of the 6-day workshop. To begin with, it is important to mention here that data analysis is done throughout the product development cycle (Gall \& Borg, 1989). The data collected from feedback given by the five HMs in the preliminary test prior to the workshop and the formative assessment talk back after each session and after each day were analyzed to modify the schedule and the activities of the PBL training module. Also, the evaluation given at the end of each day was analyzed to determine what worked and what did not work during the training. This information was used to modify the workshop operation of each day. A report was written at the end of each day regarding what worked well, what needed some modifications, and what was deleted from the PBL Teaching Module.

The data collected from pre-evaluation at the beginning of the workshop and postevaluation and the end of the workshop determined the level of skills, competence, confidence, conviction, and motivation the training imparted to the participants. These elements are also referred to as "indicators" of the effectiveness of the PBL module. The analysis of those indicators or the word analysis was done by comparing the pre and postevaluation responses in relation to those indicators. The results of completing teacher evaluations on the imaginative teaching vignette was analyzed as well by comparing the 
pre- and post-training results. The difference was used to measure the knowledge or skills acquired by the participants.

To determine the effectiveness of the module, a comparison was made between participants' expectations of what the training hoped to provide and what they actually learned. Using a simple scale of 1-3: 1-did not meet my expectations, 2-met my expectations, and 3-exceeded my expectations, participants answered the question: Did the workshop meet your expectations? The frequency of these responses measured the how closely the workshop and its curriculum met the expectations of the participants.

\section{Ethical Guidance: Bias and Position of Power}

I believe I had a unique position in this study, which worked to my advantage. I did this study in the school district where I was a teacher 10 years ago. That gave me some familiarity with the system in such a way that I was not a total stranger. However, there had been many changes in educational policies and practices during the last 10 years, ones with which I was not familiar in the current system. This raised my curiosity to learn what was happening, and in a way made me dependent on the knowledge of true insiders. Moreover, I had never been a principal myself. I had to learn from the participants as an inside observer. Finally, I did not have direct or executive power over the participants or of any school. The fact that I am a Catholic Priest of the Moshi Diocese did not automatically give me power over schools in Moshi diocese and its operations. However, it might have given me a bit of respect and likelihood of HMs to listen to my opinion, basing on their Catholic tradition, even if not all were Catholics. I had also the power of knowledge since I facilitated the workshop as a doctoral student of 
Portland State University (PSU). I had some experience concerning the educational system of Tanzania and expertise on educational leadership. These worked to my advantage in that it was likely for the HMs to respond to my invitation to participate in this study because they might be convinced that I had something to offer them in their leadership tasks. At the same time I was dependent on their goodwill as to what they wanted to share with me and how much they were willing to participate.

To ensure freedom of expression without the fear of consequences, instead of using their names, participants were given their secret number to be used for pre- and post-evaluation, talk back forms at the end of every session, and the evaluation at the end of each day. During the first session, the participants were asked to establish their own group rules and how they would like their information to be handled. The information revealed in the sessions and participants' feedbacks were treated as confidential.

Participants were free to opt out at any time or refuse to participate in any section of implementation without consequence. To ensure this, their superintendent, the Mwenge University President, some faculty in the Education department and the bishop of Moshi were invited to participate at the closing sessions only. They were invited to witness the final presentations, which expressed the findings and learning of the participants. Finally, the bishop and superintendent and the University leadership and faculty participated in the closing ceremony in which Bishop Amani offered certificates to the participants.

\section{Chapter Summary}

PBL best suits this study since it addressed the current real problem of student underachievement within a school system where school leadership did not have adequate 
training or the instructional skills to solve the problem. The R\&D cycle offered a framework with seven steps through which the product was developed and refined. The final revision was made after the actual field test, making the product ready for use training high school principals in Tanzania on how to develop instructional leadership skills through ESCI. Data were collected during the workshop and in the schools when I visited 11 of them. Data collection and analysis were done as the PBL Teaching Module was implemented during the 6-day workshop and through the use of the revised teacher evaluation instrument in high school classrooms after the workshop. The revised evaluation instrument was the byproduct of the PBL Training Module. As a researcher, I have the unique position of being relatively familiar with the school system of Tanzania without being a real insider within the system. I do not hold power over the participants, and since the information was de-identified and participants were free to opt out at any time during the process, I did not anticipate any danger or harm to the participants. This research was completed within six months. 


\section{CHAPTER IV \\ PBL RESEARCH STUDY: ANALYSIS AND FINDINGS \\ Introduction}

Quality education for all students is desired by all education stakeholders

including teachers, students, parents, and leaders. In Tanzania, the existing data show that this desire for quality education for all students is compromised, especially at secondary/high school level. It is a paradox of failure: there are too few students who transition from grade school to high school and more than $50 \%$ of those who transition to high school fail (United Republic of Tanzania, Ministry of Education and Vocational Training, 2011). This fact makes one wonder, is there anything that can be done to save our failing students?

This question brought me to the education leadership program at PSU. When I came to the program, I was aware of the problem of student achievement in Tanzania, first as a student of that system for six years, although I was blessed to be in one of the best schools in the country, St. James Seminary, and second as a teacher of the same school for four years. I always wondered if my fellow teachers from other schools throughout the nation could be helped to make their students do a little better since some of these schools had a failure rate of $100 \%$.

As a student in the education program in the United States, I was exposed to a different education system. The one difference that stood out prominently was that teachers are supposed to be supported and coached in their teaching profession by their 
principals. Teacher evaluation is used as a school leadership tool of improving teaching and learning. According to Klein (2010), supporting and holding teachers accountable makes a real difference in student learning and performance. This observation influenced my choice of this study which was conducted in the time frame as Figure 6 shows.

As part of this study, I conducted an extensive literature review exploring the factors of quality teaching and learning and the role of leadership. The literature confirmed that quality teaching is a primary factor that influences student learning and performance. School leadership was ranked as number two in student learning and achievement. (Chenoweth \& Everhart, 2002; DuFour, 2010; Leithwood et al., 2004; Marzano et al., 2005; Sanders \& River, 1996). Research also attests that ESCI is a leadership tool that helps improve teaching and learning (Danielson, 2007; Marshall, 2009). My thought from these findings was that Tanzanian HMs could improve student achievement by doing ESCI with their teachers.

When I began this research work on my dissertation, I chose a qualitative research methodology because I was looking for a curriculum that could develop the qualities and skills of school leaders. I chose a PBL approach aligned with steps in the R\&D process because it is focused on real problems experienced by practitioners in the field, and because it leads to actually solving problems of practice (Borg \& Gall, 1989; Bridges \& Hallinger, 1995). In this way, the above information became part of Step one of R\&D process. 


\section{Personal Experience}

1985-1991:High school

Student at St. James
2000-2003: High school Teacher at St. James
2003-2006: Graduate school of Education Student - Walsh Univ., Ohio.

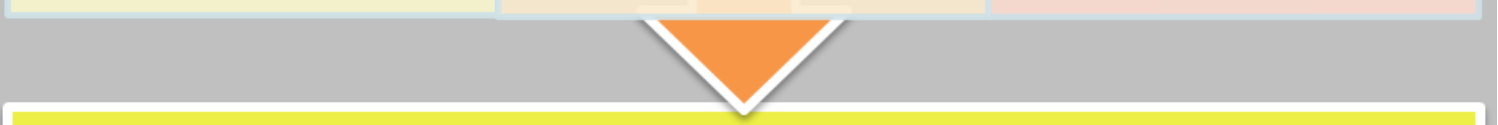

\section{Literature Review}

2009-2011: Educationa leadership, teaching and learning, leadership theories
2011-2013: Teacher evaluation models, quaitilty teaching and teacher evaluation.

\section{Pilot Study}

August - December 2011: Pilot study which established that student achievement is a number one leadership challenge.
Explore some statistics from the Ministry of Education of Tanzania that confirmed that student achievement is a prorblem.

\section{Creation of the PBL Model}

2012 : Creation of the PBL Curricullum to train 24 High school HMs about ESCI

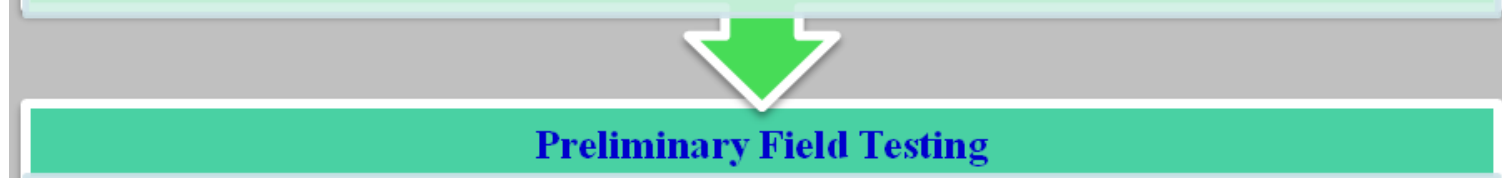

2012: The Module was field tested with my supervisor, cohort class, the professor at Mwenge University and 5 HMs of Moshi Catholic Schools.

\section{Main Field Testing}

July 30 - August 4, 2012: Six-day workshop with $24 \mathrm{HM}$ of Moshi to field test the module. The ESCI was done using vignettes and role playing in the four discussion groups and in the main cohort group.

Note: This shows the time-line of curriculum development and field testing of this study.

Figure 6. The research development timeline. 
To better understand the current student achievement problem, I conducted a pilot survey study with $21 \mathrm{HMs}$ of Moshi Catholic high schools from August to December 2011. With the help from my advisor and Dr. Moti Hara, the research specialist of the Graduate School of Education of PSU, I designed questionnaires and distributed them to the $21 \mathrm{HMs}$. The analysis of the data showed that student achievement was the number one leadership challenge of the HMs. The national statistics from the Ministry of Education and the NECTA also confirmed that it was a national problem. This supported my initial suggestion that the HMs should be asked to improve teaching and learning through ESCI (United Republic of Tanzania, Ministry of Education and Vocational Training, 2011). But the HMs had no formal leadership training, and so 19 out of 21 said they did not know about ESCI and that they had never used it. I concluded that the only way to get them do ESCI was to inform them through leadership training. Thus, I began the process of creating a PBL curriculum.

This led me to Step 2 of the R\&D process. In the course of planning, I initially developed a 6-day workshop plan to implement a PBL module for HMs in Tanzania. Preliminary plans included 18 sessions loaded with topics to be processed, group activities and goals and objectives for each session. In Step 3, I further developed the 6day plan with course content and training resources thus developing a preliminary form of a PBL module for Tanzanian HMs.

The preliminary module was field tested four times as Step 4 of R\&D process. First it was tested with my advisor, then with my doctoral cohort group. In Tanzania it was tested with Dr. Kidevu, the chair of graduate program of education leadership at 
Mwenge University, and then it was field tested with five HMs of Moshi. The findings were used to refine the curriculum, which is Step 5. Changes were made including the addition of Danielson's (2009) enhancing professional development training kit. This framework was chosen because it is comprehensive and was specifically a framework for teaching high schools. The number of group discussions was reduced from too many to manageable and two more indicators, "conviction and motivation," were added to the goals of the curriculum. This means, the curriculum was intended to impart not only skills, competence, and confidence to employ ESCI, but also motivation for doing it and conviction that it has the ability to make a difference in education improvement.

The indicator of competence was included because people tend to do what they feel they are good at doing. Confidence was included as an indicator as a means to make the HMs feel that they know what they are doing; they can do it and are ready to answer teachers' questions if needed. These two indicators are the product of knowledge and skills about teacher evaluation. This means, the PBL module was intended to give the participants skills to have what it takes to conduct teacher evaluation and be willing and confident enough to actually do it. The five HMs who participated in the preliminary field testing added conviction with the argument that they are likely to commit doing teacher evaluation if they convinced that it will make a difference. They also added motivation with the argument that motivation will make HMs likely to create time for teacher evaluation despite their busy schedules.

The main field testing, which is Step 6, took place in Moshi, Tanzania from July 30 to August 4, 2012. There were 18 sessions of about two and half hours each. Session 
activities included learning computer skills for leadership use, attending lectures on such topics as art and science of quality teaching and learning, and teacher evaluation or ESCI. Sessions also included hands-on activities in which participants did ESCI through vignettes and role playing. The phrase or acronym ESCI was preferred over "teacher evaluation" because, as one participant reminded the group, "For us 'teacher evaluation' is something that we do to the teacher at the end of the year to assess annual performance, which might lead to appraisal or salary increment" rather than professional growth and development. In this study, teacher evaluation and ESCI are used interchangeably though culturally, the terms may have slightly different meanings among the study participants.

Since the participants were going to do teacher evaluation in their schools after training, they needed an evaluation tool. Two sessions were dedicated to adapting Danielson's teacher evaluation tool to make it culturally relevant for the Tanzanian school system. This process answered a secondary research question, which questioned if Danielson's tool, created for American schools, could be used in Tanzania. Participants were proud of their new tool because its adaptation was a product of their work. They used it to develop and practice their teacher evaluation knowledge and skills using vignettes and role playing in small groups.

Through discussion they explored the possible causes of the problem of student underachievement. They used the Four Domains of the Danielson teaching model namely: planning and preparation, classroom environment, instruction and professional responsibilities and suggested what each HM should do to solve the problem of chronic student underachievement. During last day of the workshop, participants made action 
plan-based presentations to demonstrate what they learned and their future strategies of implementing ESCI in their schools. The participants also equipped themselves with the leadership skills of dealing with teacher resistance and legal and ethical issues through the process of a consultancy protocol, which is basically a group-process tool to help school leaders identify a problem to make informed decisions on challenging leadership issues (Harmony Education Center, 2012). The group dealt with four real cases.

Step 7 used the findings from main field testing to refine the PBL module. Among changes made to the module, additional time for role playing was added, and the process of adapting Danielson's tool was changed from an individual to group process and computer-assisted session.

The implications of the outcomes answered my primary research question. The question was whether the PBL curriculum could give the HMs what it takes to professionally employ ESCI. For the HMs to do ESCI, the module had to improve their leadership skills and empower them with competence, confidence, conviction, and motivation for doing ESCI. One of the clear outcomes was that the participants were not only aware of the problem, but also became aware that they were part of the problem because of their ineffective instructional leadership. One participant commented with regret, "I feel terrible that all these years I closed my eyes thinking the problem had nothing to do with me, but with teachers and students. I witnessed so many young people trashing their lives without knowing that I contributed to the problem." Another one commented, "I thought I was too busy, and I was, but doing trivial things while neglecting my real duty." 
Another implication was to witness how participants exercised their leadership in small groups to maximize session time. For example, during the process of adapting the Danielson evaluation tool, participants were directed to do that work individually and bring their report to the group. This would yield 24 reports. Instead, they did the work in the groups, thus yielding only nine reports to the larger group. Those who felt they were not ready to convince their teachers about ESCI asked for my help. As a result, I visited 11 schools and did short seminars with teachers about ESCI. After the seminars, teachers embraced ESCI with enthusiasm as evidenced by their comments to me.

My primary research question was further answered by post-training, participant self-assessment, and the evaluation of the PBL curriculum. Participants' pre-evaluations were compared with post-evaluations. Analysis of this comparison clearly showed that the PBL curriculum training changed the way participants viewed themselves in terms of four key indicators related to their skills, competence, confidence, and motivation to do ESCI in the future. They had greater skills, competence, confidence, and motivation after training than before. They also explicitly stated that the module either met or exceeded their expectations. In short, the research question was answered affirmatively that the PBL module can train Tanzanian HMs and makes them feel capable of using ESCI to improve student learning and performance.

The participants also evaluated the curriculum content materials and the facilitator. They were both rated as being "very good” or "exceptional.” My overall experience with this study was that it was long, demanding and very tiring, but very rewarding in terms of what it accomplished and the difference I anticipate it will make in 
the future. I was blessed to have such a committed group of leaders who sacrificed their personal time to learn ESCI. I was also amazed at the great support from my professors, colleagues, and the Superintendent of Moshi. I strongly believe that the PBL module will continue to do great service for education in Tanzania.

\section{Stages of R\&D Process}

\section{Step 1: Research and Information Collection}

Personal experience. The first step began with my personal experiences. When I was a high school teacher, I always wondered if anything could be done to improve the performance of our students. Some were doing very well, but some were not. I had always wanted to help my colleagues who were struggling to do their best. Like the story of Mr. Busara in the preface, I felt helpless because I did not know what to do to help. I also knew that leadership was needed for progress in an organization. So I directed my curiosity toward high school leadership wondering, if there is anything HMs could do to solve the problem of chronic student underachievement. This curiosity not only led me to the educational administration program at PSU, but also influenced the choices I made during this study.

I had another personal experience as a graduate student at both Walsh University in Canton, Ohio and at PSU in Portland, Oregon. I discovered that teachers in the United States are not left alone after college, or at least they are not supposed to be. Ideally are helped through different programs and by their principals improve their pedagogical skills (Fink \& Markholt, 2011). I also discovered that teacher evaluation is a common practice throughout the United States which can help teachers improve their teaching 
skills. I wondered if Tanzanian HMs could be taught to do the same with their teachers. With all these thoughts and ideas in mind, I wanted to create a curriculum that would help Tanzanian HMs improve teaching and learning. I assumed school leaders, if trained, can make a difference.

From my personal experiences, I also learned that something can be initiated to help solve the problem. Although there are many factors that influence quality teaching and learning, leadership intervention in helping teachers appeared to work well in the United States despite some resistance from teacher unions because it makes teachers accountable for student learning outcomes (Fink \& Markholt, 2011). But I needed to know more about how school leaders can actually help to solve the problem of student under achievement.

From the national statistics. I learned that the problem of student achievement is a national problem (see Appendix A). I also learned that the education stakeholders are not satisfied with the current situation of our schools (D. Mushi, 2010). Commenting on the 2010 results, Bishop Isaac Amani of Moshi said, "Something must be done to change the current school system in which more than half of our students are failed. This is morally unacceptable" (I. Amani, personal communication, May 15, 2011). The superintendent demonstrates the same view in his comment regarding the same exam results, "Our HMs and teachers need some help to improve academics in our schools. I am sure they are not happy with the national results but they do not know what to do to improve teaching and learning that will improve student performance” (W. Ruwaichi, 
personal communication, August 13, 2011). The common assumption here is that improving teaching and learning will improve student performance.

Literature review. I conducted a preliminary literature review on such topics as organizational leadership, teaching and leadership theories, instructional and transformational leadership, effective schools, quality teaching and learning, school culture and climate, and school policy and politics. I then narrowed my focus in the literature review to factors that influence student performance.

The literature affirmed some of my assumptions. One of them is that, to improve student performance, school leaders should make quality teaching and learning a number one priority of their leadership duties (J. R. Blase \& Blase, 2004; Chenoweth \& Everhart, 2002; Fink \& Markholt, 2011). I also learned that training HMs with the aim of improving quality teaching is possible and is the best approach of solving the problem of student achievement because it addresses the primary factors that influence student achievement, namely quality teaching and leadership (Leithwood et al., 2004; Leithwood et al., 2010; Marzano et al., 2005). The literature also revealed that teacher evaluation or as it is referred to in this study as ESCI, was the best instructional leadership intervention to improve quality teaching and learning (Danielson, 2007; Marshall, 2009).

Pilot survey: August to December 2011. To identify the real problems as experienced by practitioners in the field and get their personal views on their challenges, I conducted a pilot survey study with the HMs of Moshi Catholic School District, Tanzania from August through December 2011. With the input from my advisor and from the department of education research specialist of PSU Dr. Moti Hara, I developed 
questionnaires (Appendix C). In consultation with the superintendent of Moshi Catholic Schools, I sent the questionnaires to Tanzania. Of the $28 \mathrm{HMs}$ who were invited to answer the questionnaire, 21 responded. I coded and analyzed the data which established the following:

- Among the HMs leadership challenges, student achievement ranked number one.

- The HMs wanted to solve the problem but did not know how or what to do.

- HMs longed to improve their leadership skills through some form of learning but did not have the opportunity. The professional development program was not exercised.

- They did not know how to professionally conduct ESCI and some had never heard of it.

- They did not know at all about Danielson's teacher evaluation model. They did not have any specific evaluation model they could refer to. As one said, "I have always thought classroom evaluation is a professorial thing, it was not my job. I know nothing about it."

- They did not do instructional evaluation except for two HMs who did it in a nonprofessional manner. It was an unpopular practice with expected teacher resistance.

From this knowledge, workshop training appeared to be the best option to impact academic improvement in Tanzanian schools. Moshi Diocese Catholic School District was selected for this study for number of reasons. First, I have support from the diocesan leadership. The superintendent of Moshi, Rev, William Ruwaichi, is my classmate and my personal friend. He had promised to give his support as I needed. Second, it was because of my familiarity with the area. I was born and raised in the area; I also studied and taught in the same educational system although there are some changes from the time I was teaching. Third, it was because of the enthusiasm shown by the participants of the pilot survey. Some of their responses included such personal comments as, "Can 
somebody help us to understand how to make teachers improve their work?" Another participant commented, “The national exams results embarrass me every year. I wish I knew what to do to change." Fourth, I was able to provide professional development using of the facilities available at Moshi for the workshop. The Moshi-Longuo retreat center was ideal for this study because it is a five-story building which can accommodate 50 people at the same time with a kitchen and dining area with a personal cook. This was very convenient because whenever I needed to extend sessions, it did not interfere with the schedule of other residents. The facility has three big conference halls, comfortable chairs and tables. It was a perfect place for this kind of a workshop.

\section{Step 2: Planning Objectives, Learning Activities, and Small-Scale Testing}

At this stage I formulated the plan for the PBL module in the form of a detailed schedule. The relevant topics for improving HMs' instructional and transformation leadership skills were identified and included in the plan. Participants made a formative assessment of every session and talk back assessments at the end of every day. In total there were four major assessments, pre- and post-workshop assessment, and participants' anticipation of what they thought they would learn with what they actually learned. There were also 15 formative assessments and 6 talk back assessments. The topic per session, group activities of every session, and course objectives were articulated to the participants, and course objectives of every session were presented as demonstrated in Table 6. At this second step, I also formed research questions. 
Table 6

The Workshop Schedule, Group Activities, and Course Objectives

\begin{tabular}{|c|c|c|c|c|}
\hline อ & $\begin{array}{l}\cdot \overline{0} \\
\bar{n} \\
\tilde{n}\end{array}$ & $\begin{array}{c}\text { TOPICS PER SESSION AND ITS } \\
\text { EVALUATION }\end{array}$ & $\begin{array}{c}\text { GROUP } \\
\text { ACTIVITIES }\end{array}$ & $\begin{array}{c}\text { COURSE } \\
\text { OBJECTIVES/ WHAT } \\
\text { THEY LEARNED }\end{array}$ \\
\hline \multirow[t]{3}{*}{1} & $1^{\text {st }}$ & $\begin{array}{l}\text { 1. Introduction: Getting situated, given } \\
\text { numbers, name tags, assigned in } \\
\text { groups and given the training } \\
\text { binders. } \\
\text { 2. Pre-evaluation: inform about what } \\
\text { you know and what you will learn. } \\
\text { 3. Video Clip by Joel Klein on Joel } \\
\text { Klein: Accountability: What's it Really All } \\
\text { About. } \\
\text { 4. What do you anticipate to know } \\
\text { about ESCI. } \\
\text { 5. Formative assessment }\end{array}$ & $\begin{array}{l}\text { 1. Attend the lecture } \\
\text { 2. Video clip on } \\
\text { Quality Teaching } \\
\text { 3. Fill the evaluation } \\
\text { forms } \\
\text { 4. Questions and } \\
\text { Answers }\end{array}$ & $\begin{array}{l}\text { 1. Get started } \\
\text { 2. Measure what they } \\
\text { know and what they } \\
\text { want to know } \\
\text { 3. Give a general picture } \\
\text { of the Training Module } \\
\text { 4. Assess the effectiveness } \\
\text { of the session }\end{array}$ \\
\hline & $2^{\text {nd }}$ & $\begin{array}{l}\text { The art and science of school } \\
\text { leadership: Instructional and } \\
\text { Transformational Leadership } \\
\text { 1. Is instructional supervision and } \\
\text { evaluation done? Why and why not? } \\
\text { 2. Evaluate NECTA } 2011 \text { Form IV } \\
\text { exam results and their interpretation } \\
\text { 3. What would you like to change in } \\
\text { the exam results of } 2011 \text { in your } \\
\text { school? } \\
\text { 4. Formative assessment of the session }\end{array}$ & $\begin{array}{l}\text { 1. Small Groups } \\
\text { discussion } \\
\text { 2. Presentations in } \\
\text { the Cohort group }\end{array}$ & $\begin{array}{l}\text { 1.Linking Leadership } \\
\text { duties to teaching } \\
\text { 2.Identify the existing } \\
\text { problem of student } \\
\text { failure } \\
\text { 3. Brain storm on what is } \\
\text { needed to change the } \\
\text { situation } \\
\text { 4. Learn from others' } \\
\text { experiences }\end{array}$ \\
\hline & $3^{\text {rd }}$ & $\begin{array}{l}\text { 1. Danielson's Video Clip on ESCI } \\
\text { 2. Why instruction leadership is needed } \\
\text { for ESCI? } \\
\text { 3. Formative assessment of the session } \\
\text { 4. Talk back - assessment of the day }\end{array}$ & $\begin{array}{l}\text { 1. Watch the video } \\
\text { 2. Discussions in } \\
\text { small groups } \\
\text { 3. Presentations }\end{array}$ & $\begin{array}{l}\text { 1. Evaluate their likes and } \\
\text { dislikes of the process; } \\
\text { conducting ESCI }\end{array}$ \\
\hline 2 & $1^{\mathrm{st}}$ & $\begin{array}{l}\text { 1. Make an evaluation of imaginary } \\
\text { teacher using the Vignette } \\
\text { 2. Formative assessment of the session }\end{array}$ & $\begin{array}{l}\text { 1. In Groups-make } \\
\text { evaluation of the } \\
\text { teacher in the } \\
\text { vignette } \\
\text { 2. Presentations }\end{array}$ & $\begin{array}{l}\text { 1. Measure participant } \\
\text { skills of determining } \\
\text { effective instruction, } \\
\text { conduct evaluation, } \\
\text { communicate feedback }\end{array}$ \\
\hline & $2^{\text {nd }}$ & $\begin{array}{l}\text { 1. Lecture on what makes Quality } \\
\text { Teaching using Fink and Markholt's } \\
5 \text { Dimensions of effective teaching } \\
\text { 2. Formative assessment of the session }\end{array}$ & $\begin{array}{l}\text { Attend the Lecture } \\
\text { on Principles of } \\
\text { Quality Teaching of } \\
\text { any subject at any } \\
\text { level }\end{array}$ & $\begin{array}{l}\text { 1. Acquire Instructional } \\
\text { skills quality of } \\
\text { teaching and learning }\end{array}$ \\
\hline
\end{tabular}


Table 6 (continued)

\begin{tabular}{|c|c|c|c|c|}
\hline$\vec{\Xi}$ & 言 & $\begin{array}{c}\text { TOPICS PER SESSION AND ITS } \\
\text { EVALUATION }\end{array}$ & $\begin{array}{c}\text { GROUP } \\
\text { ACTIVITIES }\end{array}$ & $\begin{array}{l}\text { COURSE } \\
\text { OBJECTIVES/ WHAT } \\
\text { THEY LEARNED }\end{array}$ \\
\hline & $3^{\text {rd }}$ & $\begin{array}{l}\text { Discussion on Fink and Markholt's } 5 \\
\text { Dimensions } \\
\text { - Presentations from small group work } \\
\text { - Formative assessment of the session } \\
\text { - Formative assessment of the Day }\end{array}$ & $\begin{array}{l}\text { 1. Group discussion } \\
\text { on the Dimensions } \\
\text { of teaching } \\
\text { 2. Presentations }\end{array}$ & $\begin{array}{l}\text { 1. Acquire Instructional } \\
\text { skills and express them } \\
\text { to others } \\
\text { 2. Build confidence of } \\
\text { instructional leadership }\end{array}$ \\
\hline \multirow[t]{3}{*}{3} & $1^{\text {st }}$ & $\begin{array}{l}\text { DANIELSON'S } 4 \text { DOMAINS-Domain } \\
\text { 1: Planning and Preparation: } \\
\text { 1. What will work in your school and } \\
\text { why? } \\
\text { 2. What won't work and why? } \\
\text { 3. What will you add in the rubrics and } \\
\text { why? } \\
\text { 4. Formative assessment of the session }\end{array}$ & $\begin{array}{l}\text { 1. Evaluate the } \\
\text { Danielson's } \\
\text { evaluation tool in } \\
\text { the Groups } \\
\text { 2. Presentations }\end{array}$ & $\begin{array}{l}\text { 1. Acquire knowledge of } \\
\text { Danielson's } \\
\text { framework } \\
\text { 2. Build a culturally } \\
\text { responsive Evaluation } \\
\text { tool for Tanzanian } \\
\text { Schools } \\
\text { 3. Build competence and } \\
\text { confidence in } \\
\text { practicing ESCI }\end{array}$ \\
\hline & $2^{\text {nd }}$ & $\begin{array}{l}\text { 1. Domain 2: Classroom Environment- } \\
\text { the same work as of } 1^{\text {st }} \text { session } \\
\text { 2. Formative assessment of the session }\end{array}$ & $\begin{array}{l}\text { Group discussions } \\
\text { and presentations }\end{array}$ & $\begin{array}{l}\text { 1. Acquire knowledge of } \\
\text { Danielson's } \\
\text { framework } \\
\text { 2. Build competence and } \\
\text { confidence ESCI }\end{array}$ \\
\hline & $3^{\text {rd }}$ & $\begin{array}{l}\text { 1. Domain 3: Instruction-the same } \\
\text { work as of } 1^{\text {st }} \text { and } 2^{\text {nd }} \text { sessions } \\
\text { 2. Formative assessment of the session } \\
\text { 3. Formative assessment of the Day }\end{array}$ & $\begin{array}{l}\text { Group discussions } \\
\text { and presentations }\end{array}$ & $\begin{array}{l}\text { 1. Acquire knowledge of } \\
\text { Danielson's } \\
\text { framework } \\
\text { 2. Build competence and } \\
\text { confidence ESCI }\end{array}$ \\
\hline 4 & $1^{\mathrm{st}}$ & $\begin{array}{l}\text { Domain 4: Professional } \\
\text { Responsibilities-same work as of } \\
\text { Yesterday's sessions } \\
\text { Formative assessment of the session }\end{array}$ & $\begin{array}{l}\text { Group discussions } \\
\text { and presentations }\end{array}$ & $\begin{array}{l}\text { 1. Skills of Danielson's } \\
\text { framework } \\
\text { 2. Build competence and } \\
\text { confidence ESCI }\end{array}$ \\
\hline & $2^{\text {nd }}$ & $\begin{array}{l}\text { Adaptation Danielson's evaluation } \\
\text { rubrics } \\
\text { Formative assessment of the session }\end{array}$ & $\begin{array}{l}1^{\text {st }} \text { do it individually. } \\
2^{\text {nd }} \text { in the Groups. } \\
3^{\text {rd }} \text { make } \\
\text { presentations in the } \\
\text { cohort group }\end{array}$ & $\begin{array}{l}\text { 1. Acquire ESCI skills of } \\
\text { Danielson's } \\
\text { framework } \\
\text { 2. Build competence and } \\
\text { confidence- } \\
\text { Instructional } \\
\text { Leadership through } \\
\text { ESCI }\end{array}$ \\
\hline
\end{tabular}


Table 6 (continued)

\begin{tabular}{|c|c|c|c|c|}
\hline ลे & 言 & $\begin{array}{l}\text { TOPICS PER SESSION AND ITS } \\
\text { EVALUATION }\end{array}$ & $\begin{array}{c}\text { GROUP } \\
\text { ACTIVITIES }\end{array}$ & $\begin{array}{c}\text { COURSE OBJECTIVES/ } \\
\text { WHAT THEY } \\
\text { LEARNED }\end{array}$ \\
\hline & $3^{\text {rd }}$ & $\begin{array}{l}\text { 1. Feedback communication and } \\
\text { discussion after evaluation } \\
\text { 2. Characteristics of Effective feedback } \\
\text { [Video Clip] } \\
\text { 3. Formative assessment of the session } \\
\text { 4. Formative assessment of the Day }\end{array}$ & $\begin{array}{l}\text { 1. Attend the } \\
\text { lecture } \\
\text { 2. Watch a Video } \\
\text { clip } \\
\text {-Both done in } \\
\text { the cohort group }\end{array}$ & $\begin{array}{l}\text { 1. Acquire ESCI skills of } \\
\text { Danielson's framework } \\
\text { 2. Build competence and } \\
\text { confidence-Instructional } \\
\text { Leadership through } \\
\text { ESCI }\end{array}$ \\
\hline \multirow{3}{*}{5} & $1^{\mathrm{st}}$ & $\begin{array}{l}\text { 1. Vignette-application of the rubrics. } \\
\text { 2. Role Play on how to communicate } \\
\text { feedback from the vignette } \\
\text { 3. Formative assessment of the session }\end{array}$ & $\begin{array}{l}1^{\text {st }} \text { do it } \\
\text { individually } \\
2^{\text {nd }} \text { in the Groups } \\
3^{\text {rd }} \text { make } \\
\text { presentations in the } \\
\text { cohort group }\end{array}$ & $\begin{array}{l}\text { To compare the results of } \\
\text { the vignette with the } \\
\text { former vignette evaluation } \\
\left(1^{\text {st }} \text { session of Day } 1\right) \text {. This } \\
\text { will determine the } \\
\text { relevance of using rubrics } \\
\text { in doing ESCI }\end{array}$ \\
\hline & $2^{\text {nd }}$ & $\begin{array}{l}\text { Discussion on their findings and } \\
\text { changes they plan to make as a result of } \\
\text { this workshop } \\
\text { Formative assessment of the Session }\end{array}$ & $\begin{array}{l}\text { Role play on doing } \\
\text { ESCI in the small } \\
\text { groups and in the } \\
\text { cohort. }\end{array}$ & $\begin{array}{l}\text { 1. Acquire effective } \\
\text { feedback } \\
\text { communication skills } \\
\text { 2. Reinforce competence } \\
\text { and Confidence in } \\
\text { doing ESCI }\end{array}$ \\
\hline & $3^{\text {rd }}$ & $\begin{array}{l}\text { Discussion on their findings and } \\
\text { changes they plan to make as a result of } \\
\text { this workshop } \\
\text { Formative assessment of the Session } \\
\text { Formative assessment of the Day }\end{array}$ & $\begin{array}{l}\text { Role play on doing } \\
\text { ESCI in the small } \\
\text { groups and in the } \\
\text { cohort. }\end{array}$ & $\begin{array}{l}\text { 1. Acquire effective } \\
\text { feedback } \\
\text { communication skills } \\
\text { 2. Reinforcing } \\
\text { competence/Confidence } \\
\text { in doing ESCI }\end{array}$ \\
\hline 6 & $1^{\text {st }} 2^{\text {nd }}$ & $\begin{array}{l}\text { Action plan presentations of the Small } \\
\text { groups to a Panel of Educational } \\
\text { Leaders from Moshi : Bishop, } \\
\text { Superintendent, President of Mwenge } \\
\text { University, Professors of Education } \\
\text { leadership of Mwenge University, etc. }\end{array}$ & $\begin{array}{l}\text { Cohort group } \\
\text { And the panel of } \\
\text { educational leaders } \\
\text { and experts }\end{array}$ & $\begin{array}{l}\text { Demonstrate their skills, } \\
\text { confidence and } \\
\text { competence of using } \\
\text { Danielson evaluation tool } \\
\text { to do teacher evaluation }\end{array}$ \\
\hline & $3^{\text {rd }}$ & $\begin{array}{l}\text { - Unfinished Business } \\
\text { - Post Evaluation } \\
\text { - } \text { Conclusion } \\
\text { - } \text { Issuing of Certificates [By } \\
\quad \text { Superintendent or Bishop or the } \\
\text { President of Mwenge] }\end{array}$ & Cohort Group & \\
\hline
\end{tabular}


The primary question is, Can the PBL curriculum I created effectively prepare Tanzanian HMs to professionally conduct teacher evaluation or ESCI using Danielson evaluation tool in view of improving the quality of teaching and learning? The secondary research question was formulated to address the cultural relevance of Danielson (2007) tool. Since this tool was created for American school system, the question was, Can the Danielson evaluation tool, which is suitable for American school system, be used in Tanzanian school system? With these questions came the formation of the first part of the instructional leadership-training module or curriculum. This included the goals and objectives of the module which were:

- The learners will be able to use the resources provided in the PBL module in understanding the relationships between key variables: (a) between instructional and transformational leadership, (b) between quality teaching and learning, and (c) between ESCI and quality teaching and student achievement.

- The learners will develop a knowledge base about instructional leadership that helps in solving the problem of student achievement in their school.

- The learners will be able to demonstrate an understanding of conducting teacher evaluation using Danielson's evaluation tool by participating in the group discussion, role playing, and developing an action plan to present to Moshi educational leaders on how they will implement ESCI in their school environment and culture.

- The learners will be able to demonstrate an understanding of the relevance of the school culture by participating in the process of acculturating the Danielson teacher evaluation process for Tanzanian schools.

- The learners will be able to analyze the school's problem of student underachievement, its main cause, and provide a rationale for changes to take place.

- The learners will be able to personalize their understanding of how to use Danielson's model of instructional evaluation by presenting a two-year action plan. 
I sent these goals to the superintendent and the HMs with an invitation to participate in this study. The invitation letter can be found in Appendix C. They all approved the goals and accepted the invitation by May 2012. The HMs added some topics, which were not directly related to quality teaching and learning, like budgeting, school safety assurance, purchasing, transportation, and financial management. These were not part of the sessions, but they were addressed in private lectures at night, and they are not part of this study.

At this point I continued to narrow my literature review to focus on instructional evaluation, teacher evaluation, or ESCI, and its impact on improving quality teaching and learning. The review covered such topics as different evaluation models including formal evaluation (Danielson, 2007; Marzano, et al., 2011), clinical evaluation (Goldhammer, 1969); mini-evaluation (Marshall, 2009); and informal evaluation or "Walk Through" (Acheson, \& Gall, 2003; Downey, English \& Steffy, 2004). I also continued to build the outline of the PBL module and its curriculum. The focus now was on how to use ESCI through the Danielson model as a leadership tool to improve the quality of classroom teaching and learning in Tanzanian schools.

In the course of identifying the topics to be included in the PBL curriculum, it helped me to deepen my knowledge of instructional and transformation leadership and how the lack thereof can make the efforts of improving education fruitless. The relationship between these two leadership approaches is that instructional leadership helps the HM to focus the attention to the professional improvement of the teacher and ensure the teaching and learning resources are available. The transformation leadership 
helps the HM to build a caring working relationship, which is necessary to build collaboration with teachers and get the best out of their professional work (Bass \& Riggio, 2006; J. R. Blase \& Blase, 2004; Nguni, 2005). I learned the importance of making my research study focused by articulating the scope and content of every session. The formative assessment after every session and the talk back after every day helped to refine the sessions and adjust the schedule as it was needed. The assessments and the constant refining of the sessions made every session a mini-testing of the PBL module.

\section{Step 3: Developing Preliminary Form of the Product}

In consultation with my advisor, I formulated the PBL module or curriculum. With the goals and objectives included, the curriculum reflected the content of a 6-day residency workshop with the Moshi HMs. Each day was to have three sessions of two and a half hours per session. The venue was the Longuo Retreat Center in Moshi Diocese, which also has a retirement home for priests. The residence building and the workshop hall are shown in Appendix X. The tentative dates were to be July 23-28, 2012. However, there was a funeral service of Rev. Canute Temu who was one of the retired priests of Moshi. The funeral service and internment took place at the retreat center on July 28. Because of this, the Superintendent's secretary Mariana Kileo called all the HMs to inform them of the date change to training from July 30 to August 4, 2012.

At step three, I continued working on the contents of the PBL module. My advisor, Dr. Tom Chenoweth helped with the buying of a computer printer. I also bought a projector for PowerPoint presentations during the training. Other materials included a large binder that contained the entire contents of every session. At the back of the binder 
was a hard copy of printed resources for participants to read. I also bought some name tags and enough pens and markers for the participants.

The module included some lecture sessions on instructional and transformational leadership skills. It was also designed to include a great deal of group discussions and presentations using PowerPoint and role play. The main content of instructional and transformational leadership was from the works of: J. Blase and Blase (2001), Fosnot (2005), Marzano et al. (2005), Fink and Markholt (2011), Fullan (2001), J. R. Blase and Blase (2004), and Leithwood et al. (2004). I also included some works on teacher evaluation and different evaluation models as mentioned above in Step 2. The content also included teaching materials on the general elements of quality instruction and the role of ESCI in improving teachers' pedagogical skills. Danielson's evaluation tool was also included in the binder. The workshop resources such as the printer, relevant articles, books, a laptop, binders, audio and visual recorders, and a projector were packed, ready for the research work in Moshi. I downloaded and saved on the flash drive some video clips of Joel Klein. At this time I defended my dissertation proposal and got the exemption approval from the Human Subject Research Review Board. Since my research was focused on field testing the PBL curriculum I created, it did not need a full board review because there were no identifiable risks for human beings. The Human Subject Research Review Board approval and dissertation proposal approval documents were the official permission that I could field test the PBL module. I arrived in Tanzania on July 6, 2012. This gave me almost three weeks of being in the area before the workshop. Although I was busy visiting with family and friends and guiding a group of 17 friends 
from America, this time was beneficial for me because I had enough time to consult with the superintendent about what to expect. It was also the time to buy other small materials I could not carry from the United States such as wall posters, sticky notes, and writing pads.

Once again, Step 2 of the R\&D process taught me about the importance of receiving formative feedback while preparing my materials and doing further research. My advisor and my cohort were very helpful in identifying things I would need for the workshop. They suggested that I should have a co-facilitator to make my work manageable. They helped me think about a backup plan as well as having a hard copy of all my presentations in case there would be no power. My colleague, Paul Coakley, supplied me with some DVDs related to the daily duties of a principal. The work on Step 3 of the R\&D process helped me to understand that when working on such a complex and detailed workshop, one needs to share the process with friends and colleagues who understand the process and are able to share their insights, support, corrections, and critiques. Even if I was the primary developer of the PBL module, I felt that it was also a collaborative effort with my advisor, professors, and cohort group.

\section{Step 4: Preliminary Field Testing}

The PBL curriculum had four stages of preliminary field testing. Stage one took place when I presented the plan, content, and procedures of all 18 sessions of the PBL module to my advisor. He approved the organization and the contents. He made some corrections, which were helpful in refining the module and will be explained in Step 5 . 
His concern was that the sessions had too much content for the two hours assigned per session.

The second preliminary testing was done in my cohort group. I presented step by step the procedure of all sessions. Their concern was the same as the advisor. Their comments were noted to help with the revision of the curriculum.

Following the advice of my advisor and my Doctoral cohort, I had a conference with the President of Mwenge University, Dr. Philbert Vumilia on July 18, 2012. I shared my plan with him and asked if there was any professor in the graduate education administration department who will be interested co-facilitating with me. I was concerned to be the only facilitator that the training might be overwhelming. He suggested Dr. Kidevu. I met with him in his office and shared my plan with him. He agreed to cofacilitate the workshop with me and signed the letter of consent. On July 22 and 23, 2012, I met with Dr. Kidevu and reviewed the entire PBL curriculum with him. We laid down the plan and roles each would play. He did not have any suggestions on the contents other than one comment on the schedule.

The fourth preliminary testing took place in the same week with five HMs of Moshi. They participated in the preliminary field test and had agreed to serve as smallgroup facilitators. We met for two days on July 25 and 26, 2012. Each day had two sessions of three and a half hours per session. The first day took place at the Greesburg Hotel and the second one at the superintendent's conference room in Moshi. The main activities were to walk the HMs through the entire curriculum and answer their questions. I coached them on how to exercise their group leadership roles as directed by the group 
leadership protocol we agreed upon. They did two evaluation activities using Danielson's (2007) rubrics. At first they evaluated an imaginary teacher using a vignette, and then they did a role play in the group. The conference room was converted into a "chemistry classroom" role play. One participant played the role of the teacher, and another was the HM. The other three were the students, and I was an observer. The emphasis was placed on how the HM formed and communicated the feedback to the teacher in a cooperative, nonthreatening/authoritative way. He proved to be supportive, empowering, and encouraging to the teacher who was leading the conversation, pointing out his high points and where he needed to improve. The participants and I were impressed by the way this was done. The participant who played a teacher commented on his experience with passion, "It felt so empowering. I felt I was supported and important, and the HM really cared about me as a person and about what I was doing. I just loved it.” Participants filled out formative assessment forms to recommend changes they would like to make in the module. The findings were used to refine the product and the schedule.

The process of preliminary testing helped teach me that patience is needed when dealing with field testing because of unavoidable inconveniences. For example, when we met at Greesburg Hotel the room next to our conference hall was a pool table room. At times it was too noisy. I also learned that it is important to be flexible. I also discovered that regardless of how organized and prepared one might be, there is always room for improvement and additions. The PBL module would not be what it is today if it were not for input from my advisor, my cohort and the five HMs who participated in preliminary testing. Since the HMs were the ones to directly experience the study problem of low 
student achievement in the field, they had many very informative observations and suggestions. Their input is explained in Step 5.

\section{Step 5: Main Product Revision}

Based upon my personal observations and the participants' oral and written comments, findings were generated that helped refine the PBL module and make some changes. From my advisor, it was decided that having an official Danielson training kid would help. The kit, which had a manual book and a DVD, was bought and included among the training resources of the module. The American DVDs are formatted to play in American. Therefore I had to us multisystem DVD player or computer that could read the American-formatted DVDs. The kit was specifically designed to enhance professional development of high school principals in improving teaching and learning through teacher evaluation. This was a perfect kit for my audience because they were the high school HMs or principals.

Since every session needed to be evaluated for its functionality and the assessment results were used to refine the following sessions, formative assessment of every session was included in the PBL module. Also, at the end of every day another assessment, referred to as talk back, was added to evaluate the effectiveness of the every session and of every day.

From my doctoral cohort group and my advisor, it was suggested that the number of group members was too large. There were eight members in every group. Revision was made and the number was reduced to five participants per group. Also from the five HMs who participated in the preliminary testing, it was decided that having four to five 
group presentations per day were too many, and the time was not sufficient. The five HMs suggested in their report, "Group work takes time because we want everybody to participate and be on the same page. We need to reduce the number of groups and intensify participation." This number was reduced to three presentations; two in the small groups and one in the cohort group. This also led to the adjustments of the schedule from having too many activities to having fewer activities and a more manageable schedule. To ensure active participation, each participant had at least one opportunity to represent their small learning group in making a presentation to the entire cohort group or the class as a whole.

Pre- and post-testing assessments were modified to add participants' expectations. This means participants were asked to articulate what they expected the PBL module would give them before the training in terms of improving their school leadership. After training they evaluated the process and wrote what they actually got from the training.

Role playing took more time than planned when testing was done with the five HMs. Because of this, the schedule and the time for group activities were adjusted. Role playing was modified and limited to six sessions, four in the small groups and two in the cohort group. The original plan was to have eight role playing sessions in total. Also more time was allocated for the role playing sessions increasing from 40 minutes to about one hour in length.

The five HMs participants did pre- and post-workshop evaluations. The participants also discovered that after the preliminary test they were convinced that teacher evaluation is actually doable, not as complicated as they thought, and can make a 
difference in education. They also felt motivated to implement it in their schools and curiosity about whether or not it could improve teaching learning in their schools. Selfassessments indicated that they actually felt they gained the knowledge/skills, confidence, and competence to administer ESCI after the workshop. Their responses were expressed in such words as:

I am confident that teacher evaluation is doable and can make a difference in my school. Actually, I now know how to do teacher evaluation and I am convinced it will help both my teachers and my students. This training took just a short time, but I feel I have what it takes to do teacher evaluation without intimidation. After knowing what I know now, I can't wait to try it in my school. I am excited and very hopeful that finally I can do something to improve academics. This training was an eye opener for me. It was so helpful to make me question, what is my primary duty and what matters most in my leadership?

The participants also suggested that their presentations should be up to standard by using PowerPoint. Two sessions were set for teaching PowerPoint as an added topic to the curriculum. Their free time was reduced by 10 minutes every morning and evening to make up for those two sessions. Twenty participants out of twenty-four had never used PowerPoint before.

The module's effectiveness was to be measured by participants' pre and post selfassessment to determine if it managed to impart knowledge/skills, competence and confidence of doing ESCI. The five HMs suggested the addition of two more indicators of motivation and conviction. These were added to the pre and post self-evaluation form.

Reflective Knowledge from Step 5. Going through the process of making revision of the PBL module reminded me of the importance of keeping my mind open to learn from the experience and expertise of others. Although it matters how well things are prepared when doing this type of R\&D research, there is always room for improvement. 
This process reminded me as a researcher and leader of the importance of inclusion. The process reflected a constructivist approach in the sense that the knowledge base was built by the sharing of the participants' prior knowledge and experiences and each modification of the PBL module made the product better than the previous version. For the participants, the training process was like a moment of rediscovery of their resources and expertise. I believe that this rediscovery added to their self-esteem and selfconfidence as evidenced by the statements given by the five HMs who participated in the preliminary field test. One commented, "I have always thought that I could not face a teacher during the evaluation and tell him where he messed up. But through this practice, I discovered I have that courage to do it." Another participant wrote in the formative assessment, "Ignorance has been my best enemy. It made me avoid doing teacher evaluation which is something I need most in my career and for my students." These insights increased my own courage to and enthusiasm to do the main field testing.

\section{Step 6: Main Field Testing}

The main field testing of the PBL module curriculum took place at Longuo Retreat Center in the Catholic Diocese of Moshi, Tanzania from July 30 to August 4, 2012. This section highlights the objectives and happenings of the individual sessions and what I learned from the session process and outcome. The overall outcome of the sessions was analyzed at the end of the sessions.

Checking-in and introduction. Most of the participants reported on Sunday evening, July 29, 2012. After dinner, the superintendent of Moshi Catholic schools, Rev. William Ruwaichi opened the workshop by his introductory speech. Addressing the 22 
participants (two more participants arrived Monday morning), he emphasized on how this training was long awaited saying, "Even if the participants are here voluntarily, this was a long-awaited training, and I wish every HM could be here." He introduced Dr. Kidevu and me as facilitators. After the inaugural speech, we reviewed the goals and objectives of the workshop and discussed the schedule (see Table 7).

\section{Table 7}

\section{Goals and Objectives of the Workshop}

At the end of this workshop, every participant is expected to:

1. Acquire an understanding of the headmaster/headmistress [HM] work as an instructional leader, and know the problems, frustrations, and challenges associated with the job.

2. Acquire the sense of what is involved in performing teacher evaluation or ESCI.

3. Acquire some knowledge of making priorities in the principal's excise of leadership and give quality teaching and learning their due priority and importance.

4. Acquire skills, confidence, competence, motivation, and conviction of professionally doing ESCI. It takes experts to create experts (Fink \& Markholt, 2011). This course work is intended to make the HMs instructional leaders and experts for their teachers whose focus is to improve the quality of teaching and learning.

5. Develop competencies and confidence in the instructional leadership role and facilitate instructional improvement through supervision, evaluation, and feedback. Facilitate teacher improvement through appropriate professional development programs

Note: Goals and objectives of the training were also accompanied by guiding questions. See Appendix F.

Participants were given their binders with only the materials they needed for the

first two sessions. This was designed to minimize pre-assessment bias. The rest of the materials were passed out as the workshop continued. Participants signed the informed consent forms allowing for photographs and video and audio recording. Each was given a nametag and assigned a random number to be used instead of their name in order to keep their information anonymous. The participants were assigned in their groups. The four group leaders were introduced to the members of their groups. The group leaders were the five HMs who participated in the preliminary testing. One of them was left as a 
substitute in case one leader had an emergency and had to leave the group. The rest of that evening was spent for socialization and getting to know each other.

Day 1, sessions 1 \& 2: Leadership and basic computer skills. The participants used the first two sessions of day one on Monday, July 30, 2012, to learn PowerPoint presentations. Every two participants had one laptop. At the end of the second session the participants demonstrated their understanding of PowerPoint by creating new slides, inserting figures and tables, editing the slides, and making actual presentations in the small groups and in the cohort group. One participant commented, "I am amazed at how quickly I could actually learn this thing. I always thought using a computer in public was not my thing. But now I am actually having fun using PowerPoint.” Another participant said, "I thought I was too old to learn computers. But this has proved me wrong." The participants were expected to use the computer skills to make their presentations formal and professional during this study.

Day 1, session 3: PBL curriculum overview of and pre-evaluation. I regard this session as the first official session of our workshop because the first two dealt with prerequisite computer skills. The objective of the session was to get started, measure what the participants knew prior to training, identify the problem and assess the effectiveness of the session. I began with introducing cohort ground rules to the participants. The protocol contained rules such as punctuality, the use of cell phones during the session, the scope of participation of every participant and the like. The purpose was to ensure maximum participation and diminished disruption during the 
training. The protocol is shown in the Appendix E. This activity was followed by a discussion about the goals and objectives of the workshop which were as follows:

During this session, the participants also conducted a pre-workshop selfassessment about their professional knowledge or skills, competence, confidence, conviction, and motivation to implement ESCI in their schools. This was to measure what they knew prior the training. They also stated what they expected to learn. This would be compared later on with what they actually learned after training to measure the effectiveness of the PBL module through pre- and post-evaluation. The analysis of participant responses was conducted after a post-training assessment during the last session to make a pre/post comparative analysis.

Participants spent some time evaluating and interpreting the NECTA 2011 exam results. As demonstrated in Table 2, they all agreed that student achievement is a problem. One participant with an emotional tone observed, "It is a shame to me to look at those numbers. This is embarrassing. Please, I need help here." Another one supported this sentiment by saying, "No one among us can claim that he or she does not need academic improvement. Even if your schools did well last year, it does not mean you can't do better, so we all need help." I totally agree with this

These kinds of statements were heartening to me because they signify a thirst for learning, solution seeking, and promised cooperation. I learned that the participants were vulnerable in the sense that they knew the severity of the problem and they also knew that they had limited knowledge to address it. They were receptive, committed, and ready to 
accept new suggestions as one of them commented, "I am committed to do whatever helps to raise student performance in my school."

Before the end of the session, each participant filled a formative assessment form. In it the participants briefly explained what they knew before the session, what they learned and what they plan to change because of what they learned. They also gave their suggestions on how to improve the next session. Since this was the last session of the day, they also filled another talk back assessment form and evaluated the activities of the entire day. The participants were also given the materials presenting the Danielson framework and the reading guidelines as shown in Appendix K. They were to begin processing the information on their own before they brought it to their groups for discussion and presentation the following day.

Day 2, session 1: Art and science of quality teaching. The session began with the participants attending a lecture on the art and science of school leadership: Transformational and Instructional Leadership. The objective was to make a link between their leadership and quality teaching and learning. Participants actively engaged in the group discussion on why transformational and instructional leadership were needed and explore their contribution to the quality teaching and learning. It was important for the participants to learn about transformation leadership. As Burns (1978) and Bass (1985) observed, it enhances the motivation, morale, and their staff connecting their sense of identity and self to the project and the collective identity of the school. Transformational leadership demands the HMs be role models and inspires them, making them engaged, and encourages them to take greater ownership for their work and to enhance their 
performance. On the other hand, instructional leadership deals with leaders' daily duties such as teacher evaluation, budgeting, scheduling, and facilities maintenance and any other involvement with specific aspects of teaching and learning. Effective instructional leaders are intensely involved in curricular and instructional issues that directly affect student achievement (Cotton, 2003). These topics were presented in the form of a lecture and discussed in the small groups.

At the end of group discussion, each group made a brief presentation to the cohort group to share their findings. Their presentations demonstrated their understanding of the influence of leadership to quality education with these statements from groups 2 and 4 respectively:

- Instructional leadership makes the HM focus on teaching and learning as the sole business of the school and makes the HM a supplier of learning resources. The instructional leadership role gives academic activities the priority they disserve and ensures that HMs strive for academic excellence.

- Transformation leadership calls for the HM to lead by example, nurture the human and social needs of the staff, inspires staff to excel, reward innovations, and encourage school change and new ways of doing things to improve academics.

After a 10-minute break, the participants watched the Danielson's video, Enhancing Professional Practice, High School (Danielson, 2009). They then had a discussion on the importance of doing classroom supervision and evaluation. There was a heated debate about why and why not ESCI should be conducted. Among the justifying reasons as to why ESCI should be done were such statements as:

- It holds teachers accountable.

- It is focused on helping teachers to be the best teachers they ought to be. 
- No one can know everything, so even experienced teachers can be helped to improve.

- Through ESCI teachers and the HM become partners in the school business of teaching

- Without constant improvement, teachers will grow rust and as so will our students.

- We all need to be told what is working well in our profession and what needs to be improved. I found out that ESCI helps us to do that.

On the other hand, some claimed that classroom evaluation and supervision are not necessary with such statements as:

- It will intimidate teachers and demean their respect in the eyes of their students.

- Is national exam not enough to measure whether a teacher is teaching well or not?

- I found doing ESCI disrespectful to my teachers who are professionals.

- I am afraid to do ESCI because I do not know how to do it and after all I don't have time.

- Is ESCI not for student teachers? What does it have to do with experienced teachers?

- Danielson sounds convincing, but we cannot do it here because we do not know this stuff.

With these statements, the objective of the session of wanting the participants to express their likes and dislikes about ESCI was achieved. From my observation, the cohort group was almost evenly divided between those who support teacher evaluation and those who do not. However, they spoke with passion and interest to know more. One commented, "I need to know more about teacher evaluation, then I will give my assessment whether I like it or not." Before the end of the session, the participants were given a vignette to read during break and work on it on the next session. The vignette was 
about a narration of classroom instruction of Mr. Salema who was teaching Letter Writing in the Language Art class. They also gave their formative assessment of the session.

Day 2, session 2: Conducting ESCI without rubrics-vignette. The session began with the participants conducting ESCI of an imaginary teacher using the vignette given in the last session. This was done in small groups after which each group made a presentation to the cohort. During the discussion and presentations, the participants began correcting each other how to form and communicate feedback. One presenter was challenged by his colleagues because he did not have any positive attributes in his feedback. He responded by saying, "I mentioned to my teacher only what she needed to correct. Isn't that what she needs to know?" Another participant expressed her struggle, "I could see what was not working well with the teacher, but how can I tell her that? It will hurt her so bad."

From these kinds of comments the objective of the session, which was to measure the participants' skills of determining effective instruction, conduction of teacher evaluation, and communicating feedback was achieved. From the vignette exercise, I learned that most of the participants were struggling with how to formulate a balanced approach to feedback that must have both positive attributes and ideas for improvement (Danielson, 2007). I also noticed that the Danielson's (2007) video had some impact on them as they some were referring to what they watched and heard to justify a claim like participant 12 who said, "Attacking a teacher with negatives only is not right. The video showed that we have to begin with what worked well, and then introduce what needs to 
be corrected." This signified to me that they were paying attention and learning the right to do ESCI. This type of discussion also achieved another objective of the session, which was to give participants an opportunity to learn from each other. Participants filled out the formative assessment forms before the break.

Day 2, session 3: Factors of quality teaching and learning. In the first part of the session the participants attended a lecture on what makes quality teaching and learning. The lecture was adopted from the five dimensions of teaching and learning (Fink \& Markholt, 2011, pp. 23-84). This segment was important since the HMs had no training whatsoever on how ESCI works. The objectives were to enable the participant to acquire skills to identify the elements of quality instruction, and build to their confidence and competence as instructional leaders capable of conducting ESCI. The session objectives were also to minimize or eliminate any possible feelings of intimidation when evaluating a professional teacher. One HM commented: "How can I evaluate a biology teacher when I am not a biologist?" After the lecture the participants held a discussion in their groups. They also made presentations to the cohort group on the relationship between school leadership and quality classroom instruction.

From the group presentations, the participants demonstrated some understanding of the elements of quality teaching and learning. Among the qualities of effective teaching and learning the participants mentioned were:

- Well-prepared lesson plans that are inclusive of all students.

- Teachers with content knowledge and who know how to communicate it.

- Having transparent and well-known assessment procedures in which the students know what is expected of them and how grades are awarded. 
- Teachers who are focused on helping all students learn and who offer extra assistance for struggling students.

- Adequate supply of teaching and learning materials by the school administration.

- School discipline that creates a good environment for quality learning including punctuality.

- Following updated national syllabi and the directives of NECTA.

- Teaching relevant things not only for exams but also for life as the national policy of "Education for Self Reliance" demands.

- Good environment free from too much noise, with good ventilation and enough light.

I also observed the participants extending the conversation to the dinner table.

During break times they were in groups of threes and fours discussing about the elements of quality teaching and learning. One participant at my dinner table commented, "How is it that we have never had this kind of discussion in my entire career while that is what we do?" One HM suggested with some regrets, "I think we need to go back to school. This training exposes too much my ignorance." She encouraged her colleague as she replied, "That is why we are here, to learn and know what we did not know. This must be an ongoing process." These kinds of comments made me realize that the PBL module was achieving its intended objectives of challenging the current status quo of the HMs, making them aware of what they do not know with regard to improving education in their schools and giving them skills, competence, and confidence. One HM wrote in the formative assessment, "We have been here only for two days and I feel like I am a new person. I am convinced by the end of the workshop I will be a new leader."

This was the last session for the day so the participants filled out both the sessions' formative assessments and the talk back assessment for the entire day. Dr. 
Kidevu was excused from facilitating the sessions because of failure to adhere to the PBL module guidelines and implement PLB with fidelity. He came back on the last day to participate in the action-plan presentations. It was difficult for me to make this decision, but I had to because of what was at stake. Through this decision, I also demonstrated my leadership to the participants and normalized what they do or need to do with their staff: that leadership demands some tough decision-making and critical conversations. In the formative assessment, a few participants agreed with the decision I made with such comments as, "I am glad Dr. Kidevu is no long here. He was confusing to me." Another participant wrote, "I like systematic approach we are doing, unlike Kidevu who was 'beating around the bush.'”

Finally, participants were asked to prepare lesson plans of their choice to be used for role paying in the late sessions. Four participants were asked to write about the most challenging leadership issue they ever dealt with. The case should deal with an ethical or legal issue. These cases were to be processed later in the consultancy protocol session.

\section{Day 3, sessions 1-3 \& day 4, session 1: Adaptation process of Danielson tool.}

The focus of the sessions was on the Danielson (2007) evaluation framework and its adaptation to make it culturally sensitive to the Tanzanian school system. This was one continuous process; that is why all four sessions were combined. A lecture was given on Danielson's Four Domains and how they can influence quality teaching and learning. This was followed by individual reading and group discussions on Danielson's teacher evaluation model. Participants processed two domains in this session. The participants became familiar with the materials of the Four Domains of the framework. The objective 
was to make the participants familiar with Danielson's evaluation tool and then, if they saw its value in their contexts, adapt it to fit into their school system. In this session all the participants focused on Domains 1 and 2: Planning and Preparation and Classroom Environment (Danielson, 2007, pp. 43-108). In their groups they answered three questions with regard to Domain 1 to 4: (a). What will work in your school and why? (b) What will not work and why? (c) What will you add to make it work better for your school?

Tuesday and Wednesday evenings were set aside with no group or individual activities scheduled. This was to give the participants time to read and process the Four Domains at their own pace. They followed the reading guideline which articulated 10 steps in the process of adapting Danielson's evolution tool, as shown in Appendix K.

- First, each participant just read through the domains' contents and the rubrics, which took roughly 2-3 hours. They reported that after reading through the content, they could articulate the main concepts of each domain. This was demonstrated by their casual talks during coffee or lunch breaks. One observed, "I can tell where this is leading. It is fascinating what teaching contains." The conversation was around the Four Domains and how they can work in their individual schools to improve academics. It was a joy to observe how they talked with passion and excitement. One vice HM commented in the group during break time, "I am sad because my HM is not here, although I am happy that he sent me. I can see what difference this knowledge will make in my school." His colleague responded, "We will never be the same, I am so excited."

- The participants reread the same materials, one domain at a time. As they read, they identified the content that they thought was incompatible with their school system and culture. They substantiated their claims with reasons. To their surprise, they said they did not find many of those elements. For the most part, the contents seemed to fit well with their school system. Some participants circled certain words, some highlighted them, and still some wrote them either at the edge of page or on their writing pads. This process appeared simple because almost all completed the task within two hours. 
- Then, the participants were asked to write additional information that would make the Four Domains a more effective tool for instructional evaluation in their particular school contexts. Here they changed the style or procedure contrary to the guidelines. Instead of working individually to come up with new and relevant information as the guidelines directed, they informally formed groups of two and three. They met in their rooms, the hallways, the recreation room, and outside under the trees on the lawn. They discussed and added whatever relevant information they needed after the group discussion and consensus. Interestingly, as I noted in my journal that evening, the groups had some particular patterns. There were three groups with two members and six groups with three members each. There was some homogeneity in these groups in terms of gender and the structure or the nature of their schools, whether it was single gender or coeducational, boarding, or commuter. With an exception of one group, which had two males and one female, the rest of the groups had members of the same gender. Later, during the consultancy protocol session, they revealed that HMs who led similar type schools tended to share their challenges and accomplishments primarily with one another.

- One of them read drafts of the evaluation instrument they had modified to the same group members. Not only did I allow this informal process to continue, but I liked it better than what I had suggested in the guidelines because it saved time, and it was more engaging and more efficient. Instead of having 24 reports from each individual, the participants had only nine report outs from their respective informal groups. As one participant indicated "It was more efficient because we could share and weigh out our thoughts before we agreed with the changes we wanted to suggest." Another participant said, "It was easier to have one read and the rest listen for accuracy and clarity than have each read our own work for the same purpose." Lastly, it was easier and faster as they reported, taking less than an hour to get this work done.

- They also discussed and wrote the justifying reasons why they made changes with the purpose of making the domains culturally sensitive or more effective in improving the quality of classroom teaching and learning. Here they kept working in their informal groups. One justified this process as he said, "We thought the reasons would be more compelling and credible because they involved more than one mind in the thought process."

- From the beginning of the workshop, the participants were divided into four formal discussion groups of six members each. To save time, I assigned each group one Danielson evaluation domain to deal with in the adaptation process. Group One dealt with Domain 1 which is planning and preparation, while Group Two dealt with Domain 2 classroom environment. Group Three worked on Domain 3, instruction and Group Four dealt with Domain 4, professional responsibilities. The groups used the session time for their discussions and presentations. 
- They were to do a discussion on the final drafts from the informal groups began in the formal groups. However, there was a problem because some members did not have the final copy of their informal group work. To solve this problem, they used about thirty minutes to copy it by hand. They discussed and adopted the changes suggested from the small groups. Each group secretary kept the record of the final copy, which was presented to the larger cohort by a group representative for final discussion before it officially became part of the final evaluation tool.

- The large group discussed the validity of the adjustments made by each small group. All the suggested brought to the large group were accepted after discussion. The final copy of the adapted domain was used to make changes on the Danielson's evaluation rubrics.

- Since each member of the cohort had read and processed the Four Domains in smaller groups, participation in the larger group was lively and active throughout the entire adaptation process. This process went smoothly and fairly quickly because the participants seemed to have mastered the content of the Four Domains. They were able to explain each of the Four Domains thoughtfully within the context of their particular schools. Comments included, "That will not work in my school because parental involvement is kept minimum" or "As HMs we have been neglecting this responsibility on Domain 4 because teachers are mandated by the Ministry of Education to participate in local community events which are compatible to our educational values."

- The final adapted copy of the domains and the rubrics were written. At this point, we had a culturally responsive version of the Danielson's teacher evaluation tool. Its summary and how they will use it was presented by the cohort secretary as an "Action Plan" presentation on the last day of the training in the presence of the cohort members and the invited guests.

Since we had a printer in the workshop room, we printed the final adapted copy for each participant. This was their new leadership tool for teacher evaluation. The process of adaptation of the Danielson evaluation tool for the HMs of Moshi was completed. This was the final product HMs needed to begin implementing ESCI in their schools in January 2013. It is important to mention here that the HMs said that they did not have any other evaluation tool prior to adapting Danielson's. 
At the end of every session the participants gave their formative assessment and their talk back assessment at the end of the day. The findings of all the sessions are provided in this chapter as general findings in Step 6 of the R\&D process, the main field testing.

\section{The Relevancy of Adapting the Tool}

The adaptation process of the Danielson teacher evaluation framework went very well. Some participants gave such comments as: "It helped me to envision how this can work in my school and with my teachers." Each small group had members representing the diversity of Tanzanian secondary schools: girls' schools, boys' schools, coeducational schools, boarding schools, and commuter schools. There was only one group that had a member from a public high school. Because of this representation, I felt comfortable letting them deal with only one domain per group. It also saved time because they would need two more days if each group would have dealt with all four domains.

The reading guidelines stipulated in the PBL module were very helpful in a number of ways. Several commented, "They helped me to keep focused while reading reflectively." One participant verbalized:

I was reading not only to understand what is being said, but to relate it to my school. All the time I was trying to answer the question: Does this seem to work in my school? Will I be comfortable with it? Will my teachers be able to work with it? It was both informative and powerful.

My observation on the participation, contributions, questions and answers, challenges, and critiques given by the participants suggested that they had understood the content well. Their passion and energy suggested that they were ready and willing to use the adapted and culturally relevant tool. Most important, it answered the secondary research 
question, "Can the Danielson tool created for American schools also be used (or adapted for use) in Tanzania?" The answer is, yes, but the tool has to be adapted and acculturated before it can be relevantly used in Tanzanian schools.

\section{Findings: The Changes Made to Make Danielson's Tool Culturally Relevant}

The Danielson evaluation tool is comprised of the four teaching domains of: planning and preparation, classroom environment, instruction and professional responsibilities systematically; it is arranged to reflect teaching four levels of standards. These standards are: unsatisfactory, basic, proficient, and exceptional. Teachers are evaluated using these standards depending on what they are able to demonstrate as articulated by the rubrics. The changes were made in the process of adaption by removing, modifying, or adding the following elements:

Removed. Participants suggested that the unsatisfactory standard be declared as unaccepted in the diocesan schools. They recommended that any teachers who happen to be in that category improve their own teaching within one semester or with remedial measures within one year. They did not say what would happen if this benchmark was not met. For this to take effect, it has to pass through the diocesan policy-making process. Basic standard was also challenged. The participants advised that teachers should be required to grow out of that category within two years. Remedial measures to help teachers improve may be used if needed. This leaves the acceptable standards to be proficient or distinguished.

Modified: Teacher's communication with the parents. The participants used the following statements to explain why they eliminated this element from the rubrics: 
- Since most of the schools are boarding schools, parents have little to no influence on the running of the school or what happens in the classroom.

- There is an established protocol of communication with parents. The Deans of Studies and of Discipline are the official persons to communicate with parents on academic and discipline issues respectively.

- The deans are informed by the teachers. The HM communicates with the parents on serious issues that might lead to suspension or dismissal. The vice HM acts in this capacity when the HM is absent.

- Student participation in the assessment process: Participants said that the assessment and performance standard is determined hierarchically from national to classroom level. There is a pass mark for the nation. The dioceses and districts can set their own standards. However, they cannot be lower than the national pass mark. For example, if the national pass mark is $60 \%$, the diocesan pass mark can be $70 \%$, the schools can set $75 \%$ as their pass mark, and individual teachers can set $80 \%$ as the pass mark in their class.

- Diversity was defined in terms of students' religions and tribes. Color was not the issue. Student and teacher populations are from same African black color but they come from different tribes and different religions that have different beliefs and values.

- Special needs students were identified as those who struggle with academics due to poor academic backgrounds from their respective primary schools, on one hand, and the commuter students in the rural schools who have no electricity at home, on the other. The latter have limited time for homework because they can only do their homework before the sunset. Some use kerosene lamps or candles but they are also limited because some families cannot afford due to lack of finances.

Additions. The following elements were added to the Danielson (2007) tool:

- Compliance of the lesson plan and instruction to the current national syllabus from the ministry of education and the directives of NECTA. Since the national exams are given based on the standards articulated by these two national bodies, failure to follow their directives would mean the failure of students in the national exams.

- Adherence to the dress code because all schools, private and public alike, have a uniform code for students as part of the classroom environment.

- Contents of instruction should adhere to the national policy of "education for self-reliance." Therefore, the contents of instruction have to be relevant to the student's real life, now and in the future. This was the concept that was 
introduced to the Tanzanian education system in 1967 by Julius Kambarage Nyerere, the first president of Tanzania (Nyerere, 1967). It is also good for student motivation because if students can see the relevance of what they are studying in their real life, and not only to pass the test, they more likely to engage.

- Group activities should promote a deeper understanding of the content, making a connection of the content with real life by reflecting its application to the real life.

- Teachers' ethical standards were added to reflect and direct teachers to use appropriate and professional language as opposed to vulgar language, dress code (although they do not have uniform code) and general behavior in and outside of school.

These changes were reflected in the new rubrics. At the end of the workshop, each participant was given the adapted rubrics. It was interesting to see this tool in its adapted form as shown in Appendix R, and to identify what was added or removed from the original Danielson rubrics. The adaptation also elaborated the revised terms or phrases in the rubric to make them more explicit so that teachers could easily understand them.

The participants made their formative assessment of the session in which 11 members requested more time during the larger group discussion to allow more participants to share their experiences. With consensus of the participants, 10 minutes were added to the third session by extending the session time and reducing the evening free time. This request continued to confirm that participants were motivated to learn and wanted use every chance to get the most out of the workshop.

Day 4, session 2: Conducting ESCI with rubrics-vignette. The first part of this session dealt with the Danielson's (2007) evaluation rubrics. One of the objectives of the session was to for the participants to have their culturally sensitive evaluation tool, which was the product of their work. The participants used the changes they had made in the 
Danielson's Four Domains and adapted them into the rubrics. The rubrics are the summary of the Four Domains. I was amazed that this work was done within only 40 minutes in the small groups. Participants demonstrated their mastery of the contents of the evaluation tool by substantiating their points through paraphrasing the domains' content without looking at their written notes. When I pointed out that I was impressed by their mastery of the module content, one participant said with pride, "Fr. Siamoo, we are not stupid. The fact is we can be experts only if we are informed. I feel like an expert of teacher evaluation right now and I can't wait to show my teachers what I know and what we can do to change our school national exams scores."

In the second part of the session, the participants began the practice of using Danielson (2007) evaluation rubrics, since every domain has its rubric, to evaluate an imaginary teacher using the same vignette they did at the beginning of the workshop. The objective of this activity was to determine if there was a difference in participant ESCI skills and the use of rubrics as they evaluated and gave feedback to the imaginary teacher post training. Some of the feedback statements are presented in Table 8 to show the comparison. It also signified the knowledge about ESCI the participants had acquired thus far. 
Table 8

Teacher Evaluation-Vignette

\begin{tabular}{|c|c|}
\hline $\begin{array}{c}\text { Feedback without rubrics- } \\
\text { vignette }\end{array}$ & Feedback with rubrics-vignette \\
\hline $\begin{array}{l}\text { - The teacher did not pay } \\
\text { attention to students' } \\
\text { questions. } \\
\text { - The teacher did not seem to } \\
\text { know what he was talking } \\
\text { about. } \\
\text { - "You did not prepare you } \\
\text { lesson plans because you } \\
\text { did not give it nor even say } \\
\text { it to your student" } \\
\text { - "How do you expect } \\
\text { student will learn while } \\
\text { others were sleeping in } \\
\text { your class?" } \\
\text { - I was not impressed with } \\
\text { your teaching. } \\
\text { You could do better than } \\
\text { that. I trust you because } \\
\text { you are an experienced } \\
\text { teacher. }\end{array}$ & $\begin{array}{l}\text { - I should have asked you to give me your lesson plans. However, } \\
\text { you did very well in allowing student to contribute to what they } \\
\text { were learning. On the other hand, you could have connected } \\
\text { your letter-writing lesson to the student's real life showing them } \\
\text { how this lesson can save them in things like job application } \\
\text { when they graduate. This might have attracted more students to } \\
\text { pay attention and take this lesson more seriously. Does this } \\
\text { make any sense to you? What else you think you could improve } \\
\text { for the next class? } \\
\text { - For the time I was in your class, I thought you did a really good } \\
\text { job in engaging your students, even if two were sleeping. You } \\
\text { pointed out the types of letters and their differences, right at the } \\
\text { begging of the class. However, you could engage those students } \\
\text { who were not paying attention by asking them questions or } \\
\text { making them stand at the back of the class. What is your } \\
\text { suggestion? } \\
\text { Mr. Salem, you did very well in your class today and I am sure } \\
\text { there are some areas you can even make them better. To your } \\
\text { opinion, what do you think went well and where do you think } \\
\text { you could do better? }\end{array}$ \\
\hline
\end{tabular}

Note: The left side shows the feedback of teacher evaluation before participants had the knowledge of Danielson's tool and the right side shows the evaluation of the same teacher with the knowledge and skills of ESCI

From the above comparison, it suggests that the PBL module was effective in informing the participant on how to conduction ESCI. It was clear from my observation that at the end of the workshop the participants knew what was required of them to do ESCI. Not only did they publicly declare that they would do teacher evaluation, but they also had a timeframe of two years to do all the Four Domains. They also asked for another workshop after the two years to evaluate their practice. The post-training feedbacks are more professional, balanced, supportive, and empowering when compared to the pre-training responses on the left. Participants verbalized statements that indicated 
their confidence such as, "I feel like an expert of ESCI" and "I can't believe that I know this stuff so well now."

Day 4, session 3: Conducting ESCI in the group-role play. The participants shifted from analyzing an imaginary teacher from a vignette to doing teacher evaluation through role playing. Two groups had five members and the other two had six members (including the public school HM). One group member played the role of the teacher, another acted as the as HM and the other group members played the role of students. The HM made the observation of teaching, and then communicated the feedback. This process was discussed in the group to help refine the HM's feedback. The intentions were to give feedback, which was more supportive and empowering allowing the teacher to take the in the evaluation process. The procedure was repeated in the larger group where one small group repeated what they did in the small group. Once again, the members of the larger group contributed in articulating how best the feedback could be formed and communicated. Participant 18 corrected her group leader saying, "Even if you had a balanced feedback of both positive and negative comments, you should begin with the positive ones. People normally want to hear how good they are before hearing what they should correct." I liked the passion and precision of the participants as they corrected each other trying to be as precise with what the rubrics as possible. Participant 9 wrote in the formative assessment, "Conducting ESCI is a new knowledge to us. I suggest that we become faithful to what the rubrics suggest rather than trying to make up our own stuff." The participants also wrote in their talk back assessments commenting on the activities of the whole day. The first two days had a lot of asking more time for discussion but also 
some assessments indicated what they learned like, "I did not know how powerful my position was in terms of influencing student achievement." Or "the day was very productive especially the lectures and group discussions. Please, keep it up.” Although training began each day at 8:00 a.m. and ended after 7:00 p.m., there was no single complaint of overworking.

Day 5, session 1-2: Conducting ESCI in the group-role playing. The two sessions of Friday morning followed the exact pattern and procedure of the previous session. Participants continued with ESCI role playing by using the adapted culturally sensitive Danielson rubrics. They developed various lesson plans focused on Math, Geography, Biology, Chemistry, English, African Literature, History, Economics, Commerce, Bookkeeping, and Bible Knowledge. The objective was to give as many participants as possible a chance to practice conducting ESCI either in their small groups or in the larger group. All of them had a chance to play the role of a HM, develop and communicate feedback to the teacher and be critiqued by their peers. One expressed his experience by saying, "It was easy to critique my peers, but when I got there as a HM, I had to remember the key principles: 'I am here to support and not to judge, I have to have balanced feedback, and I have to allow my teacher to lead the process."' Another participant from the same group said, "I felt so empowered and important when the HM was saying what I was good at in teaching. I don't think I will ever forget those compliments."

The formative assessment had no new recommendations. The assessments articulated what participants learned and how they felt about it. Participant 11 wrote, "It 
feels so good to know that now I can evaluate and supervise teaching in any class.” Participant 2 said, "I am happy because I can supervise any teacher of any subject.” This confidence was also observed when the participants were making presentations. They spoke from the heart, more often than not, without reading any notes.

\section{Day 5, session 3: Dealing with teacher resistance, the consultancy protocol.}

The overwhelming majority of participants had asked in their formative assessments and talk backs for a session on how to handle ethical and legal issues in the course of implementing ESCI. This was anticipated and included in the PBL module under the consultancy protocol session. According to Harmony Education Center (2012), “A consultancy is a structured process for helping an individual or a team think more expansively about a particular, concrete dilemma" (para., 1). The participants followed the consultancy protocol guidelines as shown in Appendix S.

Each group processed one real case that was prepared by a group member. The case topics covered how to handle: sexual allegations between a teacher and a student; a teacher resistance to change; a labor court order or union order with regards to teacher's discipline; and policy implementation from the Ministry that seems to contradict diocesan policy.

One of the things both participants and I learned from this process was that the participants had almost all the resources and expertise they needed to solve these problems. The participants appreciated sharpening their leadership decision-making skills through the consultancy protocol process. As Participant 24 commented,

For years I have been struggling with decision-making process in times of crisis or major problems. I wish I knew this consultancy protocol earlier; it would have 
saved me time, money, and reputation. This is great, not only for legal and ethical issues, but also for major disciplinary issues of teachers and students. If these are not addressed adequately, the overall improvement of quality teaching and learning will suffer.

The participants publicly committed to use it to learn from each other's experiences before making major decisions in the future. The consultancy protocol process was also viewed as a good opportunity to build collaboration between the HMs and share expertise between schools.

Since this was the last session for the day, the participants made both formative and talk back assessments. That majority of the assessment reflected the appreciation of what they learned with such comments as, "This was a great week in my career." Another comment read, "This was the most intense workshop I ever attended, but also most productive." One participant gave a caution for future workshops of this kind saying, "This was too dense for just six days. I do not have idea how we managed to take all this but I would advise take two weeks to do the same training." One compared it with the army drill saying, "This training reminded me of the time I was in the army. It has the same intensity like the army drill."

Day 6, sessions 1-3: Action-plan presentations; demonstration of ESCI. This was the last day of the workshop. The objectives of the session were for the participants to demonstrate what they had learned and to articulate how they were going to use it in their schools. Among the guests who attended the final action plan presentations and certification ceremony were Bishop Isaac Amani of Moshi (The CEO of Moshi Catholic Secondary schools), the Superintendent, the President of Mwenge University, and five professors from the Department of Education of Mwenge University. 


\section{Demonstration of the Findings}

The participants spent time in the discussion groups to answer these two questions: What might cause ineffective teaching and learning in my school? What are the possible solutions to the problems? The findings were presented to the main cohort group and discussed. This was part of action-plan presentations.

Identified causes of the problem. During the action-plan small-group presentations, participants identified some dominant contributing factors to poor teaching and learning as evidenced by low student achievement in their schools. Each participant contributed to the content of the action plan. Their contributions were compiled to make a group action plan presentation. The cohort secretary presented those factors, which were reported as common to all or the majority of the schools included the following:

- Most teachers do not develop lesson plans claiming that they do not have enough time to do so.

- Some tenured teachers, content for years with basic performance and maintenance of the status quo, resist change designed for improvement.

- Some classes have inadequate or unsuitable furniture, such as old chairs, tables, and desks.

- Some school environments are not safe for quality learning. Some classes and students' living quarters are not up to standard and do not meet the fire safety codes i.e. doors open inward and windows have grills.

- Experienced teachers tend to use their old teaching notes or materials regardless of the changes that have been made by the updated national syllabi and NECTA directive.

- Most teachers do not use teaching aids and activities relevant to student interests. Some teachers do not have teaching strategies that are inclusive of all students. If they offered extra help to the struggling students through independent after-school classes, they charged the parents extra pay. Some corrupt teachers used this loophole and offered inferior classroom instruction, 
but superior independent after school classes in order to attract more students and earn more money.

- Some teachers avoid active leadership roles in the school, local communities, and /or diocesan and district projects claiming that it takes too much of their personal time.

- Some teachers demonstrate unprofessional and unethical behavior in school and in the community by their language, dress, and drinking behavior.

- A few schools mentioned cases of inappropriate sexual relationships between teachers and students.

\section{Suggested Solution: Danielson Teacher Evaluation Model}

Participants had a consensus agreement that they would do the following as part of implementing ESCI in response to each domain:

1. Before the beginning of the new school year on January 2013, the HM will present the academic improvement plan to the school board.

2. At the beginning of each academic semester, each HM will lead a discussion with teachers in a staff meeting on how they will implement the plan as a team.

3. The HM will set time for teachers to learn about teacher evaluation and the HM or the delegate who attended the training will lead the short seminar on the roles of teachers in the evaluation process. It was suggested that young teachers might be good resources because they might still remember how it was done with them when they were student teachers. One participant suggested that HMs can invite professors from Mwenge or from one of the three teacher training colleges, all located in Moshi, to assist with this process. 
4. The HM or the delegated assistant HM will do all or some of the following on a regular basis as part of their daily instructional leadership duties to ensure that teachers are complying with the acceptable teaching standards of the Four Domains.

Domain 1: Planning and preparation. The first group gave their action plan presentation and led a discussion on how to implement this domain in schools as an attempt to solve current problems. Among other things, the following were suggested as the HM's implementation strategies:

- Random checking of teachers' lesson plans a few hours before the class

- Simply ask teachers to show the HM their lessons a few moments prior to class. For example, the HM might stop at the teacher's desk and ask, "When is your next class? May I see your lesson plan?" All teachers must be treated the same way.

- Attend the first part of the class to hear the lesson plan explained to the students and/or written on the board. Make sure to give feedback in a supportive manner.

- Ask the teacher to leave a copy of the lesson plan on your desk, with your secretary, or in your mailbox one day before the class. Randomly choose the teachers and the days for checking on their lesson plans, but be inclusive of all teachers.

The participants identified the relevancy of this leadership routine. Even if the HM did not have time to thoroughly read through the lesson plan, this strategy will encourage teachers to comply with the acceptable teaching standards in which they must always prepare lesson plans. One participant observed, "By the fact that a teacher is pushed to make a lesson plan, he/she is forced to think through the lesson. That in itself improves the quality of the lesson." The advice was given that the HM should make time to read through the lesson plans and give feedback. One group leader reminded, "We are 
mandated by our teaching profession, by the Ministry and Diocesan policies that every teacher must prepare a lesson plan. As leaders, we have just been careless to enforce this mandate. This is the time, because we now know how to do it." When too busy, the HM was advised to temporarily delegate this to an assistant. This also enforced collaboration between the administrative staff to get the work done. To be consistent and up to standard, it was strongly advised that the HM should always use the standards as articulated in the adapted Danielson's (2007) evaluation tool.

Domain 2: The classroom environment. The second group gave their action plan presentation and led the discussion on how best to implement Domain 2 . The following are some resolutions that HMs could adopt to ensure that the classroom is conducive for quality teaching and learning:

- Ask the teacher to show and explain the teaching aids for the lesson

- Visit the class to see how the teaching aids are employed and class activities are conducted; check on class space, arrangement and accessibility of the teaching materials.

- Talk to the teacher, Dean of Studies, and the school Bursar if major classroom rearrangements are needed such as new furniture, repainting the classroom, light adjustments, and ventilation. If major funds are needed, reflect this in your upcoming school maintenance budget.

- To minimize distractions and endure proper discipline in the classrooms, talk with the Dean of Discipline to ensure the student dress code is being enforced fairly with all students.

- Enforce the rule of punctuality to protect instructional time. Teachers and students must be in and out of class on time. The HM should model this and lead by example.

- Have at least two responsible school timekeepers to ensure the protection of instructional time. 
Domain 3: Instruction. The third group gave their presentation and led the discussion regarding a possible action plan for Domain 3. This domain was identified as the core of teaching and learning. The presenting group and the audience agreed that what happens here is what influences student achievement. This is in line with what the literature claims. In the action plan, the participants identified steps the HM can take to improve the quality of classroom instruction. These include the following:

- Visit the teachers in class to assess and evaluate their instructional strategies and skills using the adapted Danielson's rubrics. Let the teacher lead the discussion for empowerment, encouragement, and support to monitor own professional growth.

- Lead by example by demonstrating the highest standard if the HM teaches a class.

- Each teacher should have a classroom evaluation visit at least twice each semester.

- Strictly adhere to the Danielson's standard of instructional evaluation by observing such things as being cooperative and nonjudgmental, immediately giving feedback identifying what worked best and what needs some improvements. Always use the rubrics for objectivity and consistency.

- Encourage teachers to offer free, remedial classes on evenings, weekends, or holidays for students with special needs. Lead by example. A few HMs reported that they had been doing this, and some teachers were following their example by offering free evening and weekend classes for struggling students.

- Ensure adequate supplies of teaching and learning materials and reflect this in your yearly budget. Empower the Academic Dean to help with academic improvement.

Domain 4: Professional responsibilities. The fourth group gave the presentation on Domain 4 and led the discussion in which the participants identified what the HM could do to improve the current situation:

- Instruct teachers to give the HM their annual plan for professional responsibilities in the school, local community, diocese, district, and nation. 
They should give the HM a written report of their involvement at the end of every semester.

- Appoint teachers to represent the school in local community, diocesan, or district events.

- Ensure the safety of all confidential school records.

- During a staff meeting, discuss the necessity of the teachers' dress code for professional appearance and reputation, appropriate school representation, and develop an agreed-upon consensus of teachers.

- Identify teacher professional activities outside the school including singing in the church choir, leading the parish council or a church committee, membership or leadership in the village committees, and involvement in the parents' association as well as diocesan or district projects.

- Publicly acknowledge any teacher's participation and contribution in professional activities or projects. This will encourage others to do the same.

It was also a time to get some final remarks from different attendees including me as the facilitator, cohort representatives, the Superintended and the Bishop of Moshi. In his remarks the Bishop Amani of Moshi acknowledged the competence, confidence, the passion and skills demonstrated by the participants during the presentations. The bishop commented:

I was not in the training, but today's presentations gave me a clear picture of how intense and informative the training was. The passion you demonstrated is real and it tells me that it will bring change in our schools. I loved what I saw. My only concern is that not all the diocesan schools were represented here. We need every HM to get this kind of training so that we can move together as a diocese.

The bishop was reminded that participation was voluntary of which he responded, "They made a poor choice then by not participating."

The Superintendent of Moshi Rev. Ruwaichi congratulated the participants for taking initiatives of what he called "academic reform." He promised to invite those HMs who did not participate to figure out how they can learn from their pears as he said, "I am 
sure if they knew what this training could give them, they would be here. There is no sane person who would deny this precious gift for our teachers and our students." The cohort secretary gave his remarks on behalf of the participants. He expressed his appreciation for this training which he said, "have turned not only our perspectives about our responsibilities as leaders, but will turn how teachers do their work and how students get the best in our school institutions." He reminded the audience how the participants were dedicated saying, "we did not have a minute to waste and were very tired at the end of the day, but we saw the fruits." My remarks highlighted their hard work, commitment and desire to learn and encouraged them to bring the same "fire" to their schools. I also accepted their request of preparing another workshop at the end of 2014 for evaluation of their experience and deepen their knowledge of instructional leadership. The workshop was ended by a concluding ceremony and issuing of Certificates to the 24 participants.

\section{Step 7: Operational Product Revision}

The data collected from my observations, participants' comments, the formative assessment after every session, the talk backs at the end of each day, group processes, and cohort discussions were used to refine the curriculum. These changes were made to the module:

- The number of role play sessions was reduced to three in a day, two in the groups and one in the cohort. The time of group discussion was increased. Each group member would have a chance to lead group discussions and make at least one presentation to the cohort group. For example, group leaders were directed to assign and keep track of who had played the role of HM either in the small group or in the cohort or larger group. No one was allowed to repeat playing that role before the rotation was completed whereby every member had a chance to be the HM and thus be required to develop and communicate feedback. 
- Increased time of group discussion to allow full participation and contribution of every member and give enough time for group activities. For example, on day one of training, the overwhelming number of formative assessments suggested that during group discussion some members were denied an opportunity to contribute because time was not long enough. When group time was given thirty more minutes, this suggestion disappeared from formative assessment feedback and the majority of the members were content with the discussion time although they almost always used most of their break time. I had to push them to use their break time for break. One participant noted an appreciation for the added time:

It allowed more HMs to share their personal experiences. This is where our experiences are informed and refined by the theories and expertise of the scholars. Here is where the rubber meets the road. I, personally, used this time to personalize the content and skills with the help of my colleagues.

- Increased the session time from two to two and a half hours per session, and increased the training time from six to seven and a half hours in a day. This change was done on the second day of the training. However, at the same time, increasing the intensity of the training and lengthening the day and made it more tiring. The oldest member of the class commented, "I do not know where I got the energy of being so rigorous for such long days. It was like miracle."

- Put more emphasis on the feedback and communication in the role play sessions. Each participant should have a chance to develop and provide feedback. As noted before, the group leaders made sure that each member played a HM or a teacher role either in the small groups or in the cohort. Participant 4 wrote this on the talk back assessment, "I had to catch myself when I was communicating feedback to make sure that I used lower voice, supportive tone while maintaining my role as a leader and expert of quality teaching. This had very good feeling for me." Another participant wondered, "I did incredibly well in the group as a HM, can I be that good with my teachers too. It will be great."

- Encouraged role play to continue in the groups during the free or recreational time. This is because it is impossible to get all the time participants want to do enough role playing. One participant asked, "Can we add more days for role playing?" Once they know what to do, they can continue to practice at their own private times.

- Changed the adaptation process of Danielson's Domains and rubrics to ensure cultural relevancy. Instead of each individual working on identifying what appears to be incompatible with the Tanzanian school culture and adding elements that promote quality teaching and learning, the process was done in smaller problem-solving groups of two or three individuals. Instead of 
individuals working on their own and sharing a final copy of their work with the larger group or class as a whole, they worked in groups. This saved time and added quality to the work because it was a group-thought process. Instead of having 24 reports, we had only nine from the groups.

- The daily schedule will only reflect the main course work. The technology session will not be part of the module. This is to make the workshop less tedious for the presenter(s) and participants, giving them more time to do their homework and to relax.

Facilitator(s) should set time for quick school visits after training for a short seminar with teachers. Several schools can merge for a single visit to save time and travel.

Although Stage 8: Operational field testing, Stage 9: Final product revision, and Stage 10: Dissemination and Implementation complete the R\&D process, they are not included in this study. Chapter 5 highlights their position in future research work.

\section{Research Questions}

The study's primary research question (Is the PBL module effective in helping the HMs of Moshi Tanzania become instructional leaders capable of conducting teacher evaluation or ESCI?) and secondary question (Is the Danielson teacher evaluation model, created primarily for the American school system, able to be used or adapted for use in the Tanzania school system?) were answered through the evaluation of the PBL module by pre- and post-training self-assessments of workshop participants. The comparison of how they rated themselves on those elements of knowledge/skills, confidence, competence, conviction, and motivation will help to answer the research questions. The analysis of the words before and after the workshop shows what impact the PBL module had on them. This analysis measures the effectiveness of the module.

\section{Evaluation of the PBL Module Effectiveness: The Analysis of Words}

The participants were asked to rate themselves on their knowledge/skills, competence, confidence, conviction, and motivation about ESCI. They gave statements 
of their choice that best expressed how they thought and felt. The responses were classified into positive, negative, or neutral phrases. Negative responses indicate lack of that quality about ESCI. Neutral means they were not sure or did not have it enough, and positive means they had it. The pre-assessment was done just after the introduction and presentation on the goals and objectives of the workshop. The post-assessment was done right after the training was completed.

\section{Knowledge or Skills}

The question was: How do you feel about the knowledge or skill you have to professionally conduct ESCI? The participants' responses are shown in Table 9.

Table 9

Pre-Workshop Self-Assessment on Knowledge/Skills to Conduct ESCI

\begin{tabular}{|c|c|c|}
\hline Negative & Neutral & Positive \\
\hline $\begin{array}{l}\text { - I am not trained to do it } \\
\text { - I do not have the knowledge of ESCI } \\
\text { - I am not familiar with the ESCI } \\
\text { - No, Thanks } \\
\text { - I am not a professor, so I don't know! } \\
\text { - I do not remember how it is done } \\
\text { - I wasn't hired to be a "teachers' } \\
\text { watchdog" } \\
\text { - I do not know anything about ESCI } \\
\text { - I have been a teacher for } 21 \text { years and a } \\
\text { HM for } 13, \text { I am not up to learning new } \\
\text { challenging things. } \\
\text { - We are doing fine, I do not need it. } \\
\text { - We can survive without ESCI } \\
\text { - We are fine with what we do. }\end{array}$ & $\begin{array}{l}\text { - I doubt if I can learn this } \\
\text { - I am not sure if it will work } \\
\text { - I don't know if teachers will like } \\
\text { it } \\
\text { - I am not sure if I know anything } \\
\text { about it, it has been too long } \\
\text { - Is it proven to bring results? } \\
\text { - Are we not tired of learning new } \\
\text { things, which don't work? } \\
\text { - I do not have my decisions made } \\
\text { yet. } \\
\text { - I will see where this takes me } \\
\text { - Even if I know it, do I have to do } \\
\text { instructional evaluation? }\end{array}$ & $\begin{array}{l}\text { - I have done it, so I } \\
\text { know it } \\
\text { - I have not done it } \\
\text { myself, but I } \\
\text { remember how it } \\
\text { was done to me as } \\
\text { a student-teacher } \\
\text { - Classroom } \\
\text { evaluation is the } \\
\text { best way to keep } \\
\text { your teachers on } \\
\text { their toes. They } \\
\text { don't like it, but I } \\
\text { love it. }\end{array}$ \\
\hline
\end{tabular}

Note: The total number of responses was $24 ; 12$ out of 24 responded negatively, 9 were neutral and 3 were positive. 
The responses of the same question after the training produced the following statements about knowledge or skill as grouped in the Table 10.

\section{Table 10}

\section{Post-Workshop Self-Assessment on Knowledge/Skills to Conduct ESCI}

\begin{tabular}{|c|c|c|}
\hline Negative & Neutral & Positive \\
\hline $\begin{array}{l}\text { - I still do not } \\
\text { know all the } \\
\text { details of every } \\
\text { step of clinical } \\
\text { supervision. I } \\
\text { needed more } \\
\text { time to digest } \\
\text { its contents. }\end{array}$ & $\begin{array}{l}\text { - I learned a lot, but } \\
\text { this training needed } \\
\text { more time to allow } \\
\text { the content to sink } \\
\text { in } \\
\text { - I will need refresher } \\
\text { course after a while. } \\
\text { This stuff was too } \\
\text { dense for me. } \\
\text { - I now know it now } \\
\text { but I do not know } \\
\text { how to get my } \\
\text { teachers buy in. } \\
\text { - I still doubt if my } \\
\text { teachers will love it } \\
\text { although I know the } \\
\text { procedure } \\
\text { I need more training } \\
\text { to feel comfortable } \\
\text { with the process. }\end{array}$ & $\begin{array}{l}\text { - Now I have the knowledge/ skills. } \\
\text { - I thought I knew, but what I knew is nothing } \\
\text { compared to what I know now. } \\
\text { - Yes } \\
\text { - I am thankful to know how to conduct teacher } \\
\text { evaluation. } \\
\text { - I feel I am now an expert of classroom evaluation. } \\
\text { - I am ready to begin trying this thing in my school. } \\
\text { - I have never felt that empowered as a leader as I am } \\
\text { right now. I can't wait to use it. Thank you. } \\
\text { - I really know this stuff now } \\
\text { - I am so happy to know what I know now } \\
\text { - I wish I had this knowledge before, especially the } \\
\text { consultancy protocol. It was a real deal. } \\
\text { - This training was so helpful. Please, bring more of } \\
\text { this kind. } \\
\text { - Yes, I have the knowledge I need to do evaluation. } \\
\text { - It feels good to have this knowledge and skills. } \\
\text { - I fell like a new person basing on what I know now } \\
\text { about teaching and learning and how to help it } \\
\text { happen. } \\
\text { - I am glad to know how to communicate feedback } \\
\text { - I hell. } \\
\text { - Yes, I am thankful for this knowledge } \\
\text { - It is great to have this kind of skills. The work begins. }\end{array}$ \\
\hline
\end{tabular}

Note: Of the 24 total responses, only 1 was negative, 5 were neutral and 18 were positive. After training the overwhelming majority of comments were positive. 
There was a shift in how the HMs viewed themselves regarding having the knowledge and skills of ESCI. The pre-training responses showed that the overwhelming majority felt that either they did not have the knowledge or skills of ESCI or they were doubtful. On the contrary, the post-training responses indicated that almost all the participants felt they possessed the knowledge and skills for conducting ESCI. At the end of the workshop, all the negative responses had disappeared. Even the one participant, who felt that he did not know the details of clinical supervision, indicated that he needed more time to digest the information because the training was too fast. Note that he did not deny having the skills or the knowledge. He was at least optimistic that more time might help him learn the details of the content. Even those in the neutral column acknowledged having learned something after training, only they felt that they either needed more time or some other strategies to convince their teachers about the values of what they knew. This last concern was addressed by asking me (the facilitator) to visit their schools and have a brief seminar with the teachers. I visited 11 schools. To me, this was a good indicator that the module was successful in imparting the classroom evaluation skills to the participants. This fulfilled one of the goals of the curriculum.

\section{Participants’ Competence and Confidence}

I always believed that it is difficult to be interested in doing something one is not good at. It was anticipated that the training module would make the participants not only knowledgeable about ESCI but also believe that they are good enough to do it. This is what I mean by competence and confidence respectively in this study. The participants were asked to rate themselves on how competent they thought they were before and after 
the training. I combined the two elements because the participants said they could not make a clear distinction between the two and they were allowed to answer the two questions as if they were one and write their responses on both given spaces. They followed the same pattern of using their personal phrases or sentences. They responded to these two questions: How do you feel about your competence in doing ESCI with your teachers? How do you feel about your confidence in doing ESCI with your teachers? The classification of their pre- and post-training response statements are expressed by Table 11 and Table 12 respectively. The responses are in the scale of negative, neutral, or positive. The analysis of the pre- and post-responses of the workshop responses is given. The same assessment was done after the training that produced the following statements.

Table 11

Pre-Workshop Levels of Competence and Confidence

\begin{tabular}{|c|c|c|}
\hline Negative & Neutral & Positive \\
\hline $\begin{array}{l}\text { - I do not have the ability to professionally } \\
\text { conduct ESCI } \\
\text { - I do not have that competence } \\
\text { - I am not prepared for this } \\
\text { - No, thanks. } \\
\text { - Honestly, I don't think I can do it } \\
\text { - No, I cannot do this } \\
\text { - I am not good at this and I don't want to } \\
\text { embarrass myself before my students and } \\
\text { staff, please! } \\
\text { - No. } \\
\text { - No, I was not taught. } \\
\text { - I am not competent doing ESCI. } \\
\text { - No knowledge so, no confidence. }\end{array}$ & $\begin{array}{l}\text { - No enough competence } \\
\text { - What I know about ESCI is } \\
\text { not good enough for my } \\
\text { competence or confidence } \\
\text { - I am not that good } \\
\text { - I really do not know if I have } \\
\text { what it takes to do it } \\
\text { - I do not know. } \\
\text { - I am not sure. } \\
\text { - I do not know. } \\
\text { - Not sure. } \\
\text { - It is hard to tell. } \\
\text { - Probably a little. }\end{array}$ & $\begin{array}{l}\text { - I have done it } \\
\text { before, so yes, I } \\
\text { can do it with } \\
\text { confidence } \\
\text { - I think I have } \\
\text { enough experience } \\
\text { of doing it } \\
\text { - I can. }\end{array}$ \\
\hline
\end{tabular}

Note: Of the 24 responses on confidence and competence, 11 were negative, 10 were neutral and only 3 were positive. 
Table 12

Post-Workshop Levels of Competence and Confidence

\begin{tabular}{|c|c|c|}
\hline Negative & Neutral & Positive \\
\hline- & $\begin{array}{l}\text { - I feel good enough that I can do } \\
\text { it, although I will need to take } \\
\text { time and practice it more } \\
\text { - I did great on the role play in my } \\
\text { group. I wonder if I can do the } \\
\text { same with my teachers! } \\
\text { - I would be happier to get more } \\
\text { training after the first semester of } \\
\text { trying doing it. } \\
\text { - I am not quite sure. } \\
\text { - Probably. }\end{array}$ & $\begin{array}{l}\text { - I feel I can take off from here and begin ESCI } \\
\text { in my school } \\
\text { - Yes, I feel competent enough now. } \\
\text { - I am good, the job begins } \\
\text { - I feel competent enough } \\
\text { - I never thought I would be so conversant in } \\
\text { such a short time } \\
\text { - I feel like am an expert on this } \\
\text { - I am confident, I will do it } \\
\text { - I am OK now } \\
\text { - I feel confident, I will surely do it. } \\
\text { - I have what it takes to do ESCI. } \\
\text { - Yes, both competent and confident. } \\
\text { - Yes, with the skills I have I feel competent } \\
\text { enough to begin doing the job. } \\
\text { - I am skilled, competent, confidence and ready. } \\
\text { - I am ready to begin. }\end{array}$ \\
\hline
\end{tabular}

Note: Of the 24 total responses, there was no single negative comment, 5 were neutral and 19 were positive.

Before training, the overwhelming majority of comments were either negative or neutral with regards to their competence and confidence in doing ESCI. After the training, however, there was not a single participant who felt that he was not good enough (incompetent) or could not do (not confident) ESCI. This indicated a shift in the participants' perceived confidence and competence compared to their pre-training assessment. The post training statements suggest that the workshop imparted confidence and competence in conducting ESCI because the majority of comments moved into the positive column. Even those who expressed their competence or confidence in the neutral column after training suggested they felt they still needed more practice or some kind of 
assurance that it they will be as effective with their teachers as they were in their groups.

I believe their competence will increase with practice and experience. This was another

indicator that the module can train HMs to improve quality teaching and learning through

ESCI.

\section{Motivation}

Under motivation, the participants followed the same pattern and rated themselves prior to and after the workshop. This element was suggested by the five HMs who participated in the preliminary testing. Motivation encourages persistence and perseverance. There were no positive responses. The pre-workshop responses are listed in Table 13.

Table 13

Pre-Workshop Levels of Motivation to Conduct ESCI

\begin{tabular}{|c|c|c|}
\hline Negative & Neutral & Positive \\
\hline $\begin{array}{l}\text { - No motivation for me. } \\
\text { - I don't see what to be motivated for } \\
\text { - Not at all. } \\
\text { - No. } \\
\text { - No } \\
\text { - No. } \\
\text { - Teachers don't like it, so it is not fun. } \\
\text { - Not yet. } \\
\text { - Not for me. } \\
\text { - It sounds too demanding and } \\
\text { challenging. } \\
\text { - Let me be honest, no. } \\
\text { - It appears stressful. } \\
\text { - I do not like it, so no motivation. }\end{array}$ & $\begin{array}{l}\text { - I do not know } \\
\text { - I feel like I need it, but afraid will not be } \\
\text { able to do it } \\
\text { - I doubt if it is worthy of my tight } \\
\text { schedule. } \\
\text { - I do it not because I love it but because it } \\
\text { keeps teachers responsible, otherwise, I } \\
\text { would not care for it. } \\
\text { - Probably it will come as I learn. } \\
\text { - I want to do it only time mars it. } \\
\text { - Not sure. } \\
\text { - Not sure. } \\
\text { - I do not know yet. } \\
\text { - It is hard to tell. }\end{array}$ & - \\
\hline
\end{tabular}

Note: Of the 19 total responses, 13 were negative, 10 were neutral and no positive response. One participant did not answer the pre-training question on motivation. 
All the responses were either negative or neutral with no single positive response.

Also, the pre-workshop responses were fewer and almost identical. A few participants did not answer this question despite my emphasis that no space should be left blank. After the workshop, the participants were asked the same question and these were the responses (see Table 14).

Table 14

Post-Workshop Levels of Motivation to Conduct ESCI

\begin{tabular}{|c|c|c|}
\hline Negative & Neutral & Positive \\
\hline $\begin{array}{l}\text { - ESCI } \\
\text { sounds } \\
\text { great, but I } \\
\text { still can't } \\
\text { see how I } \\
\text { will have } \\
\text { enough } \\
\text { time for } \\
\text { this? } \\
\text { - It takes } \\
\text { too much } \\
\text { time. }\end{array}$ & $\begin{array}{l}\text { - I think I struggle } \\
\text { to create room in } \\
\text { my schedule for } \\
\text { this at least for a } \\
\text { very teacher to be } \\
\text { evaluated once in } \\
\text { a semester. } \\
\text { - My schedule is } \\
\text { too full; I have to } \\
\text { delegate some } \\
\text { things to have } \\
\text { room for this. }\end{array}$ & $\begin{array}{l}\text { - This is a gold time for me, ESCI is a must. } \\
\text { - I have been looking for anything that will help teachers } \\
\text { improve their standard of teaching. Now it is here, thanks to } \\
\text { God. } \\
\text { - This is a priority. } \\
\text { - I can't wait to get back to class. } \\
\text { - I can see how my teachers will enjoy this because ESCI is not } \\
\text { for judgment, but for support and improvement. } \\
\text { - I love it. It will make me know what is going on in classes } \\
\text { almost on the daily basis. } \\
\text { - Not only will I improve academics, but I am a problem solver } \\
\text { through consultancy protocol. } \\
\text { - I could anyone not do this after knowing it? } \\
\text { - I am really looking forward to begin my job. } \\
\text { - I feel ashamed that improving education was not my priority. } \\
\text { - ESCI will be a number priority. } \\
\text { - It is now my business, I have to do it at any cost. } \\
\text { - This is it. I will do it. }\end{array}$ \\
\hline
\end{tabular}

Note: Of the 17 total responses, 2 were negative, 2 neutral and 13 were positive. Two participants said they need to adjust their schedule and two still struggled to figure out how their busy schedule can accommodate teacher evaluation. During the action plan presentations these doubts did not surface. Probably they had been resolved by then.

Compared to the pre-workshop assessment, the post-workshop assessment on motivation had overwhelmingly positive responses. The motivation of the participants was not only seen in their self-assessments, but was also evident in their group 
discussion, class presentations, and break-time casual talks. They appeared to have been "fired up" with interest and passion, wanting to go back and apply their new knowledge. The positive response statements were numerous, longer, and more diverse. The negative responses were related to time factors. The group's action-plan presentations and the last summary presentation clarified some of the concerns. Since these responses were anonymous, I could not trace them back to see if the negative responders had changed their minds or were of the same opinion. Those in the neutral column said they wanted to do it, but they needed to make some adjustments. One will do it in a limited fashion, at least each teacher will be evaluated once a semester and the second will delegate some of his duties so as to create time for classroom evaluation. Generally, the responses and observation indicated that participants were more motivated after the training than before. This was another indicator that the PBL module was successful in preparing HMs for ESCI.

\section{Conviction}

This element was added during the preliminary field testing of the module. Conviction is believed to be the driving inner force that helps us to do things because of their anticipated effect. This means HMs are likely to do ESCI if they are convinced it has the ability to improve the quality of teaching and learning. Motivation on the other hand, was viewed as the inner driving force that helps people to like doing things without being forced. The assumption was that if HMs are convinced that teacher evaluation is doable and can improve the quality of teaching and learning, they will be more likely do it. This applies to the other elements that were assessed by this study. The participants 
had to be convinced that they had the skills, the competence, and confidence they needed in order to do ESCI. However, the question that addressed this element was not fully answered. All the participants responded to the pre-evaluation, but only six out of twentyfour responded to the post-training evaluation due to lack of time. They had left this last question to finish after the concluding ceremony, but they never went back; lunch and packing got in the way. Because of this, this element is not included among the indicators of measuring the success of the curriculum. However, based on their passion, enthusiasm and their public commitment to do teacher evaluation, I personally think they were convinced that ESCI will work and have the ability to make a difference, despite a paucity of data to that effect.

The overall analysis shows that the PBL module managed to answer the primary research question. The analysis of the words and the responses of the self-assessment indicated that the participants felt that they had what it takes to professionally conduct ESCI. The secondary question was answered in Step 6 of the process R\&D, on Wednesday, August 1, 2012, Sessions 1-3 and Thursday, August 2, 2012, Session 1. This was the time the participants processed the adaptation of the Danielson evaluation tool. For this tool to be relevant and culturally sensitive it needed to be acculturated first.

\section{Participants' Expectations: Were They Met or Not?}

Because the participants had been longtime practitioners in teaching and school leadership, they were, in a way, experts in the field. Based on the Busara's story in the preface and pre-evaluation responses, the majority of the participants knew about the problem, their limitations to solve it, and what they needed to have to effectively 
influence quality teaching and learning. Therefore, their expectations on what they would get from the PBL curriculum were compared with what they actually learned from it to measure whether or not the training met their expectations. The participants were asked to write their pre- and post-evaluation responses in the provided forms. They were to limit their entries to one to two statements. For accuracy and consistency, they were asked to read the pre-evaluation first before writing the post-evaluation. Their actual entries are listed in Table 15.

Table 15

Participant Pre- and Post-Workshop Expectations

\begin{tabular}{|l|l|l|}
\hline \multicolumn{1}{|c|}{$\begin{array}{c}\text { PRE-WORKSHOP RESPONSES } \\
\text { this workshop? }\end{array}$} & $\begin{array}{c}\text { POST-WORKSHOP RESPONSES } \\
\text { Did you learn what you } \\
\text { expected/anticipated learning in this } \\
\text { workshop? }\end{array}$ \\
\hline 1 & $\begin{array}{l}\text { What do you expect/anticipate to learn from } \\
\text { help/uplift teachers who have the tendency of } \\
\text { being late for classes and lazy in teaching. } \\
\text { Even after several warnings, the problem } \\
\text { remains. } \\
\text { - I want to learn how to improve student } \\
\text { performances }\end{array}$ & $\begin{array}{l}\text { - I really learned what I anticipated, that is } \\
\text { instructional leadership, instructional } \\
\text { evaluation and supervision, how to help } \\
\text { teachers to set high expectations for } \\
\text { learners' high academic achievement. I got } \\
\text { more than I expected, thank you. }\end{array}$ \\
\hline 2 & $\begin{array}{l}\text { Tool that will help me to supervise the school } \\
\text { and make it more effective in teaching and } \\
\text { learning } \\
\text { - How to be firm to my teachers without being } \\
\text { bully }\end{array}$ & $\begin{array}{l}\text { - The workshop enhanced what I knew and } \\
\text { deepened it, I am thankful for it. It was well } \\
\text { done. Congratulations for a job well done. }\end{array}$ \\
\hline 3 & $\begin{array}{l}\text { How to treat my staff to follow my lead by } \\
\text { making them buy-in and improve academics } \\
\text { without always being pushed? }\end{array}$ & $\begin{array}{l}\bullet \text { Yes, I learned what I wanted in this } \\
\text { workshop; but it was too dense, more time } \\
\text { was needed. }\end{array}$ \\
\hline
\end{tabular}


Table 15 (continued)

\begin{tabular}{|c|c|c|}
\hline 空 & $\begin{array}{l}\text { PRE-WORKSHOP RESPONSES } \\
\text { What do you expect/anticipate to learn from } \\
\text { this workshop? }\end{array}$ & $\begin{array}{l}\text { POST-WORKSHOP RESPONSES } \\
\text { Did you learn what you } \\
\text { expected/anticipated learning in this } \\
\text { workshop? }\end{array}$ \\
\hline 4 & $\begin{array}{l}\text { - Anything that will make me a better leader. } \\
\text { - Anything that will help raise student } \\
\text { performance }\end{array}$ & $\begin{array}{l}\text { - I am so happy that I know now how to do } \\
\text { ESCI } \\
\text { - To improve teaching and learning process }\end{array}$ \\
\hline 5 & $\begin{array}{l}\text { - I anticipate getting the skills and techniques } \\
\text { that will enable me to effectively improve } \\
\text { academics. I have struggled with this for } \\
\text { years now. I must say, I do not know } \\
\text { anything about ESCI. My school is in bad } \\
\text { shape. This workshop might save my } \\
\text { employment, God help! }\end{array}$ & $\begin{array}{l}\text { - Frankly speaking, I did not have a clear } \\
\text { picture of what this workshop was all about. } \\
\text { But now I realize that what I have learned } \\
\text { here not only will it help improve academic } \\
\text { performance at my school, but also to raise } \\
\text { integrity of my school. I feel like a new } \\
\text { person now, Thank you }\end{array}$ \\
\hline 6 & $\begin{array}{l}\text { - To maximize quality teaching and learning in } \\
\text { my school. I do not know what to do to my } \\
\text { teachers to just improve a bit. It is } \\
\text { outrageous! }\end{array}$ & $\begin{array}{l}\text { - I learned a lot of skills more than I deserve. } \\
\text { This was an eye opener. My teachers are } \\
\text { now my priority. Sadly I realized that I } \\
\text { contributed it to their laziness. No more. } \\
\text { Thanks. }\end{array}$ \\
\hline 7 & $\begin{array}{l}\text { - I would like to learn how to really help my } \\
\text { teachers to be good teachers and to help my } \\
\text { students be good students }\end{array}$ & $\begin{array}{l}\text { - I have attained more knowledge than what I } \\
\text { anticipated. Thank you so much. I wish I } \\
\text { had this training about } 7 \text { years ago! }\end{array}$ \\
\hline 8 & $\begin{array}{l}\text { - Know about ESCI and to deal with its } \\
\text { challenges } \\
\text { - Be more supportive to teaching and learning } \\
\text { - How to set a good example and model } \\
\text { effective teaching to my teaching staff }\end{array}$ & $\begin{array}{l}\text { - Yes, I did get so many skills I was not } \\
\text { familiar with before. So this workshop } \\
\text { enriched me in different areas of my work } \\
\text { and makes me comfortable in my daily } \\
\text { school leadership activities and teaching. }\end{array}$ \\
\hline 9 & - School leadership techniques & - Yes, more than I asked for, thank you \\
\hline 10 & $\begin{array}{l}\text { - How to communicate negative feedback after } \\
\text { teacher is evaluation } \\
\text { - How to handle resistance of teachers who } \\
\text { don't like any change }\end{array}$ & $\begin{array}{l}\text { - I am sure of one thing; I learned how to help } \\
\text { my teachers to do better in improving our } \\
\text { students to do better. } \\
\text { - Thank you for consultancy protocol. }\end{array}$ \\
\hline 11 & $\begin{array}{l}\text { - How to be more professional as in } \\
\text { instructional leader who knows not only what } \\
\text { I am doing but also what every teacher is } \\
\text { doing and push them to the next level of } \\
\text { performance. }\end{array}$ & $\begin{array}{l}\text { - Yes, thank you. I feel so good because I was } \\
\text { about to send my vice! }\end{array}$ \\
\hline 12 & $\begin{array}{l}\text { - Improve my ability to improve the grades of } \\
\text { my students not only in the classes I teach but } \\
\text { of all the students in my school } \\
\text { - Make both teachers and student accountable } \\
\text { for teaching and learning }\end{array}$ & $\begin{array}{l}\text { - Wow! I feel to be a new person, new } \\
\text { perspective, energized and ready to launch } \\
\text { academic reform in my school. }\end{array}$ \\
\hline
\end{tabular}


Table 15 (continued)

\begin{tabular}{|c|c|c|}
\hline 䒺 & $\begin{array}{l}\text { PRE-WORKSHOP RESPONSES } \\
\text { What do you expect/anticipate to learn } \\
\text { from this workshop? }\end{array}$ & $\begin{array}{c}\text { POST-WORKSHOP RESPONSES } \\
\text { Did you learn what you expected/anticipated } \\
\text { learning in this workshop? }\end{array}$ \\
\hline 13 & $\begin{array}{l}\text { - After going through the entire schedule of } \\
\text { the workshop, I really want to know about } \\
\text { "Consultancy Protocol." I do not have clue } \\
\text { of what this is and how can it help me as } \\
\text { an educational leader }\end{array}$ & $\begin{array}{l}\text { - Yes, and beyond, only the schedule was too } \\
\text { tight to share our experiences. }\end{array}$ \\
\hline 14 & $\begin{array}{l}\text { - I want to know more about what makes a } \\
\text { quality teacher and how I can be of help to } \\
\text { make my teachers quality teachers. }\end{array}$ & $\begin{array}{l}\text { - Yes, I learned more than I expected. } \\
\text { - Intelligent presenter, Fr. Peter you really know } \\
\text { this stuff. }\end{array}$ \\
\hline 15 & - I want to know about the skills of ESCI & - Yes, I did and thank you \\
\hline 16 & $\begin{array}{l}\text { - I expect to get some new information about } \\
\text { how to be a more effective HM }\end{array}$ & $\begin{array}{l}\text { - Yes. I was amazed that you kept me running } \\
\text { all day long with my spirit up. It was good. }\end{array}$ \\
\hline 17 & $\begin{array}{l}\text { - How to make a new vision of my school } \\
\text { that reflects our goals and objective of } \\
\text { quality teaching and higher student } \\
\text { performances }\end{array}$ & $\begin{array}{l}\text { - Personally, I learned exactly what I really } \\
\text { wanted to study, and yes, more than what I } \\
\text { could ask for. It was more organized and } \\
\text { informative than I could ever imagine. } \\
\end{array}$ \\
\hline 18 & $\begin{array}{l}\text { - I want to know how to conduct ESCI } \\
\text { - I want to see the anticipated challenges of } \\
\text { ESCI and how to tackle them }\end{array}$ & $\begin{array}{l}\text { - Yes, I learned something I always struggled to } \\
\text { improve: the academic performance in my } \\
\text { school. In fact, I had more than I asked for. } \\
\text { - However, the ESCI challenges were not } \\
\text { explicit. }\end{array}$ \\
\hline 19 & $\begin{array}{l}\text { - How to make teachers and other staff own } \\
\text { their responsibility without waiting to be } \\
\text { pushed. } \\
\text { - Do ESCI and make constructive feedbacks }\end{array}$ & $\begin{array}{l}\text { - Yes } \\
\text { - It was very well organized, but I did not } \\
\text { understand Dr. Kidevu (name changed). I am } \\
\text { glad he left early. }\end{array}$ \\
\hline 20 & $\begin{array}{l}\text { - How to do ESCI and communicate } \\
\text { feedback without making the teacher feel } \\
\text { like singled out or unqualified. }\end{array}$ & $\begin{array}{l}\text { - Yes, I learned what I anticipated. My only } \\
\text { regret is I got this knowledge too late, close to } \\
\text { my retirement! }\end{array}$ \\
\hline 21 & $\begin{array}{l}\text { - I want to know whatever will make me a } \\
\text { better leader, whatever will raise my } \\
\text { student achievement. I am tired their } \\
\text { failures. }\end{array}$ & $\begin{array}{l}\text { - Yes, I now have new hope. } \\
\text { - The whole thing was informative and inspiring } \\
\text { and Fr. Peter was outstanding teacher, sharp. }\end{array}$ \\
\hline 22 & $\begin{array}{l}\text { - How to do ESCI effectively } \\
\text { - How to make my teachers agree with it } \\
\text { since it sounds to be a new thing in the } \\
\text { system and my teachers are very opposed } \\
\text { to new things! }\end{array}$ & $\begin{array}{l}\text { - Yes, I really got more than that. However, I } \\
\text { wish we had more group discussion time. I } \\
\text { would suggest that this kind of intense } \\
\text { workshop to be done at least in two weeks. }\end{array}$ \\
\hline 23 & $\begin{array}{l}\text { - How to use consultancy protocol in } \\
\text { decision-making. My school is in the } \\
\text { countryside and I do not have an easy } \\
\text { access to legal consultations. }\end{array}$ & $\begin{array}{l}\text { - Absolutely, only it was too intense, too much } \\
\text { to process within a short time. I am really } \\
\text { tired, but very happy. More workshops of this } \\
\text { kind, please. }\end{array}$ \\
\hline 24 & $\begin{array}{l}\text { - Just anything I can do to make teachers do } \\
\text { their job. Current performance is not good. }\end{array}$ & - Yes, I feel really tired, but it worth it. \\
\hline
\end{tabular}


Overall, the responses clearly and powerfully indicate that all the participants believed that the training gave them what they expected. The overwhelming majority indicated that it gave them more than their expectations. This suggests that the PBL module curriculum can successfully train the HMs of Tanzania to become leaders of academic improvement through teacher evaluation. In my opinion, the data indicate that the workshop was very successful and the leaders view the curriculum as being potentially effective. Despite the fact that the participants felt that the workshop was great and appreciated the training, it is important to mention here that reform is in the implementation too. I do not assume they all left with the follow through to implement the plan with full fidelity despite their promises to do so. The follow up workshop in 2014 will establish if they actually followed with fidelity or not. This will be Step 8 of R\&D process.

\section{The PBL Module and Leadership Improvement}

All participants expressed their satisfaction with the training and believed that it would improve their overall instructional leadership. As part of the evaluation, the participants were asked if they thought the training had made them better or more effective instructional leaders and why or why not they thought so. They all responded affirmatively that the workshop improved their skills making them better instructional leaders with the following words:

- Absolutely, I am a better leader now than I have ever been.

- Yes, because I know how to do what I have been longing to do for years, only I did not know how to do it: To support my teachers and help them to improve their teaching and the performance of our students. 
- Yes, for sure; just because of what I know now and what I am going to do with it.

- Yes, I am. I just wish I knew many years ago what I know now.

- I am not a headmaster, but this training will make me even a better academic dean than I have been. I wish all the school administrators would have this opportunity of learning this stuff.

- Certainly.

- I don't know for sure if I am a better leader than I was, but I am sure I have some new skills, which will help improve academics in my school.

- Sure, no doubt. It is because of what I can do now with ESCI and problem solving through consultancy protocol.

- Yes, because of this training. I feel like I am a new person in my role as a school leader.

- Without any doubt. I can now be of help to my teachers who are really struggling to improve doing their job.

- Yes, because I can use the hard working spirit of teachers and student to improve performance.

- Yes, I feel it. I am very thankful and happy.

- Yes, because I have grown professionally.

- Much better for sure because of this new knowledge. I am convinced it will help.

- Yes, it is obvious.

Clearly, these responses indicate that the training managed to give the participants a sense of personal leadership improvement. The participants felt that they grew professionally. They had a better understanding of what will help them to be successful in improving academics and the spirit of both teachers and students. They appeared to be convinced that ESCI will improve the quality of education and they are looking forward to it. These responses further answered the primary research question, that the PBL can train the 
Tanzanian HMs to increase their instructional leadership capacity and help them improve quality classroom teaching and learning. These outcomes answer the study's primary research question.

\section{Implication of Training Outcomes}

The workshop participants indicated that the PBL module curriculum was effective in imparting the necessary skills for them to effectively conduct teacher evaluation. They also demonstrated their passion and readiness to influence quality teaching and learning by employing the culturally adapted Danielson teacher evaluation tool. By employing the PBL research method, the study was set up with the intention of offering a solution to the current number one school leadership challenge, student underachievement as measured at the conclusion of the fourth year by the Form Four National Exams.

This study addressed the real problem by training the participants in how to use ESCI as a leadership tool to improve teaching and learning with the goal of improving student achievement (Peterson, 2000). The training resulted in HMs who had never used ESCI before to become willing participants in its use. It also made it attractive for those few who had tried it, but had been discouraged because of its unpopularity and the resistance it provoked. Participant 17 aptly commented, "One needed to be a fighter to do teacher evaluation. However, with these new skills, I am no longer a fighter but a supporter of my teachers' teaching and learning. I am sure every teacher wants to be supported so as to be the best teacher, and that is exactly what this training has given me." Supposedly this will reduce or eliminate teacher resistance. On a similar note, 
Participant 15 said, "I made my work harder and increased opposition by the way I did classroom evaluations. I did not know any better." This demonstrates that the training increased administrative professionalism in conducting teacher evaluation. Participants also indicated that their new skills would make their leadership work more effective and enjoyable. One wrote, "I would have been a more effective and happier HM if I knew what I know now. I think now my school has a brighter future."

\section{Participants' Self-Awareness}

The training also offered self-awareness strategies on how the HMs need to establish their priories if they want to improve quality teaching and learning in their schools. While the majority reported that before the workshop they never considered that supporting and coaching teachers was their job, they demonstrated and verbalized their understanding to the contrary after the training. The training also increased the participants' confidence in performing their administrative duties, especially that of doing ESCI. Those who had expressed feeling intimidated to evaluate "experienced and seasoned professional teachers" did not seem to feel so after the workshop. Participant 3 reported, "Out of my ignorance, I used to avoid doing what I actually needed to do to make my teachers and students successful." The ESCI, which was viewed as waste of time before the workshop, was viewed as a great instructional leadership tool after the training. Participant 6 expressed this by saying, "Now I realize that what I have learned here is very necessary for me as a school head in order to improve academic performance at my school." After the workshop, there was not a single comment indicating that HMs were uncomfortable or unwilling to use ESCI. 
A deeper awareness was evident when the participants expressed their remorse as they realized that their old leadership styles contributed to the existing problem of student underachievement and they had actually hurt teachers and students because of their ignorance. Seven participants gave the same comment in their formative assessment, "I never knew I was part of the problem; I am so sorry!" Participant 11 said, "My only regret is that I came to know this too late in my career. I would have been a better HM if I knew this twenty years ago. However, it is better to know late than never." The comment of Participant 23 highlights the implication of the training outcome when he states,

The training affirmed and brightened what I knew vaguely; that is, teaching and learning is the sole business of school. Secondly, it affirmed the indispensable role of the teacher in student achievement. And most importantly, for the first time to me, it outlined my role in the entire school business, my priorities and my influence. I feel ashamed because I contributed to the failure of my teachers, students, and my school. I will surely make up for it, and I think ESCI is a tool, which will help me to just do that.

All the participants openly and publicly committed to elevate teaching and learning as high priorities in their daily schedule. They also committed to start using the teacher evaluation tool form beginning in January 2013 after doing the necessary preparations.

\section{Exercise of Leadership During the Study}

The participants applied adult learning principles and exercised their leadership roles through the workshop process, both individually and in small-group situations (MacKeracher, 2004). They generated ideas, volunteered to represent their groups as they made group presentations to the cohort, asked for more time to get the task done, and even met during their break times to get the group-work assignments done. They also took the initiation to remind their peers of class ground rules to reduce distractions, 
maximize their training time, and ensure the smooth running of workshop sessions. They generously shared their experiences and expertise, thus becoming their own resources (Lambert, 1998). For example, on the second day, Participant 5 drove back to his school at night to collect the updated version of NECTA directives for the cohort. Consultancy protocol practice pushed this collegial sharing of leadership roles to a higher level especially when participants were addressing serious legal and ethical issues that affect academics. Collaborative leadership and shared problem solving were valued and preferred over their typical isolation (Senge, 1990; Peterson, 2000). The workshop demonstrated what HMs can achieve when they work together collaboratively.

The entire training process was very reflective. This encouraged the participants to relate the content and concepts of the curriculum to their school environment and culture. In so doing, as some of them shared, it helped them personalize the information they were processing. This, in turn, was expected to make the application of knowledge in their schools easier as Participant 2 observed,

Whether I was reading the training materials or we were in the discussion, I was constantly asking myself, 'How will this new approach work in my school? How will it work best with my teachers? Where will I put this in my busy schedule?' This makes me feel that the final product is mine and will work for me. In my mental map, I knew where and how each item will be applicable.

This helped, at least conceptually, to bring their school climate and culture into the learning process. It means the participants did not only learn the concepts of teacher evaluation, but they personalized the learning as they tried to fit its application to their schools. As one commented, "This learning was not about improving education in 
general, but to me it was improving education as it works in my school. I feel as if it was done for me and my school."

The curriculum also built a sense of optimism for a better secondary school future. The majority of the participants felt confident enough to coach their teachers by explaining the content and the procedures of ESCI before its implementation. Those who felt they needed some help to bring teachers on board were very appreciative to have me do a short seminar for their teachers introducing the Danielson (2007) teacher evaluation framework. They were all optimistic and enthusiastically ready to begin what they called "Academic Reform." Some participants expressed concerns about those HMs who did not volunteer to participate in this study as Participant 3 articulated:

As the saying goes, 'You can reject the word, but never the invitation,' our colleagues have missed the greatest opportunity of their career as school leaders. My concern is, we won't be moving forward together as a diocese unless something is done for them to make them part of this education reform. I am certain our effort to improve academics will yield much fruits for our teachers and our students, but how about the students in the schools of our colleagues who did not come? They deserve better education too!

The superintended promised to try to find some ways for those who did not participate to learn from the trained HMs. I offered my email address and phone number in case they would need some further clarification after reading the contents and learning from the trained HMs. At this time, at least two HMs have emailed and one made a phone call to me.

Despite the fact that most of the participants still had some concerns about how to make room in their busy schedules to do ESCI with every teacher, not doing ESCI was not an option. As Participant 4 commented in the cohort class, "No doubt that this will 
make us super busy, but is worth doing it. Everything else should be second after teaching and learning. This is the heart of our job."

The participants appreciated the commitment of the superintendent to visit HMs regularly and offer support as they begin and continue to implement teacher evaluation. The teachers I visited also appreciated the implementation of the ESCI with the view that it will bridge the gap between what teachers actually do in classrooms and what the HMs assume is going on in their classrooms. The majority of the teachers expressed their anticipation that teacher evaluation will make them feel cared for and their work appreciated. In expressing this optimism, Mike, a teacher of Mboreni secondary school said,

Finally, there is something to force us to always act professionally in our job. We all know and have the intention of always be professional in our teaching jobs, but it is a very daunting task for a teacher who is so overloaded with such many classes to teach. At the same time, we cannot afford sacrificing our professionalism because of having too much to do. I think ESCI will hold all of us, teachers and HMs, accountable to our teaching profession. And the best news is my HM will be part of the process for support, encouragement, correction, and improvement. I strongly believe this will get us somewhere in our desire to improve student learning and performance.

Both HMs and teachers were optimistic that ESCI was a needed tool that was expected to influence academic improvement. Since all the participants expressed their readiness, willingness, and eagerness to begin using their evaluation tool for academic reform, I strongly believe that they will actually use it. Its actual outcome as measured by increased student achievement is yet to be known. 


\section{School Visits: Teachers' Short Seminar}

As mentioned before, some HMs requested that I visit their schools to launch what they called "Academic reform to improve student achievement." In our brief meeting after the workshop we came up with the schedule of the time I should be in their respective schools. I used three days to visit 11 schools. The seminary took about one and a half to two hours. The first 45 minutes was my brief presentation about the Danielson's evaluation tool and how it is used and the rest of the time was a question-and-answer session.

The overall teachers' reactions began with skepticism. First, they had a common question which was, "Where will a teacher get time to make lesson plans while he/she is overloaded with classes to teach?" This question was asked by teachers of all the schools I visited. I used the analogy of a too-busy surgeon and asked the teachers if any would agree to be operated on with unsterilized tools because the surgeon just did not have time to prepare due to the large number of patients he needs to serve daily. The answer was easy to understand since it pointed out the necessity of keeping their professionalism at any cost. Also, the HM will be fully involved and that will help to address those issues. Second, the majority thought that the evaluation tool was planned for the HMs to play "gotcha" with teachers. However, after the presentation and answering their questions for clarification, they appeared to be comfortable with it. This was evidenced by such comments as:

- It is really nice to have the rubrics with me so that I can know what is expected.

- I like the fact that I will be leading the conversation and determining my own growth. 
- The best part is that the HM is not there to judge me but to help me become the best teacher I can possibly be. We all like that.

- I am actually excited about this because I can see how this will build a good working relationship between teachers and the HM, and bring that professional relationship to the higher level. I can't wait to see this happen in my school.

- Finally we have something, which will let my HM know what I am doing in class. With all due respect, I doubt if there is any person in the administration who knows what is going on in class except to blame somebody when national exams results are bad.

- I like the emphasis on collaboration and especially retaining my autonomy and my teaching style. To my opinion, this is the best tool for my personal assessment and growth without even depending on the HM's visit to my class.

\section{Overall Personal Experience of the Process}

Going though the process of this study was quite an experience for me. At first I had difficult time identifying the indicators for measuring the effectiveness of the curriculum in training school HMs to lead school reform for academic improvement. In the preliminary field test, the participants not only approved the three indicators of skill, confidence, and competence that I had suggested, but also they added two more, conviction and motivation. This was a learning moment for me when I realized that participants can be a great resource in the study, identifying issues the researcher might have overlooked.

Despite positive outcomes of informed, confident, competent, and motivated school leaders, developing the PBL module, preparing for the workshop and facilitating it implementation was extremely complex and tiring. I created electronic files, which had the contents and activities of each daily session and backup plans in case the first ones failed. This was extremely helpful in making the workshop run smoothly. 
The actual fieldwork consisted of many more tasks than anticipated. Because I was the only facilitator, every day was overloaded. I was actively engaged from 7am to after 10:00 pm every day. However, every day was rewarding in terms of its achievements. What helped most was that I kept the participants interested and engaged. I ended every session with a brief overview of what the next session would offer. This kept their anticipation alive as participants 3, 9, 18 and 21 indicated in their end of session formative assessment with these statements, "I can't wait to take part in the following session." Similarly participants 5, 6, 11, 16 and 23 commented, "I am looking forward to the next session."

One of the concerns I had when I was preparing the PBL training module was how to get the participants to do their homework knowing that they were volunteering to take part in this study and I could not hold them accountable if they did not do their homework. What I discovered was to the contrary. During the training, I discovered that I had to push them to take a break or go for coffee. This was a good problem to have. Their passion, seriousness, and eagerness to learn gave me moral strength to keep going even when I was feeling exhausted.

Respecting the participants' experiences and expertise in dealing with their problems eliminated resistance for change and afforded me respect as an expert who was there to help them better use their personal expertise and resources. A cohort participant highlighted this as one of their unique experiences compared to many other workshops they had attended. As some of them publicly articulated, they disliked to be told what to do without taking part in the decision-making process. To my (and their) surprise, they 
were rich resources for each other. In this way the training gave the participants a chance to discover and rediscover their own leadership skills and abilities. This experience affirmed my belief that change cannot be imposed but rather facilitated in such a way that the people are led to own their own change. I believe this is exactly what the workshop did for the participants.

The PBL process helped in keeping the participants interested and engaged in this study. Because the participants were dealing with the problem they themselves identified in the pilot study, they had ownership of it. I believe this contributed to their passion and commitment. The process also generated more than what was anticipated such as suggesting the diocesan schools policy change and the setting the new, higher teaching standards.

The last observation of my personal experience is that both HMs and the teachers I visited were at first skeptical of the evaluation process. Particularly the teachers were apprehensive saying that ESCI might cause many to be fired. However, once they were assured that its main purpose was to assist them to improve the quality of teaching and learning, they welcomed it. One commented, "Who doesn't want this? I want to be supported and helped to improve, to be the best teacher I can ever become. This is the best news to me." It is important for the facilitator and the HM to make sure that the participants have a clear understanding of the purpose of teacher evaluation. Their relief was seen when teachers realized that ESCI does not require teachers to abandon their familiar teaching skills and style. They are not even charged to learn unfamiliar teaching models, but to improve that they already know. Yet, I think it may require some if not 
many teachers to make fundamental changes and shifts in their approaches to teaching. I believe the HMs are equipped to professionally deal with those who might resist because of not wanting to make the needed shift. This will make them put into action what they learning during the "consultancy protocol" process.

\section{PBL and Its Benefits}

In this study, HMs became co-investigators of the research problem. The chronic problem of low student achievement in Tanzania was identified by these same HMs through this study's initial 2011 pilot research study. Although the HMs identified 12 problems associated with school leadership, student achievement was ranked number one. The PBL approach, which emphasizes group work during the field testing of the product or workshop curriculum, helped the participants gain a deeper understanding of the problem, articulate its possible causes, demonstrate new insights, identify solutions, and publicly commit to action plans requiring the implementation of new and innovative solutions. The participants were proactive, self-directed, self-motivated, and passionate about using various resources and data, and they loved working in teams or groups. The process offered them an opportunity to rediscover the wealth of their own professional expertise and strengths among each other and provided hope for a new beginning, growth, and improvement in their school leadership roles. They embraced the group activities and owned the knowledge, content, and implementation strategies generated from them.

The PBL module also gave me, as a facilitator, an opportunity to be a team player in the learning process. As a result of my participation, I have a deeper understanding of 
the problem and of its possible solutions. This is the brilliance of Constructivist learning. I lived it though the training process. We benefited from the collective expertise of the workshop participants and managed to merge our experiences with emerging leadership research, theories, and scholarship gained in the doctoral dissertation process at PSU.

\section{Conclusion}

At the beginning stages of both the preliminary and main field testing of this PBL module, participants demonstrated some doubts as to whether they would be able and willing to conduct teacher evaluations. This was expressed by both verbal and by nonverbal cues. For example, on the first day of training, several participants wrote in their formative assessments that they did not believe this workshop would change the way they do things in their schools. Participant 17 wrote, "We know how workshops are run, 'many words than mean nothing.' I wonder if this is one of them." One participant even questioned in class, "Why is the schedule so tight as if we are studying something of major importance? This time is crucial for us to relax." At the end of training the participants had just the opposite expression. They deemed the training process respectful, informative, transformational, and a wake-up call for change. Participants committed to take action in improving academics in their schools by using Danielson's teacher evaluation tool, and asked the superintended to help and hold them accountable for it. The PBL module/curriculum helped the participants to reflect on the ethical standards of their leadership. They examined their core values, beliefs, priorities, and customs that had not been examined before. This is a necessary ingredient of school reform or change because people stand up for what they value and believe in (Deal \& 
Peterson, 1999; Fullan, 2001; Zemelman, 2005). Participant 6 aptly captured the experience of how the training changed his mindset by this comment:

Frankly speaking, I did not have a clear picture of what this workshop was all about; partly, because I did not know much about ESCI. But now I realize that what I have learned here is very necessary for me as a school head in order to improve academic performance at my school, but also to develop integrity and ethical conduct of both my staff and students. We have been entrusted the lives of the young people of this nation with only one goal: to help them unlock their future lives through education. But for the most part we have been acting as if their education didn't matter that much. To me, this workshop was a wakeup call. I feel ashamed for what I have been, but inspired for what I will be in terms of keeping students' education number one in my priorities.

In retrospect, the workshop introduced a new approach of involving the practitioners in the field to work on developing the solution to the existing problem. They loved the fact that their experiences and expertise were respected and called for. The difference between what the participants had been hitherto experiencing and the adaptation of Danielson's (2007) evaluation tool made them owners of the process and of the tool which respects their school system and culture. They felt empowered to determine the time frame of its implementation.

Despite the challenges encountered during this study, the entire research process was very fulfilling. The amount of material and resources in the curriculum combined with reading books and journal articles, watching video clips, and participating in multiple role play practice sessions proved to be too much for the allocated time. The participants' thirst for knowledge and their willingness to sacrifice their personal and break times helped to provide more training time to get the work done. All the participants and the facilitator were very gratified with the content, the process, and the final outcomes of the workshop. All the participants expressed their new and positive 
attitudes about ESCI and their willingness to put them into practice with the hope of improving the quality of teaching and learning and raising student achievement to new heights in Tanzania's secondary schools. 


\section{CHAPTER V \\ THE FUTURE OF PBL MODULE AND RECOMMENDATIONS \\ Introduction}

Twenty-one secondary schools HMs, two vice HMs, and one academic dean participated in the 6-day workshop on developing the instructional leadership skills of high school principals in Tanzania. Prior to the workshop, which was the main field testing of the PBL curriculum, five HMs had participated in a 2-day workshop for preliminary testing of the same module. The implications of this study for the participants and the education system of the Catholic schools of Moshi Diocese were beyond anyone's expectations. Based on personal observations and the indicators that measure the effectiveness of the curriculum, the goal of the curriculum was successful (i.e., helping train HMs to use teacher evaluation as an instructional tool for improving teaching and learning). Comparing what the participants anticipated they would achieve and what they actually achieved through the workshop demonstrates that the training module accomplished its objectives. All of the participants indicated that the training either met or exceeded their expectations. The participants not only reported having acquired knowledge, skills, confidence, competence, and motivation to conduct teacher evaluation as a means of improving academics, they also appeared passionate and eager to go out and apply their new instructional skills and tools. One participant commented, "Personally, this training ranks number one of all professional development I have ever 
attended because it gave me what I needed most, namely skills to improve the quality of education for my students."

This chapter highlights the impact of the study specifically on the school leaders and teachers, and generally on the future standard of education in Moshi schools and possibly schools throughout Tanzania. Since the main stakeholders in educational systems are the students, it is anticipated that this PBL module will also positively influence student learning and performance. The outcomes of the study include, but are not limited to, improvement of leadership skills for the participants, rekindling the spirit of passion in their leadership duty for improving teaching and learning, renewing a sense of hope that academic reform is possible and that HMs can facilitate school change by identifying and learning new instructional improvement strategies. The unexpected implications include the decision participants took of setting new and higher standards for teaching, identifying, and analyzing the possible underlying causes of the existing problem of student achievement, and using Danielson's Domains to propose possible solutions.

This study was a great opportunity for me to learn as a researcher and practitioner. The following section on advice to school leaders and future researchers will highlight my personal insights from this study. While conducting this study, I met some obstacles and roadblocks that made it more difficult than anticipated. Despite the roadblocks, I still believe that the work of this dissertation was successfully done by accomplishing the seven steps of the R\&D process. However, my work as an educational leader and researcher is not yet complete. This chapter explores my next endeavors in R\&D stages 
eight, nine, and ten. This also demonstrates the beauty of following a PBL research approaches that will professionals on task beyond the initial and immediate learning and research outcomes.

\section{Future Implications of the PBL Curriculum}

\section{R\&D Steps 8 \& 9: Operational Field Testing and Final Product Revision}

The end of this dissertation does not mark the end of my research work. My plan for the next step in the R\&D cycle is that the current refined PBL module will be used to conduct training with the same group in 2014 as participants requested. This will be Step 8 of R\&D cycle. The next step strives to enrich the curriculum with teachers' and students' experiences after participating in the first implementation of ESCI. The 2014 is intended to bring in not only the HMs' experiences of using the Danielson's evaluation tool to do ESCI, but also the experiences and reflections of both the teachers and students. One way of doing this is that in the first step the HMs will be given time to shared their experiences of implementing ESCI. The emphasis could be given on what went well, what was most challenging, and how did they face or resolve those challenges. They might even propose what they think they needed to know more to make the classroom evaluation process easier. The second step could involve teachers by inviting them to share their experience with ESCI. Did it help them improve their teaching, and how? What was most helpful? What they would like to change to make it more effective and user friendly? The third step could involve students who witnessed ESCI in their classrooms. What was it like for them and how did that experience translates into their understanding of teachers' and HMs' work in their learning? It is in my plan to prepare 
and help facilitate the 2014 workshop, as the HMs and the Superintendent of Moshi requested. The findings of all this would further refine and enrich the product for future training of HMs. The process of refining the module will be Step 9 of R\&D process.

\section{Step 10: Dissemination and Implementation}

I envision the use of PBL to benefit other school districts of Tanzania. Another option is to suggest to the Secretary of Education of the Tanzanian Episcopal Conference (TEC) of the Catholic Bishops to use the curriculum for the Catholic Schools education reform program in all the 34 Catholic dioceses of Tanzania. The current Secretary, in proposing the education reform for the Catholic schools in Tanzania said, "We are desperately looking for anything that can help improve academics in our schools." I believe that the PBL module can be part of the answer to their questions. This initiative would amount to a dissemination of the product to a wider audience, reflecting Step 10 of the $R \& D$ process.

\section{Use PBL Module to Train HMs of Other School Districts}

The curriculum was successful. This success calls for a replication of the same process in the future to train more HMs to help improve the quality of education in Tanzania. The concern of HMs about the problem of student achievement was selfevident in the pilot study, in the national statistics, and in the field testing of the module. Since this study was the first to be done in the district, and probably in the country, to address the problem, it can be done in other school districts as well.

The PBL experience helped the participants to reflect on the problem of low student achievement from their leadership perspective and take responsibility for it 
instead of pointing a blaming finger to others like teachers, students, parents, higher authorities, or the system. As a result of the training, they indicated a shift in the trend of their thoughts and values. Instead of perceiving themselves as inadequate to improve academics, through ESCI they ended by affirming themselves as capable and willing to it. Instead of viewing ESCI as not being their responsibility, as a waste of their precious time, as a way of creating a battlefield with teachers or feeling intimidated to evaluate experienced teachers, they viewed ESCI as a great leadership tool for academic reform, helping and supporting teachers, and helping them to fulfill their number one leadership role: to ensure quality teaching and learning (J. Blase \& Blase, 2001; Fullan, 2001). This was the major and most desired outcome shift of the study. I believe every education stakeholder in Tanzania wants to see this kind shift in every HM. I believe that this PBL module can help the districts of Tanzania with their long-term educational improvement agendas.

\section{Use PBL Module to Train Teachers on ESCI}

Another option would be to adopt the curriculum and make it suitable for training teachers. Since this PBL module was specifically designed to train school leaders, it has to be modified to meet the needs of teachers who are not in school leadership roles. This modification might be an area for further exploration and research. HMs who would be well versed with the teacher evaluation process could be given further training to become facilitators. Then they could use the module and train teachers on ESCI process. This idea was mentioned a few times by the teachers of the schools I visited. One teacher from Nsoo Secondary School suggested, "Since we, teachers, are required to lead the 
discussion of our evaluation process, I think it will be of benefit to us to have some kind of a more extensive training on how to play our roles well." This greater involvement of teachers has the potential of increasing cooperation among teachers and HMs, thus making the evaluation process easier and more collaborative because teachers would know well what is expected of them. As their roles become clearer it would encourage them to take more of a lead in their own teaching improvement process. Teachers need to be informed about how the process works so that they can be active participants in a collaborative process, and when ESCI is demystified, teachers can work alone, with a coach, and/or with a peer to develop and deepen their pedagogical skills and in turn improve student achievement.

\section{PBL Module and Annual Leadership Professional Development}

The diocesan and district department of professional development could take another improvement step the development of their HMs and teachers. This PBL module could be used for conducting training of HMs and teachers in the course of the school year as part of their mandatory annual professional development requirements. One of the complaints participants had was that they did not have regular annual professional development learning programs, and those few workshops or seminars they did have were shallow and did not have much to do with their leadership challenges. On this note, one participant commented, "I attended those workshops to relax, not to learn because practically there was nothing substantial to learn." Another participant challenged the authority saying, "All these years the authority expects us to improve but they do not 
teach us how. Our leaders need to learn as well from this workshop what to give us if they really want us to do our job well and effectively as HMs."

\section{University Curriculum for Future HMs Training}

In talking to Dr. Kidevu of Mwenge University, he indicated that Mwenge University would look for the possibility of adopting the curriculum into the graduate school of education's administration program. Other universities could do the same. This course would be taken by future school leaders in training, but it could also be taken by the HMs who are in the field and need to complete their continuing education requirements. They would consider it a class, receive a grade, record it in their continuing professional development time, and in some districts it could translate into their annual appraisal and pay increment. HMs would also be encouraged to work among themselves to solve problems and would be reminded that they are their own best resources for idea generation and morale boosting.

\section{Creating Leadership Collaboration and Support}

Participants' collaboration and sharing of resources during the field testing was outstanding. The comment of one of the participants as they were exploring their leadership challenges using the consultancy protocol highlights this observation. "I am truly amazed that as HMs, we seem to have all the insights and solutions to our leadership problems. What we need is a professional means and reason for meeting regularly to process our challenges." From this insight, further exploration is needed to see if the Moshi HMs could form a local professional organization which will provide an opportunity of meeting regularly to continue sharing their resources in support of each 
other. I believe this organization would offer HMs more opportunities for their professional growth and improvement. The superintendent's office could facilitate and help with the formation of this organization.

\section{Setting High Leadership Standards and Expectations}

Another possible next step is to use the same product to conduct a workshop with the same group and use their experiences, plus the experiences of teachers and students to set the school leadership performance standards and develop rubrics of evaluating those standards. It would be part II of their training. Follow-ups, application, coaching, and mentoring are very important for sustaining improvement efforts. Without such opportunities, change will not likely be sustained over time or with typical changes in leadership.

This could help also to set high leadership standards and expectations for the HMs, just as for teachers, with regard to quality teaching and learning. During the main field test, the participants adopted Danielson's (2007) teaching standards and raised the bar for the teachers by suggesting that they should be on the proficient and exceptional categories only. What would happen if the same thing would be done for the school leaders and students? If leadership expectations would be set high, how would this change the HMs planning and priorities? How would it make them function differently? How would it impact overall student learning and achievement? I think this would demonstrate an equity standard that every major stakeholder in the field of education is held accountable for realizing high standards and expectations. Marzano et al. (2005) observed that the best recipe for high performance in any organization is high 
expectations and standards. In this case, Tanzanian school organizations are not exceptional. All of the above mentioned ideas and questions call for further exploration and research that will provide answers to the Tanzanian educational system as a whole.

\section{Recommendations to School Leaders and Researchers}

\section{To Build HMs’ Instructional Leadership Capacity}

To build instructional leadership capacity that can influence quality teaching and learning, knowledge and skills are needed. If education is to be improved by using teacher evaluation as an instructional leadership too, the HMs are expected to understand the content and the procedure of conducting teacher evaluation. That is why I recommend that lecture sessions be included in the PBL curriculum. The topic can include quality teaching and learning, teacher evaluation and its impact in quality student learning and performance, and instructional and transformation leadership. It is important not to assume that the participants know some of those skills that seem obvious to others; it is better to ask if there is doubt. On this, one participant commented, "One would think we would know these things after spending 22 years in the leadership career, but I did not know them."

Using evidence-based articles, books, and video clips helped the participants to build conviction and motivation that what they are learning works; some can be purchased in the educational leadership training centers and some can be downloaded from the Internet. Videos had significant impact on the participants as one commented, "If support teachers and holding them accountable has such a big impact, it seems like 
one can focus on that single aspect and bring a real change in the academic improvement."

I strongly recommend that training schedule should give enough time for role play. This is where confidence and competence of the participants is built or increased. Participants are given time to put into action what they have learned and receive feedbacks. They are challenged, corrected, encouraged, and congratulated, all of which are necessary in building their instructional leadership confidence and competence. All these are pivotal for building HM's leadership capacity that will help to implement ESCI.

As for potential doctoral researchers, I would suggest there is a beauty to PBL as a learning mechanism, as it encourages the researcher to identify the problem in the field and ask practitioners in the field to share how they experience it from their points of view. This allows the researcher to identify the problem in a very authentic way. This PBL method works well with research requirements, especially with Human Subjects Committee, and sometimes leads to a quicker approval since the researcher is studying the development of a product rather than a person or group of people. PLB requires the researcher to refine and test the product in a recursive fashion and it makes the product more polished and possibly more applicable in a variety of contexts since the product is reviewed by various practitioners in the field. Because the product may evolve as practitioners suggest, researchers should be prepared and organized so that they can face many changes through the multiple reiterations of the R\&D cycle.

I am thankful to know the power of PBL as a research approach to solving problems. The success of this study is the outcome of the work of Edwin Bridges, the 
pioneer of PBL research, and the mentoring of my advisor Tom Chenoweth, $\mathrm{PhD}$. The major goals of any PBL research study include, “(1) Acquisition of the knowledge base underlying administrative practice, (2) development of administrative skills, (3) development of problem solving skills and (4) development of lifelong learning skills" (Bridges \& Hallinger, 1992, p. 20). This study successfully explored these goals in terms of building instructional leadership skills of HMs of Tanzania to solve the problem of student underachievement.

\section{Using PBL Module Procedure and Its Intended Outcome}

The PBL curriculum was designed for school leaders of the Tanzanian education system. My recommendation to school leaders and researchers who want to use this curriculum to train HMs begin with taking enough time for preparation of the training materials. The PBL facilitators have to be very organized. The module is long, comprehensive, and detailed. Therefore, it demands strong organizational skills. To help with organizing the materials, the facilitators might choose to make a checklist of all the materials one will possibly need for training.

Make sure all the content, training materials, and aids are at the site and available within a few minutes from the training hall. Additionally, choose a training facility carefully. The site used in this study was large enough to allow four groups to have discussions in the hall without distracting each other. This was convenient and saved time since transitions from small group to larger group activities took place without excessive movement or wasting of time. Another problem was that it was impossible to videotape group activities and also facilitates the workshop. It would benefit future facilitators to 
have a volunteer to deal only with audio and/or video recording. I regret not having this person because I could not video tape most of the group activities. Journaling helped to keep my records straight.

Facilitators need to believe in themselves. After doing all the necessary planning and preparation, they need to believe and demonstrate that they know the contents of the curriculum and have confidence. If the participants are kept interested, they are likely to go an extra mile to get the work done. It is important to remember that facilitators are also role models for the HMs. It is important that the participants see in the facilitators' example what they will reenact with their teachers. This includes teaching and leadership behaviors such as being firm, considerate, and respectful. The facilitator must also protect instructional times, paying particular attention to individual needs without compromising the group needs, holding participants accountable while helping them to reach their goals, and avoiding making excuses by taking responsibility.

Journaling is one of the most important components of qualitative research (Creswell, 2007). I would advise researchers to keep a journal at all times during the workshop. Some observations can be critically important, but if they are not recorded, they can easily be forgotten. Journaling my observations was very helpful in recording important individuals' verbal quotes and reactions. For example, journaling helped me especially during the first two days of scheduling modification. We used my journal entries as discussion points to make effective changes in the schedule, the groups' activities, and the refinement of the module itself. Having discussion about what I observed became a reality check. Whether my interpretation of what was observed was 
correct or not, it demonstrated that I cared about what the participants were doing and my concern for their well-being. Such behavior was actually a demonstration of transformational leadership, which was also one of the topics in the PBL training module. Based on the experience of time pressure and the density of the curriculum, I would suggest that this kind of workshop be given in seven days instead of six with at least two group facilitators for shared leadership. This would allow facilitators and participants to have adequate time to process the content and give groups more time for discussion, experience sharing, and role playing. I think that shared leadership leads to doing a better job. One person could be focused on the content and the other on process. They could share their observations and make adjustments as needed. While one is presenting the other could be taking care of set up, logistical needs, etc. Since it is impossible to foresee everything and to have enough time for everybody, flexibility is important. It is essential to remain open-minded to accommodate new ideas and new ways of doing things so long as they are in line with the training goals. It is also important for the facilitators to focus on the curriculum only and avoid any other side training because such activities would likely consume the training time and exhaust participants and facilitators. If it is identified that training such as computer skills are important for this PBL module training, then it must to be done prior to the workshop or in private sessions at night. I would also advise the facilitators to have a loose schedule around the training time in case some important follow up is needed.

Workshop participants were great resources to each other and had a wealth of knowledge and expertise to share. Giving them adequate time in the group process to 
share their experiences is a key to successful training. Finding a balance between presenting new content and letting participants process it is an inherent dilemma in training. Since they are the ones experiencing the problem in the field, it is sensible to assume that they understand it better than anyone else. Generally school leaders have good intentions and the majority of them work hard to improve education, but they may also have limited skills around certain practices such as teacher evaluation. Group discussions helped not only in developing a deeper understanding of the problem, but also helped in personalizing possible solutions, implementation strategies and classroom applications.

If training is done on a voluntary basis, the facilitator has the obligation to protect those who choose not to participate. There is a tendency to push the reform agenda by the participants in such a way that it might be unfair to those who rightly choose not to participate in the study. There was also some pressure from the bishop of Moshi and the superintendent toward those who chose not to attend the workshop. Taking leadership responsibility and protecting them from being penalized or mandated to participate is as important as ensuring confidentiality of those who participated. If the study will result in a new policy that will be generated as a result of the training that will affect all the schools, it is beyond the scope of study because a new policy was not one of the goals of the curriculum, but would only be a potential consequence of it. The participants asked for the Diocesan Board of Education to make a policy to high-quality teaching in which the Danielson's teaching standards of "Proficient" and "Exceptional" will be the only acceptable standards in the diocesan schools. The proposal was, teachers who fall under 
the "Unsatisfactory" and "Basic" standard will be given sometime to improve or else they will have the leave the diocesan schools. As I write this paper, I am not aware if this policy has been proposed to the Diocesan Board of Education yet.

\section{Conclusions}

\section{PBL Module Can Improve instructional Leadership of HMs}

This study had many positive outcomes. Because of these outcomes, I believe this PBL module and curriculum can equip school leaders to initiate and implement educational improvement programs. The curriculum can improve HMs' instructional leadership skills and make them believe in themselves as leaders with confidence, competence, and the motivation necessary to effectively exercise their leadership roles through ESCI. The anticipated outcome of this journey is improved student achievement. Since survey data suggest that Moshi HMs got excited to begin the process of improving teaching and learning through ESCI, I believe it can also motivate HMs in other school districts.

\section{PBL Module Can Make HMs Academic Reform Agents}

Quality teaching is created by constant improvement of teachers' instructional skills (Acheson \& Gall, 2003; Danielson, 2011). This improvement needs the facilitation and support of the school's leaders. Workshop participants confirmed that it is their responsibility to help create an environment conducive to learning and provide professional leadership assistance for teachers to achieve professional improvement. This study confirms that HMs can be trained to be the agents of education reform by initiating and implementing academic improvement through teacher evaluation. 


\section{Self-Awareness, Leadership Responsibility, and Commitment}

As a result of the training module, the participants changed their thoughts about themselves and about what ESCI can do to improve teaching and learning. They talked about the rediscovery of their own expertise and resources and what they can achieve by working in collaboration. They talked about and demonstrated their good intentions and passion to improve student learning and achievement. They felt honored, but also challenged, as one participant termed it, "I feel honored to be given a chance to develop my instructional leadership skills and explore what I think is most challenging in my job as a school leader, but I also felt challenged when I discovered my leadership style was part of the problem."

HMs demonstrated a high level of commitment, seriousness in their collaborative work, and a new passion for the success of all students. I witnessed similar positive emotions among the teachers of the schools I visited, although the comments were more reserved than those made by their HMs who had participated in the workshop. It is my hope that these same emotional qualities will be ignited in teachers who will be part of the ESCI implementation. Though we will not know the definitive impact of implementation of ESCI and its potential impact on student achievement until more research is conducted in 2014, in the long run, I suspect that many more HMs and teachers in high schools throughout Tanzania will be transformed when the PBL module is further disseminated or taken to scale. 


\section{Resources and Collaboration Among the Participants}

This study also helped the participants to rediscover the power of collaborative work in their leadership roles. It was a joy to see the participants exercise their leadership by taking initiative as they formed their informal groups, set private times for discussion, and even gave up their breaks and relaxation times to get their work done. They proved to be disciplined, caring, hardworking, and passionately driven leaders. They gently confronted each other, especially when they were processing some legal and ethical leadership issues, by using the consultancy protocol model. One observed,

I would never have thought that we could build this level of collaboration and trust within such a short time. I was embarrassed but glad to hear my colleagues confronting me when I was trying to defend my lame decision in that case of paying teachers who had not been in school for five months. We need more of this collaboration and sharing if we really want to be better leaders.

\section{Knowledge, Confidence, Competence, and Motivation for Doing ESCI}

At the end of the workshop, participants verbalized that they believed they now had what it takes to professionally conduct productive teacher evaluation. They spoke with passion that signified their motivation to do it in their own school contexts. Their action-plan presentation demonstrated not only their competence in the sense of mastering the skills of conduction ESCI, but also confidence by showing that they believe in themselves in doing teacher evaluation. One professor from Mwenge University gave this comment in response to the participants' action plan presentation,

Listening to your action-plan presentations gave me conviction that you really know the content and the process of doing teacher evaluation. You showed such competence and confidence in answering our question that it is hard to believe you learned all this just within this week. 
They also publicly set a time frame to implement Danielson's Four Domains of teaching. They asked for diocesan leadership to provide support and requested another workshop for evaluation of their implementation efforts. All this indicates that the PBL module or curriculum was successful. Its main goal was to get the participants understand and want to improve student learning and achievement through teacher evaluation. This goal was well accomplished. For the first time, they publicly confessed that students have not been the main cause of their low achievement, and they are not to be blamed. Teachers and school leaders must take responsibility for the student low achievement, as one participant worded it,

In my staff meetings and in our district meetings we have constantly blamed our students and teachers for bad national examination results. We normally say our students are not serious in education and our teachers are not teaching properly. We pretended that we, as leaders, are immune from their failures. Now there is new hope because, for the first time in my 16 years of school leadership, I witnessed leaders saying they are part of that problem and are willing to take action. This is the best news to me. We cannot correct others unless we are willing to correct ourselves. After all, it is part of our Catholic and Christian duty.

This comment took a religious tone because all of the participants were Christians. They took it as one of their religious awareness and spiritual exercises as one participant quoted form the Bible, "First remove the beam from your own eye, and then you'll see clearly enough to remove the speck from your brother's eye" (Luke, 6:42). This confession and self-correction was a necessary turning point for educators to take responsibility for the existing problem and focus its improvement. Without this acknowledgment, I believe the blame game would continue and change would be impossible. This in itself was a great accomplishment of the training and shows the 
quality of the PBL module. Accepting the responsibility is the best ground for improvement ( Reeves, 2010).

This study not only changed the negative attitudes of the HMs toward their students and teachers with regard to student performance, but also changed the perspective of the superintendent toward the HMs. Based on what he witnessed in the groups' and cohort presentations on the last day of the training, the superintendent commented,

I knew my HMs were struggling and were working hard, all things considered. What I did not know was their level of passion and commitment. This inspired me. I love what I saw. My commitment to support them in this education reform movement in the diocese is guaranteed.

Though the primary emphasis of this study was the improvement of student achievement through leadership, and the primary beneficiaries of the research were to be the HMs, teachers, and students of Tanzania, I was also impacted by this work. Though the participants expressed how they were impressed by my knowledge when answering their leadership questions, what they did not know was how much I learned from the entire process, particularly from them: their resilience, caring, and readiness to try new ways to improve their profession. It was a profound moment of learning and rediscovery of my own teaching and leadership talents and skills. This experience reminded me of the words of my father Michael Siamoo on May 28, 2003, as we hugged farewell on my way to America for my studies (translated into English), when he said,

Son, never stop learning because what you have learned is never enough, because there are always new things to learn, because your mind is not full and will never be full, because through learning you will know the secrets of the victors, the reason for the failures, the courage of the warriors, and the fear of the cowards. Once you know, you can pick the one you want to become. 
I feel privileged to be part of this study's participants' lives and career stories as I continue to write my own life story. This was another gift of this study to me. This fact echoes the reflective words of Ruiz, (2004) as he stated,

At times we are privileged to help other people write their life story. In so doing we became an integral part of their story. At the same time we write our own story as we help them write theirs. And there, they also become an integral part of our life story. (p. 66)

For sure, the participants are an integral part of this study, which is part of my academic life story. I had always wanted to be part of change in education, and this is just the first step.

The participants and I believe that high standards and clear expectations are the two common elements that will raise the bar of performance. Nelson Mandela supported this belief in his two famous quotes: "It is not where you start but how high you aim that matters for success" (as cited in Goodreads, 2013, para. 49). He also said, "One cannot be prepared for something while secretly believing it will not happen" (as cited in Goodreads, 2013, para. 39). The continuous work of educational improvement must be given priority in Tanzania as a primary step in the poverty alleviation program. Failure to improve our education through quality teaching and learning of all our students will guarantee a perpetuation of the current problem of economic stagnation and of poverty for Tanzania’s current and future citizens. 


\section{REFERENCES}

Acheson, K.A., \& Gall, M. D. (2003). Clinical supervision and teacher development: Preservice and inservice applications $\left(5^{\text {th }}\right.$ ed.). New York, NY: John Wiley \& Sons, Inc.

Acheson, K. A., \& Gall, M. D. (2013). Clinical supervision and teacher development (6th ed.). New York, NY: Wiley.

Anderson, S. E. (2001). Improving schools through teacher development: Case studies of the Aga Khan Foundation projects in East Africa. Retrieved March 22, 2010, from http://www.comminit.com/ma2003/sld-8726.html

Bass, B. M. (1985). Leadership and performance beyond expectations. New York, NY: Collier Macmillan.

Bass, B. M., \& Avolio, B. J. (1994). Improving organizational effectiveness through transformational leadership. Thousand Oaks, CA: Sage.

Bass, B. M., \& Riggio, R. E. (2006). Transformational leadership (2nd ed.). Mahwah, NJ: Psychology Press.

Blase, J., \& Blase, J. R. (2001). Empowering teachers: What successful principals do $\left(^{\text {nd }}\right.$ ed.). Thousand Oaks, CA: Corwin Press.

Blase, J. R., \& Blase, J. (2004). Handbook of instructional leadership: How successful principals promote teaching and learning (2nd ed.). Thousand Oaks, CA: Corwin Press.

Bolman, L. G., \& Deal, T. E. (2003). Reframing organizations: Artistry, choice, and leadership (3rd ed.). San Francisco, CA: Jossey-Bass.

Bolman, L. G., \& Deal, T. E. (2011). Reframing organizations: Artistry, choice and leadership. New York, NY: John Wiley \& Sons.

Bridges, E. M., \& Hallinger, P. (1992). Problem-based learning for administrators. Eugene, OR: University of Oregon ERIC Clearinghouse on Educational Management. 
Bridges, E. M., \& Hallinger, P. (1995). Implementing problem-based learning in leadership development. Eugene, OR: University of Oregon ERIC Clearinghouse on Educational Management.

Burns, J. M. (1978). Leadership. New York, NY: Harper \& Row.

Catholic Diocese of Moshi. (n.d.). Secondary schools and seminaries. Retrieved from http://home.catholicweb.com/moshidiocese/files/SECONDARY_SCHOOLS_AN D_SEMINARIES.pdf

Chenoweth, T., \& Everhart, R. (2002). Navigating comprehensive school change: A guide for the perplexed. Larchmont, NY: Eye on Education.

Cotton, K. (2003). Principals and student achievement: What the research says. Alexandria, VA: Association for Supervision and Curriculum Development.

Creswell, J. W. (2007). Qualitative inquiry and research design: Choosing among five approaches. Thousand Oaks, CA: Sage.

Cuban, L. (1988). The managerial imperative and the practice of leadership in schools. State University of New York Press.

Cunningham, W. G., \& Cordeiro, P. A. (2000). Educational Administration: A problembased approach. Needham Heights, MA: Allyn \& Bacon.

Danielson, C. (2007). Enhancing professional practice: A framework for teaching. Alexandria, VA: Association for Supervision and Curriculum Development.

Danielson, C. (2009). Enhancing professional practice a framework for teaching: High school. Alexandria, VA.: Association for Supervision and Curriculum Development.

Danielson, C. (2011). The framework for teaching evaluation instrument. Princeton, NJ: The Danielson Group.

Daresh, J. C. (2002). What it means to be a principal: Your guide to leadership. Thousand Oaks, CA: Corwin Press.

Day, C., \& Leithwood, K. A. (2007). Successful principal leadership in times of change: An international perspective. Dordrecht, The Netherlands: Springer.

Deal, T. E. (1994). The leadership paradox: Balancing logic and artistry in schools (1st ed.). San Francisco, CA: Jossey-Bass. 
Deal, T. E., \& Peterson, K. D. (1999). Shaping school culture: The heart of leadership (1st ed.). San Francisco, CA: Jossey-Bass.

deBlij, H. J., \& Muller, P. O. (2007). Realms, regions and concepts (13th ed.). Hoboken, NJ: Wiley.

Downey, C. J., English, F. W., \& Steffy, B. E. (2004). The three-minute classroom walkthrough, changing school supervisory practice one teacher at a time. Thousand Oaks, CA: Corwin Press.

Downey, C. J., Steffy, B. J., English, F. K., Frase, L. E., \& Poston, W. K., Jr. (2004). The three-minute classroom walk-through: changing school supervisory practice one teacher at a time. Thousand Oaks, CA: Corwin.

DuFour, R. (2010). Raising the bar and closing the gap: Whatever it takes. Bloomington, IN: Solution Tree.

Ernest, P. (1994, March). Varieties of constructivism: Their metaphors, epistemologies and pedagogical implications. Hiroshima Journal of Mathematical Education, 2, $1-14$.

Fink, S., \& Markholt, A. (2011). Leading for instructional improvement: How successful leaders develop teaching and learning expertise (1st ed.). San Francisco, CA: Jossey-Bass.

Flannery, A. (1999). Vatican Council II: The conciliar and post conciliar documents. Northport, NY: Costello Publishing.

Fosnot, C. T. (2005). Constructivism: Theory, perspectives, and practice. New York, NY: Teachers College Press.

Fullan, M. (2001). Leading in a culture of change (1st ed.). San Francisco, CA: JosseyBass.

Fullan, M. (2005). The meaning of educational change: A quarter of a century of learning. In A. Lieberman (Ed.), The roots of educational change: International handbook of educational change (pp. 202-216). New York, NY: Springer. Retrieved from http://dx.doi.org/10.1007/1-4020-4451-8_12

Fullan, M. (2008). The six secrets of change: What the best leaders do to help their organizations survive and thrive (1st ed.). San Francisco, CA: Jossey-Bass.

Gall, M. D., \& Borg, W. R. (1989). Educational research: A guide for preparing a thesis or dissertation proposal in education. New York, NY: Longman. 
Gall, M. D., Gall, J. P., \& Borg, W. R. (2006). Educational research: An introduction (8th ed.). New York, NY: Allyn \& Bacon.

General Assembly of the United Nations. (1948, December 10). The universal declaration of human rights. Retrieved March 25, 2011, from http://www.un.org/en/documents/udhr/index.shtml

Glanz, J., \& Glanz, J. (2006). What every principal should know about instructional leadership. Thousand Oaks, CA: Corwin Press.

Glickman, C. D. (2002). Leadership for learning: How to help teachers succeed. Alexandria, VA: Association for Supervision and Curriculum Development.

Goldhammer, R. (1969). Clinical supervision: Special methods for the supervision of teachers. New York, NY: Holt, Rinehart and Winston.

Goodreads Inc. (2013). Nelson Mandela quotes. Retrieved from http://www.goodreads.com/author/quotes/367338.Nelson_Mandela

Hallinger, P. (2003). Leading educational change: Reflections on the practice of instructional and transformational leadership. Cambridge Journal of Education, 33(3), 329-351.

Hallinger, P., \& Murphy, J. (1986). The social context of effective schools. American Journal of Education, 94(3), 328-355.

Hallinger, P., \& Murphy, J. (1987). Instructional leadership in the school context. In W. Greenfield (Ed.), Instructional leadership: Concepts, issues, and controversies (pp. 179-201). Boston, MA: Allyn and Bacon.

Harmony Education Center. (2012). Consultancy protocol overview. Retrieved from http://www.nsrfharmony.org/protocol/doc/consultancy.pdf

Howell, J. P., \& Costley, D. L. (2006). Understanding behaviors for effective leadership. Upper Saddle River, NJ: Pearson Prentice Hall.

Independent Evaluation Group. (2010). Project performance assessment report Tanzania: Human resources development pilot project, Primary education development program, and Secondary education development program 
(Document of The World Bank No. 55383). Dar es Salaam, Tanzania. Retrieved from www.google.com/url? sa=t\&rct=j\&q=\&esrc=s\&source=web\&cd=1\&ved= 0CCIQFjAA\&url=http\%3A\%2F\%2Flnweb90.worldbank.org\%2Foed\%2Foeddocl ib.nsf\%2FDocUNIDViewForJavaSearch\%2FE47151332B519C27852577840069 2CD7\%2F\%24file\%2FPPAR_Tanzania\%2520-\%2520First\%2520n\%2520 Secondary\%2520Educ\%2520Dev\%2520and\%2520HR\%2520Dev\%2520Pilot.pdf \&ei=FOQ_T6KaO4iviQKM2qi3AQ\&usg=AFQjCNG67V6gB635NPZrMZCelgfr KpvbAw\&sig2=Q1EfGJDA23cp-sQzOsUKrg

Johnson, B., \& Christensen, L. B. (2008). Educational research: Quantitative, qualitative, and mixed approaches (3rd ed.). Los Angeles, CA: Sage.

Klein, J. (2010). Accountability: What's it really all about? New York, NY: Columbia Business School. Retrieved from https://www.youtube.com/ watch?v=WTEPXxxuytY

Klein, J. (2012). Educational innovations for the future. New York, NY: Columbia Business School. Retrieved from https://www.youtube.com/watch?v= Un5hKLKqmk8

Lambert, L. (1998). Building leadership capacity in schools. Alexandria, VA: Association for Supervision and Curriculum Development.

Leithwood, K., Begley, P. T., \& Cousins, J. B. (1994). Developing expert leadership for future schools. Bristol, PA: Psychology Press.

Leithwood, K., Harris, A., \& Strauss, T. (2010). Leading school turnaround: How successful leaders transform low-performing schools. San Francisco, CA: JosseyBass.

Leithwood, K., \& Jantzi, D. (1999). The relative effects of principal and teacher sources of leadership on Student engagement with school. Educational Administration Quarterly, 35(5), 679-706. doi:10.1177/0013161X99355002

Leithwood, K., Jantzi, D., \& Steinbach. (1999). Changing leadership for changing times. Buckingham, PA: Open University Press.

Leithwood, K., Louis, K. S., Anderson, S., \& Wahlstrom, K. (2004). How leadership influences student learning: Review of research. St Paul, MN: Center for Applied Research and Educational Improvement, University of Minnesota.

Leithwood, K., \& Mascall, B. (2008). Collective leadership effects on student achievement. Educational Administration Quarterly, 44(4), 529-561. doi:10.1177/0013161X08321221 
Leithwood, K., Mascall, B., \& Strauss, T. (Eds.). (2009). Distributed leadership according to the evidence. New York, NY: Taylor \& Francis.

Leithwood, K., \& Riehl, C. (2003). What do we already know about school leadership? A paper presented at the annual meeting of the American Education Research Association, Chicago, IL

Lodhi, A. (1944). Muslims in Eastern Africa: Their past and present. Nordic Journal of African Studies, 3(1), 88-98.

MacKeracher, D. (2004). Making sense of adult learning (2nd ed.). Toronto, Canada: University of Toronto Press.

Marshall, K. (2009). Rethinking teacher supervision and evaluation: How to work smart, build collaboration, and close the achievement gap (1st ed.). San Francisco, CA: Jossey-Bass.

Marzano, R. J., Frontier, T., \& Livingston, D. (2011). Effective supervision: Supporting the art and science of teaching. Alexandria, VA: Association for Supervision and Curriculum Development.

Marzano, R. J., Waters, T., \& McNulty, B. A. (2005). School leadership that works: From research to results. Aurora CO: Mid-continent Research for Education and Learning.

Mazonde, I. N. (Ed.). (2007). Culture and education in the development of Africa. Darkar, Senegal. Retrieved from http://unpan1.un.org/intradoc/groups/public/ documents/idep/unpan003347.pdf

Muhammad, A. (2009). Transforming school culture: how to overcome staff division. Bloomington, IN: Solution Tree Press.

Mushi, D. (2010). The National Form Six National Exam announcement: Catholic schools continue to "lead." Retrieved July 25, 2011, from http://kiongozi.tripod.com/kitaifasep3.html

Mushi, P. A. K. (2009). History and development of education in Tanzania. Dar es Salaam, Tanzania: African Books Collective.

Newman, F., King, B., \& Youngs, P. (2000, April). Professional development that addresses school capacity. Paper presented at the annual meeting of the American Research Association. New Orleans, LA. 
New American Bible. (2005). New York, NY: Oxford University Press.

Newman, F., King, B., \& Youngs, P. (2000, April). Professional development that addresses school capacity. Paper presented at the annual meeting of the American Research Association. New Orleans, LA.

Nguni, S. C. (2005). Transformational leadership in Tanzanian education: A study of the effects of transformational leadership on teachers' job satisfaction, organizational commitment and organizational citizenship behaviour in Tanzanian primary and secondary schools (Unpublished Doctoral Dissertation). Radboud University, Nijmegen, Netherlands. Retrieved from http://dare.ubn.kun.nl/bitstream/2066/56137/1/56137.pdf

Nkolimwa, D. (2011, January 27). Form IV exam passes drop sharply. The Guardian, pp.

Nyerere, J. K. (1967). Education for self-reliance. Dar es Salaam Tanzania: Government Printer.

Oduro, G. K., Dachi, H., \& Fertig, M. (2008). Education leadership and quality education in disadvantaged communities in Ghana and Tanzania. Retrieved from http://www.emasa.co.za/files/full/M.Fertig.pdf

Ott, J. S. (1996). Classic readings in organizational behavior (2nd ed.). Belmont, CA: Wadsworth.

Palmer, P. J. (2007). The courage to teach: exploring the inner landscape of a teacher's life (10th anniversary ed.). San Francisco, CA: Jossey-Bass.

Peterson, K. D. (2000). Teacher evaluation: A comprehensive guide to new directions and practices (2nd ed.). Thousand Oaks, CA: Corwin Press.

Quinn, D. M. (2002). The impact of principal leadership behaviors on instructional practice and student engagement. Journal of Educational Administration, 40(5), 447-467.

Reeves, D. B. (2010). Transforming professional development into student results. Alexandria, VA: Association for Supervision and Curriculum Development.

Rodney, W. (1981). How Europe underdeveloped Africa (rev. ed.). Washington, DC: Howard University Press.

Ross, J. A. (1992). Teacher efficacy and the effects of coaching on student achievement. Canadian Journal of Education, 17(1), 51. doi:10.2307/1495395 
Roueche, J. E., Baker, G. A., \& Rose, R. R. (1989). Shared vision: Transformation leadership in American community colleges. Washington, DC: Community College Press.

Ruiz, M. (2004). The voice of knowledge: a practical guide to inner peace. San Rafael, Calif. : Amber-Allen Pub.; Distributed by Publishers Group West.

Sanders, W. L., \& Rivers, J. C. (1996). Cumulative and residual effects of teachers on future student academic achievement. Knoxville, TN: University of Tennessee, Value-Added Research and Assessment Center.

Senge, P. (1990). The fifth discipline: The art and practice of the learning organization (1st Currency pbk. ed.). New York, NY: Doubleday/Currency.

Smith, W. F., \& Andrews, R. L. (1989). Instructional leadership: How principals make a difference. Alexandria, VA: Association for Supervision and Curriculum Development.

Tanzania Education Network. (2007a). A brief history of education in Tanzania. Retrieved from http://www.tenmet.org/public_html/index.php?option= com_content\&view=article \&id=19\&Itemid=54

Tanzania Education Network. (2007b). Strengthening education in Tanzania: CSO contribution to the education sector review 2007. Retrieved from http://docaea.aide-et-action.org/data/admin/tan_zania_-_strengthening_education.pdf

Tanzania Institute of Education. (2011). About TIE. Retrieved March 23, 2012, from http://www.tie.go.tz/index.php/about-us

Tanzania Planning Commission. (n.d.). The Tanzania development vision 2025. Retrieved March 3, 2012, from http://www.tanzania.go.tz/vision.htm

Thomas, M., \& Vavrus, F. (2009, December). Lessons from teaching in action: Developing, implementing, and sustaining a teacher-training professional development program. St Paul, MN: University of Minnesota.

Tracy, S. (1995). How historical concepts of supervision relate to supervisory practices today. The Clearing House, 68(5), 320-324.

Tucker, P. D., \& Stronge, J. H. (2005). Linking teacher evaluation and student learning. Alexandria, VA: Association for Supervision and Curriculum Development.

UNESCO. (2009). Education. Retrieved from http://www.unesco.org/new/en/education/ 
United Republic of Tanzania. (2008). Education development program 2008-2017. Retrieved from http://www.globalpartnership.org/media/library/

Country_Documents/Tanzania/2008-01-Tanzania-Mainland-Sector-Plan.pd

United Republic of Tanzania, Ministry of Education and Culture. (2000). Secondary education master plan (SEMP) 2001-2005. Retrieved from http://www.moe. go.tz/index.php?option=com_docman\&task=doc_view \&gid=27\&Itemid=622

United Republic of Tanzania, Ministry of Education and Vocational Training. (2007). Education statistics. Retrieved June 12, 2010, from http://moe.go.tz/statistics.html

United Republic of Tanzania, Ministry of Education and Vocational Training. (2011). Statistics from independence to 2011. Retrieved February 19, 2012, from http://www.moe.go.tz/index.html

United Republic of Tanzania., Ministry of Education and Vocational Training. (2012). Secondary education. Retrieved November 9, 2012, from http://www.moe.go.tz/ index.php?option=com_content \&view=category \&id=303\&Itemid=616

Weimer, M. (2002). Learner-centered teaching: Five key changes to practice (1st ed.). San Francisco, CA: Jossey-Bass.

World Bank Group. (2012). The World Bank. Retrieved April 13, 2012, from http://www.worldbank.org/

Yukl, G. A. (2001). Leadership in organizations (5th ed.). Englewood Cliffs, NJ: Prentice Hall.

Zemelman, S. (2005). Best practice: Today's standards for teaching and learning in America's schools (3rd ed.). Portsmouth, NH: Heinemann. 
APPENDIX A

NATIONAL EXAM RESULTS OF MOSHI 


\begin{tabular}{|c|c|c|c|c|c|c|c|c|}
\hline Form Four 2 & 011 Natic & onal resu & Its of Mo & hi Cath & olic schoo & & & \\
\hline $\begin{array}{l}\text { SCHOOL } \\
\text { NAME }\end{array}$ & \begin{tabular}{|c|} 
St. \\
Anwarite \\
{$[\mathbf{G}]$}
\end{tabular} & $\begin{array}{c}\text { Kibosho } \\
\text { [G] }\end{array}$ & $\begin{array}{c}\text { Kiraeni } \\
\text { [G] }\end{array}$ & $\begin{array}{c}\text { Kirua } \\
{[\mathrm{C}]}\end{array}$ & $\begin{array}{c}\text { K'mundu }^{\prime} \text { [C] } \\
\end{array}$ & $\begin{array}{l}\text { Kisomach } \\
\text { i [C] }\end{array}$ & $\begin{array}{c}\text { Lombeta } \\
{[\mathrm{C}]}\end{array}$ & Majengo [C] \\
\hline $\begin{array}{l}\text { TOTAL No OF } \\
\text { CANDIDATES }\end{array}$ & 57 & 167 & 151 & 94 & 58 & 72 & 151 & 348 \\
\hline \%PASSED & 91 & 83 & 61 & 6 & 7 & 0 & 0 & 37 \\
\hline \%FAILED & 9 & 17 & 39 & 94 & 93 & 100 & 100 & 63 \\
\hline $\begin{array}{l}\text { SCHOOL } \\
\text { NAME }\end{array}$ & $\underset{[C]}{\operatorname{Mlama}}$ & Amka [C] & $\begin{array}{l}\text { Narumu } \\
{[\mathrm{C}]}\end{array}$ & $\begin{array}{c}\mathrm{Nsoo}[\mathrm{C} \\
]\end{array}$ & $\begin{array}{l}\text { Osale } \\
{[\mathrm{C}]}\end{array}$ & $\begin{array}{c}\text { Sangiti } \\
{[\mathrm{C}]}\end{array}$ & $\begin{array}{c}\text { St. } \\
\text { James } \\
{[B]}\end{array}$ & $\begin{array}{l}\text { St. Mary } \\
\text { Goreti [C] }\end{array}$ \\
\hline $\begin{array}{l}\text { TOTAL No OF } \\
\text { CANDIDATES }\end{array}$ & 60 & 32 & 82 & 68 & 81 & 50 & 40 & 159 \\
\hline$\%$ PASSED & 57 & 1 & 51 & 35 & 42 & 60 & 90 & 93 \\
\hline \% FAILED & 43 & 99 & 49 & 65 & 58 & 40 & 10 & 7 \\
\hline $\begin{array}{l}\text { SCHOOL } \\
\text { NAME }\end{array}$ & $\begin{array}{c}\text { Visitatio } \\
\text { n [G] }\end{array}$ & $\begin{array}{l}\text { Uru Sem. } \\
{[B]}\end{array}$ & $\begin{array}{l}\text { Uru Sec. } \\
{[\mathrm{C}]}\end{array}$ & $\begin{array}{l}\text { Usseri } \\
{[\mathrm{C}]}\end{array}$ & \begin{tabular}{|c|} 
Maua \\
Sem. [B]
\end{tabular} & $\begin{array}{c}\text { Uomboni } \\
{[\mathrm{C}]}\end{array}$ & $\begin{array}{c}\text { Marangu } \\
{[\mathrm{C}]}\end{array}$ & Ungwasi [C] \\
\hline $\begin{array}{l}\text { TOTAL No OF } \\
\text { CANDIDATES }\end{array}$ & 79 & 44 & 72 & 51 & 32 & 94 & 116 & 127 \\
\hline$\%$ PASSED & 90 & 100 & 19 & 8 & 100 & 4 & 39 & 8 \\
\hline \% FAILED & 10 & $\mathbf{0}$ & 86 & 92 & $\mathbf{0}$ & 81 & 61 & 96 \\
\hline
\end{tabular}

Note: The letters represent the following: $G=G i r l s$ only, $B=$ Boys only, $C=$ Coeducational-Boys and Girls] 


\begin{tabular}{|c|c|c|c|c|c|c|c|}
\hline \multicolumn{8}{|c|}{$\begin{array}{l}\text { Table } 2 \\
\text { The Form Four National Exam Results for 2000-2009 }\end{array}$} \\
\hline \multirow[t]{2}{*}{ Year } & \multicolumn{4}{|c|}{ Division } & \multirow{2}{*}{ \% Passed } & \multirow{2}{*}{$\begin{array}{c}\% \\
\text { Failed }\end{array}$} & \multirow{2}{*}{$\begin{array}{l}\text { Total No of } \\
\text { Candidates }\end{array}$} \\
\hline & I & II & III & IV & & & \\
\hline 2000 & 4.1 & 5.7 & 16.0 & 52.6 & 78.4 & 21.6 & 47389 \\
\hline 2001 & 4.5 & 5.7 & 18.2 & 49.1 & 77.4 & 22.6 & 50820 \\
\hline 2002 & 6.4 & 8.2 & 21.6 & 50.1 & 86.3 & 13.7 & 49512 \\
\hline 2003 & 7.2 & 7.3 & 23.6 & 50.0 & 88.1 & 12.0 & 62359 \\
\hline 2004 & 4.8 & 8.4 & 24.6 & 53.7 & 91.5 & 8.5 & 63487 \\
\hline 2005 & 5.2 & 6.5 & 21.9 & 55.7 & 89.3 & 10.7 & 85292 \\
\hline 2006 & 4.5 & 6.9 & 24.3 & 53.4 & 89.1 & 10.9 & 85865 \\
\hline 2007 & 5.1 & 8.6 & 21.9 & 54.7 & 90.3 & 9.7 & 125288 \\
\hline 2008 & 3.5 & 6.4 & 16.8 & 56.9 & 83.6 & 16.3 & 163855 \\
\hline 2009 & 1.9 & 4.4 & 11.6 & 54.7 & 72.5 & 27.5 & 248336 \\
\hline
\end{tabular}

Note: Although the Ministry of Education counts students with Division IV as passed, thus making the pass rate percentage high, this study excludes Division IV from the pass rates. 
APPENDIX B

PBL CURRICULUM 


\section{Instructional Leadership Training Module}

Developing the Instructional Leadership Skills of Secondary School Headmasters and Headmistresses in Tanzania

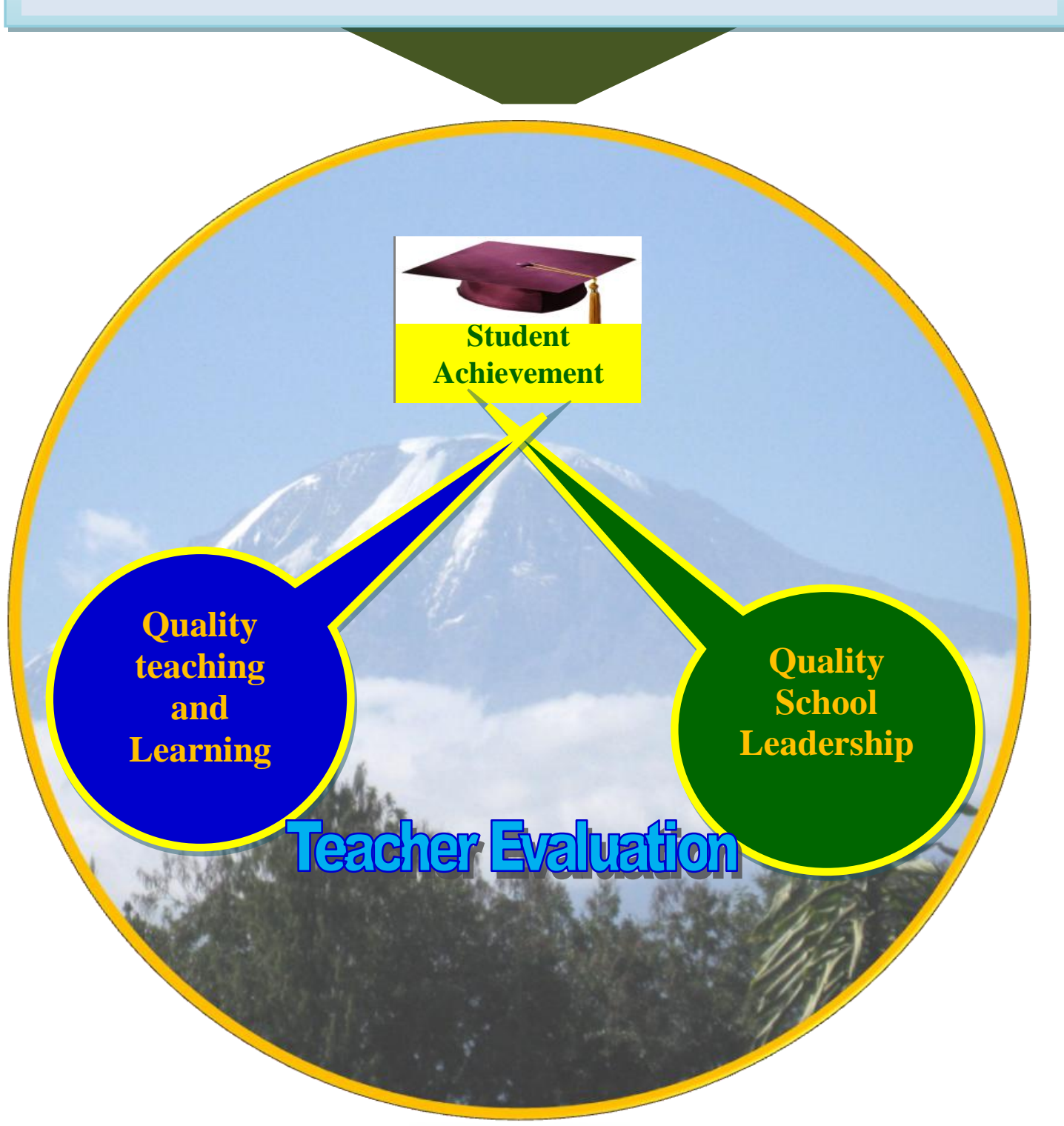

PROBLEM BASED LEARNING CURRICULUM

\section{Peter Siamoo}




\section{PBL INSTRUCTIONAL LEADERSHIP TRAINING MODULE}

\section{Improving the Quality of Teaching and Learning for Student Achievement: Using Teacher Evaluation or Evaluation and Supervision of Classroom Instructional [ESCI]}

\section{INTRODUCTION}

Write a letter of invitation to the participants early to give them time to adjust their schedules. If possible, make this invitation 6 months prior to the training workshop.

Explain to the participants how training should be conducted: how many days needed, reporting time, facility needed, what if they commute, etc. Depending on the environment and the facility in which the training is done, explain to the participants in detail all the logistics that will make the training productive and seamless.

Reporting Day: Preferably one day prior to training Sessions 1

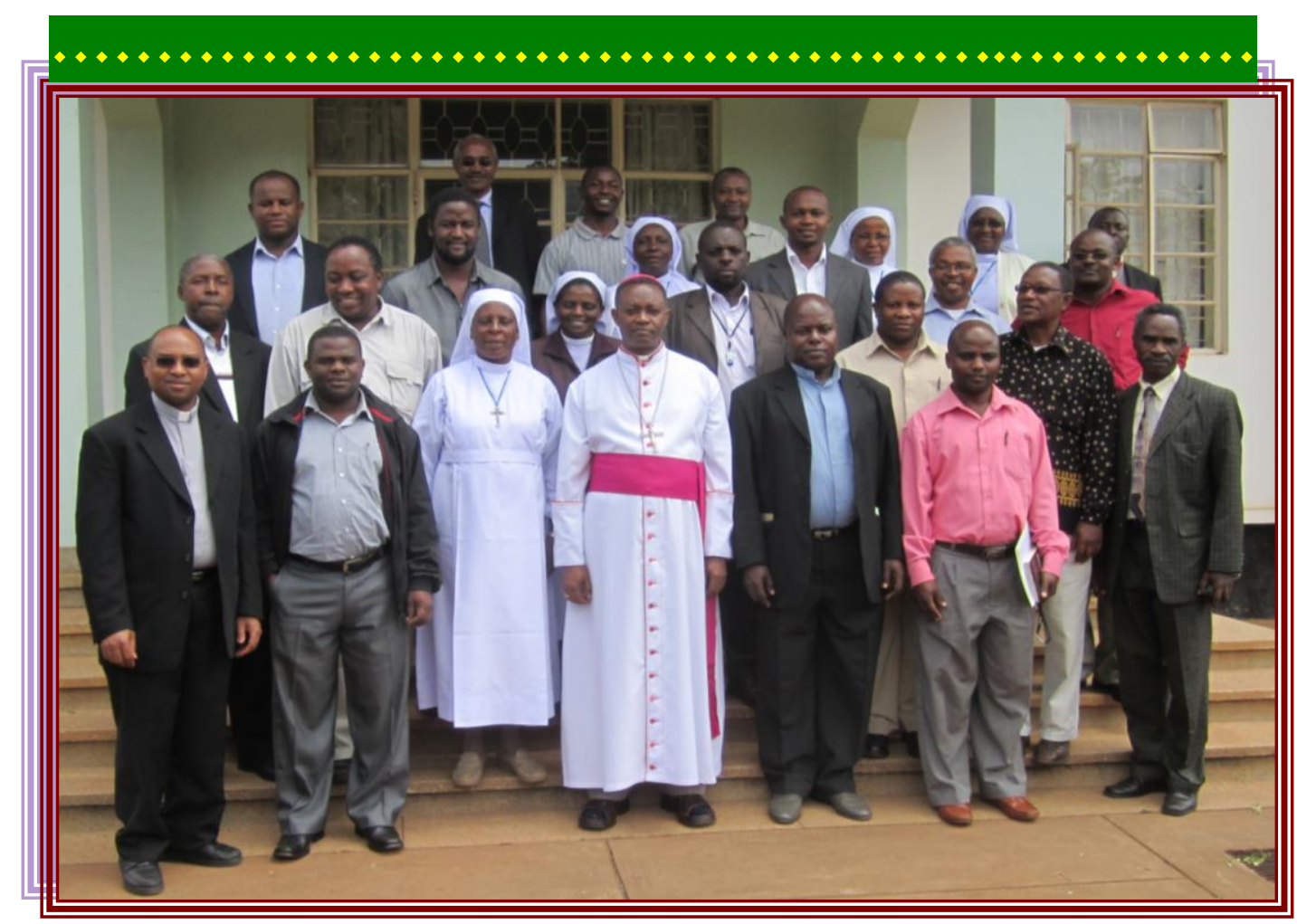

Group Picture of the PBL Workshop Participants. Bishop Amani (in the middle), and on his right is the superintendent of Moshi, Fr. Bill Ruwaichi. First on the left is Fr. Siamoo (the workshop facilitator). 


\section{Table of Contents}

\begin{tabular}{|c|c|c|c|}
\hline \multicolumn{3}{|c|}{ Problem Based Training Module - Cover } & 198 \\
\hline \multicolumn{3}{|c|}{ Problem Based Learning Training Module - Introduction } & 199 \\
\hline \multicolumn{3}{|c|}{ Table of Contents } & 200 \\
\hline \multicolumn{3}{|c|}{ General Overview } & 203 \\
\hline \multicolumn{3}{|c|}{ Example of Conceptual Representation of the Presenting Problem } & 205 \\
\hline \multicolumn{3}{|c|}{ Training Preparation Check List and Resources } & 206 \\
\hline \multirow[t]{20}{*}{ Day 1: } & Session 1 & & 208 \\
\hline & & Workshop/Classroom Protocol & 209 \\
\hline & & Course Objectives & 210 \\
\hline & & Course overview - Purpose of the Workshop & 211 \\
\hline & & General Guiding Questions & 212 \\
\hline & & Schedule, Training Activities and Course Objectives & 213 \\
\hline & & Recipe for Student High Achievement & 217 \\
\hline & & $\begin{array}{l}\text { Conceptual Representation of Teacher Evaluation and its } \\
\text { Impact }\end{array}$ & 218 \\
\hline & & Leadership Protocol & 219 \\
\hline & & Pre-Evaluation: Self Assessment & 221 \\
\hline & & Formative Assessment & 223 \\
\hline & Session 2 & & 225 \\
\hline & & Guiding Questions & 226 \\
\hline & & Teacher Pre-Training Evaluation: Vignette 1 & 227 \\
\hline & & Teacher Pre-Training Mini-Evaluation: Vignette 2 & 233 \\
\hline & & Formative Assessment & 240 \\
\hline & Session 3 & & 242 \\
\hline & & Art and Science of Instructional Leadership & 243 \\
\hline & & Supervisor's Behavior and its effects on Teachers & 246 \\
\hline & & Formative and Talk back Assessment & 248 \\
\hline Day 2: & Session 1 & & 250 \\
\hline
\end{tabular}




\begin{tabular}{|c|c|c|c|}
\hline & & 2010 National Form IV Exam results - Moshi Catholic Schools & 251 \\
\hline & & 2011 National Form IV Exam results - Moshi Catholic Schools & 252 \\
\hline & & $\begin{array}{l}\text { 2000-2009 National Form IV Exams Results - Nation-wide } \\
\text { statistics }\end{array}$ & 253 \\
\hline & Session 2 & & 255 \\
\hline & & Best Practice: Dimensions of Teaching & 256 \\
\hline & Session 3 & & 265 \\
\hline & & Conceptual representation of ESCI dynamics & 266 \\
\hline & & Transformational and Instructional Leadership- ESCI & 267 \\
\hline & & Marshall's Teacher Evaluation Module - Conceptual Figure & 268 \\
\hline Day 3: & Session 1 & & 270 \\
\hline & & Danielson's Four Domains & 271 \\
\hline & & Domain 1 & 271 \\
\hline & Session 2 & & 275 \\
\hline & & Domain 2 & 276 \\
\hline & Session 3 & & 280 \\
\hline & & Domain 3 & 281 \\
\hline Day 4: & Session 1 & & 285 \\
\hline & & Domain 4 & 286 \\
\hline & Session 2 & & 291 \\
\hline & & Danielson Evaluation Rubrics & 292 \\
\hline & & The Guidelines for Adaptation Process & 295 \\
\hline & Session 3 & & 298 \\
\hline & & Evaluation of Imaginary Teacher - vignettes & 299 \\
\hline & & Consultancy Protocol: Dealing with Resistance & 300 \\
\hline Day 5: & Session 1 & & 302 \\
\hline & & Guidelines for Role play & 303 \\
\hline & Session 2 & & 305 \\
\hline & & Guidelines for Role play & 306 \\
\hline & Session 3 & & 307 \\
\hline
\end{tabular}




\begin{tabular}{|c|c|c|c|}
\hline & & Guidelines for Role play with Consultancy Protocol 2 & 307 \\
\hline \multirow{16}{*}{ Day 6: } & Session 1 & & 309 \\
\hline & & Action-plan Presentations & 309 \\
\hline & & Guidelines for the Action Plan Presentations & 310 \\
\hline & Session 2 & & 312 \\
\hline & & Action Plan Presentations & 312 \\
\hline & & Cohort Secretary Summary Presentation & 312 \\
\hline & & Post Evaluation - Self Assessment 1 & 313 \\
\hline & Session 3 & & 316 \\
\hline & & Concluding Remarks \& Unfinished Business & 316 \\
\hline & & Post Evaluation: Self Assessment 2 - Expectations & 317 \\
\hline & & Appendices A \& B & 319 \\
\hline & & Adapted Danielson's Rubric & 319 \\
\hline & & Evaluation of the workshop/Training & 321 \\
\hline & & Certification Ceremony & 324 \\
\hline & & Resources - References & 325 \\
\hline & & Appendices C-Z & $\begin{array}{c}327 \\
- \\
387\end{array}$ \\
\hline
\end{tabular}




\section{GENERAL OVERVIEW}

The renowned organizational leadership scholars once said, "The sole business of school is to teach and learn" (Bolman \& Deal, 2003). Students come to school to study and make their career path through education. When they fail, this aim is somewhat crushed. That is why the agenda of student quality learning and achievement has been at the heart of educational leadership practice at all levels in all countries, developed and underdeveloped. The need for education reform in order to make schools effective for enhancing quality classroom teaching and learning has been the song of many nations, Tanzania included. This makes improving teaching and learning to raise student achievement a number one priority of any school leader (Blase \& Blase, 2004; Chenoweth \& Everhart, 2002; Danielson, 2003, Fink \& Markholt, 2011; Fullan, 2003, Fullan, 2005; Leithwood, Louis, Anderson, \& Wahlstrom, 2004; Leithwood, Harris, \& Strauss, 2010; Marzano, Waters, \& McNulty, 2005, Marzano, 2011, Marshall, 2009). However, it is frustrating to all educational stakeholders when Headmasters and Headmistresses [HMs] who are working so hard to improve the performance of their students, are not able to achieve this goal. What is even more frustrating to the HMs is that some of school stakeholders like Students, Parents and even leadership, might blame the school leadership for the poor performance. However, we all know that teachers are the ones who can make a difference. This means, if student achievement is directly influenced by classroom teaching as the researchers unequivocally attest, then teachers are directly responsible for student achievement. But teachers work under the leadership of the HM. The failed multiple attempted solutions signify the need for a new approach. I am proposing that school leaders should be reminded of or learn and implement instructional leadership skills, which directly impact the improvement of quality instruction of their teachers. Specifically the Evaluation and Supervision of Classroom Instruction (ESCI) is a proven instructional leadership skill that support, coach, and help teachers to unleash their pedagogical potentials. In this way, the HM becomes the source of quality teaching and learning in his/her school, not only by 
holding teachers and students accountable for their teaching and learning, but also by being an instruction leader who supports, coaches, and sets the standard of quality teaching in his/her school. Without this, low student achievement is assured!

As leaders of Catholic schools, we have a moral obligation to ensure that the life dreams of our students are not shattered while they are under our care. The Vatican II Document on Declaration on Christian Education (Gravissimusm Educationis) affirms this moral obligation to all who are working in the Catholic Schools. It is time to boldly claim instructional leadership in our schools and make quality teaching and learning a priority as it will be measured by student achievement. This is the driving force of this PBL module. It is expected to give you not only the leadership skills that will particularly address the quality of teaching of your teachers, but also give you "the how" of approaching them and helping them to improve their teaching on the daily basis. Teachers must be experts of teaching. Experts are made, and you have been entrusted with the role of making sure that your teachers are experts of teaching. The workshop, which will be conducted using this module, is intended to make you an expert of experts! The bottom line is, we all have the moral obligation to make sure that our students are given the best education they deserve to the best of our abilities, regardless of whether they are in the Catholic or public/government schools. As a school leader, this must be your number one priority. 
Example of the Conceptual Presentation: The Problem, Past-attempted Solutions and New

\section{PROBLEM}

Identify the Problem you are trying to solve. In this case, High School Student achievement is low, it less than $\mathbf{5 0 \%}$

\section{PAST ATTEMPTED SOLUTIONS WHICH DID NOT SOLVE THE PROBLEM}

1. Use one Curriculum nationwide - While uniformity is good because it ensures that students of the same grade level are learning the same contents throughout the country, this does not necessarily improve the quality of teaching and learning.

2. Mandate Teacher Training Program in all Universities Students are failed before they reach the college level, so there are not enough students to be recruited as future teachers.

3. Student Centered Teaching/Constructivism: While this was a good approach, school leaders were left out of the process. The application of this teaching process was dropped because teachers did not have support they needed in the field.

\section{Evaluation and Supervision of Classroom Instruction (ESCI)} or Teacher Evaluation: This was done by very few principals and it was unpopular because it was done in an unprofessional manner: Top-down, authoritative and threatening teachers and

SOLUTION: Improve instructions by training school leaders to help and support teachers to improve the quality of teaching and learning. This PBL curriculum should help the leaders to focus on instructions (Instructional L.) while building professional relationships with teachers for support and coaching (Transformational L.). The 


\section{TRAINING PREPARATION CHECK LIST AND RESOURCES}

1. Name Tags - enough for all the participants

2. Laptop

3. Projector

4. Printer and enough toner or ink

5. Photocopier - if not attached to the printer. At least make sure you can access it if it is in the facility where training is taking place.

6. Presenter's Main Binder with all the material contents for all the sessions.

7. Resources: DVDs, printed articles, relevant books, markers, sticky-notes, writing pads, enough pens and pencils.

8. Charlotte Danielson Training Kit - Enhancing Professional Practice for High School Principals.

9. Enough binders for all the Participants.

10. Formative assessment forms [both printed and Electronic copy]

11. Printed Power Point Slides, in case you do not have electricity.

\section{RESOURCES}

a. Danielson's Enhancing Profession Training Kit - For High School Principals

b. Relevant Articles and books on Instructional Leadership, Transformation Leadership, Teacher Evaluation, School Reform and change, Improving Student Learning and Achievement, Leadership behavior and its impact on the organization, Collaborative leadership process, etc. The facilitator and participants much have and use the following books:

Danielson, C. (2007). Enhancing professional practice: A framework for teaching. Alexandria, VA: Association for Supervision and Curriculum Development.

Danielson, C. (2009). Enhancing professional practice: A framework for teaching high school.Alexandria, Va.: Association for Supervision and Curriculum Development.

Danielson, C. (2011). The framework for teaching evaluation instrument. Princeton, NJ: The Danielson Group.

Fink, S., \& Markholt, A. (2011). Leading for instructional improvement: How successful leaders develop teaching and learning expertise (1st ed.). San Francisco, CA: Jossey-Bass. 


\section{NOTICE: DATA COLLECTION}

Use the space below to write your observations, participants' comments; things you would like to change/modify/add for the next session. Write any data you need to remember for your writing. 


\section{Day One - Session One}

\section{Education does not mean teaching to know what they do not know: it means teaching them to behave as they do not behave.}

John Ruskin (1819-1900) English critic

* Introduction: Getting situated. If this is research work, give numbers (to be used instead of names during self assessment to make the information anonymous). Give the participants name tags, assigned each participant to the small groups and get. Give them the Instructional Leadership Training Module binder.

* Workshop Protocol - General rules for cohort group. Let them discuss and add anything they think will help with concentration, discipline and productivity.

* Goals and objectives of the workshop. Articulate this well to draw their interest and motivation.

* Course overview - purpose to the workshop: What they are expected to learn and how will it help their leadership for quality teaching and learning.

* Pre-evaluation: Self assessment about your skills, competence, confidence, motivation and conviction about ESCI. Make sure participants do this in a timely manner.

* Self assessment - What do you anticipate this training will give you? Your anticipation, what are you longing to know about quality pedagogy, student learning and achievement?

* Formative assessment: What did you do before this session? What did you learn? What more do you want to know? What will you change in your leadership as a result of what you learned in this session?

NOTE: This will be done after every session. Leave enough forms on the desks. ON THE DATA COLLECTION SHEET: To write your observation, Participants relevant comments, any group dynamics that might help in the writing process. 

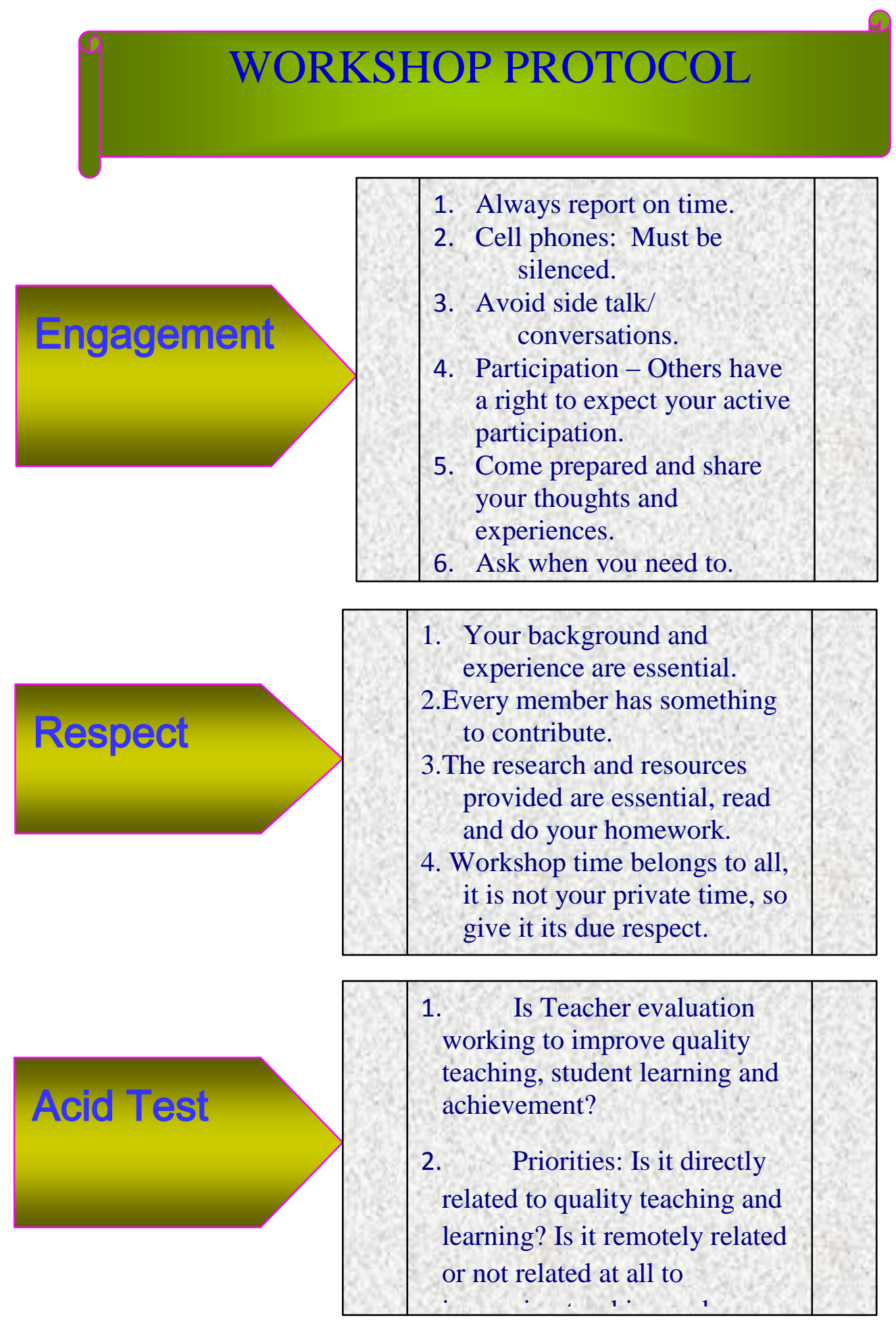


\section{COURSE OBJECTIVES}

\section{Getting situated, Introduction, \& workshop objectives}

The following questions will explore what you know about and what you want to learn about instructional leadership in terms of using the evaluation tool to enhance teaching and learning.

\section{Guiding Questions}

1. What do I need to do as a Headmaster/headmistress [HM] to improve teaching and learning in my school?

2. What are the major factors that influence quality teaching and learning and how can I make them applicable in my school?

3. Is there anything else I can do under my power to help teachers improve student learning and achievement?

4. What are other HMs doing in their schools which seems to help increase academic performance that is not in my school?

5. How are my leadership style and priorities associated to the current quality of teaching and students' performance? 


\section{Course overview - Purpose of the Workshop}

\section{Instructional evaluation and supervision Learning Goals and Objectives}

\section{At the end of the workshop the participants are expected to get the following:}

5. Acquire an understanding of the headmaster/headmistress [HM] work as an instructional leader, problems, frustrations and challenges associated with the job.

6. Acquire the sense of what is involved in performing teacher evaluation including classroom instructional evaluation and supervision.

7. Acquire some ways of making priorities in the principal's exercise of leadership and give instruction its due priority and importance.

8. It takes expertise to create expertise (Fink \& Markholt, 2011). This course work is intended to make the $\mathrm{HM}$ an instructional instructor and expert so as to be able to train his/her teachers and make them instructional experts as well.

9. Add some competencies and confidence in the instructional leadership role and facilitate instructional improvement through supervision, evaluation, feedback and teachers' improvement through appropriate professional development programs.

Acquire motivation for doing teacher evaluation after knowing what it can achieve and be willing to do it. Also acquire and express the conviction of what teacher evaluation can do to improve teaching and learning. 


\section{General Guiding questions: prior knowledge \& anticipation}

The following are brainstorming questions to help the participants explore the scope of the training module and its scope or coverage.

1. What do you know about improving student achievement through Instructional Evaluation and Supervision?

2. What do you want to know about your role as an instructional leader in terms of quality instruction for your teachers?

3. How do student learning and achievement connect to instructional supervision and evaluations?

4. What does the HM need to know to become an efficient instructional leader by performing formal, informed instructional supervision and evaluation in any discipline at any level?

5. If you were to choose one thing that your school will be known for, what will that be?

6. What are some of the ways in which a school leader might approach the task of establishing a school's and his/her personal leadership priorities?

7. How is supervision and evaluation helpful in the decision making to initiate school change, improve teacher's instructions, student learning and achievement?

8. How is instructional supervision and evaluation connected to the key roles of the HM?

9. How do I use my knowledge as HM to develop my commitment to institutionalize the instructional and transformational leadership?

10. How do you exercise your leadership so as to directly improve student learning and achievement? 


\section{Schedule: Training Activities and Course Objectives of the Module}

Improving the Quality of Teaching and Learning for Student Achievement: Using

Evaluation and Supervision of Classroom Instructional [ESCI]

\begin{tabular}{|c|c|c|c|}
\hline $\begin{array}{c}\text { DAY } 1 \\
\text { Sessions }\end{array}$ & TOPICS PER SESSION & $\begin{array}{l}\text { SCOPE OF } \\
\text { PARTICIPATION } \\
\text { AND GROUP } \\
\text { ACTIVITIES }\end{array}$ & COURSE OBJECTIVES \\
\hline $1^{\text {st }}$ & $\begin{array}{l}\text { Introduction: Getting situated, } \\
\text { given numbers, name tags, } \\
\text { assigned in groups and given the } \\
\text { training kit. } \\
\text { - Pre-evaluation: information } \\
\text { about what you know and what } \\
\text { you learn in this workshop. } \\
\text { - Course overview - purpose of the } \\
\text { workshop } \\
\text { - Formative assessment - What are } \\
\text { you longing to know about ESCI? }\end{array}$ & $\begin{array}{l}\text { 5. Attend the } \\
\text { lecture } \\
\text { 6. Video clip on } \\
\text { Quality } \\
\text { Teaching } \\
\text { 7. Fill out the } \\
\text { evaluation forms } \\
\text { 8. Questions and } \\
\text { Answers }\end{array}$ & \begin{tabular}{|l} 
5. Get started \\
6. Measure what they \\
know and what they \\
want to know. \\
7. Give a general picture \\
of the Training Module \\
8. Assess the \\
effectiveness of the \\
session.
\end{tabular} \\
\hline $2^{\text {nd }}$ & $\begin{array}{l}\text { Do teacher evaluation using the } \\
\text { Vignette } \\
\text { Formative assessment of the session }\end{array}$ & $\begin{array}{l}\text { 3. In Groups - do an } \\
\text { evaluation of the } \\
\text { teacher in the } \\
\text { vignette } \\
\text { Presentations }\end{array}$ & $\begin{array}{l}\text { 1. Measure what they } \\
\text { know about teacher } \\
\text { evaluation, determining } \\
\text { effective instructions, } \\
\text { make evaluation, } \\
\text { communicate feedback }\end{array}$ \\
\hline $3^{\text {rd }}$ & $\begin{array}{l}\text { The art and science of school } \\
\text { leadership: Instructional and } \\
\text { Transformational } \\
\text { 1. Is instructional supervision and } \\
\text { evaluation done? Why and why not? } \\
\text { 2. Evaluate NECTA } 2011 \text { Form IV exam } \\
\text { results and their interpretation } \\
\text { 3. What would you like to change in } \\
\text { the exam results of } 2011 \text { in your } \\
\text { school? } \\
\text { Formative assessment }\end{array}$ & $\begin{array}{l}\text { 3. Small Groups } \\
\text { discussion } \\
\text { 4. Presentations in } \\
\text { the Cohort } \\
\text { group }\end{array}$ & $\begin{array}{l}\text { 5. Linking Leadership } \\
\text { duties to teaching } \\
\text { 6. Identify the existing } \\
\text { problem of student } \\
\text { failure } \\
\text { 7. Brain storm on what is } \\
\text { needed to change the } \\
\text { situation } \\
\text { Learn from others }\end{array}$ \\
\hline
\end{tabular}




\begin{tabular}{|c|c|c|c|}
\hline $\begin{array}{l}\text { DAY } 2 \\
\text { Sessions } \\
1^{\text {st }}\end{array}$ & $\begin{array}{l}\text { Danielson's Video Clip on Evaluation } \\
\text { of Classroom instruction } \\
\text { Why is instruction leadership needed } \\
\text { for ESCI? } \\
\text { Formative assessment of the session } \\
\text { Formative assessment of the day. }\end{array}$ & $\begin{array}{l}\text { 4. Watch } \\
\text { video } \\
\text { 5. Groups } \\
\text { discussion } \\
6 . \quad \text { Presentati } \\
\text { ons }\end{array}$ & $\begin{array}{l}\text { 1. Evaluate their likes and } \\
\text { dislikes of doing evaluation }\end{array}$ \\
\hline $2^{\text {nd }}$ & $\begin{array}{l}\text { Lecture on what makes Quality } \\
\text { Teaching using } \\
\text { Fink and Markholt's } 5 \text { Dimensions of } \\
\text { effective teaching } \\
\text { Formative assessment of the session }\end{array}$ & $\begin{array}{l}\text { Attend the Lecture } \\
\text { on Principles of } \\
\text { Quality Teaching of } \\
\text { any subject at any } \\
\text { level }\end{array}$ & $\begin{array}{l}\text { 1. Acquire Instructional } \\
\text { skills of teaching and } \\
\text { learning }\end{array}$ \\
\hline $3^{r d}$ & $\begin{array}{l}\text { Discussion on Fink and Markholt's } 5 \\
\text { Dimensions } \\
\text { - Presentations from the group work } \\
\text { - Formative assessment of the session } \\
\text { Formative assessment of the Day }\end{array}$ & $\begin{array}{l}\text { 1. Group } \\
\text { Discussion on the } \\
\text { Dimensions of } \\
\text { teaching } \\
\text { 2. Presentations }\end{array}$ & $\begin{array}{l}\text { 1. Acquire Instructional } \\
\text { skills and express them to } \\
\text { others } \\
\text { 2. Build confidence of } \\
\text { instructional leadership }\end{array}$ \\
\hline $\begin{array}{l}\text { DAY } 3 \\
\text { Sessions } \\
1^{\text {st }}\end{array}$ & $\begin{array}{l}\text { DANIELSON'S } 5 \text { DOMAINS - Domain } \\
1 \\
\text { why? } \\
\text { What will work in your school and } \\
\text { What won't work and why? } \\
\text { why? } \\
\text { Formative assessment of the session }\end{array}$ & $\begin{array}{l}\text { 3. Evaluate the } \\
\text { Danielson's } \\
\text { rubrics in the } \\
\text { Groups } \\
\text { 4. Presentations }\end{array}$ & $\begin{array}{l}\text { 1. Acquire knowledge of } \\
\text { Danielson's framework } \\
\text { 2. Build a culturally } \\
\text { responsive Evaluation tool } \\
\text { 3. Build competence and } \\
\text { confidence in ESCl }\end{array}$ \\
\hline $2^{\text {nd }}$ & $\begin{array}{l}\text { Domain } 2 \text { - the same work as in } 1^{\text {st }} \\
\text { session } \\
\text { Formative assessment of the session }\end{array}$ & $\begin{array}{l}\text { Groups and } \\
\text { presentations }\end{array}$ & $\begin{array}{l}\text { 1. Acquire knowledge of } \\
\text { Danielson's framework } \\
\text { 2. Build competence and } \\
\text { confidence in ESCl }\end{array}$ \\
\hline $3^{r d}$ & $\begin{array}{l}\text { Domain } 3 \text { - the same work as in } 1^{\text {st }} \\
\text { and } 2^{\text {nd }} \text { sessions } \\
\text { Formative assessment of the session } \\
\text { Formative assessment of the Day }\end{array}$ & $\begin{array}{l}\text { Groups and } \\
\text { presentations }\end{array}$ & $\begin{array}{l}\text { 1. Acquire knowledge of } \\
\text { Danielson's framework } \\
\text { 2. Build competence and } \\
\text { confidence in ESCl }\end{array}$ \\
\hline
\end{tabular}




\begin{tabular}{|c|c|c|c|}
\hline $\begin{array}{c}\text { DAY } 4 \\
\text { Sessions } \\
1^{\text {st }}\end{array}$ & $\begin{array}{l}\text { Domain } 4 \text { - the same work as in } \\
\text { Yesterday's sessions } \\
\text { Formative assessment of the session } \\
\text { Formative assessment of the Day }\end{array}$ & $\begin{array}{l}\text { Groups and } \\
\text { presentations }\end{array}$ & $\begin{array}{l}\text { 1. Acquire knowledge of } \\
\text { Danielson's framework } \\
\text { 2. Build competence and } \\
\text { confidence in } \mathrm{ESCl}\end{array}$ \\
\hline $2^{\text {nd }}$ & $\begin{array}{l}\text { Adaptation of Classroom visitation } \\
\text { Danielson's evaluation rubrics } \\
\text { Formative assessment of the session }\end{array}$ & $\begin{array}{l}\text { Groups and } \\
\text { presentations }\end{array}$ & $\begin{array}{l}\text { 1. Acquire } \mathrm{ESCl} \text { skills of } \\
\text { Danielson's framework } \\
\text { 2. Build competence and } \\
\text { confidence-Instructional } \\
\text { Leadership through ESCl }\end{array}$ \\
\hline $3^{\text {rd }}$ & $\begin{array}{l}\text { Feedback communication and } \\
\text { discussion after evaluation } \\
\text { Characteristics of Effective feedback } \\
\text { [Video Clip] } \\
\text { Formative assessment of the session } \\
\text { Formative assessment of the session } \\
\text { Formative assessment of the Day }\end{array}$ & $\begin{array}{l}\text { 3. Attend the lecture } \\
\text { 4. Watch a Video } \\
\text { clip } \\
\text {-Both done in the } \\
\text { cohort group }\end{array}$ & $\begin{array}{l}\text { 1. Acquire ESCl skills of } \\
\text { Danielson's framework } \\
\text { 2. Build competence and } \\
\text { confidence-Instructional } \\
\text { Leadership through ESCI }\end{array}$ \\
\hline $\begin{array}{l}\text { DAY } 5 \\
\text { Sessions } \\
1^{\text {st }}\end{array}$ & $\begin{array}{l}\text { Vignette - application of the rubrics } \\
\text { Formative assessment of the session } \\
\text { Role Play on how to communicate } \\
\text { feedback from the vignette } \\
\text { Formative assessment of the } \\
\text { Session }\end{array}$ & $\begin{array}{l}1^{\text {st }} \text { do it individually } \\
2^{\text {nd }} \text { in the Groups } \\
3^{\text {rd }} \text { make } \\
\text { presentations in } \\
\text { the cohort group }\end{array}$ & $\begin{array}{l}\text { To measure the level of } \\
\text { expertise by comparing } \\
\text { with the former vignette } \\
\text { evaluation }\left(1^{\text {st }} \text { session of }\right. \\
\text { Day } 1 \text { ) }\end{array}$ \\
\hline $2^{\text {nd }}$ & $\begin{array}{l}\text { Discussion on their findings and } \\
\text { changes they plan to make as a result } \\
\text { of this workshop } \\
\text { Formative assessment of the } \\
\text { Session }\end{array}$ & Small groups & $\begin{array}{l}\text { 1. Acquire effective } \\
\text { feedback communication } \\
\text { skills } \\
\text { 2. Reinforcing competence } \\
\text { and Confidence in doing } \\
\text { ESCl }\end{array}$ \\
\hline $3^{\text {rd }}$ & $\begin{array}{l}\text { Discussion of their findings and } \\
\text { changes they plan to make as a result } \\
\text { of this workshop } \\
\text { Formative assessment of the } \\
\text { Session } \\
\text { Formative assessment of the Day }\end{array}$ & Small groups & $\begin{array}{l}\text { 1. Acquire effective } \\
\text { feedback communication } \\
\text { skills } \\
\text { 2. Reinforcing competence } \\
\text { and Confidence in doing } \\
\text { ESCI }\end{array}$ \\
\hline $\begin{array}{l}\text { DAY } 6 \\
\text { Sessions } \\
1^{\text {st }} \& 2^{\text {nd }}\end{array}$ & $\begin{array}{l}\text { Presentations of the Small groups in } \\
\text { the Panel of Educational Leaders of } \\
\text { Moshi : Bishop, Superintendent, } \\
\text { President of Mwenge University, } \\
\text { Professors of Education leadership at } \\
\text { Mwenge University, etc }\end{array}$ & $\begin{array}{l}\text { Cohort group } \\
\text { And the panel of } \\
\text { educational } \\
\text { leaders and } \\
\text { experts }\end{array}$ & $\begin{array}{l}\text { Demonstrate their skills, } \\
\text { confidence and } \\
\text { competence }\end{array}$ \\
\hline $3^{\text {rd }}$ & $\begin{array}{l}\text { - Unfinished Business } \\
\text { - Post Evaluation }\end{array}$ & & \\
\hline
\end{tabular}




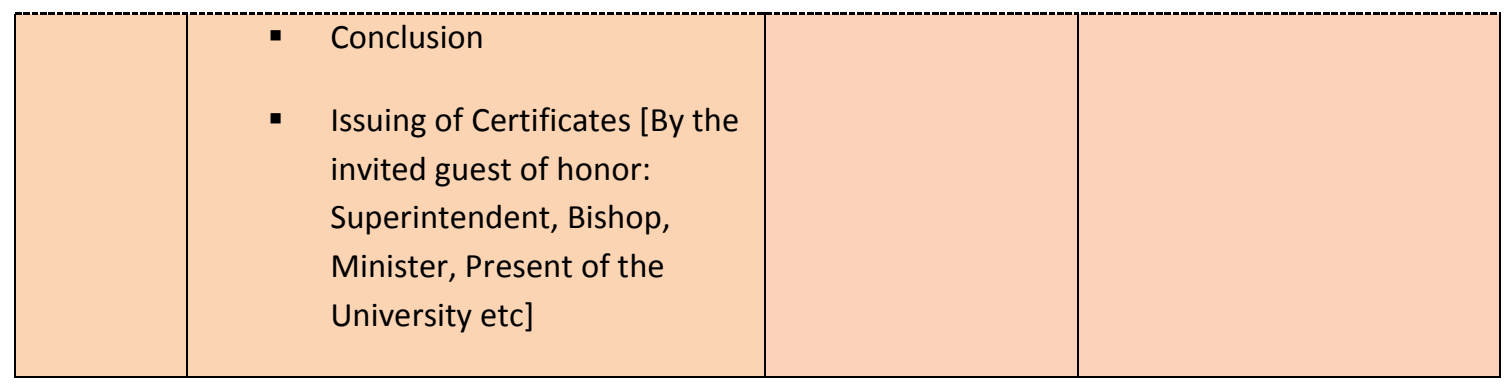




\section{Recipe for Student High Achievement}

This course or workshop comes from one simple statement of fact:

All of our schools need some improvement/reformation to make them perform better.

This work is about the role of the HM in the process of improving student Learning and Achievement.

The HM has influence and effect, at least indirectly (Chenoweth \& Everhart, 2002;

Fullan, 2001; Leithwood, Louis, Anderson, \& Wahlstrom, 2004) in the process of influencing student achievement and the feelings of the involved parties: HM, teachers and students. Simply put, the primary and most fundamental role of any HM is to ensure that teaching and learning is happening in the school (Bolman \& Deal, 2003). This is a key duty around which every other role is performed. The two leadership models that are needed are instructional leadership that will help the teacher professionally, and transformational leadership that will help the teacher to grow as a person. But to be able to do this, the HM needs some leadership training, and continual improvement through educational leadership professional development. Personal and professional growth of the teacher ensures the school will have qualified teachers who can deliver quality instructions. This gives us the simple but classic equation of student high achievement: High achievement = Quality teachers + Quality instruction. Figure.....before demonstrates this equation. 
Conceptual Representation of Teacher evaluation and its impacts Action Outcome

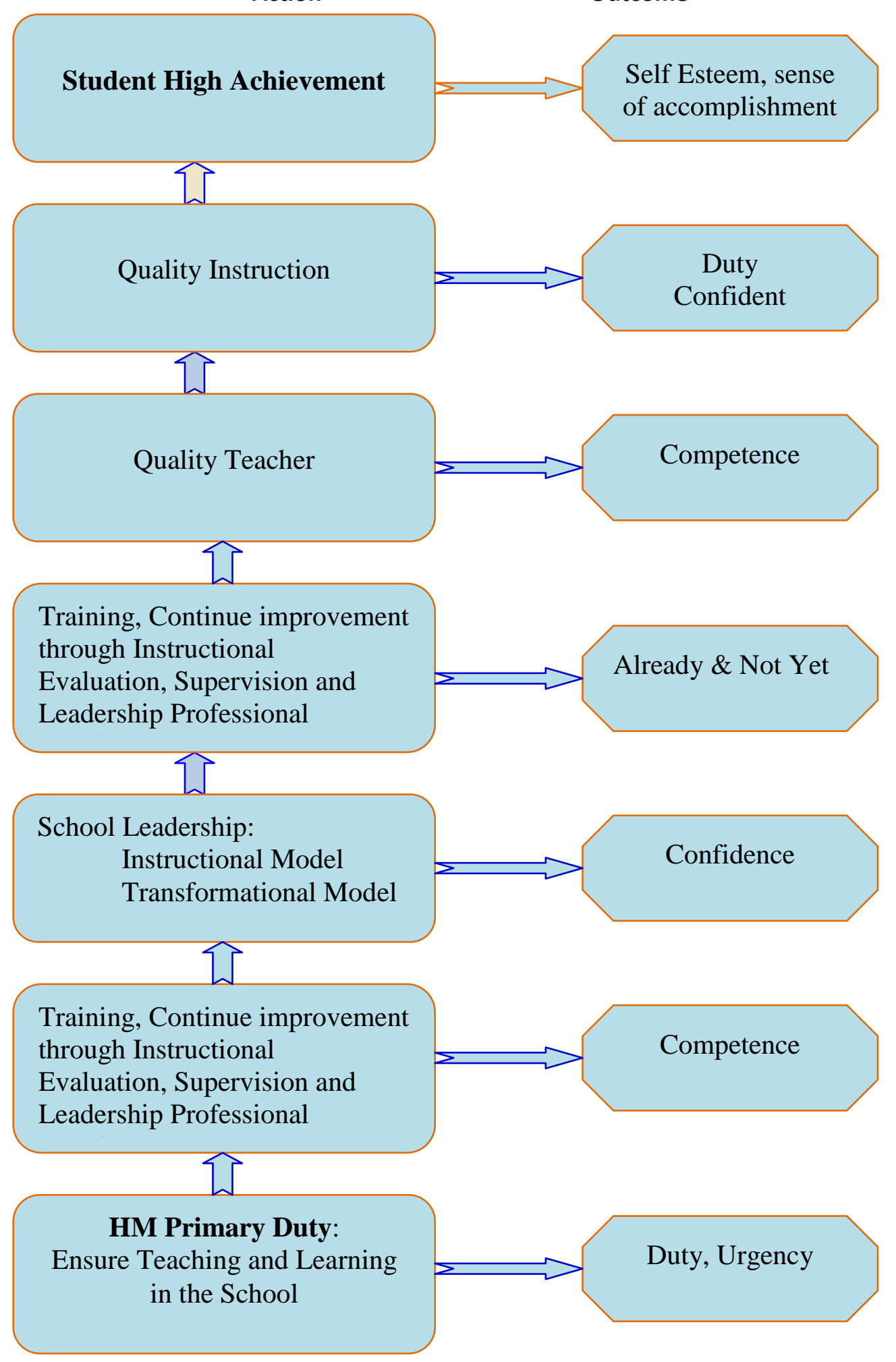




\section{Leadership Protocol}

Lead with integrity, always acting in the highest ethical traditions of public service -

- Uphold Tanzania Public Service (TPS) Values and Codes of Conduct

- Performing my duty in an impartial and professional manner

- Be active in implementing the Educational policies and programs

- Focus on achieving results and managing performance

- Place a strong emphasis on the timeliness of Ministerial Briefing

- Be openly accountable for my actions

- Provide frank, honest, comprehensive and accurate advice

\section{Act Collaboratively -}

- Promote collaboration across the portfolio

- Work cooperatively with other agencies to achieve our mission

- Build strong internal and external networks, in openness and respect

- Support my colleagues especially when things get tough

- Preserve the confidentiality of decision-making processes

- Share information and involve colleagues in decision making

\section{Foster a fair and rewarding workplace -}

- Encourage teamwork

- Respect the diversity of DEST people and their ideas

- Communicate clearly and promptly

- Set aside time for people management

- Give constructive feedback on performance

- Take time out to recognize people's contribution to our corporate commitments

- Provide flexibility to balance work and outside commitments

- Display enthusiasm, energy, corporate pride and a sense of fun

\section{Anticipate opportunities and encourage creativity}

- Seek to keep ahead of the game

- Encourage, actively debate new ideas and approaches

- Question what we do and why 
- Always look for ways of improving how we do our business

- Acknowledge mistakes, move on and keep learning

- Manage risk prudently

- Be flexible but hold fast to ethical standards 


\begin{tabular}{|c|c|c|c|c|c|}
\hline \multicolumn{6}{|l|}{ Pre-evaluation: Self Assessment } \\
\hline \multicolumn{6}{|c|}{ Scale: 1. Strongly Disagree, 2. Disagree, 3. I am not sure, 4. Agree, 5. Strongly } \\
\hline \multirow{3}{*}{$\begin{array}{l}\text { Post Evaluation Questionnaire. } \\
\text { Please, check only one box beneath the number that best } \\
\text { expresses your current feeling }\end{array}$} & \multicolumn{5}{|c|}{ BEFORE THE WORKSHOP } \\
\hline & \multicolumn{5}{|c|}{$\longrightarrow$ Disagree $\gg$ Agree } \\
\hline & 1 & 2 & 3 & 4 & 5 \\
\hline 1. I know about ESCI & O & O & $\mathrm{O}$ & $\mathrm{O}$ & O \\
\hline 2. I am familiar with $\mathrm{ESCl}$ & 0 & O & $\mathrm{O}$ & O & O \\
\hline 3. I know about the relationship between $\mathrm{ESCl}$ and quality teaching & 0 & 0 & 0 & 0 & O \\
\hline $\begin{array}{l}\text { 4. I am competent to do } \mathrm{ESCl} \text { so as to improve classroom } \\
\text { instruction }\end{array}$ & 0 & O & O & O & O \\
\hline $\begin{array}{l}\text { 5. Even if ESCl might be helpful, my schedule will never have time } \\
\text { for it }\end{array}$ & O & O & $\mathrm{O}$ & $\mathrm{O}$ & O \\
\hline 6. I am absolutely committed to use ESCI because of its value & 0 & O & $\mathrm{O}$ & $\mathrm{O}$ & O \\
\hline $\begin{array}{l}\text { 7. I know about Danielson's } 4 \text { Domains for instructional } \\
\text { improvement }\end{array}$ & 0 & O & O & O & O \\
\hline 8. I feel $\mathrm{ESCl}$ is too demanding and undoable & O & O & O & O & O \\
\hline 9. I know that $\mathrm{ESCl}$ can improve quality classroom instruction & O & O & $\mathrm{O}$ & $\mathrm{O}$ & $\mathrm{O}$ \\
\hline $\begin{array}{l}\text { 10. I have what it takes to improve student performance through } \\
\text { ESCI }\end{array}$ & 0 & O & O & O & O \\
\hline $\begin{array}{l}\text { 11. I know how to effectively formulate and communicate } \\
\text { feedback }\end{array}$ & 0 & O & O & O & O \\
\hline $\begin{array}{l}\text { 12. Improving Teaching and Learning is my number one priority as } \\
\text { a leader }\end{array}$ & 0 & O & O & O & O \\
\hline 13. ESCI will be a priority in my school leadership & 0 & O & 0 & 0 & O \\
\hline $\begin{array}{l}\text { 14. I am convinced that ESCl doesn't help improving classroom } \\
\text { instruction }\end{array}$ & 0 & 0 & 0 & 0 & 0 \\
\hline $\begin{array}{l}\text { 15. I believe that quality instruction can influence student } \\
\text { achievement }\end{array}$ & 0 & 0 & 0 & 0 & 0 \\
\hline $\begin{array}{l}\text { 16. I can still be a successful HM even if my students' achievement } \\
\text { is low }\end{array}$ & $\mathrm{O}$ & O & $\mathrm{O}$ & O & O \\
\hline
\end{tabular}




\begin{tabular}{|c|c|c|c|c|c|}
\hline 17. It is my duty to help teachers improve their pedagogical skills & O & $\mathrm{O}$ & O & O & O \\
\hline 18. Quality instruction is teacher's job, not mine as a school leader & O & O & O & 0 & 0 \\
\hline $\begin{array}{l}\text { 19. ESCl is not needed since the National Exam is enough to assess } \\
\text { teacher's instructional qualities }\end{array}$ & O & O & $\mathrm{O}$ & $\mathrm{O}$ & $\mathrm{O}$ \\
\hline 20. I can do ESCE with any teacher and at any class level & O & $\mathrm{O}$ & $\mathrm{O}$ & $\mathrm{O}$ & $\mathrm{O}$ \\
\hline 21. I feel motivated using ESCl as a tool in my leadership duties & 0 & 0 & 0 & 0 & 0 \\
\hline 22. I know that ESCl skills add to my instructional leadership quality & 0 & 0 & 0 & 0 & 0 \\
\hline $\begin{array}{l}\text { 23. I am confident that } \mathrm{ESCl} \text { can improve the quality instruction of } \\
\text { my teachers }\end{array}$ & O & O & O & $\mathrm{O}$ & O \\
\hline $\begin{array}{l}\text { 24. I feel challenged to evaluate and supervise professional } \\
\text { teachers }\end{array}$ & O & $\mathrm{O}$ & $\mathrm{O}$ & $\mathrm{O}$ & O \\
\hline 25. Regardless of my busy schedule, ESCl is a must in my school & O & $\mathrm{O}$ & $\mathrm{O}$ & O & $\mathrm{O}$ \\
\hline 26. With the skills I have, I can professionally do $\mathrm{ESCl}$ & 0 & 0 & 0 & 0 & 0 \\
\hline $\begin{array}{l}\text { 27. I am committed to use } \mathrm{ESCl} \text { as a tool to improve teaching and } \\
\text { learning }\end{array}$ & O & $\mathrm{O}$ & O & $\mathrm{O}$ & $\mathrm{O}$ \\
\hline $\begin{array}{l}\text { 28. I am confident that I can improve student achievement through } \\
\text { ESCI }\end{array}$ & O & $\mathrm{O}$ & $\mathrm{O}$ & $\mathrm{O}$ & $\mathrm{O}$ \\
\hline
\end{tabular}




\section{Formative Assessment/Evaluation - Per every session}

Please, write your evaluation and turn in this paper at the end of every session.

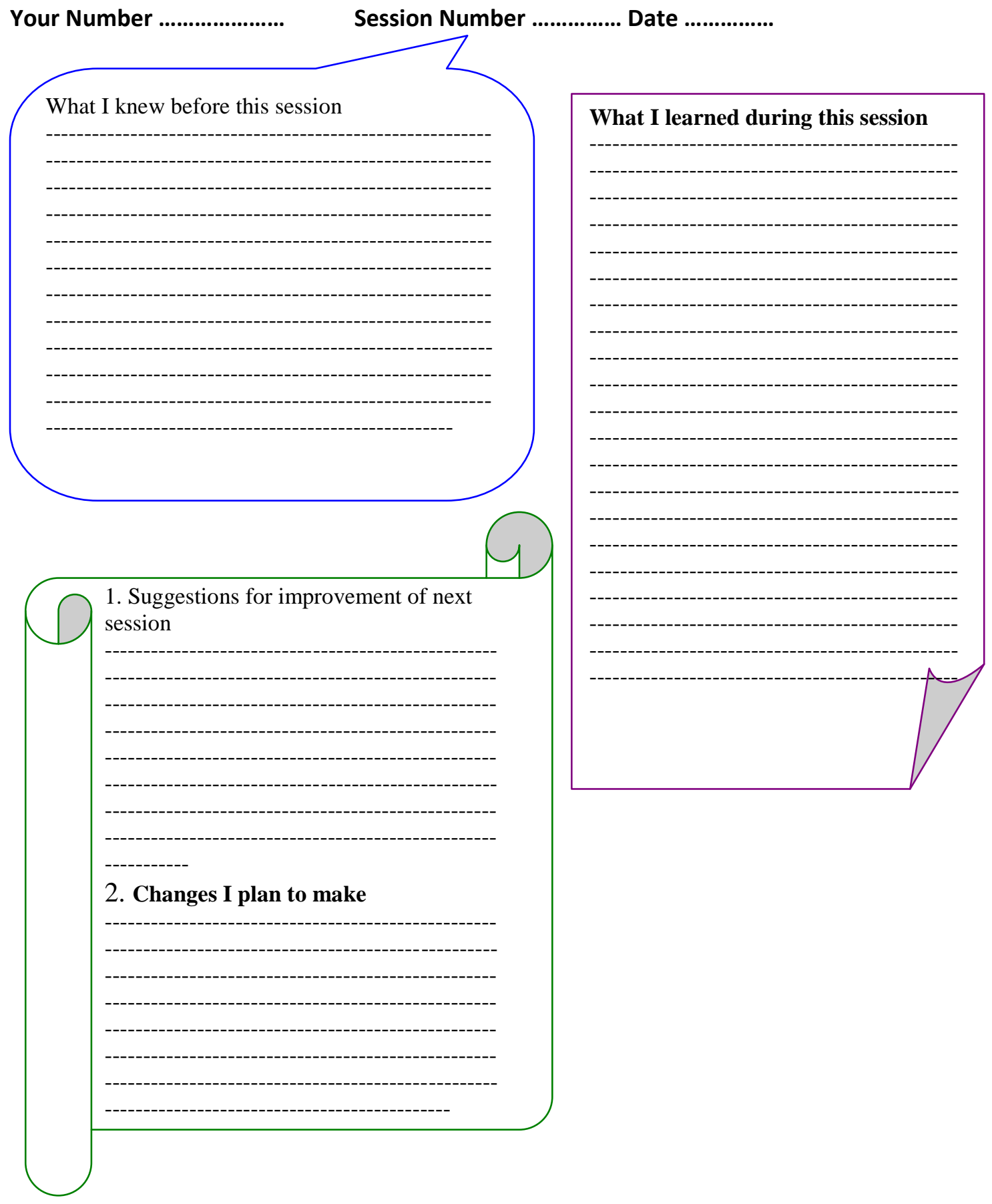




\section{NOTICE: DATA COLLECTION}

Use the space below to write your observations, participants' comments; things you would like to change/modify/add for the next session. Write any data you need to remember for your writing. 


\section{Day One - Session Two}

\section{Education is not preparation for life: education is life itself. John Dewey}

\section{Education, therefore, is a process of living and not a preparation for future living \\ John Dewey}

* Guiding Questions: These questions are intended to allow the participants to explore their personal knowledge and previous experiences with teacher evaluation. They can also make a connection between what was done to them as student-teachers and what can be done to the professional teachers in their schools to improve instructional qualities.

* Do Teacher Evaluation using your experience and knowledge - Vignette This is done by using their teaching experience without using Danielson's rubric. Keep the result to be compared with those they will do after training using Danielson's rubric.

* Formative assessment about the session

* Data Collection Sheet 


\section{GUIDING}

\section{QUESTIONS}

This session will explore what you know about and what you want to learn about instructional leadership in terms of using the evaluation tool to enhance teaching and learning.

\section{Guiding Questions}

1. What do you know about teacher evaluation or Evaluation and Supervision of Classroom Instruction (ESCI)?

2. What makes you think student achievement is your leadership challenge?

3. What do I need to do as a Headmaster/headmistress [HM] to improve teaching and learning in my school?

4. What works well in my school that motivates teaching (for teachers) and learning (for students)?

5. Is there anything else I can do under my power to improve student learning and achievement?

6. What are other HMs doing in their schools which seems to help increase academic performance that is not in my school?

7. Any other burning issues you need to address to improve teaching and learning? 


\section{VIGNETTE 1}

\section{Full time Classroom Teacher Evaluation and Supervision}

Preview of the Vignette - Scenario

Salema is an English teacher at Migombani Secondary School. This is his $11^{\text {th }}$ year as a secondary school English teacher. He is teaching Form Two classes [sophomore] here at Migombani. As you know, English is one of the mandatory subjects and Migombani does relatively well in the National Form Four Examination, with very few A's and B's, lots of C's and D's, and a few F's. As an instructional leader, you are determined to help the teachers improve their instructional skills and so improve student learning and achievement. One of your goals and passion as part of your school reform plan is to improve English language in your school. You know that the best way to do this is to help your English teachers, and in fact all teachers to do their best in their instructional job. You really want to help and see this change happening in your school. You also know from your leadership experience that the best way to help any teacher is to know his/her pedagogical strengths and weakness, and help him/her to improve where he/she is struggling and keep improving and celebrate any gained improvement and strengths.

You begin with making a review of the Form Two English curriculum or syllabus [as given by the Ministry of Education] to see what topics need to be covered for this class this semester. You also learned that Salema is teaching "Letter writing" next week. You feel good about it since it is one of the topics being covered in this semester and this tells you that he is following the prescribed curriculum. You decide to arrange for instructional evaluation and supervision with Salema as you do with the other teachers. First you remind him of your goal of doing instructional observation, as you made it clear in the staff conference at the beginning of this school year, and ask him for his lesson plan. While reviewing the lesson plan, you discover that this unit "Letter writing" for Salema will be covered in six different sessions, in his 3 doublesession class periods on Mondays. You decide you will conduct a full time observation from the beginning of the class to the end. Salema is now aware of your plan. He knows from the staff administrative announcements you made at the beginning of this academic year that you want to help them to improve their pedagogical skills and you will be making regular classroom evaluation and supervision and at times you would make unannounced instructional observation and evaluation while they are teaching. They also know that you can walk in at any time for those short class visits. All teachers were also instructed to completely ignore your presence and continue to focus on whatever was taking place in their classroom business. Students have been informed of the plan and were also instructed to ignore your presence and keep up with the normal classroom business. 
Observation:

You want to spend about 90 minutes in these double periods or sessions. You are in the Form Two classroom before Salema arrives, and you sit at the back corner of the classroom. Students are getting in, continuing with their social talks they had during break time. Class is noisy, some students are laughing, and some chasing each other around the desks and the majority have not noticed your presence. A few of those who see you end their story and just walk to their respective desks. In the middle of this Salema comes in with his pile of files and books. He goes straight to his front desk and places his teaching materials there. Then the school bell rings and all students end their social talks and activities and assume their respective positions. The class has 36 students. There are three rows of two desks each and so each row has 12 students. At this time only the noise of moving chairs and opening desks could be heard. Salema sees you and continues with his business as usual. Class prefect gives a sign, all students stand up and in unison salute their teacher, Mr. Salema:

S: Good morning Sir.

T. Good morning class, thank you. I see you were enjoying some sunshine out there [some nods, some say "yes"]. How are you doing young folks?

S: Fine.

T: OK, have your seats please. [Students get seated. Salema and students exchange some greetings on how they spent the weekend and soon Salema writes on the board: LETTER WRITING. Then he addresses the class]

Last week we concluded our topic on Conjunctions. Today we begin a new topic of Letter writing. In this unit, you will be given plenty of opportunities to apply the Conjunctions we studied, and other stuff you have studied in English classes from the day you came to this school. In other words you will put into use those things you have learned in the previous classes in the process of letter writing.

Now, turn to your neighbor and in two minutes come up with a list of all the topics you think will be applicable in the letter writing. [The class becomes noisy as students brainstorm in response to the task assigned to them. Salema keeps walking around the class and listening to how students are doing. He leans over to one group and advises, "It would be more helpful if you would write your thoughts". Then he announces, "One minute left". While he is now in front of the class, he announces that time is up. Some students complain asking for extra time. Salema then asked how many think they need extra time. Almost half of class raised their hands. "OK, two more minutes", Salema announced and the students kept working on the task]. 
T. Time is up, so please stop the discussion. Now, Paul (student), please go to the board and write the list of the topics you came up with. [This is a random pick. Paul goes and writes: Conjunctions, Articles, prepositions, clauses, nouns].

T. Very good. Sarah, please go to the board and add anything you have that is not on the list yet. [Sarah writes: pronouns, adjectives, adverbs].

T. Very well. David, do you have anything in your list that is not there? [David nods and goes on the board and writes: Communication skills, career skills]

T. Excellent. Is there anyone who has anything that is not in our list yet? [Monica goes and writes: Computer skills. Some other students go to the board and add what they had. At this point no other student had anything to add]

T. Excellent job folks. In this unit we will learn about 2 types of letters and how to write them; their similarities and differences. These are friendly or social letters and business letters.

S. How about email/fax...

T. If you talk like people who are in the bar, I cannot hear you. [Two students raised their hands]

T. Yes, Hillary.

S. How about Telegram or email?

T. Even though a telegram is not demanded by the curriculum, we will briefly see what it looks like. However, at this level we will only explore in detail two types: Friendly and Business letters. At Form Four [senior year] you will learn more about electronic letters and their ethics. [Salema noticed two students at the left-back playing, throwing pens to each other and laughing. Two other students at the back of the left row are napping with their faces in their folded hands on their desks. Salema notices this and just gave a random comment.

T: Some people are playing and sleeping here. It is up to you folks. You are wasting your time, your father's money and you will be the one failing the national exam. Let us continue. Sam, you had your hand raised up earlier, what do you want to share?

S. Do you mean in this year we will only learn about "snail mails"? [The class laughs].

T. Write down your last points, you have one minute left. [A few students are still busy writing, majority seem to have done their task since they have stopped writing. One student at the back is sleeping on the desk, her face buried in her folded arms. Salema went to the board and then announced]. Please, stop writing. [A few students are still writing. Salema seems to ignore them and writes on the board: The characteristics of Business Letters. Then he gave instructions]: Now, Monica please stand up and read what you wrote to us. [Monica was the student who was 
sleeping. She did not have anything to say. She stands, seems embarrassed, and some of the student are laughing]. Do you have any reason why you did not do anything? [The student remained silent]. Since you chose to sleep rather than to do the job, and it is against our class rule, now go to the back of the class and remain standing to the end of this session. You may take your notebook to write what we are going to discuss because at the end of this session I will give all of you a homework assignment that will require you to demonstrate a clear understanding of these characteristics. [Monica goes and stands at the back of the class]

Now, there are four columns drawn on the board, one each facing your desk row. Beginning with those seated in front, go to the column in front of you and write the characteristics of business letters you know. The following person will only add what has not been mentioned yet. Please line up and no wastage of time. So, Charles, David, Ester and Bill, lead us. [Four students go to the board and enumerate what they had written on their notebooks. Other students followed and added to the list. This exercise went smoothly and quickly.]

T. Now, look at all the lists and pick anything you think does not belong to the list and bring it to our attention. [Few hands went up]. Yes, Flora.

S. "Sharing personal stories"

T. Good observation. Why do you think it does not belong to business letters?

S. Well, because business letters are formal and they only address business issues, and not personal stories [Another hand went up].

T. Very good. Yes, Brian.

S. But personal stories can demonstrate your personal experience which needs to be shown in your business letter if you want to get the job, right? [More hands went up]

T. Good job Janet. Now who notices anything there that needs some clarification from what you have been reading about letter writings?

S. [Shouted without order]. I don't have to put all my personal contacts; that is stupid. [Three students shouted back at the same time and Salema could not tell who said what. At that point Salema jumps in]

T. Silence, please. You know very well that we do not tolerate that kind of behavior in this class. You know our rules. Everyone has a right to speak his/her mind in a respectful manner, just as Janet did. And if you want to correct another person or speak your mind, you are to do so with respect as well. That is why we have a tradition of raising hands in this school, and specifically in this class if you have something to say. Please, you will do us all a favor if you will remember to observe that. 
Now, back to the revision of our topic. Nelson, it sounded like you had something to say [Nelson was the one who shouted first]

S. I was saying it is stupid to put all my personal contact information on the letter. Things like my cell phone. This people will be barraging you all the time with commercial ads. That is what I am saying.

T. OK, good observation. Stacy, you had something, I suppose [Stacy was one of those shouted in response to Nelson].

S. Yes, I don't think it is stupid. You want to give them all the means to get you at any time if they have some concerns or need some things clarified. I think this will add to your possibility of getting that job. Otherwise if they don't get you immediately, they might pick somebody else. You want to make it easier for them if you want to be hired.

[Students are nodding and some random "yes" are heard].

T. Nelson, how do you see that response?

S. Now it makes sense, I guess.

T. Before we conclude our session which will also conclude this topic, let us see how the materials learned in this class will be assessed and what are my expectations from you all.

[Your time is out and you exit the class]

\section{Group work:}

1. Formulate the feedback for Salema [a] What went well - his teaching strengths [b] what he struggled with or where does he need to improve? [Use your rubrics]

2. Communicate this feedback to our main group in the form of a role playing-presentation [From your group, one will be Salema, and one will be the HM, and one will be a notary or secretary]. The rest will be observers and note what went well and what could be said differently and give you feedback after the presentations. The notary will write down this observation which will be shared in the main group.

3. Present your findings to the main group

POSITIVES: Adjustment - allowed more time when was asked for, Interactive: students not only bringing to class what they know, but actively sharing them by writing on the board; Acknowledgement of those who needed to ask questions and validation of their contribution; Scaffolding or assistance - when students were advised to write the list; interrogation of the unit to other subjects, scope of unit - what was there and the limit of what will be learned this time.

Class Management: by re-enforcing classroom rules but also allowing the student not to miss the learning; Constructivist approach and student engagement in the learning process- by 
brain storming first then bringing together their thoughts; Democratic and respective sharing through hand raising system; keeping students alert by random picking strategy, students were engaged keeping discussion alive and informative etc.

Class Management: by deregulating students' conversation, reminding them of the class/school rules and re-enforcing them; Constructivist approach and student engagement in the learning process- by building an argument around student's negative response which led to a powerful learning scenario; Democratic and respective by not ignoring those whose initial response was inaccurate and did not follow the rules and gave them a chance to air their views; Assessment review: before the end of the lesson.

NEGATIVES: Management: mishandling of the playing and sleeping students; not enforcing the classroom rule of asking questions by raising hands, the purpose, goal and objectives of lesson were not articulated; Assessment criteria were not give; lesson was not linked to the real life situation - how knowing this lesson will play a key role in their career.

Ignored students: Salema could check with those students who were still writing when he called for "pens down". Even if he did not want to provide more time, it is important to acknowledge that you understand their concern.

NEGATIVES: Students participation in the review of the class rules: Mr. Salem could have asked the students what was wrong with Nelson's answer, and allow them to review the rules instead of listening to him make that review. 


\section{VIGNETTE 2}

Preview of the Vignette - Scenario

\section{Mini \& Walk through Evaluation}

Read the following vignette. Assume that you are visiting their classrooms and the story tells what you witnessed. Carefully evaluate the Mr. Salema and Mrs Nawira. These are just examples. You can use other examples with a subject familiar to your teaching content area.

Mr. Salema and Mrs. Ngawira are Engilsh teachers at Migombani Secondary School. This is the $11^{\text {th }}$ year as a secondary school English teacher for Mr. Salema and the $7^{\text {th }}$ year for Mrs. Ngawira. They are both teaching Form Two classes [sophomore] at Migombani. As you know, English is one of the mandatory subjects and Migombani does relatively well in the National Form Four Examination, with very few A's and B's, lots of C's and D's, and a few F's. As an instructional leader, you are determined to help the teachers improve their instructional skills and so improve student learning and achievement. One of your goals and passion as part of your school reform plan is to improve English language in your school. You know that the best way to do this is to help your English teachers, and in fact all teachers to do their best instructional job. You really want to help and see this change happening in your school. You also know from your leadership experience that the best way to help any teacher is to know their pedagogical strengths and weaknesses, and help him or her to improve in the areas in which they are struggling. Finally, there should be a culture of continuous improvement and celebration of teacher successes.

You begin with reviewing the Form Two English curriculum or syllabus [as given by the Ministry of Education] to see what topics need to be covered for this class this semester. You also learn that Mr. Salema and Mrs. Ngawira are teaching "Letter writing" next week. You feel good about it since it is one of the topics that being covered this semester and this tells you that they are following the prescribed curriculum. You decide to do an instructional evaluation of Mr. Salema and Mrs. Ngawira as you do with other teachers. First you remind them of your goal of doing mini instructional observations, as you made it clear in the staff conference at the beginning of this school year, and ask them for their lesson plan. While reviewing the lesson plan, you discover that this unit "Letter writing" for Mr. Salema will be covered in six different sessions, in his 3 double-session class periods of Mondays; while Mrs. Ngawira had planned to cover the unit in 4 different single sessions on Thursdays. [One session is 45 minutes, so a double session class is 90 minutes]. You decide that you will make three mini observations (walk-throughs), that will take 5 to 10 minutes per observation. In your plan, you want to attend the beginning of the first session with Mr. Salema, the middle of the second session with Mrs. Ngawira and the end or concluding part of the third session with Mr. Salema. The two teachers are not aware of 
your plan. They just know from your staff administrative announcements you made at the beginning of this academic year that you want to help them to improve their pedagogical skills and you will be making regular and unannounced instructional observation and evaluation while they are teaching. They also know that you can walk in at any time for those short class visits. All teachers were instructed to completely ignore your presence and continue to focus on whatever was taking place in their classroom business. Students were also instructed to ignore your presence during class time.

First Observation:

You want to spend about 30 minutes in this session. You are in Form Two classroom before Mr. Salema arrives, and you have assumed your seat at the back corner of the classroom. Students are walking in, continuing with their social talks they had during break time. Class is noisy, some students are laughing, and some chasing each other around the desks and majority have not noticed your presence. A few of them who see you end their story and just walk to their respective desks. In the middle of this Mr. Salema comes in with his pile of files and books. He goes straight to his front desk and places his teaching materials there. Then the school bell rings and all students end their social talks and activities and assume their respective positions. The class has 36 students. There are three rows of two desks each and so each row has 12 students. At this time only the noise of moving chairs and opening desks could be heard. Mr. Salema sees you and continues with his business as usual. The class prefect gives a sign, all students stand up and in unison salute Mr. Salema:

S: Good morning Sir.

T. Good morning class, thank you. I see you were enjoying some sunshine out there [some nods, some say "yes"]. How are you doing, young folks?

S: Fine.

T: OK, take your seats please. [Students get seated. Mr. Salema and students exchange some greetings on how they spent the weekend and soon Mr. Salema writes on the board: LETTER WRITING. Then he addresses the class]

Last week we concluded our topic on Conjunctions. Today we begin a new topic on Letter writing. In this unit, you will be given plenty of opportunities to apply the Conjunctions we studied, and other parts of speech you have studied in English classes from the day you came to this school. In other words you will put into use those things you have learned in the previous classes in the process of letter writing.

Now, turn to your neighbor and for 2 minutes come up with the list of all topics you think will be applicable in the letter writing. [The class becomes noisy as students brainstorm in response to the task assigned to them. Mr. Salema keeps walking around the class and listening how 
students are doing. He leans over to one group and advises, "It would be more helpful if you would write your thoughts". Then he announces, "One minute left". While he is now in front of the class, he announces: time is up. Some students complain asking for extra time. Mr. Salema then asked how many think they need extra time. Almost half of class raised their hands. "OK, two more minutes" Mr. Salema announces and students keep working on the task].

T. Time is up, so please stop the discussion. Now, Paul (student), please go to the board and write the list of the topics you came up with. [This is a random pick. Paul goes and writes: Conjunctions, Articles, prepositions, clauses, nouns].

T. Very good. Sarah, please go to the board and add anything you have that is not on the list yet. [Sarah writes: pronouns, adjectives, adverbs].

T. Very well. David, do you have anything in your list that is not there? [David nods and goes to the board and writes: Communication skills, career skills]

T. Excellent. Is there anyone who has anything that is not in our list yet? [Monica goes and writes: Computer skills. Some other students go to the board and add what they had. At this point no other student had anything to add]

T. Excellent job folks. In this unit we will learn about 2 types of letters and how to write them; their similarities and differences. These are friendly or social letters and business letters.

S. How about email/fax...

T. If you talk like people who are in the bar, I cannot hear you. [Two students raised their hands]

T. Yes, Hillary.

S. How about Telegram or email?

T. Even though telegram is not demanded by the curriculum, we will briefly see what it looks like. However, at this level we will only explore in detail two types: Friendly and Business letters. At Form Four [senior year] you will learn more about electronic letters and their ethics. [Mr. Salema noticed two students at the left-back playing, throwing pens to each other and laughing. Two other students at the back of the left row are napping with their faces in their folded hands on their desks. Mr. Salema notices this and just says ... T: Some people are playing and sleeping here. It is up to you folks. You are wasting your time, your father's money and you will be the one failing the national exam. Let us continue. Sam, you had your hand raised up earlier, what do you want to share?

S. Do you mean in this year we will only learn about "snail mails"? [The class laughs].

\section{[You time is over, and you slowly walk out]}




\section{Group work:}

4. Formulate the feedback for Mr. Salema [a] What went well - his teaching strengths [b] what he struggled with or where does he need to improve? [Use your rubrics]

5. Communicate this feedback to our main group in the form of a role playing-presentation [From your group, one will be Mr. Salema, and one will be the $\mathrm{HM}$, and one will be a notary or secretary]. The rest will be observers and note what went well and what could be said differently and give you feedback after the presentations. The notary will write down this observation which will be shared in the main group.

6. Present your findings to the main group

What do you anticipate? This part will not be given to the participants.

POSITIVES: Adjustment - allowed more time when was asked for, Interactive: students not only bringing to class what they know, but actively sharing them by writing on the board;

Acknowledgement of those who needed to ask questions and validation of their contribution; Scaffolding or assistance - when students were advised to write the list; interrogation of the unit to other subjects, scope of unit - what was there and the limit of what will be learned this time.

NEGATIVES: Management: mishandling of the playing and sleeping students; not enforcing the classroom rule of asking questions by raising hands, the purpose, goal and objectives of lesson were not articulated; Assessment criteria were not give; lesson was not linked to the real life situation - how knowing this lesson will play a key role in their career. 
Vignette 2 .

You just walked in and found that the teacher is at the middle of the session. This session began after a short break. Mrs. Ngawira was walking into the class when the students were busy writing something. You assume your position at the end corner of the class, and apparently no one notices your presence other than Mrs. Ngawira who also gave you a quick smile and continues with her business, ignoring your presence. You pull out our note book/ evaluation form and begin writing your observation. The session continues:

T. Write down your last points, you have one minute left. [A few students are still busy writing, the majority seem to have done their task since they had stopped writing. One student at the back is sleeping on the desk, her face buried in her folded arms. Mrs. Ngawira went to the board and then announced]. Please, stop writing. [A few students are still writing. Mrs. Ngawira seems to ignore them and write on the board: The characteristics of Business Letters. Then she gave instructions]: Now, Monica please stand up and read what you wrote to us. [Monica was the student who was sleeping. She did not have anything to say. She stands, seems embarrassed, and some of the student are laughing]. Do you have any reason why you did not do anything? [The student remained silent]. Since you chose to sleep rather than to do the job, and it is against our class rule, now go to the back of the class and remain standing to the end of this session. You may take your notebook to write what we are going to discuss because at the end of this session I will give all of you a homework assignment that will require you to demonstrate a clear understanding of these characteristics. [Monica goes and stands at the back of the class]

Now, there are four columns drawn on the board, one each facing your desk row. Beginning with those seated in front, go to the column in front of you and write the characteristics of business letters you know. The following person will only add what has not been mentioned yet. Please line up and no wastage of time. So, Charles, David, Ester and Bill, lead us. [Four students go to the board and enumerate what they had written on their notebooks. Other students followed and added to the list. This exercise went smoothly and quickly.]

T. Now, look at all the lists and pick anything you think does not belong to the list and bring it to our attention. [A few hands went up]. Yes, Flora.

S. "Sharing personal stories"

T. Good observation. Why do you think it does not belong to business letters?

S. Well, because business letters are formal and they only address business issues, and not personal stories [Another hand went up].

T. Very good. Yes, Brian. 
S. But personal stories can demonstrate your personal experience, which needs to be shown in your business letter if you want to get the job, right? [More hands went up]

[Your time is out and you slowly exit the class].

\section{Group work:}

1. Formulate the feedback for Mrs. Ngawira [a] What went well - her teaching strengths [b] what she struggled with or where does she need to improve? [Use your rubrics]

2. Communicate this feedback to our main group in the form of a role playing-presentation [From your group, one will be Mrs. Ngawira, and one will be the HM, and one will be a notary or secretary]. The rest will be observers and note what went well and what could be said differently and give you feedback after the presentations. The notary will write down this observation which will be shared in the main group.

3. Present your findings to the main group

What do you anticipate! This part will not be given to the participants.

Expected Comments:

POSITIVES: Class Management: by re-enforcing classroom rules but also allowing the student not to miss the learning; Constructivist approach and student engagement in the learning process- by brain storming first then bring together their thought;

Democratic and respective sharing through hand raising system; keeping students alert by random picking strategy; students were engaged, keeping discussion alive and informative etc.

NEGATIVES: Ignored students: Mrs. Ngawira could check with those students who were still writing when he called for "pens down". Even if he did not want to provide more time, it is important to acknowledge that you understand their concern. 


\section{Vignette 3}

You come into the classroom 20 minutes before the session concludes. You are aware that this is the last session for this lesson unit or topic. You are intending to spend only 3 to 5 minutes in this evaluation. You slowly enter the class through the back door and assume your seat at the end corner of the class. You immediately notice that students are actively listening, answering questions and some are writing as Mr. Salema speaks and sometime writes on the board. As you entered Mr. Salema was writing. On the board there are these phrases in the bullet points: use formal or legal names, address people formally, list all your personal contacts and address the people with their first names. Mr. Salema underlines the last phrase. The session continues:

T. Good job Janet. Now who notices anything there that needs some clarification from what you have been reading about letter writings?

S. [Shouted without order]. I don't have to put all my personal contacts; that is stupid. [Three students shouted back at the same time and Mr. Salema could not tell who said what. At that point Mr. Salema jumps in]

T. Silence, please. You know very well that we do not tolerate that kind of behavior in this class. You know our rules. Everyone has a right to speak up his/her mind in a respectful manner, just as Janet did. And if you want to correct another person or speak your mind, you are to do so with respect as well. That is why we have a tradition of raising hands in this school, and specifically in this class if you have something to say. Please, you will do us all a favor if you will remember to observe that.

Now, back to the revision of our topic. Nelson, it sounded like you had something to say [Nelson was the one who shouted first]

S. I was saying it is stupid to put all my personal contact information on the letter. Things like my cell phone. This people will be barging you all the time with commercial ads. That is what I am saying.

T. OK, good observation. Stacy, you had something, I suppose [Stacy was one of those shouted in response to Nelson].

S. Yes, I don't think it is stupid. You want to give them the means to reach you at any time if they have some concerns or need some things clarified. I think this will add to your possibility of getting that job. Otherwise if they don't get you immediately, they might pick somebody else. You want to make it easier for them if you want to be hired. [Students are nodding and some random "yes" are heard].

T. Nelson, how do you see that response?

S. Now it makes sense, I guess.

T. Before we conclude our session, which will also conclude this topic, let us see how the materials learned in this class will be assessed and what are my expectations from you all. 
[Your time is out and you exit the class]

\section{Group work:}

4. Formulate the feedback for Mr. Salema [a] What went well - his teaching strengths [b] what he struggled with or where does he need to improve? [Use your rubrics]

5. Communicate this feedback to our main group in the form of a role playing-presentation [From your group, one will be Mr. Salema, and one will be the HM, and one will be a notary or secretary]. The rest will be observers and note what went well and what could be said differently and give you feedback after the presentations. The notary will write down this observation which will be shared in the main group.

6. Present your findings to the main group

What do you anticipate? This part should not be given to the participants.

Expected Comments:

POSITIVES: Class Management: by deregulating students conversation, reminding them of the class/school rules and re-enforcing them; Constructivist approach and student engagement in the learning process- by building argument around student's negative response which led to a powerful learning scenario; Democratic and respective by not ignoring those whose initial response was inaccurate and did not follow the rules and gave them a chance to air their views; Assessment review: before the end of the lesson.

NEGATIVES: Students' participation in the review of the class rules: Mr. Salem could have asked the students what was wrong with Nelson's answer, and allow them to review the rules instead of listening him make that review.

Again how do you know that the entire class understands letter writing? I would conduct a performance-based assessment. i.e. have each student write a hypothetical letter. They could be assessed and refined in small student groups as well as by you and the teacher.

\section{Formative Assessment as on Pg. 223}




\section{NOTICE: DATA COLLECTION}

Use the space below to write your observations, participants' comments; things you would like to change/modify/add for the next session. Write any data you need to remember for your writing. 


\section{Day One - Session Three}

\section{Education does not mean teaching to know what they do not know: it means teaching them to behave as they do not behave.} John Ruskin (1819-1900) English critic

\section{The art and science of school leadership: Instructional and Transformational}

\section{Note:}

1. Since most of the participants will be learning this for the first time, give them enough time to read and learn through lectures and group discussions.

2. The intention is to use this abbreviated recourse from Fink \& Markholt (2011) book to give them general knowledge of what constitutes quality teaching and learning.

* Is instructional supervision and evaluation done? Why and why not

* Evaluate NECTA 2011 Form IV exam results and their interpretation

* What would you like to change in the exam results of 2011 in your school?

* Formative Assessment

* Talk Back Assessment - reflecting the vision of the whole day

* Data Collection Sheet 
best for them, commend what they are good at, offer suggestions on what needs to be improved, support them as they find the best way to improve and discuss how it is to be done, provide available time and resources for its implementation.

- Empower teachers: Let them own the instructional process, honor their unique ways, allow their personal talents to enrich the instruction. No one frame that fits every kind of policy.

Promote Teachers' Professional Growth

Transformational

- Maintain visibility: non-threatening \& supportive; a sign of teachers' assurance, approval, security, confidence.

- Study literature and proven programs: to support your plan of instructional improvement. Explore topics on science and art of teaching, student achievement improvement, equity and gender equality

- Support practice of new skills [constructive model], risk taking, innovation, and creativity - to allow innovation and creativity while maintaining the standard and raising expectations.

- Provided effective [problem based] staff development programs: collaboratively come up with what teachers think will address their current quality instructional challenges; address the school goal of student learning and achievement improvement.

- Apply principles of adult growth and development: Allow teachers to own the learning and improvement process, blend the past experience and the new skills, adoptability strategies

- Praise, support, and facilitate teachers' work: Verbal, written notices, public recognition of exemplary works and celebration of good works. This builds positive school culture that values success.

- Provide resource and time: For every teacher for quality instruction improvement as will be evidenced by student improved learning and achievement

- Give feedback and suggestions: timely, collaboratively with a sense of support rather than criticism or judgmental approach

Focus in on the teacher as a person and teachers' success, growth and improvement 


\begin{tabular}{|l|l|}
\hline Foster Teacher Reflection & $\begin{array}{l}\text { Instructional \& } \\
\text { Transformational }\end{array}$ \\
\hline - Develop teachers' reflection skills -in order to construct professional \\
knowledge and develop sociopolitical insights; to be mindful of \\
policies and standards of the Tanzanian Ministry of Education and \\
the Diocese of Moshi Education department
\end{tabular}

Adopted from the handbook of instructional leadership by Blasé \& Blasé (2004).

Figure 7 shows the effect of HM's behavior to the teachers. It is important to demonstrate the best and constructive behavior since it has its influence in the teaching and learning process. 


\section{How Supervisors' Behavior - Positive and Negative - Affect Teachers}

\begin{tabular}{|c|c|c|}
\hline \multicolumn{3}{|l|}{ Figure 7: HM's Behavior } \\
\hline Positive Attributes & & Negative Attributes \\
\hline Being Visible Results in: & & Interrupting and Abandonment results in: \\
\hline $\begin{array}{l}\text { - High morale and motivation: A sense that my } \\
\text { contribution is valued, noticed, counts. } \\
\text { - Enhanced self-esteem: Important team } \\
\text { player } \\
\text { - Increased sense of security: my work is } \\
\text { noticed, might lead to tenure, promotion } \\
\text { Reflection and reflectively oriented behavior- } \\
\text { self conscious acts are likely to be repeated if } \\
\text { needed }\end{array}$ & Vs & $\begin{array}{l}\text { - Anger - feeling lost, why the good things I do are } \\
\text { not seen? Leaves teachers with bitter feelings. } \\
\text { - Low motivation- working hard does not make a } \\
\text { difference } \\
\text { - Psychic pain } \\
\text { - Feelings of no support } \\
\text { - Loss of respect for HM [principal] - he/she is not } \\
\text { here to help but to get me! } \\
\text { - Poor performance due to lack of support } \\
\text { - Downgrade instructional works - if it was that } \\
\text { important the HM would make a follow up }\end{array}$ \\
\hline Praising Results in: & & Criticizing Results in: \\
\hline $\begin{array}{l}\text { - High motivation - celebrating the result and } \\
\text { doing a good job to win more praises } \\
\text { - Feeling rewarded, cared about - the hard } \\
\text { work paid off, likely to do more } \\
\text { - Enhanced self-esteem and confidence - I can } \\
\text { do it, type of thinking } \\
\text { - Willingness to comply - since it is rewarding } \\
\text { to do that } \\
\text { - Reflection and reflectively oriented behavior } \\
\text { - choosing to do those things which are } \\
\text { likely to elicit great results that will be } \\
\text { acknowledged and praised. } \\
\text { - Enhance creativity and risk taking in trying } \\
\text { new ways of instructions for its improvement } \\
\text { Promotes efficiency, encourages corrections } \\
\text { of the flaws so as to win future praises }\end{array}$ & Vs & $\begin{array}{l}\text { Anger } \\
\text { - Low motivation } \\
\text { - Damaged self-esteem - I am not good enough for } \\
\text { him/her, no need of trying. } \\
\text { - Fear - play safe to avoid criticism } \\
\text { - Confusion - should the teacher try new skills? } \\
\text { What if they don't work? Should she hold on to } \\
\text { the old ones which do not have great results? } \\
\text { - } \text { Loss of respect and trust for HM } \\
\text { acting hypocritical to get by } \\
\text { - Resistance and rebellion - to create distance } \\
\text { between the teacher and the HM; as a } \\
\text { professional teacher no one is to tell me what to } \\
\text { do }\end{array}$ \\
\hline
\end{tabular}




\begin{tabular}{|c|c|c|}
\hline & & self care \\
\hline Extending Autonomy Results in: & & Maintaining Control results in: \\
\hline $\begin{array}{l}\text { - High motivation } \\
\text { - Enhanced self-esteem and confidence - } \\
\text { student's achievement becomes teacher's } \\
\text { achievement as well, they both take pride } \\
\text { - Increased sense of security and professional } \\
\text { discretion } \\
\text { - Reflection and reflectively oriented behavior } \\
\text { - Personal improvement is blended with } \\
\text { professional improvement and the } \\
\text { instructional good result is taken personally } \\
\text { - Motivates self improvement that results into } \\
\text { instructional expertise }\end{array}$ & Vs & $\begin{array}{l}\text { - Limited involvement in decision making (false } \\
\text { image of governance) } \\
\text { - Sense of being manipulated } \\
\text { - } \text { - Geeling abused } \\
\text { - Kills personal initiatives and creativity to improve } \\
\text { student learning and achievement } \\
\text { - Stifles collaboration, collegiality and shared goals, } \\
\text { meaning and purpose }\end{array}$ \\
\hline
\end{tabular}

Adopted from the handbook of instructional leadership by Blasé \& Blasé (2004)

\section{Formative Assessment - The same as on Pg. 223}




\section{"Talk back" Assessment:}

At the end of each day the participant will fill out other forms of "talk back" assessment to indicate the highlights of the day, point out things which did not go so well and suggest some changes.
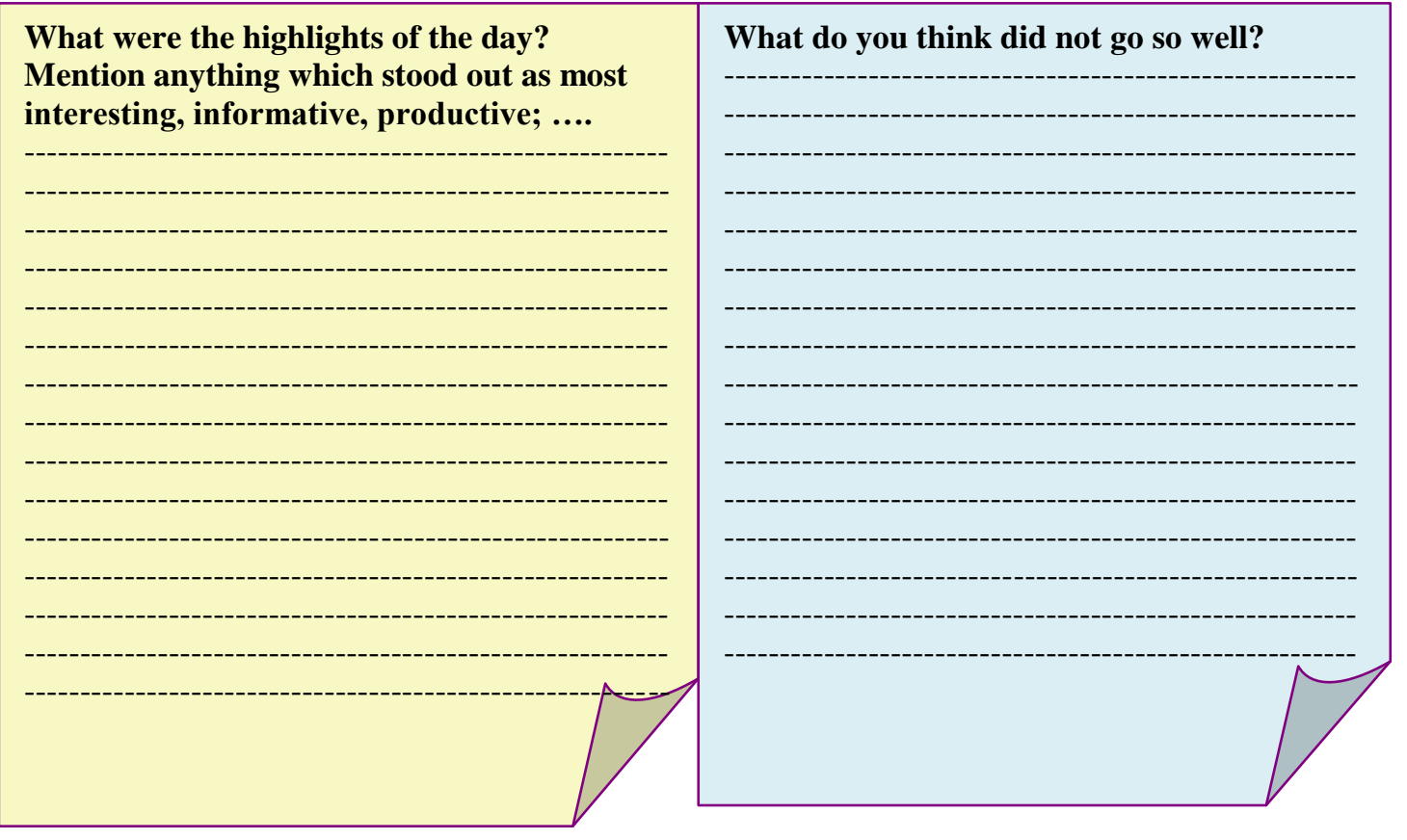

To make the sessions of tomorrow more productive what changes would you suggest?

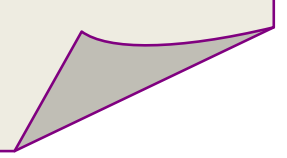




\section{NOTICE: DATA COLLECTION}

Use the space below to write your observations, participants' comments; things you would like to change/modify/add for the next session. Write any data you need to remember for your writing. 


\section{Day Two - Session One}

\section{It is in fact a part of the function of education to help us escape, not from our own time - for we are bound by that - but from the intellectual and emotional limitations of our time. T.S. Eliot}

* Danielson's Video on Teacher Evaluation and discussions (Give the participants an opportunity to hear from Charlotte Danielson the author of evaluation tool participants will be using].

* Why is Instructional and Transformational leadership needed for implementation of $\mathrm{ESCl}$ ?

- Small group work, then presentation to the cohort group

* Evaluation of Form Four National results of previous years to confirm the problem

- National Form Four Examination Results - 2010: Moshi Diocesan Schools. (You can use any year).

- National Form Four Examination Results - 2011: Moshi Diocesan Schools [You can use the results of any year to establish the claim that student achievement is a real problem and evidenced by those results].

- National Form Four Examination Results - 2000-2009: National Wide Statistics.

* Formative assessment of the session

* Data Collection Sheet. 
Form Four National Secondary/High Schools Exam Results-2010 - Moshi Catholic High Schools.

\begin{tabular}{|c|c|c|c|c|c|c|}
\hline NAME OF THE SCHOOL & $\begin{array}{c}\text { CENTER } \\
\text { NUMBER } \\
\text { S. }\end{array}$ & $\begin{array}{c}\text { TOTAL } \\
\text { No OF } \\
\text { CANDID } \\
\text { ATES } \\
\end{array}$ & $\begin{array}{c}\text { PASSED } \\
\text { DIVISION } \\
\text { I-III }\end{array}$ & $\begin{array}{c}\text { PAS } \\
\text { SED } \\
\\
\% \\
\end{array}$ & \begin{tabular}{|c|} 
FAILED \\
DIVISI \\
ON \\
IV - 0 \\
\end{tabular} & $\begin{array}{r}\text { FAILED } \\
\%\end{array}$ \\
\hline Anwarite Girls' Secondary School & 0269 & 45 & 44 & 98 & 1 & 2 \\
\hline Kibosho Girls' Secondary School & 0205 & 162 & 149 & 92 & 13 & 8 \\
\hline Kiraeni Girls' Secondary School & 0207 & 116 & 68 & 59 & 48 & 41 \\
\hline Kirua Secondary School & 0372 & 60 & 12 & 20 & 48 & 80 \\
\hline Kishimundu Secondary School & 0492 & 64 & 14 & 22 & 50 & 78 \\
\hline Kisomachi Secondary School & 0474 & 39 & 5 & 13 & 34 & 87 \\
\hline Lombeta Secondary School & 0371 & 48 & 5 & 11 & 43 & 89 \\
\hline Majengo Secondary School & 0485 & 330 & 192 & 58 & 138 & 42 \\
\hline Marangu Secondary School & 0388 & 118 & 66 & 56 & 52 & 44 \\
\hline Maua Seminary & 0130 & 34 & 34 & 100 & 0 & 0 \\
\hline Mlama Secondary School & 0508 & 59 & 26 & 44 & 33 & 56 \\
\hline Mrike Secondary School & 0504 & 43 & 5 & 12 & 38 & 88 \\
\hline Narumu Secondary School & 0557 & 56 & 39 & 70 & 17 & 30 \\
\hline Nsoo Secondary School & 0480 & 80 & 36 & 45 & 44 & 55 \\
\hline Olaleni Secondary School & 0499 & 66 & 55 & 83 & 11 & 17 \\
\hline Sangiti Secondary School & 0663 & 64 & 31 & 44 & 36 & 56 \\
\hline St. James' Seminary & 0121 & 36 & 36 & 100 & 0 & 0 \\
\hline St.Mary Goreti Secondary School & 1187 & 102 & 101 & 99 & 1 & 1 \\
\hline Ungwasi Secondary School & 0506 & 116 & 42 & 36 & 74 & 64 \\
\hline Uomboni Secondary School & 0486 & 82 & 5 & 6 & 77 & 94 \\
\hline Uru Secondary School & 0357 & 93 & 15 & 14 & 78 & 86 \\
\hline Uru Seminary & 0165 & 41 & 41 & 100 & 0 & 0 \\
\hline Usseri Secondary School & 0562 & 65 & 9 & 14 & 56 & 86 \\
\hline Visitation Girls' Secondary School & 0263 & 46 & 45 & 98 & 1 & 2 \\
\hline
\end{tabular}

NB. On Division I-III is included in the pass mark in this work. Division IV_0 is counted as failure. 2011 National Form Four (The $4^{\text {th }}$ Year) National Exam Results for Moshi High Schools 
2011 National Form IV Exam Results - Moshi Catholic Schools

\begin{tabular}{|c|c|c|c|c|c|c|c|c|}
\hline SCHOOL NAME & $\begin{array}{l}\text { St. } \\
\text { Anwarite } \\
\text { [G] }\end{array}$ & $\begin{array}{l}\text { Kibosho } \\
\text { [G] }\end{array}$ & $\begin{array}{l}\text { Kiraeni } \\
\text { [G] }\end{array}$ & $\begin{array}{l}\text { Kirua } \\
{[C]}\end{array}$ & $\begin{array}{l}\text { K'mundu } \\
{[C]}\end{array}$ & $\begin{array}{l}\text { Kisomachi } \\
\text { [C] }\end{array}$ & $\begin{array}{l}\text { Lombeta } \\
{[\mathrm{C}]}\end{array}$ & $\begin{array}{l}\text { Majengo } \\
{[\mathrm{C}]}\end{array}$ \\
\hline $\begin{array}{l}\text { TOTAL No OF } \\
\text { CANDIDATES }\end{array}$ & 57 & 167 & 151 & 94 & 58 & 72 & 151 & 348 \\
\hline \%PASSED & 91 & 83 & 61 & 6 & 7 & 0 & 0 & 37 \\
\hline \%FAILED & 9 & 17 & 39 & 94 & 93 & 100 & 100 & 63 \\
\hline $\begin{array}{l}\text { SCHOOL } \\
\text { NAME }\end{array}$ & $\begin{array}{l}\text { Mlama } \\
{[C]}\end{array}$ & $\begin{array}{c}\text { Mrike } \\
\text { [C] }\end{array}$ & $\begin{array}{l}\text { Narumu } \\
\text { [C] }\end{array}$ & Nsoo[C] & Osale [C] & $\begin{array}{l}\text { Sangiti } \\
{[\mathrm{C}]}\end{array}$ & $\begin{array}{l}\text { St. } \\
\text { James } \\
\text { [B] }\end{array}$ & $\begin{array}{l}\text { St. } \\
\text { Mary } \\
\text { Goreti } \\
\text { [C] }\end{array}$ \\
\hline $\begin{array}{l}\text { TOTAL No OF } \\
\text { CANDIDATES }\end{array}$ & 60 & 32 & 82 & 68 & 81 & 50 & 40 & 159 \\
\hline \% PASSED & 57 & 1 & 51 & 35 & 42 & 60 & 90 & 93 \\
\hline$\%$ FAILED & 43 & 99 & 49 & 65 & 58 & 40 & 10 & 7 \\
\hline $\begin{array}{l}\text { SCHOOL } \\
\text { NAME }\end{array}$ & $\begin{array}{l}\text { Visitatio } \\
\text { n [G] }\end{array}$ & $\begin{array}{l}\text { Uru } \\
\text { Sem. } \\
\text { [B] }\end{array}$ & $\begin{array}{l}\text { Uru } \\
\text { Sec. [C] }\end{array}$ & Usseri [C] & $\begin{array}{l}\text { Maua } \\
\text { Sem. [B] }\end{array}$ & $\begin{array}{l}\text { Uombon } \\
\text { i [C] }\end{array}$ & $\begin{array}{l}\text { Marang } \\
\text { u [C] }\end{array}$ & $\begin{array}{l}\text { Ungwa } \\
\text { si [C] }\end{array}$ \\
\hline $\begin{array}{l}\text { TOTAL No OF } \\
\text { CANDIDATES }\end{array}$ & 79 & 44 & 72 & 51 & 32 & 94 & 116 & 127 \\
\hline \% PASSED & 90 & 100 & 19 & 8 & 100 & 4 & 39 & 8 \\
\hline$\%$ FAILED & 10 & 0 & 86 & 92 & 0 & 81 & 61 & 96 \\
\hline
\end{tabular}

NOTE: Use the recent results to establish beyond doubt that student underachievement is a real problem in the participants' schools. 


\begin{tabular}{|c|c|c|c|c|c|c|c|}
\hline \multicolumn{8}{|c|}{$\begin{array}{l}\text { Table } 2 \\
\text { The Form Four National Exam Results for 2000-2009 }\end{array}$} \\
\hline \multirow[t]{2}{*}{ Year } & \multicolumn{4}{|c|}{ Division } & \multirow{2}{*}{$\begin{array}{l}\text { Percent } \\
\text { Passed }\end{array}$} & \multirow{2}{*}{$\begin{array}{c}\text { Percent } \\
\text { Failed }\end{array}$} & \multirow{2}{*}{$\begin{array}{l}\text { Total No o } \\
\text { Candidates }\end{array}$} \\
\hline & 1 & II & III & IV & & & \\
\hline 2000 & 4.1 & 5.7 & 16.0 & 52.6 & 78.4 & 21.6 & 47389 \\
\hline 2001 & 4.5 & 5.7 & 18.2 & 49.1 & 77.4 & 22.6 & 50820 \\
\hline 2002 & 6.4 & 8.2 & 21.6 & 50.1 & 86.3 & 13.7 & 49512 \\
\hline 2003 & 7.2 & 7.3 & 23.6 & 50.0 & 88.1 & 12.0 & 62359 \\
\hline 2004 & 4.8 & 8.4 & 24.6 & 53.7 & 91.5 & 8.5 & 63487 \\
\hline 2005 & 5.2 & 6.5 & 21.9 & 55.7 & 89.3 & 10.7 & 85292 \\
\hline 2006 & 4.5 & 6.9 & 24.3 & 53.4 & 89.1 & 10.9 & 85865 \\
\hline 2007 & 5.1 & 8.6 & 21.9 & 54.7 & 90.3 & 9.7 & 125288 \\
\hline 2008 & 3.5 & 6.4 & 16.8 & 56.9 & 83.6 & 16.3 & 163855 \\
\hline 2009 & 1.9 & 4.4 & 11.6 & 54.7 & 72.5 & 27.5 & 248336 \\
\hline
\end{tabular}

Note: Although the Ministry of Education counts students with Division IV as passed, thus making the pass rate percentage high, this study excludes Division IV from the 


\section{NOTICE: DATA COLLECTION}

Use the space below to write your observations, participants' comments; things you would like to change/modify/add for the next session. Write any data you need to remember for your writing. 


\section{Day Two - Session Two}

Tell me and I'll forget; show me and I may remember; involve me and I'll understand.

Chinese proverb

* What are the factors that make quality teaching and learning? Lecture on the

Dimensions of Effective Teaching by Fink \& Markholt (2011).

* Write down the feedback

* Communicate the feedback to the teacher

* Formative assessment of the session

* Data Collection Sheet. 


\section{Best Practice: Dimensions of Teaching Things principals should know about teaching and learning.}

There are five basic things which must be demonstrated by any competent teacher. When the principal is doing instructional evaluation, these 5 dimensions are the indicators of the teacher's quality instruction in the classroom. The principal has a choice to focus on one or more indicators per every visit he/she makes, formulate feedback and communicate that feedback in the form of collaborative discussion. The purpose has to be very clear that it is to enhance and provide support to ensure quality instruction.

\begin{tabular}{|c|c|}
\hline \multicolumn{2}{|c|}{ Figure 4: 5 Dimensions and 13 Sub-dimensions } \\
\hline Five Dime & ions and Thirteen Sub-dimensions of Teaching and Learning \\
\hline $\begin{array}{l}\text { 1. Purpose: } \\
\text { Pay attention to } \\
\text { ways that the } \\
\text { lesson purpose is } \\
\text { made clear in the } \\
\text { context of the } \\
\text { lesson and the } \\
\text { extent to which } \\
\text { the lesson is } \\
\text { meaningful and } \\
\text { relevant to } \\
\text { standards and } \\
\text { teaching points. }\end{array}$ & $\begin{array}{l}\text { Standards } \\
\text { - Clearly articulated, connected to external standards as stipulated in } \\
\text { the Ministry of Education syllabus for what students should know } \\
\text { and be able to do } \\
\text { - The lesson is based on standards that are meaningful and relevant } \\
\text { beyond the task at hand [for example, related to a broader purpose } \\
\text { or context such as problem solving, citizenship, community serving, } \\
\text { patriotic spirit, nationalism, equity, peace and justice issues and so } \\
\text { on] and help the student learn and apply transferable knowledge } \\
\text { and skills } \\
\text { - Lesson is intentionally linked to other lessons previously covered or } \\
\text { will be taught in the future in support of students meeting the } \\
\text { required standards } \\
\text { - How the lesson is applicable to the real life of students out in the } \\
\text { world }\end{array}$ \\
\hline
\end{tabular}




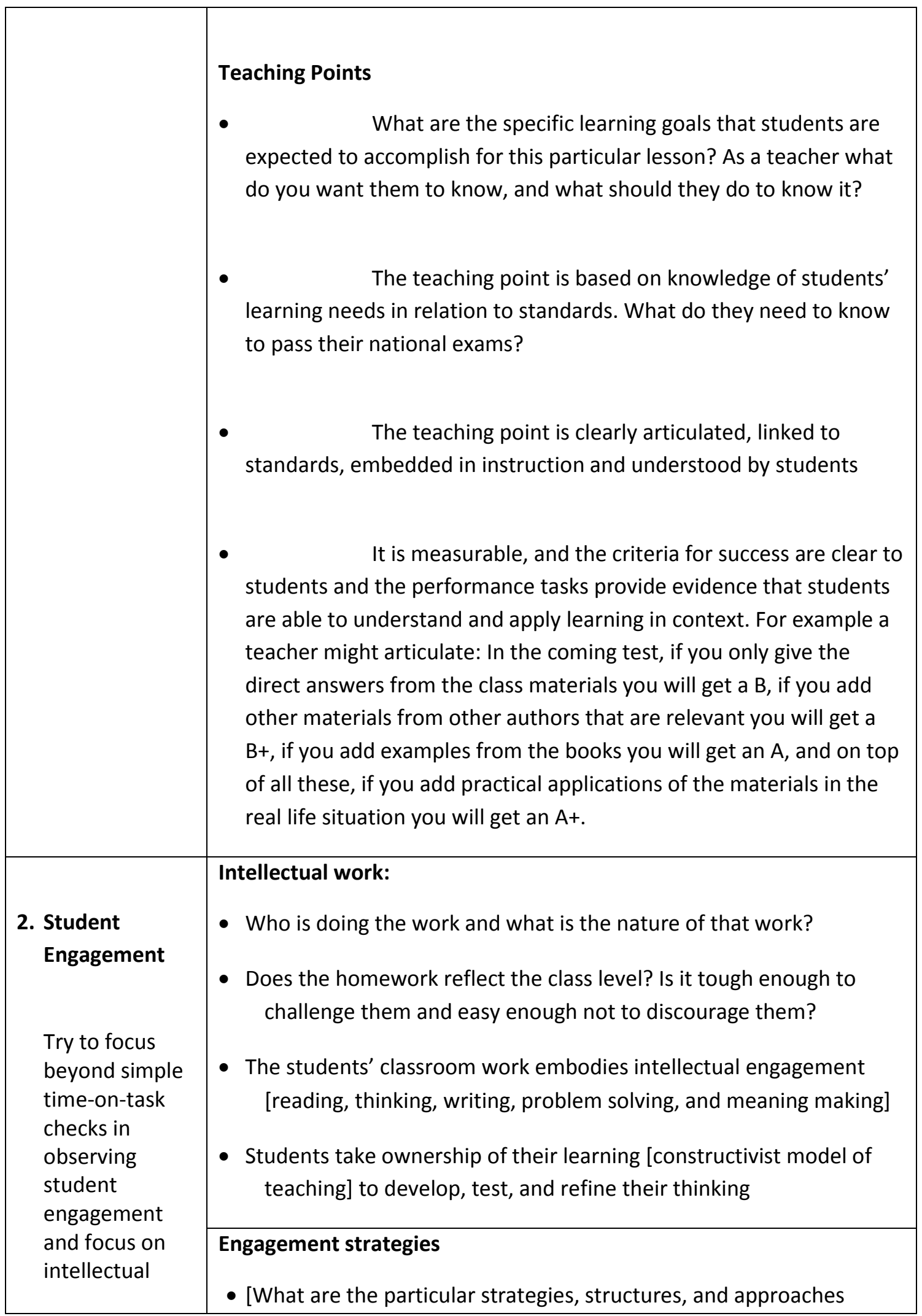




\begin{tabular}{|c|c|}
\hline $\begin{array}{l}\text { works, } \\
\text { strategies used } \\
\text { for } \\
\text { engagement } \\
\text { and how } \\
\text { students talk in } \\
\text { this class }\end{array}$ & $\begin{array}{l}\text { teacher is using to engage students? - Things like picking students } \\
\text { randomly to answer a question, form brief peer sharing of ideas, } \\
\text { small groups' discussion to process information and encourage } \\
\text { after class group discussion among students to demonstrate what } \\
\text { they have learned and learn from the peers. } \\
\text { - Engagement strategies capitalize and build on students' background } \\
\text { knowledge [a good use of students' funds of knowledge], } \\
\text { experience and responses to support rigorous and culturally } \\
\text { relevant learning. } \\
\text { - Engagement strategies encourage equitable and purposeful student } \\
\text { participation and ensure that all students have access to, and are } \\
\text { expected to participate in learning. [For example, a teacher might } \\
\text { articulate that active participation in his class will be observed and } \\
\text { will have } 10 \text { points in the final grade] }\end{array}$ \\
\hline & $\begin{array}{l}\text { Talk } \\
\text { - Try to answer the question: What is the substance of student } \\
\text { engagement as embodied in communication between and } \\
\text { among students and between students and the teacher? } \\
\text { - Student talk that reflects discipline-specific habits of thinking and } \\
\text { ways of communicating [business terminologies in the business } \\
\text { class, biological terms in the normal conversation in the } \\
\text { biological class, etc.] } \\
\text { - Student talk embodies substantive and intellectual thinking }\end{array}$ \\
\hline $\begin{array}{l}\text { 3. Curriculum and } \\
\text { Pedagogy } \\
\text { Teacher shows } \\
\text { instructional } \\
\text { strategies and } \\
\text { style that ensures } \\
\text { quality teaching; } \\
\text { observing the }\end{array}$ & $\begin{array}{l}\text { Curriculum /Syllabus } \\
\text { - Assessing the instructional materials e.g. texts, tasks, aligned with } \\
\text { the lesson plan } \\
\text { - Match the texts with those recommended by the Ministry of } \\
\text { Education and National Examination Council of Tanzania [NECTA] } \\
\text { - Instructional materials [e.g., texts, resources] and task are } \\
\text { appropriately challenging and supportive to all students and are } \\
\text { aligned with the teaching point and content area standards and }\end{array}$ \\
\hline
\end{tabular}




\begin{tabular}{|c|c|}
\hline \multirow[t]{3}{*}{$\begin{array}{l}\text { national } \\
\text { curriculum } \\
\text { suggested by the } \\
\text { ministry of } \\
\text { education syllabi } \\
\text { and meeting the } \\
\text { required } \\
\text { standards. }\end{array}$} & $\begin{array}{l}\text { culturally and academically relevant } \\
\text { - The lesson materials and tasks are related to a larger unit and to the } \\
\text { sequence and development of conceptual understanding over time. } \\
\text { - The lesson material fulfill the dual purpose of education in Tanzania } \\
\text { at secondary school level: prepare the student for higher education } \\
\text { according to the given standards and make them productive citizens } \\
\text { ready to serve their community } \\
\text { - There is a relevant connection between the lesson materials and } \\
\text { the real life situation of the students, and appropriately challenge } \\
\text { the student to analyze and figure out their daily living situations. }\end{array}$ \\
\hline & $\begin{array}{l}\text { Teaching approaches and strategies } \\
\text { - Identifying what pedagogies are used and how instructions reflect } \\
\text { pedagogical content knowledge } \\
\text { - The teacher makes decisions and uses instructional approaches in } \\
\text { ways that intentionally support the instructional purposes. } \\
\text { - Instruction reflects and is consistent with pedagogical content } \\
\text { knowledge and is culturally responsive in order to engage students } \\
\text { in disciplinary habits of thinking } \\
\text { Teaching approach is consistent with the national instructional } \\
\text { policy [student centered constructivism pedagogical model] to meet } \\
\text { the national teaching standards }\end{array}$ \\
\hline & $\begin{array}{l}\text { Scaffolds for learning: } \\
\text { - Observing how the teacher balances the interplay of explicit } \\
\text { teaching, scaffolding for the gradual release of responsibility and } \\
\text { for students choice and ownership } \\
\text { - The teacher uses different instructional strategies based on planned } \\
\text { and in-the-moment decisions to address individual learning needs } \\
\text { - Using teaching strategies that honor the individual student's talents } \\
\text { and pace of learning with the mindset that no one frame that fits all } \\
\text { - Encourage and offer tips and support for students' group learning at } \\
\text { their private study times -for both the boarding and commuter }\end{array}$ \\
\hline
\end{tabular}




\begin{tabular}{|c|c|}
\hline & students \\
\hline 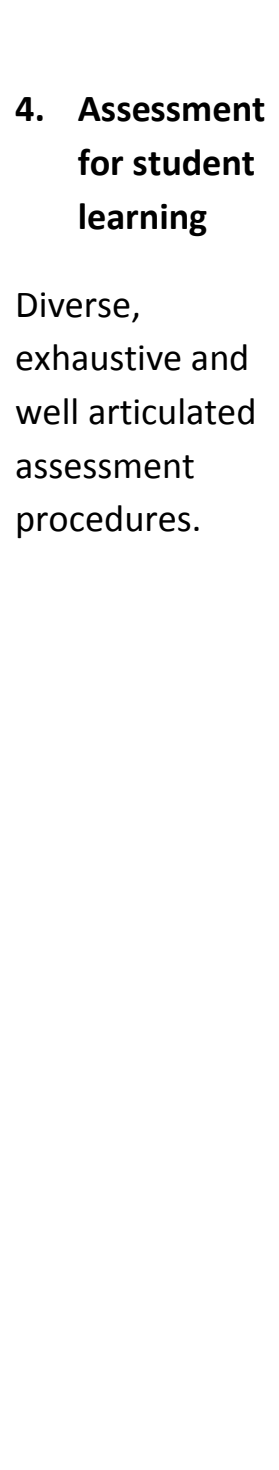 & $\begin{array}{l}\text { Assessments - different ways: } \\
\text { - Look for the ways teachers expect students to demonstrate learning } \\
\text { in relation to the lesson objectives, specific content demands and } \\
\text { transferable skills. } \\
\text { - Student being part of own assessment in relation to the teaching } \\
\text { point. } \\
\text { - Criteria of assessment are clearly articulated and communicated to } \\
\text { students to be aware of what the expectations are in the learning } \\
\text { process } \\
\text { - Teacher creating multiple assessment opportunities, expect all } \\
\text { students to demonstrate learning } \\
\text { - Assessment methods and tools have to be efficient to gather } \\
\text { comprehensive and quality information about the learning style and } \\
\text { the needs of each student. Evidence to support the assessment of } \\
\text { individual student is encouraged such as anecdotal notes, } \\
\text { conferring, student work samples, and previous academic } \\
\text { recognition either from the class, the school, the region or national. } \\
\text { - The teacher using observable systems and routines for recording } \\
\text { and using student assessment data such as charts, conferring } \\
\text { records, portfolio and rubrics } \\
\text { - Keep track and communicate to the individual student his/her } \\
\text { why he/she thinks that progress happened or did not happen. }\end{array}$ \\
\hline
\end{tabular}




\begin{tabular}{|c|c|}
\hline \multirow{4}{*}{$\begin{array}{l}\text { 5. Classroom } \\
\text { environment } \\
\text { and culture } \\
\text { Classroom } \\
\text { arrangement } \\
\text { ensures safety, } \\
\text { accessibility, } \\
\text { enhances learning } \\
\text { and minimizes } \\
\text { distraction. }\end{array}$} & $\begin{array}{l}\text { - Assessment criteria, methods, and purpose are transparent and } \\
\text { students have a role in their own assessment to promote learning }\end{array}$ \\
\hline & $\begin{array}{l}\text { - Injustments: } \\
\text { - Instructional decisions or moves made in the moment to better } \\
\text { during the course of the lesson. } \\
\text { - The teacher plans instruction based on ongoing assessment and an } \\
\text { understanding of students, standards, texts, tasks, and pedagogical } \\
\text { content knowledge. } \\
\text { - Teacher makes in-the-moment instructional adjustments based on } \\
\text { student understanding, e.g., teacher might choose to make a } \\
\text { revision of the previous lesson if he/she discovers that students do } \\
\text { not have the necessary pre-requisite knowledge for the current } \\
\text { lesson to be understood; might change the homework to fit into } \\
\text { more understanding of the lesson materials, etc. }\end{array}$ \\
\hline & $\begin{array}{l}\text { Use of Physical Environment } \\
\text { - How teachers use resources and space to purposefully support and } \\
\text { scaffold student learning] } \\
\text { - The physical arrangement of the classroom (for example, the } \\
\text { meeting area, desk arrangement and student seating, visibility of } \\
\text { the teaching resources to all students, teacher's desk location, and } \\
\text { so on). } \\
\text { - The teacher uses the physical space of the classroom to assess } \\
\text { student understanding and support learning (for example, teacher } \\
\text { moves around the room to observe and confer with students; } \\
\text { teacher is in a position where he/she can see all the students in the } \\
\text { room). }\end{array}$ \\
\hline & \\
\hline
\end{tabular}




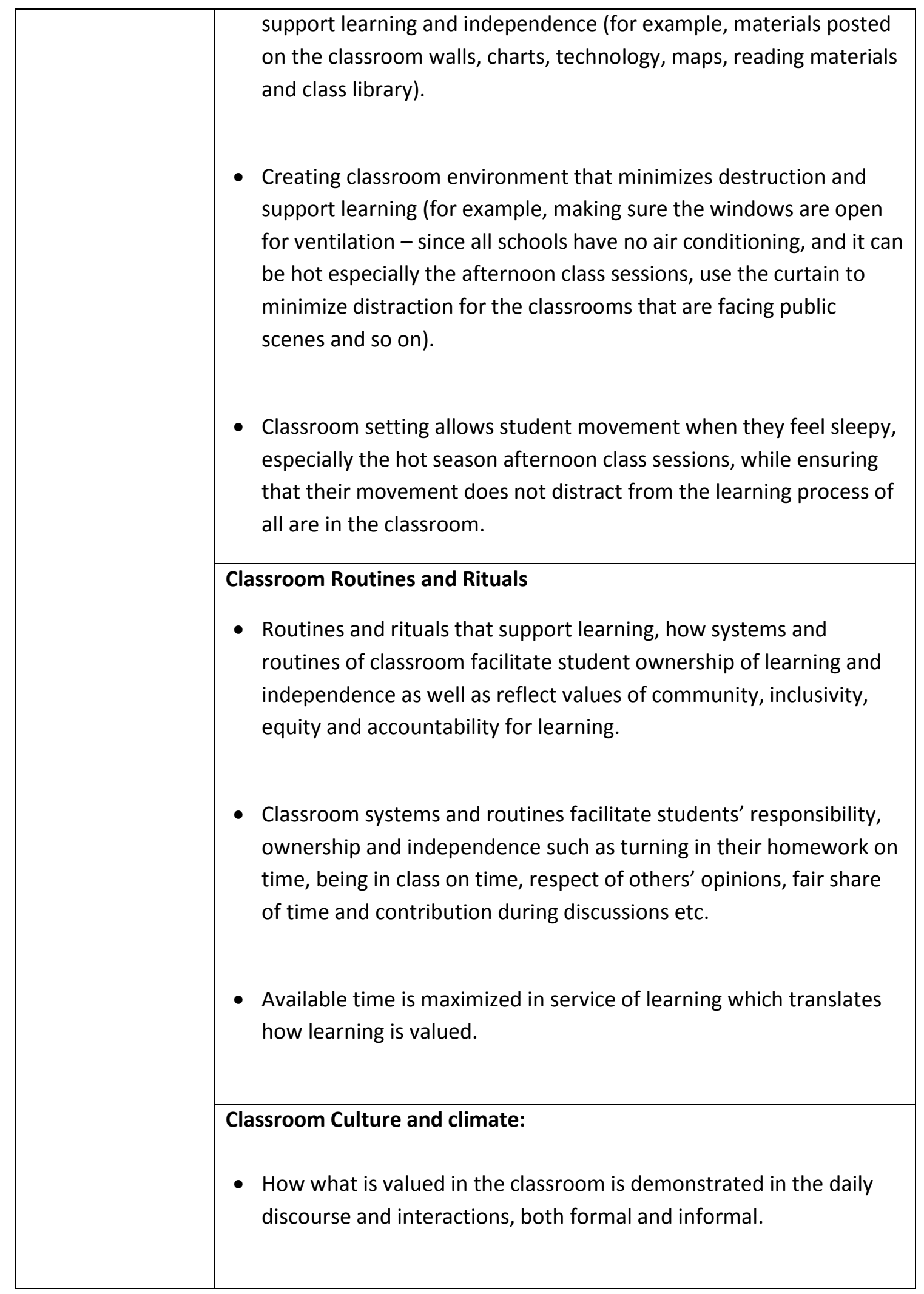




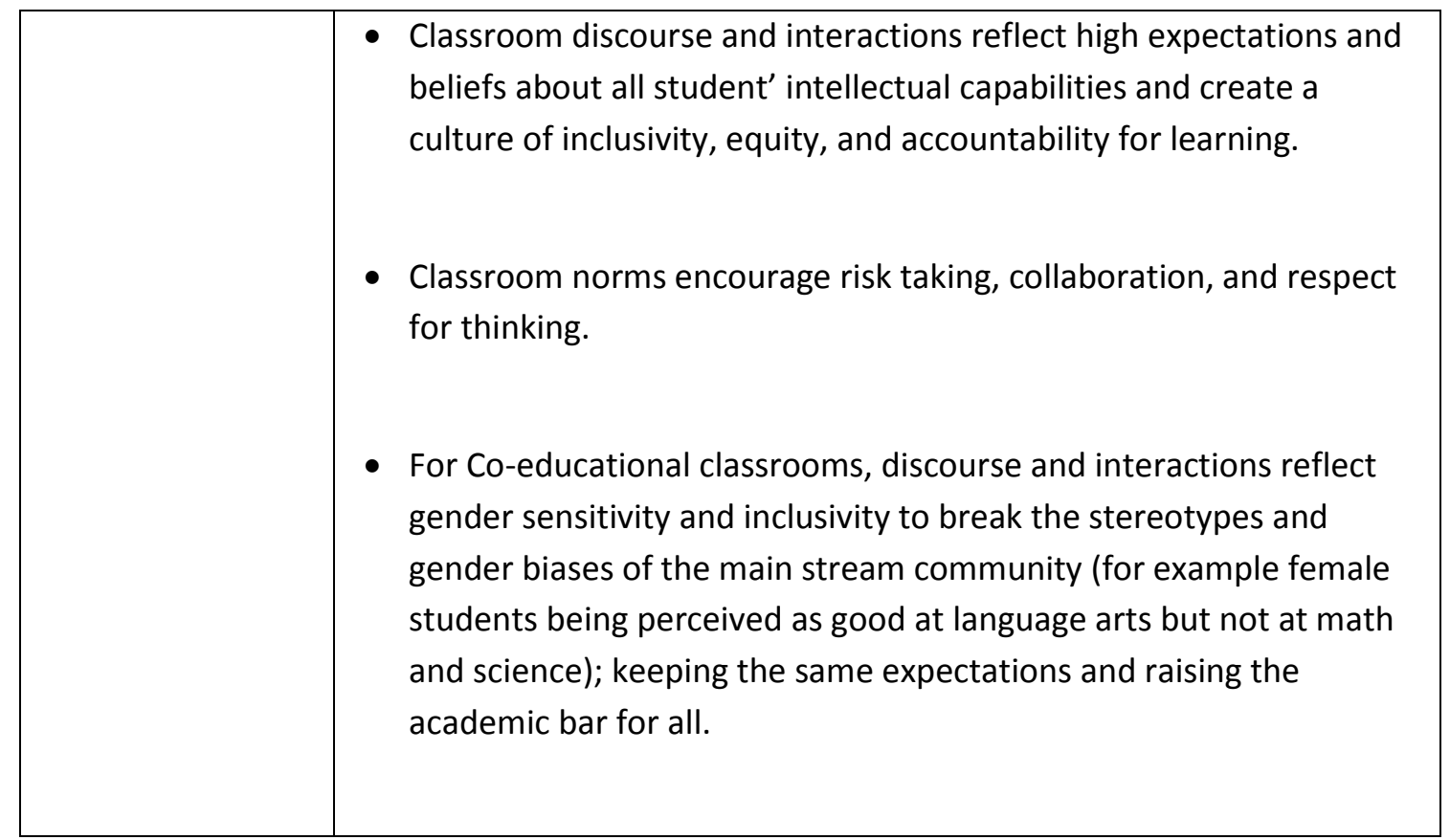

Adopted from the classroom instruction evaluation model of Fink and Markholt (2011)

\section{Formative Assessment as on Pg. 223}




\section{NOTICE: DATA COLLECTION}

Use the space below to write your observations, participants' comments; things you would like to change/modify/add for the next session. Write any data you need to remember for your writing. 


\section{Day Two - Session Three}

\section{Education is the most powerful weapon which you can use to change the world.}

Nelson Mandela

It is impossible for a man to learn what he thinks he already knows. Epicletus

* Group Discussion and presentations on Quality Teaching using Fink and Markholt's 5 Dimensions of effective teaching - Group process after the lecture of the last session. The intention to all the participants to digest and personalize the information.

* Lecture on Conceptual Representation of ESCI Dynamics: How the teacher and the principal interact in the process of teacher evaluation using both instructional and transformation leadership models to promote both professional and personal growth of the teacher in view of improving pedagogical skills and commit to quality teaching and learning. The anticipated result is quality teaching and learning for student achievement.

* Formative and Talk Back assessment about the session

* Talk Back assessment about the whole day 


\section{Conceptual Representation of Transformational and Instructional Leadership} and Teacher Evaluation Process

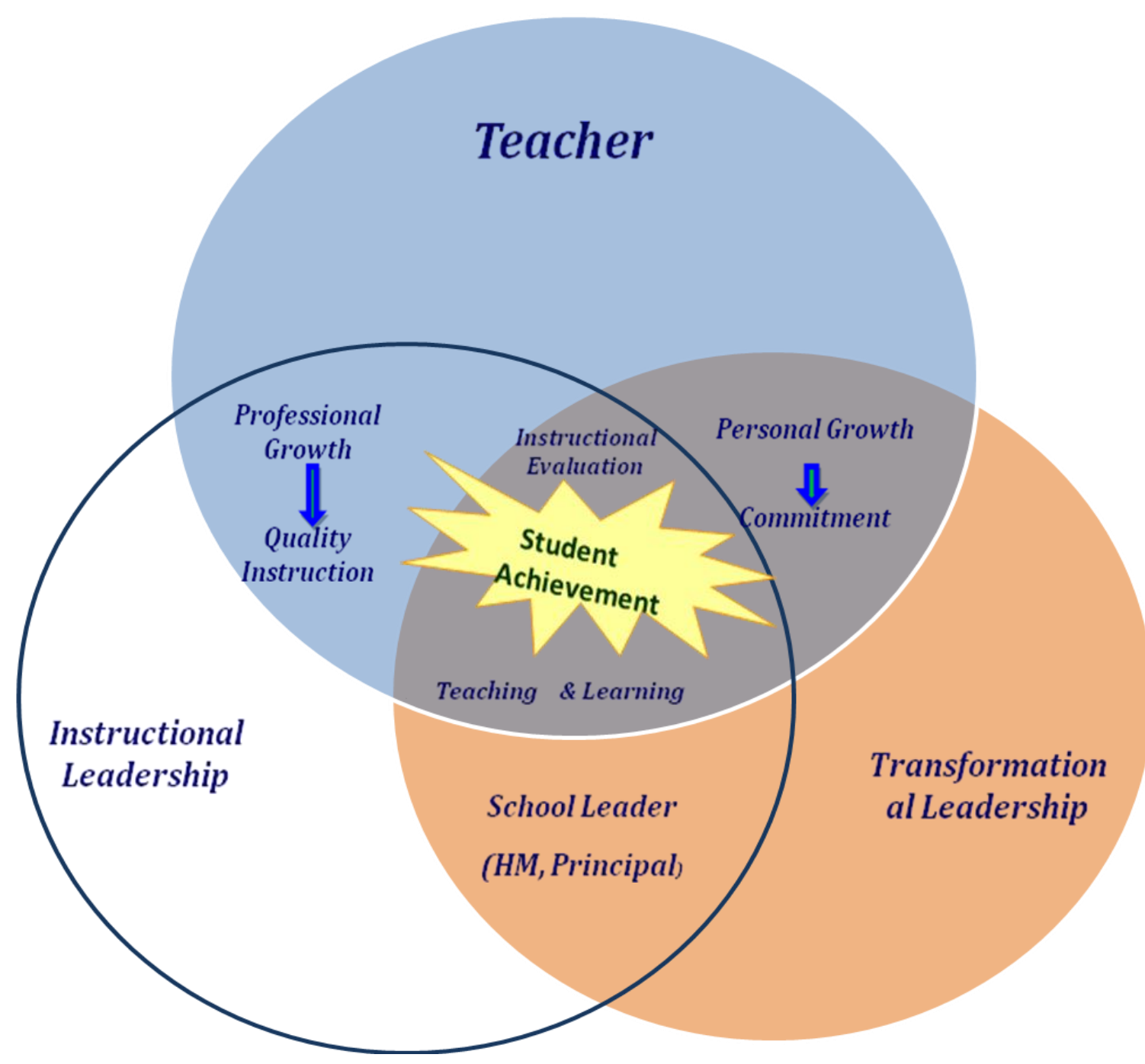

Blasé \& Blasé, 2004; Bass \& Riggio, 2006 
Conceptual Representation of Instructional and Transformational Leadership and ESCI

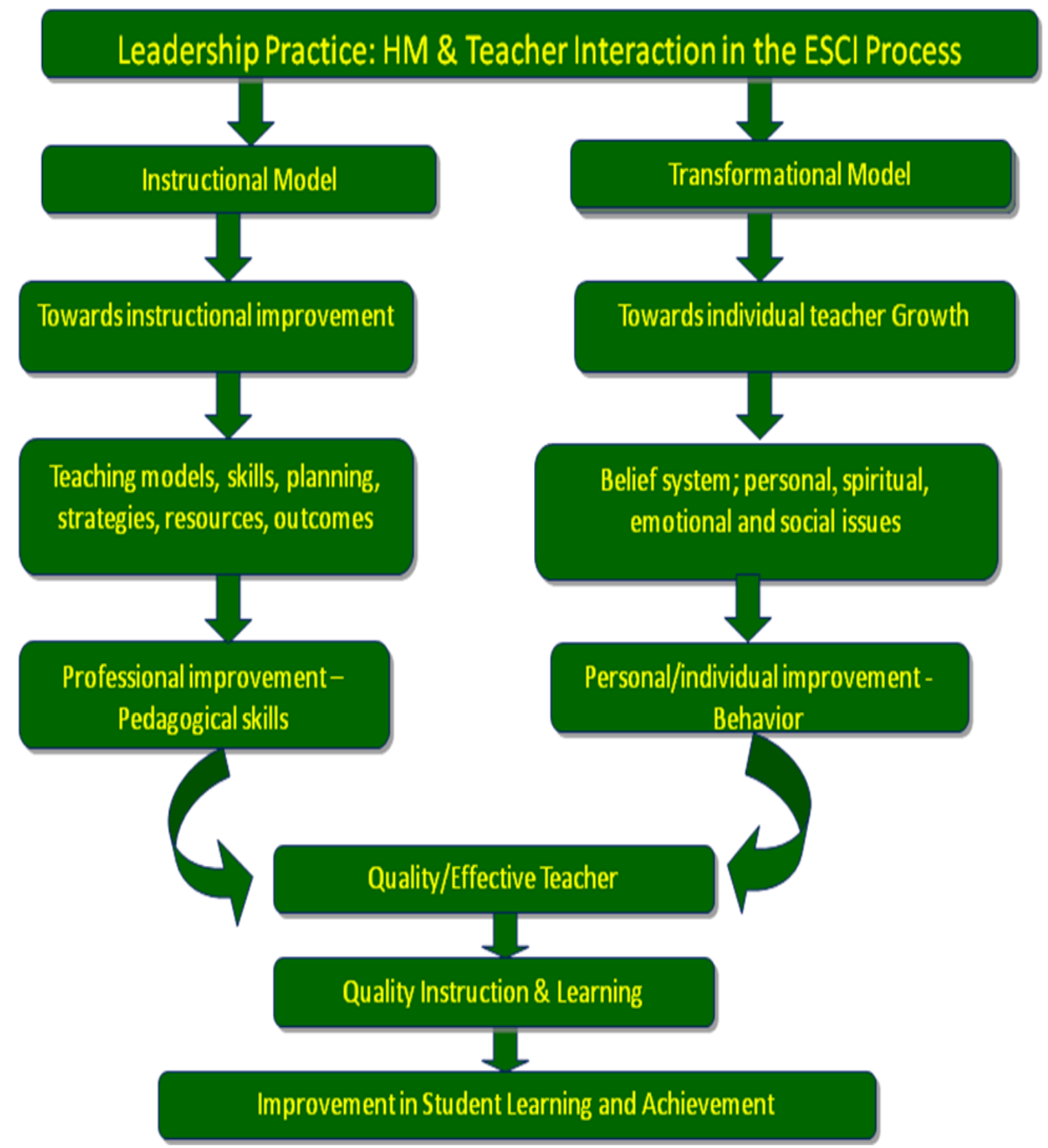

Glanz, 2006; Blasé \& Blasé, 2007 


\section{Marshal's Teacher evaluation Model}

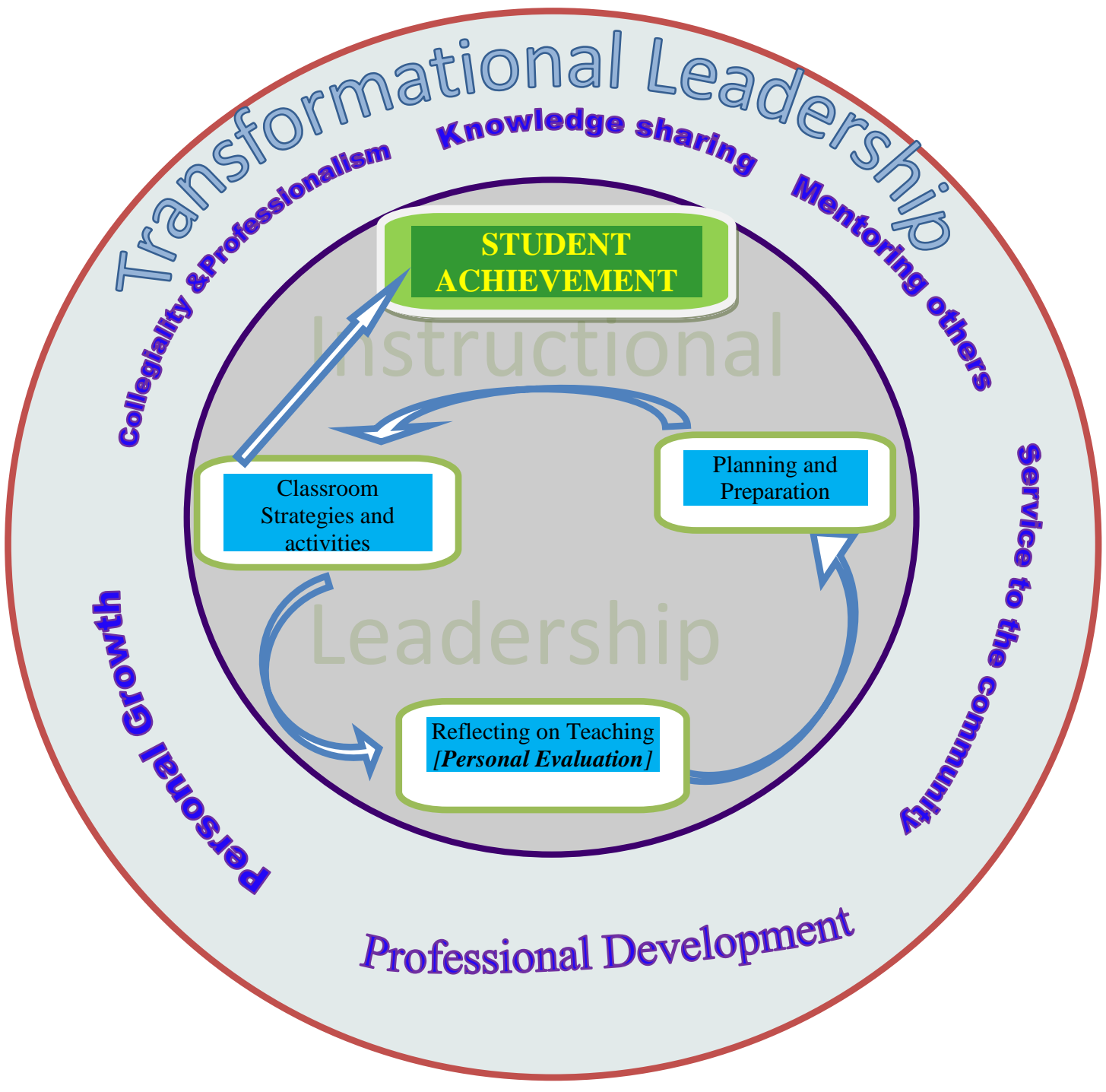

Source: Marshall, 2009

Formative Assessment as on Pg. 223 and "Talk back" assessment as on Pg. 248 


\section{NOTICE: DATA COLLECTION}

Use the space below to write your observations, participants' comments; things you would like to change/modify/add for the next session. Write any data you need to remember for your writing. 


\section{Day Three - Session One}

\section{It is in fact a part of the function of education to help us escape, not from our own time - for we are bound by that - but from the intellectual and emotional limitations of our time. T.S. Eliot}

* DANIELSON'S TEACHING DOMAINS - Domain 1: In the small groups

- Give a general overview of Domain 1

- Groups to discuss the contents of Domain 1 in the context of their schools.

- What will work in your school and why?

- What won't work and why?

- What will you remove from the rubrics and why?

- What will you add to the rubrics and why?

* Presentations in the Cohort Group: Identify what was added or removed from all the groups to make one comprehensive list for the entire cohort group.

* Questions

* Formative assessment of the session

* Data Collection Sheet 


\section{FOUR DOMAINS OF TEACHING RESPONSIBILITY}

These four domains contain rich and diverse materials which will help the HM in the process of teachers' instructional supervision and evaluation. Remember, you do not have to get all these instructional positive elements of your teacher in the single evaluation. It will take time for the teacher to demonstrate these in a variety of settings. These domains represent the highest qualities of the teacher and it is hard to get a teacher who will demonstrate them exactly the way they are. However, since you know what the highest qualities are, it will help you, the head of the school and instructional activities, to help your teacher towards these highest qualities of their professionalism.

The following domains are adopted from Danielson (2007).

\section{A CONTENT OF THE DANIELSON'S TEACHING DOMAINS:}

DOMAIN 1: Planning and Preparation

Demonstrating Knowledge of Content and Pedagogy: content and lesson structure, knowledge of prerequisite materials and their relationship to the lesson and other content related materials.

- Knowledge of the content and the structure of the discipline: Teacher displays the extensive knowledge of the key concepts of the discipline and their relationships to one another and other disciplines and how is it also related to the real life. While teacher allows the students to contrast their personal understanding of the concepts, the teacher demonstrates mastery of the content of the discipline and scaffolds the students in the mastery of the same contents.

- Knowledge of prerequisite relationships: Teacher's plans and practices demonstrate understanding of prerequisite relationships among topic and concepts and link to one other to ensure students' cognition and understanding not only of the concepts but also of their relationships.

- Knowledge of content-related pedagogy: competence in the discipline and demystify the myth and misconceptions of the students. Teacher's plans and practices reflect familiarity with wide range of effective pedagogical approaches in the discipline, anticipating students' misconceptions and addressing them to ensure clarity and understanding of the contents.

Demonstrating Knowledge of Students- the teacher should demonstrate the knowledge of:

- Materials appropriate to the student: age, class level and in accordance with the required standards, and of the individual students. Since students learn differently, knowledge of each student is important. 
- Learning process: how each student learns, appropriate strategies and applying this to students.

- Student's funds of knowledge: their already learned skills, knowledge, English language level and life experience. These are important to help students construct their own knowledge.

- Interest and cultural/tribal heritage: student's values, taboos - unique to the tribe or similar to other tribes; what is common and what is different. E.g. Chagga and Massai tribes.

- Student's special needs: learning, medical, social or physical

\section{Setting instruction outcomes}

- Value, sequence, and alignment - high expectations and rigor, connected to other disciplines, future lessons and life experience [remember Tanzania educational policy: education for self reliance]

- Clarity- all the outcomes are clear, written in the form of student's learning with varied assessments and student demonstrates understanding of the learning outcomes.

- Balance - they reflect different types of learning, respect both coordination and integration

- $\quad$ Suitability for diverse learners -awareness of diversity of individual learner or group and use comprehensive assessment that respects their unique way of learning.

\section{Demonstrating Knowledge of Resources}

- $\quad$ Resources for classroom use - available and accessible through the class, school, library, book store etc

- Resources to extend content knowledge and pedagogy - to enhance content and pedagogical knowledge, strive to excellence in content and teaching strategies and style. Teacher is not limited to what is prescribed in the Ministry of Education syllabus.

- $\quad$ Resources for students - where students can get more help, can be within school, or out.

\section{Designing Coherent Instruction}

- Learning activities: diverse to suit every learner, support the standards and outcomes; they stimulate cognitive functioning, problem solving and are adaptable to individual learners. 
- Instructional materials and resources - meet the required standards, suitable for learning, involves adequate use of technology and they engage students in a meaningful way.

- Instructional groups -appropriate to students learning and outcomes

- Lesson unit and structure- clear lesson's unit or structure, adaptable to students' diverse needs and theories [heads on] and activities [hands on] are compatible.

\section{Designing Student Assessments}

- Congruence with instructional outcomes - assessment is fully aligned with outcomes, content and process and is adaptable to individual students [no one frame fits all], fair and balanced. They should also meet or exceed the national standard outcomes.

- $\quad$ Criteria and standards- are clear, including student's contribution in its development. Students should know what is expected of them and have the right to ask for clarification.

- Design of formative assessments - formative design which uses both teacher and student information. Intention is to capture all the necessary information of student learning development.

- Use for planning - Future instructional plans for individual students is based on the past assessment. It can also be used for group planning or the whole class at large.

Note: Classroom instructional domains adopted from Danielson,( 2007).

\section{Formative Assessment as on Pg. 223}




\section{NOTICE: DATA COLLECTION}

Use the space below to write your observations, participants' comments; things you would like to change/modify/add for the next session. Write any data you need to remember for your writing. 


\section{Day Three - Session Two}

Education is the great engine of personal development. It is through education that the daughter of a peasant can become a doctor, that a son of a mineworker can become the head of the mine: that a child of farm workers can become the president of a great nation. It is what we make out of what we have, not what we are given, that separates one person from another. Nelson Mandela

* DANIELSON'S TEACHING DOMAINS - Domain 2: In the small groups

- Give a general overview of Domain 1

- Groups to discuss the contents of Domain 1 in the context of their schools.

- What will work in your school and why?

- What won't work and why?

- What will you remove from the rubrics and why?

- What will you add to the rubrics and why?

* Presentations in the Cohort Group: Identify what was added or removed from all the groups to make one comprehensive list for the entire cohort group.

* Questions

* Formative assessment of the session

* Data Collection Sheet 
Domain 2 - The Classroom Environment
Creating an environment of respect and rapport - teacher interaction with students \& student interaction with other students.
- Teacher interaction with students - shows genuine respect and caring for individuals as well as the group of students. Student respect is not forced by punishment but is present with or without it. Students seem to trust the teacher with sensitive information.

- Student interaction with each other: Student demonstrates genuine caring for each other, share study materials, support each other in the academic and social life, participate actively in the group studies and help each other to excel, correct each other respectively when needed, feel free to ask for help when needed from each other, and holding each other accountable. Dean of students can be instrumental to help the HM nurture this kind of spirit.

Establishing a culture of learning: Content of instructions, Expectations, and pride of work

- Importance of the content: Students demonstrate through active participation, curiosity and feeling competent to answer past national exams by using the content, and so demonstrate that they value the content. Taking notice during instruction, asking for the handout if not given, and borrowing some extra material from the teacher or library in relation to the content.

- Expectations of learning and achievement: Instructional outcomes, activities, tests, quizzes, assignments, and classroom interaction convey high expectations for all students. [The rule of thumb: pass mark should be higher than the regional and national average]. Student demonstrate the sense of having internalized this high academic standard [e.g. Students might be discontent for getting B or Division III if they learn under high expectations, while others would consider B as a victory]. Students demonstrate that substandard work is not acceptable, and seem to be enthused to meet the required high standards.

- Student pride and initiatives in work: Students demonstrate attention to detail and take obvious pride in their work, and initiating improvement for example by first doing or revising the draft work with the help of their peers, in the peer groups discussion; taking initiative to ask for extra assistance from the upper grade 


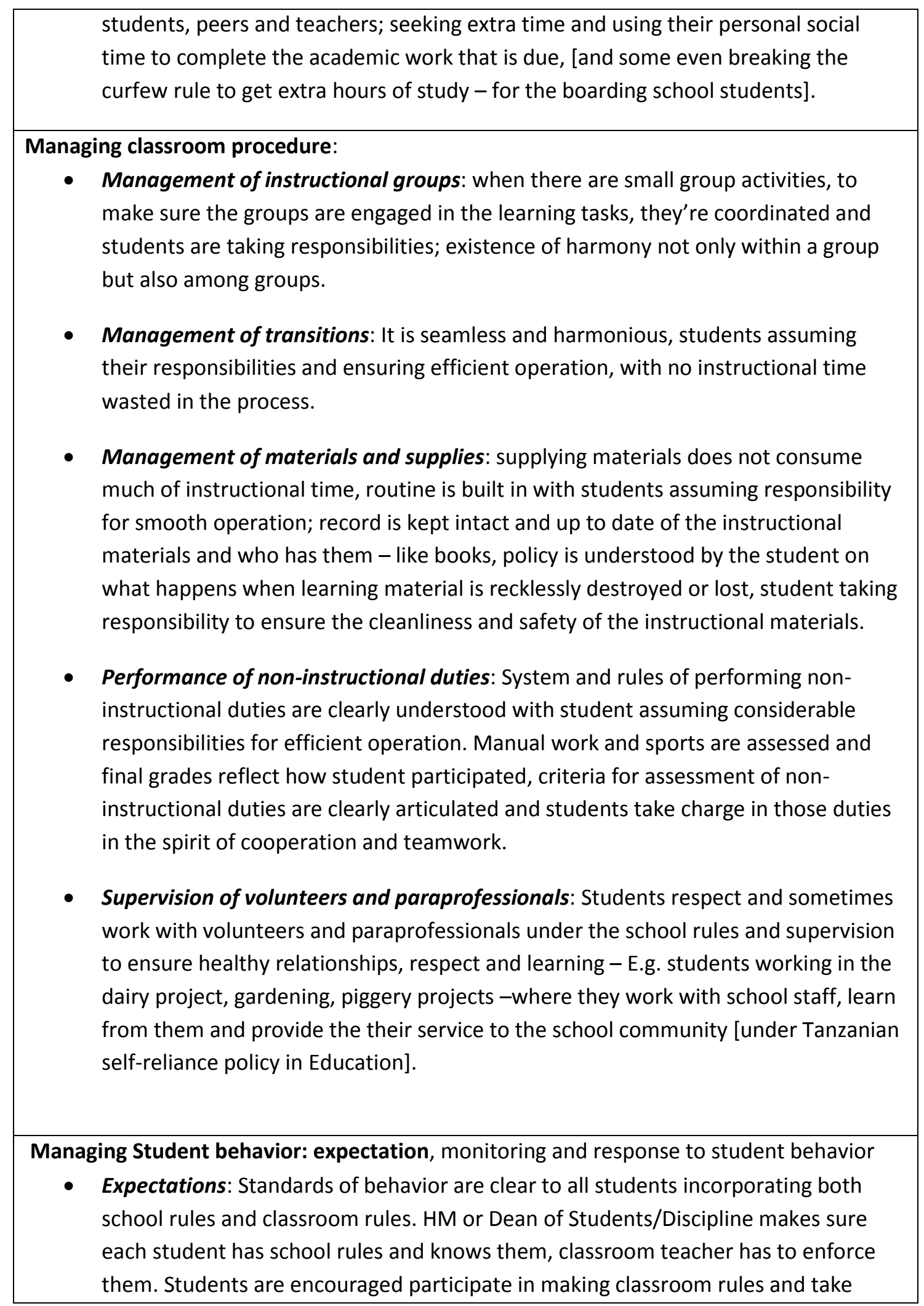




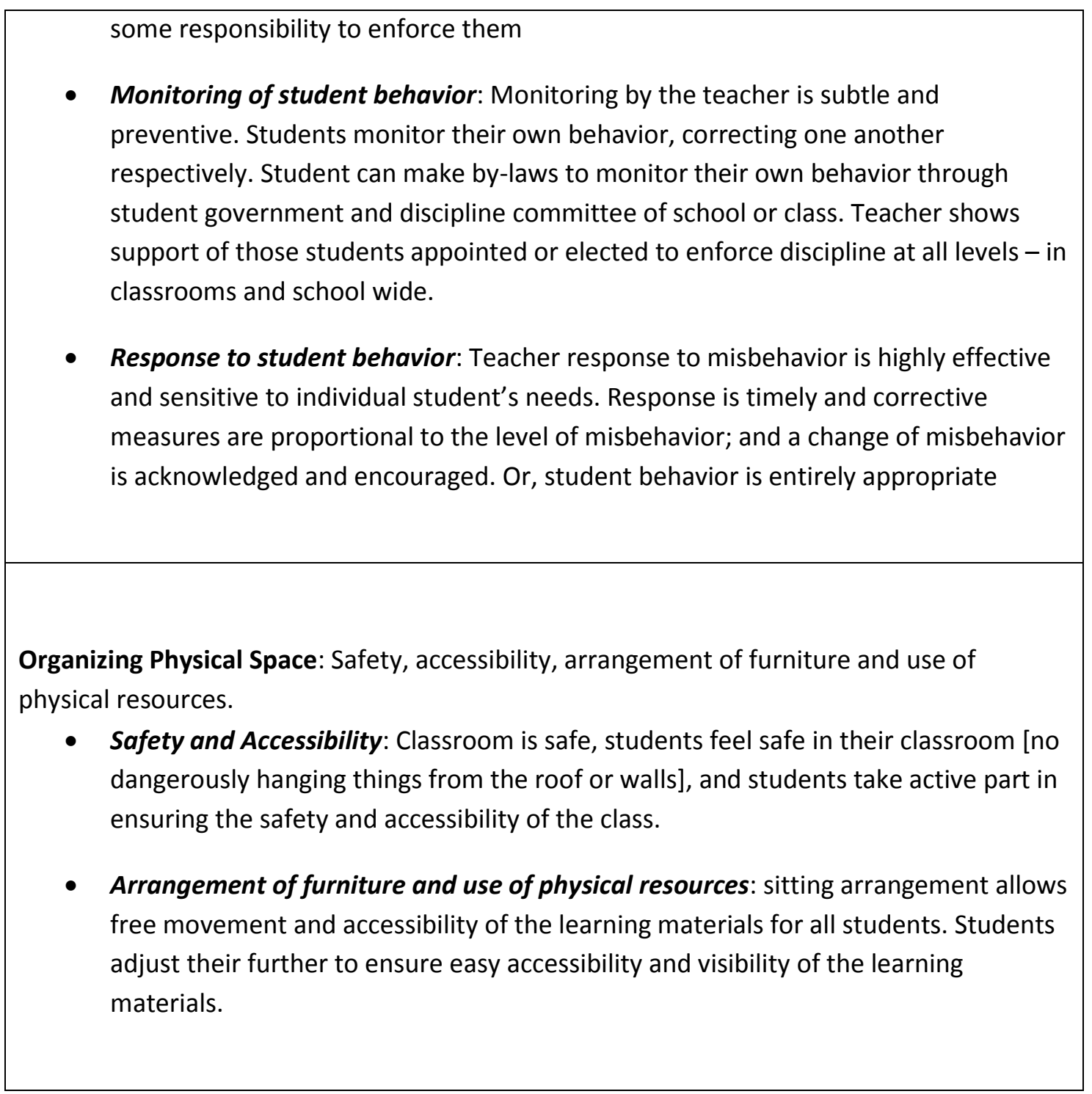

Note: Classroom instructional domains adopted from Danielson,( 2007).

Formative Assessment as on Pg. 223 


\section{NOTICE: DATA COLLECTION}

Use the space below to write your observations, participants' comments; things you would like to change/modify/add for the next session. Write any data you need to remember for your writing. 


\section{Day Three - Session Three}

I always remember the axiom: a leader... is like a shepherd. He stays behind the flock, letting the most nimble go out ahead, whereupon the others follow, not realizing that all along they are being directed from behind. Nelson Mandela

It is better to lead from behind and to put others in front, especially when you celebrate victory when nice things occur. You take the front line when there is danger. Then people will appreciate your leadership.

Nelson Mandela

* DANIELSON'S TEACHING DOMAINS - Domain 3: In the small groups

- Give a general overview of Domain 1

- Groups to discuss the contents of Domain 1 in the context of their schools.

- What will work in your school and why?

- What won't work and why?

- What will you remove from the rubrics and why?

- What will you add to the rubrics and why?

- Presentations in the Cohort Group: Identify what was added or removed from all the groups to make one comprehensive list for the entire cohort group.

* Questions

* Formative assessment of the session

* Data Collection Sheet 
Domain 3: Instruction

Commutating with Students: Expectation of learning, direction and procedure, contents explanation and the use of language both oral and written.

- $\quad$ Expectations for Learning: The purpose of the lesson or unit is made clear, including where is it situated within the broader learning, linked to student interest, how can it be used in the real world, and what students are expected to do in the learning process to get the full marks or grade at the end unit/term/school year/national exams.

- Directions and Procedures: Teacher's directions and procedures are clear to students; teacher anticipates possible misunderstanding of students and addresses it, students know the scope of their homework, contributions in the learning process and tests.

- Explanations of content: Teacher's explanation of content is imaginative and connects with student's knowledge and experience. Students contribute to explaining the concepts to their peers. Contents are connected with their application in answering the tests questions and in the real life setting. Use examples that will make sure that the content is remembered.

- Use of Oral and written language: Teacher's spoken and written language is correct and conforms to the Standard English. It is also formal with well chosen vocabularies that enrich the learning. Teacher finds opportunities to extend students' vocabulary. Every subject has its proper vocabularies [Biology, Biblical studies, Geography, etc], and so teachers encourage students to incorporate these vocabularies into their daily English conversations

Using Questioning and Discussion Techniques: questions, discussion and participation

- Quality of questions: Teacher's questions are of uniformly high quality; promote thinking, curiosity, remembering and making associations - with adequate time for students to respond. Students are encouraged to formulate many questions and contribute in answering them.

- Discussion Techniques: Not only does the teacher creates a genuine discussion among students and step out and allow them to own the discussion but also students assume considerable responsibility for the success of the discussion, they initiate topics that will enrich their learning - [can make the topics of class and school debates]. Students make unsolicited contributions to the class and discussion group. 
- Student participation: Not only the does teacher successfully engage all students in the discussion but students themselves ensure that all voices are heard in the discussion.

Engaging student in Learning: activities and assessments, grouping, materials and resources, and structure and pacing.

- Activities and assessments: All students are cognitively engaged in the activities and assignments in their exploration of the content. Students take initiation to ask and seek help (from the peers or the teacher) to get the work done up to standards.

- Grouping of students: Instructional groups are formed with the belief that all students can learn, with the balance of talented and struggling students; the groups are productive and fully appropriate to the students or to the instructional purposes of the lesson. Students take initiative in the formation or adjustments of the group (e.g. suggesting a separation of two most playful group members to allow them to engage seriously in the group work].

- Instructional materials and resources: Instructional materials and resources are suitable to the instructional purposes and engage students mentally. Students are encouraged to add more resources [books, notices, booklets, online materials, past exam questions and their answers, etc] that are appropriate to the lesson and they take initiative to share them with the rest of the class.

- Structure and pacing: The lesson has a clearly defined structure around which activities are organized, the structure is highly coherent, allowing for reflection and closure [every lesson begins with the summary of the last lesson and link it to the current]. Pacing of the lesson is appropriate for all the students.

Using Assessment in Instruction: Assessment criteria, learning monitoring, feedback and students' self assessment and monitoring their progress.

- Assessment Criteria: Students are fully aware of the criteria and performance standards by which their work will be evaluated. Students took part in developing the criteria - setting the bar higher than the regional and national standards.

- Monitoring of student learning: Teacher actively and systematically elicits diagnostic information from individual students regarding their understanding and monitors the progress of individual students. Students take part in monitoring their own progress and supply genuine reasons why they performed the way they did - what worked or did not work for them and what action they will take to ensure the success of the next step. 
- Feedback to students: Teacher's feedback to students is timely and consistently high quality; and students make use of the feedback in their learning process.

- Student self assessment and monitoring of progress: Students not only frequently assess and monitor the quality of their own work against the assessment criteria and performance standards, but also make active use of that information in their learning.

Demonstrating Flexibility and Responsiveness: Lesson adjustment, response to students and persistence

- Lesson adjustment: Teacher successfully makes a major adjustment to a lesson when needed. Teacher demonstrates the ability to learn from the students that the instructional process is not being productive [indicators: poor student participation, lack of connection with their past knowledge and experience, lack of enthusiasm and interest, sleeping during the instructional time, etc].

- Response to students: Teacher not only successfully accommodates students' question or interests, but also seizes a major opportunity to enhance learning, building on student interests or a spontaneous event.

- Persistence: Teacher persists in seeking effective approaches for students who need help (struggling students), using an extensive repertoire of strategies and soliciting additional resources from the school [consulting other teachers, using extra time for tutoring, using lab for further help, allowing the students to redo their work to bring out what was lacking, given extra homework to build up what seem to be lacking in work of the struggling students]. Basically the teachers do not quit on any of the students.

Source: Classroom instructional domains adopted form Danielson, (2007)

\section{Formative Assessment as on Pg. 223, and "Talk back" assessment as on Pg. 248.}




\section{NOTICE: DATA COLLECTION}

Use the space below to write your observations, participants' comments; things you would like to change/modify/add for the next session. Write any data you need to remember for your writing. 


\section{Day Four - Session One}

"Leadership is the art of getting someone else to do something you want done because he wants to do it."

Dwight Eisenhower

* DANIELSON'S TEACHING DOMAINS - Domain 4: In the small groups

- Give a general overview of Domain 1

- Groups to discuss the contents of Domain 1 in the context of their schools.

- What will work in your school and why?

- What won't work and why?

- What will you remove from the rubrics and why?

- What will you add to the rubrics and why?

* Presentations in the Cohort Group: Identify what was added or removed from all the groups to make one comprehensive list for the entire cohort group.

* Questions

* Formative assessment of the session

* Data Collection Sheet 
Domain 4: Professional Responsibilities

Reflecting on Teaching: Accuracy and use on future teaching

- Accuracy: Teacher makes thoughtful and accurate assessment of a lesson's effectiveness and extent to which it achieved its instructional outcomes, citing many specific examples from the lesson and weighting the relative strengths of each. Teacher might cite past national exams and how the lesson will help students answer such questions.

- Use in future teaching: Drawing from an extensive repertoire of skills, teacher offers specific alternative actions, complete with the probable success of different course of action. Teacher links the lesson with future learning and show its application in the empirical life [e.g. Legal system, citizenship responsibilities versus civics; hygiene, medical care, pest control versus chemistry/biology, etc].

Maintaining Accurate records: of students' assignments, leaning progress and other records. - Student completion of assignments: Teacher's system for maintaining information on student completion of assignments is fully effective, [keep track of student's performance], communicate to students any change in the progress; students participate in keeping their records.

- Student progress in learning: Teacher's system for maintaining information on student progress in learning is fully effective. Student is consulted to contribute to the interpretation of his/her progress [theory: if they know why the progress happened or did not happen they are likely to make a choice that will contribute to their progress].

- Non-instructional records: Teacher's system for maintaining information on student non instructional records is fully effective. Association is made between non-instructional record and student learning strategies how they contribute to instructional achievement.

\section{Communicating with Families:}

- Information about out of school instructional program: Teacher timely provides parents the information about out of school instructional programs such as study tours with details of when will it take place, how much it will cost, what are the instructional benefits of the tour and what if student cannot attend. School administration has to approve such a program before informing the parents. Students participate in formulating the program and conveying the message to their parents.

- Information about individual students: Traditionally, teacher provides the information to parents about student progress once in a semester [ 6 months] through school report sent through dean of studies. Teacher to make sure that necessary information about the student is included and signed. Response of families' concerns are handled with great professional and cultural sensitivity; and referrals are made professionally [to the dean of 
studies - for academics, dean of students (matron/patron) - for disciplinary issue, with a copy to the HM]

- Engagement of families in the instructional program: Students contribute to ideas for projects and could be enhanced by the family participation. Teacher is available on parents day to engage with individual parents if they ask and professionally handles the suggestions given by parents correlating them with the demands of the national syllabus.

Participating in a professional community: colleagues, professional inquiry, service and projects.

- Relationship with colleagues: Relationships with colleagues are characterized by mutual support and cooperation. Teacher takes initiatives of support and assuming leadership among the faculty.

- Involvement in the culture of professional inquiry: Teacher not only participates in a culture of professional inquiry, but also takes a leadership role in promoting a culture of professional role [e.g. initiating a research project to adjust or correct or change unproductive system or program]

- Service to the school: Teacher volunteers to participate in school events, making substantial contribution, and assuming a leadership role in at least one aspect of school life. Teacher takes active role and leadership in the non-instructional projects of the school, and gives advice that contributes to well being and productivity of school projects.

- Participation in school and district projects: Teacher volunteers to participate in school and district projects, making substantial contribution, and assuming a leadership role in a major school or district project. Also teacher takes active role and/or leadership in the non instructional projects of the school, and give advice that contributes to well being and productivity of school projects.

Growing and Developing professionally: content and pedagogy skills, handling feedback and service to the profession.

- Enhancement of content knowledge and pedagogical skill: Teacher seeks out opportunities for professional development and makes systematic effort to develop oneself through readings; attending workshops and seminars, advising the leadership and colleagues of the available resources for enhancing content knowledge and 
teaching skills. E.g. equipping oneself with the mandated constructivism pedagogical model.

- Receptivity to feedback from colleagues: Teacher not only welcomes feedback from the supervisor and colleagues but also seeks out feedback on teaching from both supervisor and colleagues. Teacher welcomes peer supervision and take seriously their feedback to develop his/her epistemology of his teaching and use it to improve his/her pedagogy.

- Service to the profession: Teacher not only participates actively in assisting other educators, but also initiates important activities to contribute to the profession. Teacher takes initiative to share the pedagogical skills learned individually, in the workshop and so initiates the creation of and becomes a resource of the professional learning community of his/her school

Showing professionalism: Integrity and ethical conduct, service to students, advocacy, decision making and compliance to the rules and regulations of the Ministry of Education

- Integrity and Ethical Conduct: Teacher displays and is counted on to hold the highest standard of honesty, integrity, and confidentiality and takes a leadership role with colleagues. Teacher's relationship with all students is ethical, moral and trustworthy; always presenting the picture of the ideal citizen and profession in and outside the school campus.

- Service to students: Teacher is highly proactive in serving students, seeking out resources when needed, taking pride in student achievement and proactively assisting all students to perform to their best potential.

- Advocacy: Teacher not only works to ensure that all students receive a fair opportunity to succeed, but also makes a concerted effort to challenge negative attitudes or practices to ensure that all students, particularly those traditionally underserved [female students in commuter co-educational schools and students from poor families in all schools] are honored and given equal learning opportunity in the school.

- Decision making: Teacher not only maintains open mind and participates in team or departmental decision making, but also takes leadership role in team or departmental decision making and helps ensure that such decision are based on the highest 
professional standards, they are inclusive, promote positive culture, quality learning and student achievement, and enhance high teaching professionalism.

- Compliance with school, diocese, district and Ministry of education regulations: Teacher complies fully with school, district, diocese and ministry regulations, setting himself/herself as a role model with colleagues and so plays a leadership role.

Source: Classroom instructional domains adopted form Danielson, (2007).

As I did in this study, the facilitator has to buy the Danielson Training kit. After processing the domains in the group discussions, the participants adopted the Danielson's domain and make their version which is culturally sensitive to their schools system.

\section{Formative Assessment as on Pg. 223}




\section{NOTICE: DATA COLLECTION}

Use the space below to write your observations, participants' comments; things you would like to change/modify/add for the next session. Write any data you need to remember for your writing. 


\section{Day Four - Session Two}

"If the blind lead the blind, both shall fall into the ditch."

Jesus Christ - Matthew 15:14

"The very essence of leadership is that you have to have a vision." Theodore Hesburgh

"If your actions inspire others to dream more, learn more, do more and become more, you are a leader."

John Quincy Adams

* Adaptation and adoption of Danielson's Teacher Evaluation Rubrics

* Use the given guidelines to adapt the teaching domains and the rubrics - make them culturally sensitive for Tanzanian Education system and culture.

* Small group discussion on:

- What to adopt

- What to remove

- What to change

- What to add

* Presentations to the main cohort group

* Formative assessment of the session

* Data Collection Sheet 


\begin{tabular}{|c|c|c|}
\hline \multicolumn{2}{|c|}{ Adopted Danielson Teacher Evaluation Rubrics } & \multirow[b]{2}{*}{ Basic } \\
\hline Domain & Unsatisfactory & \\
\hline $\begin{array}{l}\text { 1. Planning and } \\
\text { Preparation }\end{array}$ & $\begin{array}{l}\text { Teacher's plans reflect little } \\
\text { understanding of the content, the } \\
\text { students, their background and } \\
\text { available resources. Instructional } \\
\text { outcomes are either lacking or } \\
\text { inappropriate; assessment } \\
\text { methodologies are inadequate or } \\
\text { unknown. Lesson objectives, scope, } \\
\text { and instructional strategies are not } \\
\text { mentioned or not clear. The lesson } \\
\text { plan does not follow the current } \\
\text { curriculum of the ministry of } \\
\text { education; and does not follow the } \\
\text { National Examination Council of } \\
\text { Tanzania [NECTA] suggestions. The } \\
\text { standards are not reflected in the } \\
\text { plan. There is no link of the lesson } \\
\text { with overall national policy of } \\
\text { education for self reliance. No hands } \\
\text { on or group activities. }\end{array}$ & $\begin{array}{l}\text { Teacher's plans reflect moderate } \\
\text { understanding of the content, the students, } \\
\text { and the available resources. Some } \\
\text { instructional outcomes are suitable to the } \\
\text { students as a group, and approaches to } \\
\text { assessment are partially aligned to the } \\
\text { goal. There is little tie of the lesson to the } \\
\text { students' real life and their diverse tribal } \\
\text { values, self reliance and some connection } \\
\text { to other subjects or disciplines. There is a } \\
\text { partial link of the lesson to the current } \\
\text { curriculum of the ministry of education; } \\
\text { and NECTA directives, and overall } \\
\text { national policy of education for self } \\
\text { reliance. Group activity guidelines } \\
\text { partially reflect the understanding of the } \\
\text { content. }\end{array}$ \\
\hline $\begin{array}{l}\text { 2. Classroom } \\
\text { Environment }\end{array}$ & $\begin{array}{l}\text { Classroom environment is } \\
\text { characterized by chaos and conflict, } \\
\text { with low expectations for learning, } \\
\text { no clear standards of student conduct, } \\
\text { no class rules or they are not } \\
\text { enforced, poor use of physical space, } \\
\text { disorganized sitting order, negative } \\
\text { interactions between individuals, and } \\
\text { disruption during class; no respect } \\
\text { between teacher and student and } \\
\text { among students. There is littering, } \\
\text { chewing or eating, random talking } \\
\text { and movements during instruction } \\
\text { time; disruptive or inappropriate } \\
\text { pictures or drawings in class. No } \\
\text { enough chairs and desks for all the } \\
\text { students. There are neither known } \\
\text { expectations nor grading standards. }\end{array}$ & $\begin{array}{l}\text { Classroom environment functions } \\
\text { somewhat effectively, with modest } \\
\text { expectations for student learning and } \\
\text { conduct, and classroom routines and use of } \\
\text { space that partially support student } \\
\text { leaning. Students and the teacher rarely } \\
\text { treat one another with disrespect, some } \\
\text { disrespect among students is experienced } \\
\text { in class, and some class rules are } \\
\text { reinforced. Instructional time is not too } \\
\text { wasted and there is some efficiency in } \\
\text { distributing the learning materials. }\end{array}$ \\
\hline 3. Instruction & $\begin{array}{l}\text { Instruction is characterized by poor } \\
\text { communication, low-level questions, } \\
\text { little student engagement or } \\
\text { participation, little or no use of } \\
\text { assessment in learning, and rigid } \\
\text { adherence to an instructional plan } \\
\text { despite the evidence that it should be } \\
\text { revised or modified. No learning } \\
\text { activities or they are unrelated to the } \\
\text { learning outcome. }\end{array}$ & $\begin{array}{l}\text { Only some students are engaged in } \\
\text { learning because of only partially clear } \\
\text { communication, uneven use of discussion } \\
\text { strategies, and only some suitable } \\
\text { instruction activities and materials. The } \\
\text { teacher displays some use of assessment in } \\
\text { instruction and is moderately flexible in } \\
\text { adjusting instructional plan and in response } \\
\text { to students' interests and their success in } \\
\text { learning. Some learning activities are } \\
\text { related to the outcome. }\end{array}$ \\
\hline
\end{tabular}




\begin{tabular}{|c|c|c|}
\hline Domain & Proficient & Distinguished \\
\hline $\begin{array}{l}\text { 4. Professional } \\
\text { Responsibilities }\end{array}$ & $\begin{array}{l}\text { The teacher demonstrates low ethical } \\
\text { standards and levels of } \\
\text { professionalism, with poor record- } \\
\text { keeping systems and skills in } \\
\text { reflection, little or no communication } \\
\text { with the colleagues, and avoidance of } \\
\text { school, community, diocese and } \\
\text { district responsibilities and } \\
\text { participation in activities for } \\
\text { professional growth. No reputation in } \\
\text { the community due to unacceptable } \\
\text { behavior. }\end{array}$ & $\begin{array}{l}\text { The teacher demonstrates moderate ethical } \\
\text { standards and levels of professionalism, } \\
\text { with rudimentary record-keeping systems } \\
\text { and skills in reflection, modest } \\
\text { communication with colleagues [especially } \\
\text { dean of studies and dean of discipline], and } \\
\text { compliance with expectations regarding } \\
\text { participation in school, diocesan and } \\
\text { district projects and activities for } \\
\text { professional growth. }\end{array}$ \\
\hline $\begin{array}{l}\text { 1. Planning and } \\
\text { Preparation }\end{array}$ & $\begin{array}{l}\text { Teacher's plans reflect solid } \\
\text { understanding of the content, the students } \\
\text { and the available resources. Instructional } \\
\text { outcome represent important learning } \\
\text { suitable to most students. Most elements } \\
\text { of the instructional design, including the } \\
\text { assessments, are aligned to the goals: } \\
\text { competency to national examination and } \\
\text { preparation for service to the community. } \\
\text { Lesson's scope and its relationship with } \\
\text { other discipline are made. Most of the } \\
\text { contents are in line with the demands of } \\
\text { national syllabus and NECTA directives. } \\
\text { Group activities mostly promote the } \\
\text { understanding of the content. }\end{array}$ & $\begin{array}{l}\text { Teacher's plans based on extensive content } \\
\text { knowledge and understanding of students, are } \\
\text { designed to engage students in significant } \\
\text { learning. All aspects of the teacher's plans - } \\
\text { instructional outcomes, learning activities, } \\
\text { materials, resources, and assessments - are in } \\
\text { complete alignment and are adapted as needed } \\
\text { for individual students. They also follow the } \\
\text { directives of the national syllabus and NECTA. } \\
\text { Instructional design is in such a way that all } \\
\text { students are challenged to move to the next } \\
\text { level and all acquire significant learning which } \\
\text { is measureable. The backup plan is articulated } \\
\text { for individual students with special needs. The } \\
\text { student learning expectations are clearly stated } \\
\text { and they are aligned with national, diocesan and } \\
\text { school student achievement standards. Group } \\
\text { activities guidelines clearly articulate a deeper } \\
\text { understanding of the content, its connection to } \\
\text { real life and promote student creativity. }\end{array}$ \\
\hline $\begin{array}{l}\text { 2. Classroom } \\
\text { Environment }\end{array}$ & $\begin{array}{l}\text { Classroom environment functions } \\
\text { smoothly, with little or no loss of } \\
\text { instruction time. Expectations for student } \\
\text { learning are high, and interactions among } \\
\text { individuals are respectful. Standards for } \\
\text { student conduct are clear, and the } \\
\text { physical environment supports learning. } \\
\text { There is class order and rules are } \\
\text { reinforced to a greater degree, with no } \\
\text { unnecessary disruption of instruction. } \\
\text { Student expectations are known and are } \\
\text { fulfilled most of the time. }\end{array}$ & $\begin{array}{l}\text { Students themselves make a substantive } \\
\text { contribution to the smooth functioning of the } \\
\text { classroom, with highly positive personal } \\
\text { interactions, high expectations and student } \\
\text { pride in work, seamless routines, clear } \\
\text { standards of conducts, and a physical } \\
\text { environment conducive for high level of } \\
\text { learning: academic posters. Students take } \\
\text { initiative to keep themselves accountable by } \\
\text { setting higher standards and initiating corrective } \\
\text { measures among themselves. Students protect } \\
\text { instructional time. }\end{array}$ \\
\hline
\end{tabular}




\begin{tabular}{|l|l|l|}
\hline \multicolumn{1}{|c|}{ Domain } & \multicolumn{1}{c|}{ Proficient } & \multicolumn{1}{c|}{ Distinguished } \\
\hline & $\begin{array}{l}\text { All students are engaged in learning as a } \\
\text { result of clear communication and } \\
\text { successful use of questioning and } \\
\text { discussion techniques. Activities and } \\
\text { assignments are of high quality, and } \\
\text { teacher and students make productive use } \\
\text { of assessment. The teacher demonstrates } \\
\text { flexibility in contributing to the success } \\
\text { for the lesson and of each student. } \\
\text { Teaching aids and learning activities } \\
\text { enhance deeper understanding and are } \\
\text { aligned with the outcome. }\end{array}$ & $\begin{array}{l}\text { All students are highly engaged in learning and } \\
\text { make material contributions to the success of } \\
\text { the class through their participation in } \\
\text { discussions, active involvement in learning } \\
\text { activities and use of assessment information in } \\
\text { their learning. The teacher persists in the search } \\
\text { for approaches to meet the needs of every } \\
\text { student. The teacher provides extra help for the } \\
\text { special need students. }\end{array}$ \\
\hline 4. Professional & $\begin{array}{l}\text { The teacher demonstrates high ethical } \\
\text { standards and a genuine sense of } \\
\text { professionalism by engaging in accurate } \\
\text { reflection on instruction, maintaining } \\
\text { accurate records, communication with the } \\
\text { leadership and colleagues, actively } \\
\text { participating in school, local community, } \\
\text { diocesan and district events, and } \\
\text { engaging in activities for professional } \\
\text { development. The teacher dresses } \\
\text { professionally in school and in the } \\
\text { community. }\end{array}$ & $\begin{array}{l}\text { The teacher's ethical standards and sense of } \\
\text { professionalism are highly developed, showing } \\
\text { perceptive use of reflection, effective systems } \\
\text { for record keeping and communication with } \\
\text { leadership [dean of studies/students], taking } \\
\text { leadership roles in both school and local } \\
\text { community like parish, diocese and district } \\
\text { projects, and extensive professional } \\
\text { development activities. Where appropriate, } \\
\text { students contribute to the systems for record } \\
\text { keeping and family communication. }\end{array}$ \\
\hline
\end{tabular}

Note: The first adaptation of Danielson (2007) Teacher Evaluation Rubrics making the them reflect the Tanzanian school system and culture. Whenever this module is use, they participants must use the original Danielson training kit to adopt and acculturate the teaching domains into their education system and culture. 


\section{The Guidelines for Adapting Danielson's Teaching Domains}

On your own time read carefully and reflectively all the materials provided for Danielson's four domains. Follow these guidelines to read and do all the work associated with this assignment. This work is designed to be done progressively, so follow the numerical order in doing this work as follows:

1. Read though the longer version materials from Domain 1 to 4 . Then read the shorter version, the rubrics.

2. Re-read each domain one at a time. This time highlight or write down any word, statement, phrase, or claim that does not seem to make sense to you or seems incompatible with your school system and culture.

3. By using sticky notes, or writing on the pads given to you, suggest or add any word, statement, phrase, claim or paragraph that is not in the given domain materials, but you think will make the domain compatible to your school system and culture or will make it more effective in improving the quality of teaching and learning in your school.

4. Re-read the corrected version you have made [omitting all that you crossed out and including what you have inserted in]. Pay attention while reading to determine if it makes sense to you, if it sounds culturally sensitive to your school culture, and if you feel comfortable standing for its implementation in your school. In doing this pay attention to its meaning and flow, and see if it makes sense to you or not.

5. Write down the reasons why you think after your corrections whether the domain will make more sense or will be more effective in improving the quality of classroom teaching and learning.

6. Bring your final draft to your small group for further discussion on the same. Be prepared to give your reasons as to why you thought the changes you made should be embraced. Be reasonable and ready to change your stand if more convincing reasons contrary to yours are given. The group secretary will write the final domain draft after all the adjustments of the group are done. This draft will have all the adjustments of the individual group members as agreed or voted for by the group. The group chair will 
ensure that a fair procedure is followed to arrive at a conclusion on what is to be included or excluded in the final draft of the domain.

7. Each group will deal with only one domain. Since there are four groups, each group will have only one domain.

8. The final copy of the adapted domain will be compared with Danielson's rubrics in which changes will be made in the rubrics to reflect the changes made in the domain. The reason for doing this is that rubrics are the abbreviated form of the four domains.

9. The final copy of the group-adapted domain materials will be presented to the main cohort. The cohort will discuss the validity of the adjustments made by the group. The cohort will have the power keep the adjustments if the cohort class is convinced that they will serve the purpose, or reject them. The class can also make further adjustments by adding or removing anything that will be agreed on as making the domain/rubrics more effective and culturally relevant for their work.

10. This will be the final copy the HMs will take back to their schools and use as their leadership tool of improving and influencing quality teaching and learning.

Formative Assessment as on Pg. 223 


\section{NOTICE: DATA COLLECTION}

Use the space below to write your observations, participants' comments; things you would like to change/modify/add for the next session. Write any data you need to remember for your writing. 


\section{Day Four - Session Three}

The beautiful thing about learning is that no one can take it away from you. B.B. King

A teacher affects eternity; he can never tell where his influence stops. Henry B Adams

* Hands on - Use the rubrics and do teacher evaluation of the imaginary teacher using the same vignette.

* Put emphasis on what formation of balanced feedback, and use collaborative method to communicate the feedback.

* Formative assessment

* "Talk back" - end of the day assessment.

* Data Collection Sheet 


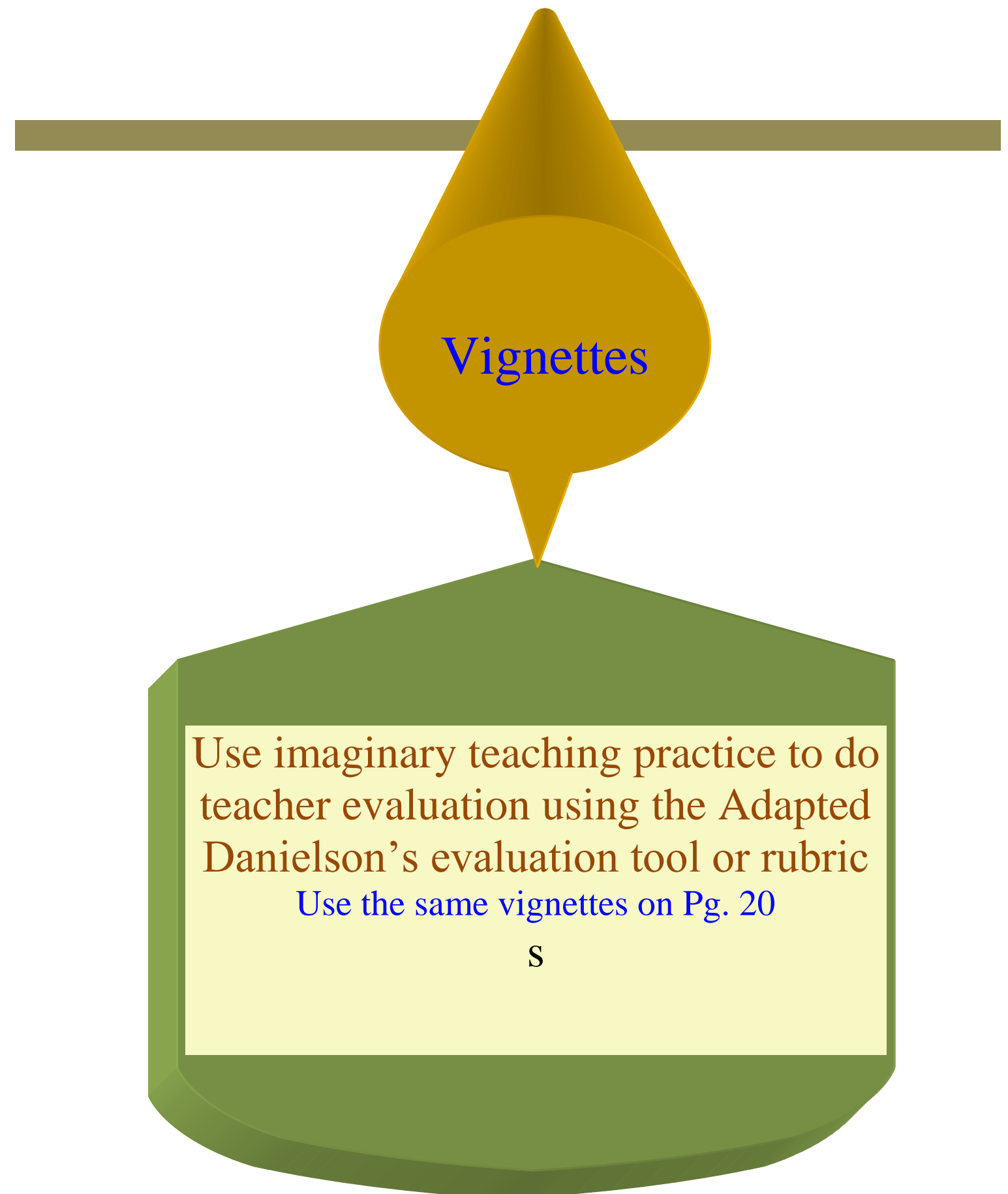

Formative Assessment as on Pg. 223 and "Talk back" assessment as on Pg. 248 


\section{Consultancy Protocol-Dealing with Resistance}

1. Introduction (2 minutes)

- Participants briefly introduce themselves (if necessary) and facilitator will review the protocol.

2. Presentation (10 minutes)

- The presenter(s) has an opportunity to share the current plan for the next steps at their school. It is important to share successes as well as growth areas related to the current instructional focus and to identify a focusing question for feedback.

3. Clarifying Questions (3 minutes)

- Participants have an opportunity to ask "clarifying" questions in order to get information that may have been omitted in the presentation that they feel would help them to understand the context and/or plan.

- Clarifying questions are matters of "fact."

- The facilitator should be sure to limit the questions to those that are "clarifying," judging which questions more properly belong in the warm/cool feedback section.

4. Warm and Cool Feedback (7 minutes)

- Participants share feedback with one another while the presenter(s) is silent. The feedback generally begins with a few minutes of warm feedback, moves on to a few minutes of cool feedback (sometimes phrased in the form of reflective questions), and then moves back and forth between warm and cool feedback.

- Warm feedback may include comments about how the work presented seems to meet the desired goals; cool feedback may include possible "disconnects," gaps, or problems. Often participants offer ideas or suggestions for strengthening the work presented.

- The facilitator may need to remind participants of the presenter's focusing question, which should be posted for all to see.

- Presenter is silent and takes notes.

5. Reflection (5 minutes)

- Presenter speaks to those comments/questions he or she chooses while participants are silent.

- This is not a time to defend oneself, but is instead a time for the presenter to reflect aloud on those ideas or questions that seemed particularly interesting.

- Facilitator may intervene to focus, clarify, etc.

6. Discussion and Debrief (5 minutes)

This will occur after all three schools have presented.

Adapted from National School Reform Faculty: www.nsrfharmony.org 


\section{NOTICE: DATA COLLECTION}

Use the space below to write your observations, participants' comments; things you would like to change/modify/add for the next session. Write any data you need to remember for your writing. 


\section{Day Five - Session One}

Aim for success, not perfection. Never give up your right to be wrong, because then you will lose the ability to learn new things and move forward with your life. Remember that fear always lurks behind perfectionism.

David M. Burns

Example is not the main thing in influencing others, it is the only thing. Albert Schweitzer

* Role play - Do ESCI in the groups and in the larger cohort group: formulate

balanced feedback (what went well, and what needs to be corrected) and

communicate the feedback in a collaborative fashion, allowing the teacher to

lead the process. Make sure every participant gets a chance to do this either in

the small or in the cohort group.

* Discussion after evaluation

* Formative assessment of the session

* Data Collection Sheet 


\section{GUIDELINES FOR ROLE PLAY}

Since this workshop is rooted in the practitioners' leadership experiences, each participant has to take part in the role play and play different roles. Each must play the teaching role of the teacher and the HM's role.

1. When you are a HM, make sure you follow the tips of good classroom supervision:

- Listen to the teacher and allow the teacher to lead the conferences.

- Attend classroom instruction and with minimal to no interaction of the teaching process.

- Give balance feedback and begin with positive points. Point out what worked best and where teacher needs to improve. It will be nice to allow the teacher begin by pointing out what he/she thought was the strong points.

- Make sure you communicate feedback as soon as possible.

Formative Assessment as on Pg. 223 


\section{NOTICE: DATA COLLECTION}

Use the space below to write your observations, participants' comments; things you would like to change/modify/add for the next session. Write any data you need to remember for your writing. 


\section{Day Five - Session Two}

"When the best leader's work is done the people say, "We did it ourselves." Lao Tzu

"Leadership can be thought of as a capacity to define oneself to others in a way that clarifies and expands a vision of the future."

\section{Edwin H. Friedman:}

"Leaders aren't born they are made. And they are made just like anything else, through hard work. And that's the price we'll have to pay to achieve that goal, or any goal." - Vince Lombardi

* Role playing - the same procedure as the previous session

* Write down the feedbacks and communicate them.

* Role Play on how to communicate feedbacks - in the small Groups

* Role Play on how to communicate feedbacks - in the Cohort Group

* Questions?

* Formative assessment of the session

\section{Guidelines for Role Play, the same as on pg. 303}

Formative Assessment as on Pg. 223 


\section{NOTICE: DATA COLLECTION}

Use the space below to write your observations, participants' comments; things you would like to change/modify/add for the next session. Write any data you need to remember for your writing. 


\section{Day Five - Session Three}

Who dares to teach must never cease to learn.

John Cotton Dana

We now accept the fact that learning is a lifelong process of keeping abreast of change. And the most pressing task is to teach people how to learn.

Peter F. Drucker

Do not train a child to learn by force or harshness; but direct them to it by what amuses their minds, so that you may be better able to discover with accuracy the peculiar bent of the genius of each.

\section{Plato}

* Role playing

* Dealing With Resistance - Consultancy Protocol Process 2: Repeat the same process to give the participants familiarity and comfort with the process.

* The same as previous sessions

\section{Guidelines for Role Play, the same as on pg. 303}

\section{Formative Assessment as on Pg. 223 and "Talk back" assessment as on Pg. 248}




\section{NOTICE: DATA COLLECTION}

Use the space below to write your observations, participants' comments; things you would like to change/modify/add for the next session. Write any data you need to remember for your writing. 


\section{Day Six - Session One}

"Keep your fears to yourself, but share your inspiration with others." Robert Louis Stevenson

"A leader must have the courage to act against an expert's advice." James Callaghan

"The price of greatness is responsibility."

Winston Churchill

\section{Guidelines for Action-Plan Presentations.}

Action Plan Groups Presentations to the larger or cohort group and the invited guests.

* Articulate the plan each has to improve teaching and learning in their schools as a result of the training. Give it a time frame and clear strategies of implementing $\mathrm{ESCl}$

Formative assessment of the session

Each group will be represented by one member to make a presentation, group members will be active to make their contributions and answer questions from the audience. 


\section{Guidelines for Action-Plan Presentation}

1. Action-Plan Presentation will be done by the small groups to the workshop cohort group and the invited guests. Each group will deal with only one of the four Danielson's Teaching Domains.

2. Each group member is required to be active in the discussion process to contribute, critique, support any point needed to be addressed to the main (cohort) group.

3. The group representative will make this presentation on behalf of the group. However, during the actual presentation the group members will actively contribute by adding, clarifying or correcting whatever is needed for the benefit of the entire audience.

4. The general structure of the presentation should be:

i. Say what you knew before this training about your role as school leader in relation to student achievement and quality teaching and learning.

ii. Highlight the discoveries you made from the training.

iii. Clearly articulate what you are going to do in your school as a result of this training.
a. What changes are you planning to make?
b. Why?
c. How?
d. When and for how long?

iv. Identify the resources at your disposal that will help you accomplish your plan?

v. What is the back-up plan in case the first plan doesn't work?

5. Be ready to answer all the questions from the audience that fall under your domain.

6. Clearly articulate any help you need from the Superintendent or any other high office to make you successful in your Teacher Evaluation Implementation Plan.

7. Identify the resources you need and their availability, to make your plan doable within the time frame you have given.

8. Tell us how you would know if you are making progress or if you are stuck. How would you evaluate your implementation progress?

9. The copy of the content of the presentation will be given to the cohort secretary to be included in the final document which each participant will take home after the workshop.

10. Any personal or group suggestions that will benefit the audience? 


\section{NOTICE: DATA COLLECTION}

Use the space below to write your observations, participants' comments; things you would like to change/modify/add for the next session. Write any data you need to remember for your writing. 


\title{
Day Six - Session Two
}

"A leader takes people where they want to go. A great leader takes people where they don't necessarily want to go but ought to be."

\author{
Rosalynn Carter
}

"The manager asks how and when; the leader asks what and why."

Warren Bennis

You can teach a student a lesson for a day: but if you can teach him to learn by creating curiosity, he will continue the learning process as long as he lives. Clay P. Bedford

\section{Action Plan Groups Presentations to the larger or cohort group and the invited guests.}

Articulate the plan each has to improve teaching and learning in their schools as a result of the training. Give it a time frame and clear strategies of implementing $\mathrm{ESCl}$.

\section{Action Plan Groups Presentations to the larger or cohort group and the invited guests.}

Cohort secretary or any appointed participant to give a presentation as a summary of their entire training experience. The preparation of this presentation will follow the same guidelines as the group presentations.

* Post-evaluation 1. Skills, Confidence, Competence, Motivation and Conviction about $\mathrm{ESCl}$.

* Formative assessment of the session.

* Data Collection Sheet.

Each group will be represented by one member to make a presentation. Group members will be active to make their contributions and answer questions from the audience. 
Post-evaluation: self Assessment

Scale: 1. Strongly Disagree, 2. Disagree, 3. I am not sure, 4. Agree, 5. Strongly

\begin{tabular}{|c|c|c|c|c|c|}
\hline \multirow{3}{*}{$\begin{array}{l}\text { Post Evaluation Questionnaire. } \\
\text { Please, check only one box beneath the number that best } \\
\text { expresses your current feeling }\end{array}$} & \multicolumn{5}{|c|}{ BEFORE THE WORKSHOP } \\
\hline & \multicolumn{5}{|c|}{${ }_{\text {Disagree }}>$ Agree } \\
\hline & 1 & 2 & 3 & 4 & 5 \\
\hline 1. I know about $\mathrm{ESCl}$ & 0 & O & 0 & O & O \\
\hline 2. I am familiar with $\mathrm{ESCl}$ & O & $\mathrm{O}$ & 0 & 0 & $\mathrm{O}$ \\
\hline 3. I know about the relationship between $\mathrm{ESCl}$ and quality teaching & O & $\mathrm{O}$ & 0 & O & O \\
\hline $\begin{array}{l}\text { 4. I am competent to do } \mathrm{ESCl} \text { so as to improve classroom } \\
\text { instruction }\end{array}$ & O & O & 0 & O & O \\
\hline $\begin{array}{l}\text { 5. Even if ESCl might be helpful, my schedule will never have time } \\
\text { for it }\end{array}$ & O & O & O & $\mathrm{O}$ & O \\
\hline 6. I am absolutely committed to use ESCI because of its value & O & $\mathrm{O}$ & O & O & O \\
\hline $\begin{array}{l}\text { 7. I know about Danielson's } 4 \text { Domains for instructional } \\
\text { improvement }\end{array}$ & $\mathrm{O}$ & $\mathrm{O}$ & 0 & $\mathrm{O}$ & $\mathrm{O}$ \\
\hline 8. I feel $\mathrm{ESCl}$ is too demanding and undoable & O & O & $\mathrm{O}$ & $\mathrm{O}$ & O \\
\hline 9. I know that $\mathrm{ESCl}$ can improve quality classroom instruction & O & $\mathrm{O}$ & O & O & O \\
\hline $\begin{array}{l}\text { 10. I have what it takes to improve student performance through } \\
\mathrm{ESCl}\end{array}$ & O & $\mathrm{O}$ & 0 & $\mathrm{O}$ & $\mathrm{O}$ \\
\hline $\begin{array}{l}\text { 11. I know how to effectively formulate and communicate } \\
\text { feedback }\end{array}$ & O & O & 0 & $\mathrm{O}$ & O \\
\hline $\begin{array}{l}\text { 12. Improving Teaching and Learning is my priority number one as } \\
\text { a leader }\end{array}$ & O & O & O & O & 0 \\
\hline 13. ESCI will be a priority in my school leadership & O & O & 0 & O & O \\
\hline $\begin{array}{l}\text { 14. I am convinced that } \mathrm{ESCl} \text { doesn't help improve classroom } \\
\text { instruction }\end{array}$ & O & $\mathrm{O}$ & O & 0 & 0 \\
\hline $\begin{array}{l}\text { 15. I believe that quality instruction can influence student } \\
\text { achievement }\end{array}$ & 0 & 0 & 0 & 0 & 0 \\
\hline
\end{tabular}




\begin{tabular}{|c|c|c|c|c|c|}
\hline 17. It is my duty to help teachers improve their pedagogical skills & O & O & 0 & O & O \\
\hline 18. Quality instruction is teacher's job, not mine as a school leader & O & O & O & O & O \\
\hline $\begin{array}{l}\text { 19. ESCl is not needed since National Exam is enough to assess } \\
\text { teacher's instructional qualities }\end{array}$ & 0 & O & O & O & O \\
\hline 20. I can do ESCE with any teacher and at any class level & $\mathrm{O}$ & $\mathrm{O}$ & O & $\mathrm{O}$ & $\mathrm{O}$ \\
\hline 21. I feel motivated using ESCl as a tool in my leadership duties & 0 & O & O & O & O \\
\hline $\begin{array}{l}\text { 22. I know that skills about ESCl add to my instructional leadership } \\
\text { quality }\end{array}$ & O & O & O & O & O \\
\hline $\begin{array}{l}\text { 23. I am confident that } \mathrm{ESCl} \text { can improve quality instruction of my } \\
\text { teachers }\end{array}$ & O & O & 0 & O & O \\
\hline $\begin{array}{l}\text { 24. I feel challenged to evaluate and supervise professional } \\
\text { teachers }\end{array}$ & $\mathrm{O}$ & $\mathrm{O}$ & O & $\mathrm{O}$ & O \\
\hline 25. Regardless of my busy schedule, ESCl is a must in my school & $\mathrm{O}$ & $\mathrm{O}$ & $\mathrm{O}$ & O & O \\
\hline 26. With the skills I have, I can professionally do $\mathrm{ESCl}$ & $\mathrm{O}$ & O & O & $\mathrm{O}$ & O \\
\hline $\begin{array}{l}\text { 27. I am committed to use } \mathrm{ESCl} \text { as a tool to improve teaching and } \\
\text { learning }\end{array}$ & $\mathrm{O}$ & $\mathrm{O}$ & $\mathrm{O}$ & $\mathrm{O}$ & $\mathrm{O}$ \\
\hline $\begin{array}{l}\text { 28. I am confident that I can improve student achievement through } \\
\text { ESCI }\end{array}$ & O & O & O & $\mathrm{O}$ & $\mathrm{O}$ \\
\hline
\end{tabular}




\section{NOTICE: DATA COLLECTION}

Use the space below to write your observations, participants' comments; things you would like to change/modify/add for the next session. Write any data you need to remember for your writing. 


\section{Day Six - Session Three}

Education cost money, but then so does ignorance.

Claus Moser

What sculpture is to a block of marble education is to the human soul.

Joseph Addison

* Concluding remarks from the invited guest of honor, the superintendent and the

presenters.

* Unfinished business

* Certification ceremony

* Conclusion

* Formative assessment of the workshop and Presenter(s) (see the Appendix)

* End of the training - Parking and departure. 


\section{POST EVALUATION: EXPECTATIONS AND THEIR UN/FULFILLMENT}

Participants should first read what they individually wrote at the beginning of the workshop [the expectations of what they will learn from the training] and then answer the following question:

\section{Did you learn what you anticipated/expected/wanted to learn in this}

\section{workshop?}

Note: Make sure every participant writes his or her number on the response sheet.

For analysis, compare each individual's expectations before the workshop and the responses if their anticipations were fulfilled.

You can use the following Table as an example of how to do your analysis:

\begin{tabular}{|l|l|l|}
\hline $\begin{array}{c}\text { Participant's } \\
\text { Number }\end{array}$ & $\begin{array}{c}\text { Responses of "What Expect to } \\
\text { Learn?" }\end{array}$ & $\begin{array}{c}\text { Responses of "Did the } \\
\text { workshop meet your learning } \\
\text { expectations?" }\end{array}$ \\
\hline 1 & $\begin{array}{l}\text { I want to know how to } \\
\text { communicate feedback } \\
\text { collaboratively }\end{array}$ & $\begin{array}{l}\text { The training exceeded my } \\
\text { expectations }\end{array}$ \\
\hline 2 & How to deal with resistant staff & $\begin{array}{l}\text { I learned something on the } \\
\text { Consultancy protocol but it } \\
\text { was not enough for me, I } \\
\text { expected more. }\end{array}$ \\
\hline 3 & $\begin{array}{l}\text { Skills of evaluating teaching and } \\
\text { learning in my school. }\end{array}$ & Yes. \\
\hline
\end{tabular}




\section{NOTICE: DATA COLLECTION}

Use the space below to write your observations, participants' comments; things you would like to change/modify/add for the next session. Write any data you need to remember for your writing. 


\section{APPENDICES}

\section{Appendix 1: Adapted Danielson evaluation Rubrics}

\begin{tabular}{|c|c|c|}
\hline & Unsatisfactory & Basic \\
\hline $\begin{array}{l}\text { Planning and } \\
\text { Preparation }\end{array}$ & $\begin{array}{l}\text { Teacher's plans reflect little understanding of the content, the } \\
\text { students, their background and available resources. } \\
\text { Instructional outcomes are either lacking or inappropriate; } \\
\text { assessment methodologies are inadequate or unknown. Lesson } \\
\text { objectives, scope, and instructional strategies are not } \\
\text { mentioned or not clear. The lesson plan does not follow the } \\
\text { current curriculum of the ministry of education; and does not } \\
\text { follow the National Examination Council of Tanzania } \\
\text { [NECTA] suggestions. The standards are not reflected in the } \\
\text { plan. There is no link of the lesson with overall national } \\
\text { policy of education for self reliance. No hands on or group } \\
\text { activities. }\end{array}$ & $\begin{array}{l}\text { Teacher's plans reflect moderate understanding of the content, } \\
\text { the students, and the available resources. Some instructional } \\
\text { outcomes are suitable to the students as a group, and } \\
\text { approaches to assessment are partially aligned to the goal. } \\
\text { There is little tie of the lesson to the students' real life and } \\
\text { their diverse tribal values, self reliance and some connection to } \\
\text { other subjects or disciplines. There is a partial link of the } \\
\text { lesson to the current curriculum of the ministry of education; } \\
\text { and NECTA directives, and overall national policy of } \\
\text { education for self reliance. Group activity guidelines partially } \\
\text { reflect the understanding of the content. }\end{array}$ \\
\hline $\begin{array}{c}\text { Classroom } \\
\text { Environment }\end{array}$ & $\begin{array}{l}\text { Classroom environment is characterized by chaos and } \\
\text { conflict, with low expectations for learning, no clear standards } \\
\text { of student conduct, no class rules or they are not enforced, } \\
\text { poor use of physical space, disorganized sitting order, } \\
\text { negative interactions between individuals, and disruption } \\
\text { during class; no respect between teacher and student and } \\
\text { among students. There is littering, chewing or eating, random } \\
\text { talking and movements during instruction time; disruptive or } \\
\text { inappropriate pictures or drawings in class. Not enough chairs } \\
\text { and desks for all the students. There are neither known } \\
\text { expectations nor grading standards. }\end{array}$ & $\begin{array}{l}\text { Classroom environment functions somewhat effectively, with } \\
\text { modest expectations for student learning and conduct, and } \\
\text { classroom routines and use of space that partially support } \\
\text { student leaning. Students and the teacher rarely treat one } \\
\text { another with disrespect, some disrespect among students is } \\
\text { experienced in class, and some class rules are reinforced. } \\
\text { Instructional time is not too wasted and there is some } \\
\text { efficiency in distributing the learning materials. }\end{array}$ \\
\hline Instruction & $\begin{array}{l}\text { Instruction is characterized by poor communication, low-level } \\
\text { questions, little student engagement or participation, little or } \\
\text { no use of assessment in learning, and rigid adherence to an } \\
\text { instructional plan despite the evidence that it should be } \\
\text { revised or modified. No learning activities or they are } \\
\text { unrelated to the learning outcome. }\end{array}$ & $\begin{array}{l}\text { Only some students are engaged in learning because of only } \\
\text { partially clear communication, uneven use of discussion } \\
\text { strategies, and only some suitable instruction activities and } \\
\text { materials. The teacher displays some use of assessment in } \\
\text { instruction and is moderately flexible in adjusting instructional } \\
\text { plan and in response to students' interests and their success in } \\
\text { learning. Some learning activities are related to the outcome. }\end{array}$ \\
\hline $\begin{array}{c}\text { Professional } \\
\text { Responsibilities }\end{array}$ & $\begin{array}{l}\text { The teacher demonstrates low ethical standards and levels of } \\
\text { professionalism, with poor record-keeping systems and skills } \\
\text { in reflection, little or no communication with the colleagues, } \\
\text { and avoidance of school, community, diocese and district } \\
\text { responsibilities and participation in activities for professional } \\
\text { growth. No reputation in the community due to unacceptable } \\
\text { behavior. }\end{array}$ & $\begin{array}{l}\text { The teacher demonstrates moderate ethical standards and } \\
\text { levels of professionalism, with rudimentary record-keeping } \\
\text { systems and skills in reflection, modest communication with } \\
\text { colleagues [especially dean of studies and dean of discipline], } \\
\text { and compliance with expectations regarding participation in } \\
\text { school, diocesan and district projects and activities for } \\
\text { professional growth. }\end{array}$ \\
\hline
\end{tabular}




\begin{tabular}{|c|c|c|}
\hline & Proficient & Distinguished \\
\hline $\begin{array}{l}\text { Planning and } \\
\text { Preparation }\end{array}$ & $\begin{array}{l}\text { Teacher's plans reflect solid understanding of the } \\
\text { content, the students and the available resources. } \\
\text { Instructional outcomes represent important learning } \\
\text { suitable to most students. Most elements of the } \\
\text { instructional design, including the assessments, are } \\
\text { aligned to the goals: competency to national } \\
\text { examination and preparation for service to the } \\
\text { community. Lesson's scope and its relationship } \\
\text { with other disciplines are made. Most of the } \\
\text { contents are in line with the demands of national } \\
\text { syllabus and NECTA directives. Group activities } \\
\text { mostly promote the understanding of the content. }\end{array}$ & $\begin{array}{l}\text { Teacher's plans based on extensive content knowledge and } \\
\text { understanding of students, are designed to engage students in } \\
\text { significant learning. All aspects of the teacher's plans - } \\
\text { instructional outcomes, learning activities, materials, resources, and } \\
\text { assessments - are in complete alignment and are adopted as needed } \\
\text { for individual students. They also follow the directives of the } \\
\text { national syllabus and NECTA. Instructional design is in such a way } \\
\text { that all students are challenged to move to the next level and all } \\
\text { acquire significant learning which is measureable. The backup plan } \\
\text { is articulated for individual students with special needs. The student } \\
\text { learning expectations are clearly stated and they are aligned with } \\
\text { national, diocesan and school student achievement standards. Group } \\
\text { activities guidelines clearly articulate a deeper understanding of the } \\
\text { content, its connection to real life and promote student creativity. }\end{array}$ \\
\hline $\begin{array}{c}\text { Classroom } \\
\text { Environment }\end{array}$ & $\begin{array}{l}\text { Classroom environment functions smoothly, with } \\
\text { little or no loss of instruction time. Expectations for } \\
\text { student learning are high, and interactions among } \\
\text { individuals are respectful. Standards for student } \\
\text { conduct are clear, and the physical environment } \\
\text { supports learning. There is class order and rules are } \\
\text { reinforced to a greater degree, with no unnecessary } \\
\text { disruption of instruction. Student expectations are } \\
\text { known and are fulfilled most of the time. }\end{array}$ & $\begin{array}{l}\text { Students themselves make a substantive contribution to the smooth } \\
\text { functioning of the classroom, with highly positive personal } \\
\text { interactions, high expectations and student pride in work, seamless } \\
\text { routines, clear standards of conducts, and a physical environment } \\
\text { conducive for high level of learning: academic posters. Students } \\
\text { take initiative to keep themselves accountable by setting higher } \\
\text { standards and initiating corrective measures among themselves. } \\
\text { Students protect instructional time. }\end{array}$ \\
\hline Instruction & $\begin{array}{l}\text { All students are engaged in learning as a result of } \\
\text { clear communication and successful use of } \\
\text { questioning and discussion techniques. Activities } \\
\text { and assignments are of high quality, and teacher } \\
\text { and students make productive use of assessment. } \\
\text { The teacher demonstrates flexibility in contributing } \\
\text { to the success of the lesson and of each student. } \\
\text { Teaching aids and learning activities enhance } \\
\text { deeper understanding and are aligned with the } \\
\text { outcome. }\end{array}$ & $\begin{array}{l}\text { All students are highly engaged in learning and make material } \\
\text { contributions to the success of the class through their participation } \\
\text { in discussions, active involvement in learning activities and use of } \\
\text { assessment information in their learning. The teacher persists in the } \\
\text { search for approaches to meet the needs of every student. The } \\
\text { teacher provides extra help for the special need students. }\end{array}$ \\
\hline $\begin{array}{c}\text { Professional } \\
\text { Responsibilities }\end{array}$ & $\begin{array}{l}\text { The teacher demonstrates high ethical standards and } \\
\text { a genuine sense of professionalism by engaging in } \\
\text { accurate reflection on instruction, maintaining } \\
\text { accurate records, communication with the } \\
\text { leadership and colleagues, actively participating in } \\
\text { school, local community, diocesan and district } \\
\text { events, and engaging in activities for professional } \\
\text { development. The teacher dresses professionally in } \\
\text { school and in the community. }\end{array}$ & $\begin{array}{l}\text { The teacher's ethical standards and sense of professionalism are } \\
\text { highly developed, showing perceptive use of reflection, effective } \\
\text { systems for record keeping and communication with-leadership } \\
\text { [dean of studies/students], taking leadership roles in both school } \\
\text { and local community like parish, diocese and district projects, and } \\
\text { extensive professional development activities. Where appropriate, } \\
\text { students contribute to the systems for record keeping and family } \\
\text { communication. }\end{array}$ \\
\hline
\end{tabular}

Note: Making the rubrics culturally appropriate to Tanzanian schools. Source: Danielson, (2007). 
Appendix 2:

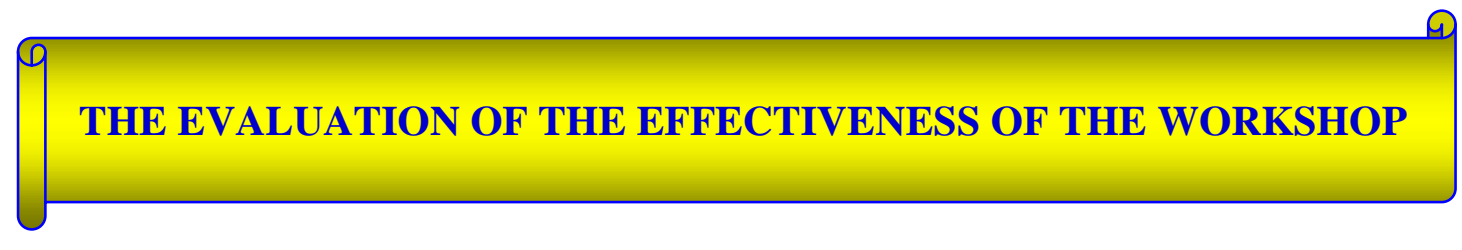

Evaluation of the Workshop, the Presenter and Competence and Confidence Indicators:

1. What did you like most in this workshop?
a)
b)
c)
d)
e)

2. What did you not like in the training process?
a)
b)
c)
d)
e)

3. What would you change to make this workshop more effective for school leaders?
a)
b)
c)
d)
e)

4. If you were to attend the same workshop again, what elements would you add?
a)
b)
c)
d)
e)

5. In the following chat, rate yourself, the presenter and the effectiveness of the workshop. Check or dark only one circle per item. 


\begin{tabular}{|c|c|c|c|c|}
\hline $\begin{array}{l}\text { SELF EVALUATION QUESTIONNAIRE } \\
\text { Measure Yourself, the Presenter(s) and the Workshop }\end{array}$ & $\begin{array}{l}\grave{0} \\
\stackrel{0}{\circ} \\
\text { II }\end{array}$ & $\begin{array}{l}\text { ס } \\
\text { ర } \\
\stackrel{11}{\sim}\end{array}$ & 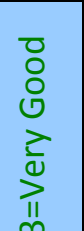 & 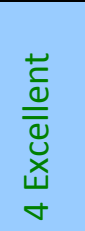 \\
\hline My confidence of conducting ESCI before this workshop & O & D & 0 & $\bigcirc$ \\
\hline My confidence of conducting ESCI Now after this workshop & $\bigcirc$ & O & 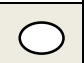 & $\bigcirc$ \\
\hline $\begin{array}{l}\text { The way I feel now in doing conference with a teacher of his/her } \\
\text { instruction }\end{array}$ & O & & $\bigcirc$ & \\
\hline My Knowledge or skills of doing ESCl before the workshop & $\bigcirc$ & & & \\
\hline My knowledge or skills of doing ESCl after the workshop & O & & & \\
\hline My level of competence in doing evaluation before the workshop & O & ) & $\bigcirc$ & \\
\hline My level of competence in doing evaluation before the workshop & $\Omega$ & & $\bigcirc$ & \\
\hline The overall rate of the presenter(s) of the workshop & O & $\bigcirc$ & $\bigcirc$ & \\
\hline $\begin{array}{l}\text { My motivation to do } \mathrm{ESCl} \text { despite by busy schedule before the } \\
\text { workshop }\end{array}$ & 0 & & $\bigcirc$ & \\
\hline $\begin{array}{l}\text { My motivation to do } \mathrm{ESCl} \text { despite by busy schedule after the } \\
\text { workshop }\end{array}$ & $\Omega$ & & & \\
\hline My conviction before the workshop that $\mathrm{ESCl}$ can make a help us & O & $\bigcirc$ & C & \\
\hline My conviction after the workshop that $\mathrm{ESCl}$ can make a help us & $\bigcirc$ & & C & $\bigcirc$ \\
\hline The overall rate of the content/materials learned in the workshop & O & O & $\bigcirc$ & $\bigcirc$ \\
\hline The effect of this workshop in my future leadership practices & 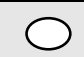 & O & O & 0 \\
\hline $\begin{array}{l}\text { The rate of skills I acquired as an Instructional Leader, through this } \\
\text { workshop }\end{array}$ & O & O & O & O \\
\hline $\begin{array}{l}\text { The possibility of improving the quality of teaching and learning in } \\
\text { my school after this workshop }\end{array}$ & $\bigcirc$ & O & $\bigcirc$ & $\bigcirc$ \\
\hline $\begin{array}{l}\text { The possibility of being a more effective leader to influence student } \\
\text { achievement in my school after this workshop }\end{array}$ & 0 & 0 & $O$ & $\bigcirc$ \\
\hline
\end{tabular}


The likelihood that I will used the skills I learned to actually conduct classroom evaluation with my teachers from now on

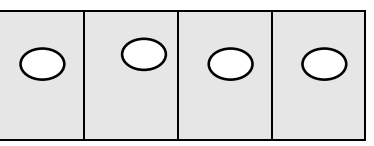

\section{Any other comments?}




\section{CERTIFICATION CEREMONRY}

1. Prepare Certificates for those who actively and successfully completed the PBL Training.

2. Invite the guest of honor to conclude the training by listening to the Action-plan presentations and give his/her concluding remarks.

3. Among the people who might be the guest of honor include, but not limited to, the bishop of the diocese, the Education District Commissioner, Education Regional Commissioner, the Minister or the Deputy Minister of Education, the President of the Local University, and the Superintendent or the Director of Education in the Diocese or District or Region.

4. Make sure the participants have met all the requirements before they are eligible for certification.

5. If the participants are using the training as part of their Graduate work in the Education Administration program, make sure you send their grades to their respective universities as needed. 


\section{RESOURCES - REFERENCES}

If you are leading the PBL Workshop for the first time, you need to read the following references to get familiarized with the content and the processes.

Danielson, C. (2007). Enhancing professional practice: A framework for teaching. Alexandria, VA: Association for Supervision and Curriculum Development.

Danielson, C. (2009). Enhancing professional practice a framework for teaching. High school. Alexandria, Va.: Association for Supervision and Curriculum Development.

Danielson, C. (2011). The Framework for Teaching Evaluation Instrument. Princeton, NJ: The Danielson Group.

Downey, C. J., English, F. W., \& Steffy, B. E. (2004). The three-minute classroom walkthrough, changing school supervisory practice one teacher at a time. Thousand Oaks, CA: Corwin Press.

Fink, S., \& Markholt, A. (2011). Leading for instructional improvement: How successful leaders develop teaching and learning expertise (1st ed.). San Francisco, CA: Jossey-Bass.

DuFour, R. (2010). Raising the bar and closing the gap: Whatever it takes. Bloomington, IN: Solution Tree.

Fink, S., \& Markholt, A. (2011). Leading for instructional improvement: How successful leaders develop teaching and learning expertise (1st ed.). San Francisco, CA: Jossey-Bass.

Goldhammer, R. (1969). Clinical supervision: Special methods for the supervision of teachers. New York, NY: Holt, Rinehart and Winston.

Goodreads Inc. (2013). Goodreads. Nelson Mandela Quotes. Retrieved from http://www.goodreads.com/author/quotes/367338.Nelson_Mandela

Hallinger, P. (2003). Leading educational change: Reflections on the practice of instructional and transformational leadership. Cambridge Journal of Education, 329-351.

Hallinger, P. \& Murphy, J. (1986). The social context of effective schools. American Journal of Education, 94(3), 328-355 
Hallinger, P. \& Murphy, J. (1987).Instructional leadership in the school context. In W.

Greenfield(Ed.), Instructional leadership: Concepts, issues, and controversies (pp179201).Boston: Allyn and Bacon.

Klein, J. (2012). Educational Innovations for the Future. New York, NY: Columbia Business School. Retrieved from https://www.youtube.com/watch?v=Un5hKLKqmk8

Leithwood, K., Louis, K. S., Anderson, S., \& Wahlstrom, K. (2004). How leadership influences student learning: Review of research. St Paul, MN: Center for Applied Research and Educational Improvement, University of Minnesota.

Marshall, K. (2009). Rethinking teacher supervision and evaluation: How to work smart, build collaboration, and close the achievement gap (1st ed.). San Francisco, CA: Jossey-Bass.

Marzano, R. J., Frontier, T., \& Livingston, D. (2011). Effective supervision: Supporting the art and science of teaching. Alexandria, VA: Association for Supervision and Curriculum Development.

Tanzania Institute of Education. (2011). Tanzania Institute of Education-Taasisi ya elimu ya Tanzania. Retrieved March 23, 2012, from http://www.tie.go.tz/ index.php/about-us

United Republic of Tanzania. (2012). Ministry of education \& vocational training. Retrieved November 9, 2012, from http://www.moe.go.tz/index.php?option= com content $\&$ view=category $\& i d=303 \&$ Itemid $=616$ 


\section{APPENDIX C}

PILOT SURVEY QUESTIONNAIRE 


\section{Pilot Survey Questionnaires}

Please, answer all the questions. If you need extra space, use a separate sheet of paper and remember to indicate the question number before the answer. Thank so much for caring about the quality of educational leadership and take your time to answer these questions. This shows your commitment in education.

[Note: HM stands for Headmaster or Headmistress as your gender may apply] Please put a check maxk $\backslash$ I only once on each item on the most appropriate answer.

\begin{tabular}{|c|c|c|c|c|c|}
\hline \multicolumn{6}{|c|}{ YOUR OPINION ON FORMAL SCHOOL LEADERSHIP TRAINING VERSUS EXPERIENCE } \\
\hline No & Item & 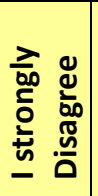 & 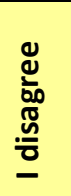 & 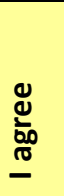 & 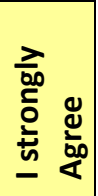 \\
\hline 1 & My college training prepared me well for my teaching career & & & & \\
\hline 2 & I took school administrative courses in my college training & & & & \\
\hline 3 & $\begin{array}{l}\text { I learned how to be the HM not from college but from my work } \\
\text { experience }\end{array}$ & & & & \\
\hline 4 & $\begin{array}{l}\text { When I began my job as HM I did not have formal school leadership } \\
\text { training }\end{array}$ & & & & \\
\hline 5 & $\begin{array}{l}\text { I believe that any teacher can be the HM without any formal } \\
\text { administrative training }\end{array}$ & & & & \\
\hline 6 & $\begin{array}{l}\text { I would have done a better job in my early years as the HM if I had } \\
\text { done some administrative courses in college }\end{array}$ & & & & \\
\hline 7 & My college training prepared me fully on how to work as the HM & & & & \\
\hline 8 & $\begin{array}{l}\text { I believe that good school leadership can improve student } \\
\text { achievement }\end{array}$ & & & & \\
\hline 9 & $\begin{array}{l}\text { School administration training and workshops will make me a more } \\
\text { effective HM }\end{array}$ & & & & \\
\hline 10 & $\begin{array}{l}\text { I have done some mistakes in handling administrative issues } \\
\text { because I was not trained how to handle them }\end{array}$ & & & & \\
\hline 11 & $\begin{array}{l}\text { Schools will be more effective if all HMs will get formal school } \\
\text { administrative training in college prior to assuming that } \mathrm{MH}^{\prime} \text { s office }\end{array}$ & & & & \\
\hline 12 & $\begin{array}{l}\text { I would like my child or a child of my best friend to attend a } \\
\text { secondary school whose HM did not have any formal administrative } \\
\text { training }\end{array}$ & & & & \\
\hline
\end{tabular}




\begin{tabular}{|c|c|c|c|c|c|}
\hline \multicolumn{6}{|c|}{ PROFESSIONAL DUTIES OF THE HEADMASTER/HEADMISTRESS [HM] } \\
\hline No & Item & 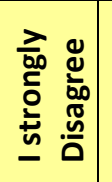 & 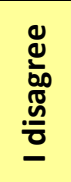 & 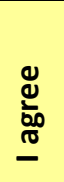 & 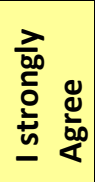 \\
\hline 1 & $\begin{array}{l}\text { If I was in college today that offers school administration courses I } \\
\text { would take them seriously }\end{array}$ & & & & \\
\hline 2 & $\begin{array}{l}\text { I still struggle with some administrative issues because I was never } \\
\text { taught in college how to handle them }\end{array}$ & & & & \\
\hline 3 & $\begin{array}{l}\text { I want my school to be among the best, only I do not know how to } \\
\text { make it happen }\end{array}$ & & & & \\
\hline 4 & $\begin{array}{l}\text { I believe that my students cannot do better than what they are } \\
\text { doing now in the national exams }\end{array}$ & & & & \\
\hline 5 & I don't know how to handle school crisis well & & & & \\
\hline 6 & $\begin{array}{l}\text { I wish someone will teach me how to hold teachers accountable for } \\
\text { the failures of their subjects/students in the national exams }\end{array}$ & & & & \\
\hline 7 & $\begin{array}{l}\text { I struggle with making effective communication, making understand } \\
\text { what I really mean }\end{array}$ & & & & \\
\hline 8 & $\begin{array}{l}\text { I wish my staff would always listen to my orders and obey my rules } \\
\text { as their boss }\end{array}$ & & & & \\
\hline 9 & We waste too much time in the staff meetings & & & & \\
\hline 10 & $\begin{array}{l}\text { I am afraid to make decisions on serious matters because I don't } \\
\text { know how to make informed tough decisions }\end{array}$ & & & & \\
\hline 11 & I feel very competent in handling school finances & & & & \\
\hline 12 & I was trained in college how to handle school budget and money & & & & \\
\hline 13 & I feel I need more skills to handle teachers' unacceptable behavior & & & & \\
\hline 14 & I know how to identify toxic/poisonous culture in my school & & & & \\
\hline 15 & $\begin{array}{l}\text { I know how to change the culture of my school to a more positive } \\
\text { culture that enhances student achievement }\end{array}$ & & & & \\
\hline 16 & $\begin{array}{l}\text { I want to change the students' discipline but I don't know the best } \\
\text { way to do it }\end{array}$ & & & & \\
\hline 17 & $\begin{array}{l}\text { I do not know how to actively engage parents in the learning } \\
\text { process of their children other than paying school fees }\end{array}$ & & & & \\
\hline 18 & My school has a formally written vision & & & & \\
\hline 19 & My school has a written mission statement & & & & \\
\hline 20 & My school has strategic planning to reach its goals & & & & \\
\hline 21 & $\begin{array}{l}\text { I am required by law to attend professional development seminars/ } \\
\text { training/ workshops }\end{array}$ & & & & \\
\hline 22 & $\begin{array}{l}\text { I was trained how to engage teachers in the decision making of the } \\
\text { major school issues }\end{array}$ & & & & \\
\hline 24 & Students ideas matter in the decision making of the school change & & & & \\
\hline 25 & My school needs reformation if it is to be more effective & & & & \\
\hline
\end{tabular}




\begin{tabular}{|l|l|l|l|l|l|}
\hline 27 & $\begin{array}{l}\text { I have hard time handling the policy of the Diocese/Ministry of } \\
\text { Education in my school }\end{array}$ & & & \\
\hline 28 & I want to learn how to handle the difficulty teachers & & & & \\
\hline
\end{tabular}

\section{FOLLOW-UP SECTION}

In the hierarchical order of priority or importance, rank the administrative study courses or classes you would like any school leader to learn in the School Leadership Professional Development Program in the coming years that will make him/her more effective instructional leader.

For example for HM Tom, Building teacher's relationship ranks number 1, financial management ranks \#4, while crisis management ranks \#2 etc. But for HM Lucy, Financial management might rank \#1, while Building teachers relationship might be \# 5 . Remember Number 1 will indicate the most crucial topic you need to learn to be the most effective school leader of your school while number 12 will indicate the least important topic. One of the measures of your effectiveness will be raising the achievement of your students.

\begin{tabular}{|l|l|}
\hline No & $\begin{array}{l}\text { ADMINISTRATIVE TOPICS OR COURSES THAT WILL MAKE THE HEADMASTER/HEADMISTRESS A } \\
\text { MORE EFFECTIVE SCHOOL LEADER }\end{array}$ \\
\hline $\begin{array}{l}\text { CONFLICT OR CRISIS MANAGEMENT-among teachers, teachers and students, among students, } \\
\text { school and community around the school, parents and teachers, teachers and school } \\
\text { administration. }\end{array}$ \\
$\begin{array}{l}\text { TEACHERS' ACCOUNTABILITY: Holding teachers responsible for student performance but also } \\
\text { supporting them to do their job well, teachers' code of conducts, who is to make it, what is their } \\
\text { input in the process of making it, what is the input of higher educational leadership-District, } \\
\text { Diocese, Ministry. }\end{array}$ \\
\hline $\begin{array}{l}\text { EFFECTIVE COMMUNICATION: } \\
\text { a. Within school-between the administration and the teachers / workers / students/ } \\
\text { parents } \\
\text { b. Outside school: between the school and the Diocese / District / Region or Zone/ Ministry } \\
\text { of Education }\end{array}$ \\
\hline $\begin{array}{l}\text { PARENTS' INVOLVEMENT IN THE SCHOOL LIFE-where they may be beneficial and where they } \\
\text { may be destructive to the normal school life; how they are to be involved and to what extent. }\end{array}$ \\
\hline
\end{tabular}




\begin{tabular}{|c|}
\hline $\begin{array}{l}\text { STUDENTS' PARTICIPATION IN THE DECISION MAKING-as part of training and to make sure their } \\
\text { voice is reflecting in decision making, when and how they should or should not be involved, } \\
\text { students' leadership board and their role in the general running of the school }\end{array}$ \\
\hline $\begin{array}{l}\text { FINANCIAL MANAGEMENT: Who is responsible, what is your role in the fund-raising/ general } \\
\text { running for the school funds, how to establish accountability structure of school monies }\end{array}$ \\
\hline $\begin{array}{l}\text { HANDLING SCHOOL DISCIPLINE: Policy making for teachers/ students/ workers/ parents; what } \\
\text { should be clear about personal and professional boundaries; what steps are taken when one } \\
\text { violates this rules; students school rules; how are they enforced, when and how to make some } \\
\text { changes; how serious the school leadership should be on discipline issues, etc. }\end{array}$ \\
\hline $\begin{array}{l}\text { BUILDING SCHOOL CULTURE OF SUCCESS: Ensuring effective teaching, holding students } \\
\text { responsible for their school tasks, building a learning environment on campus; how to build a } \\
\text { team work spirit in your school, how free teachers are in trying a new thing that might bring a } \\
\text { real change in learning and achievement; how to stop selfish motives and destructive } \\
\text { competitions }\end{array}$ \\
\hline $\begin{array}{l}\text { ORGANIZATION/SCHOOL PHYSICAL STRUCTURE: The symbolic and real meaning for your school } \\
\text { structure, environment, buildings-classroom, dormitories, social centers, playing grounds, offices, } \\
\text { structures, students' facilities, responsibilities in adding and keeping the structures, culture of } \\
\text { cleanliness, leading by action and role model, when to back up and trust the flow, etc. }\end{array}$ \\
\hline $\begin{array}{l}\text { SCHOOL IDENTITY AND SPIRIT-Vision, Mission, Goals, how to form them, who should be } \\
\text { involved, how to keep them, when and how to change them, danger of not having them, nominal } \\
\text { identity, expression of what matters, school values-compromise and non-compromise values; } \\
\text { teachers and students' attitudes on school values... }\end{array}$ \\
\hline $\begin{array}{l}\text { SCHOOL POLICY AND POLITICS: Who makes the policy, how to form or change it; who should be } \\
\text { involved and to what extent; }\end{array}$ \\
\hline $\begin{array}{l}\text { SCHOOL VISION AND MISSION - How to form school vision, who is to be involved, what is role of } \\
\text { the HM in the formation process; where should it be reflected, how is vision related to the } \\
\text { mission, how teachers and students should be involved in the formation of school vision, how to } \\
\text { set long and short term goals and strategies of school development }\end{array}$ \\
\hline $\begin{array}{l}\text { WHAT OTHER TOPICS WOULD YOU ADD? AT LEAST } 4 \text { ! } \\
1 . \\
2 . \\
3 .\end{array}$ \\
\hline
\end{tabular}




\section{NARRATIVE SECTION}

A. Demographics: Fill the blanks, or underline or circle the answer as the case may demand.

1. My gender is $[A]$ Male $\quad[B]$ Female

2. My school is: $[A]$ Boarding school $[B]$ Commuter [Day] school $[C]$ Both $A \& B$

3. My students are: $[A]$ Boys $[B]$ Girls $\quad[C]$ both boys and girls

4. The current number of teachers in my school: Males.

Female. Total.

5. Students populations: Boys. Girls Total

6. My school is in $[A]$ town area

[B] Rural area

7. How many staff do you have? [Staff are workers/employees other than teachers]

8. My school is [A] Private [B] Public-Governmental

9. For the last 5 years my school is normally among the best $[A] 10[B] 20[C] 30-50[D]$ 60-80 [E] OTHER

10. OPTIONAL: The name of my school is

\section{B. Personal and Professional}

1. What do you do best in your job as the HM?

2. What do you wish you could learn to do better at your school? 
3. When you were in college did you study formal school administration/leadership courses?

YES NO [Circle one that applies to you]

4. If "YES" mention all the administrative or leadership courses your college offered.

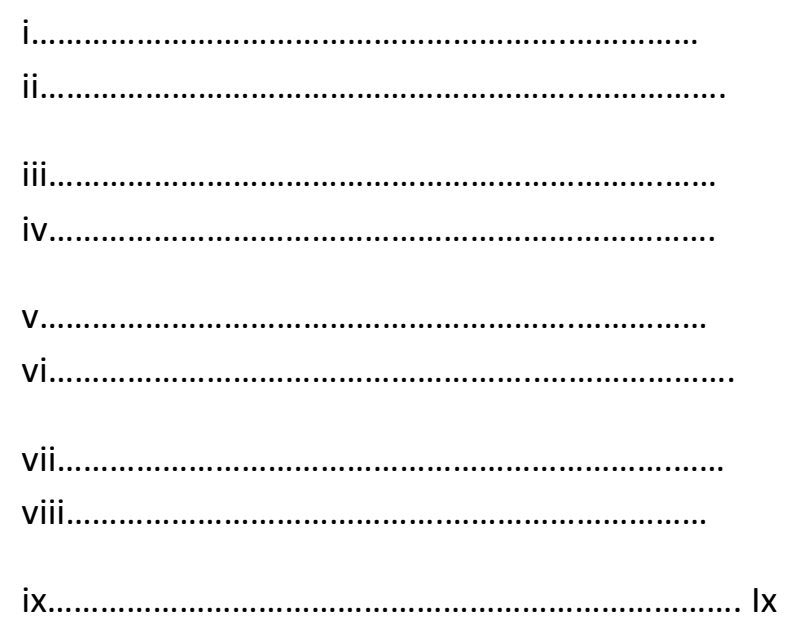

5. Mention the main struggles in your leadership [Things you are not handling well as you should or as you want to]

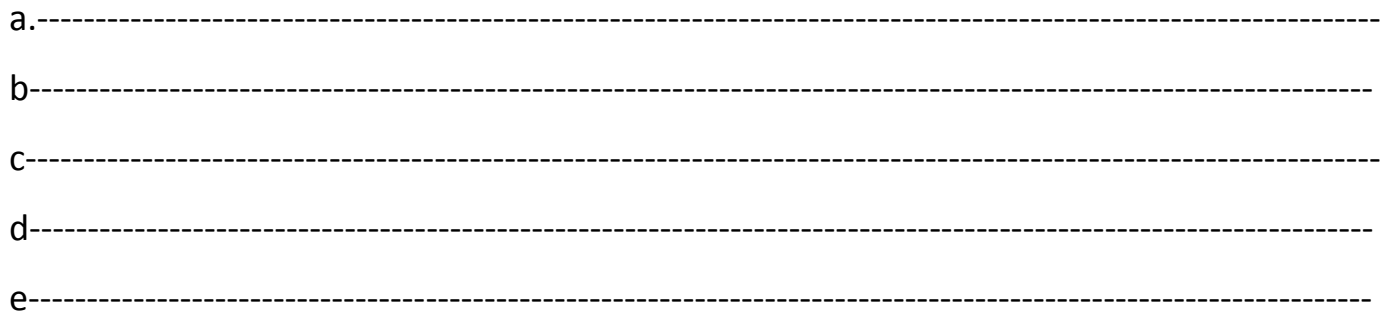

Add more on the separate paper if you need to

6. What do you think you need to do to make your school most effective, that is, to ensure students learning and graduate with competence for higher education or job? 
7. From your experience as HM what do you think Colleges should do for students who will become school HM?

8. Do you have professional development training in your career? YES NO [Circle one that applies].

If yes, is it mandatory to attend? YES NO

How many do you normally attend in a year?

Do you think it is helpful in your job as the headmaster/headmistress? YES NO

9. When did you last attend Professional Development training or workshop or seminar?

10. Any other comments?

Thank you so much for taking you precious time and answer this questions. We truly appreciate. Fr. Peter Siamoo - PSU 
APPENDIX D

PILOT SURVEY LETTER 
Fr. Peter N Siamoo

Portland State University

United States of America

Care of the Catholic Diocese of Moshi

Education Department

Dear the Headmaster/Headmistress,

First of all I would like to express my sincere and heartfelt gratitude to you for taking your precious time and answer these questionnaires. This survey is of duo purposes: One, it will help me to lay a ground of my college academic work; and second and the most important, it will help us [her in our Moshi Diocese] to prepare the ground for improving our Secondary School Leadership. That is why your input is very profound and most valuable. You are the only one who knows best what your school needs to make it the best school of your dream. You also know what you need as the headmaster/headmistress to make you more effective and successful in your job. Help us to know what you need to make the best headmaster/headmistress ever lived! So, please, give us the most honest answer you can.

There are no right or wrong answers to this survey. You can make your answers anonymous, if that will make you more comfortable and honest in answering the questions. So you don't need to identify your school or yourself, if you choose so. You can even add more items you think we need to know in order to help any headmaster/headmistress lead your school better and train more effective future school leaders.

Receive my sincere thanks for your time and your honest answers. Most of all, my appreciation also is for your dedication in making your school the best learning environment for our students.

Sincerely, Fr. Peter $\mathcal{N}$ Siamoo

Student 


\section{APPENDIX E}

INVITATION LETTER FOR THE HMs TO PARTICIPATE IN THE STUDY 
To all Moshi Catholic School Heads of the School,

C/o The Director of Education Department (Superintendent)

P. B. Box 3041 Moshi, Tanzania

Re: INVITATION TO PARTICIPATE IN THE WORKSHOP OF MY
RESEARCH STUDY ON THE EDUCATION LEADERSHIP

Headmaster/Headmistress

Thank you very much for your participation in the Pilot Study in August-December 2011. I analyzed the data you provided and established that student achievement is a number one leadership challenge of Moshi heads of the secondary schools. Your follow up phone calls and emails has further established the same. Because of this, I have decided to use my dissertation study to explore this problem. With this letter, I am inviting you to a 6-day workshop study that will take place at Longuo Retreat Center, Moshi. I have the support of your director or superintendent who has allowed you to use the workshop as your annual professional development requirement, if you choose so.

Please understand that joining in this study is absolutely free, and you can drop from the study at any time if you feel you want to do so. There is no remuneration or stipend of any kind for participating in this study.

The main activities will be field testing the Problem-Based Learning [PBL] Module I created to train school leaders and help them develop their instructional skills so as to improve teaching and learning and so enhance student achievement. If you chose to participate, you will need to be at the retreat center for six days, reporting on Sunday evening July 29, and departing on Saturday evening on August 4, 2012. If you are attending, please respond by email:

revpsiamoo@yahoo.com or call +13306397919

Thank you in advance for helping me do this important study that aims at improving our education for our students.

Sincerely

Peter Siamoo 


\section{APPENDIX F}

A LETTER TO THE SUPERINTENDENT 
Peter Siamoo

1280 NW Saltzman

RD

Portland, OR 97229

April 12, 2012

The Superintendent,

Moshi Catholic Schools District

P. O. Box 3041, Moshi, Tanzania.

Rev. William Ruwaichi,

The Superintendent of Moshi Diocese,

\section{WORKSHOP FOR TESTING A CURRICULUM FOR HIGH SCHOOL PRINCIPALS ON INSTRUCTIONAL LEADERSHIP SKILLS: July 23-28, 2012}

The mentioned workshop is planned to take place in your school district. The principals from your high school have been requested to attend a workshop in which they will be asked to participate in the field testing the Problem-Based Learning Training Module. This is a curriculum I created to respond to the current real problem of student achievement due to lack of quality classroom instruction. They will be given an opportunity to learn some instructional leadership skills, specifically on how to conduct evaluation and supervision of classroom instruction by using Charlotte Danielson's evolution tools. I have bought the Danielson evaluation kits for them.

Training is planned to take place at Longuo Retreat Center from July 23 to July 28,2012 . This time was chosen since they will be in vacation and so they are willing to use part of their vacation time for his purpose. Since they responded positively that they want to attend this workshop I am writing to let you know that this is happening in your school district. I anticipate that they will benefit from this study regardless of whether the curriculum will prove to be effective or not. This workshop will also benefit me for proving that my PBL curriculum is either effective or not, and by providing the data to refine it as the case may be.

Thank you for your cooperation in this matter. I look forward to visiting Moshi Diocese this Summer.

Sincerely 
APPENDIX G

WORKSHOP PROTOCOL 


\section{WORKSHOP PROTOCOL}

\section{Engagement}
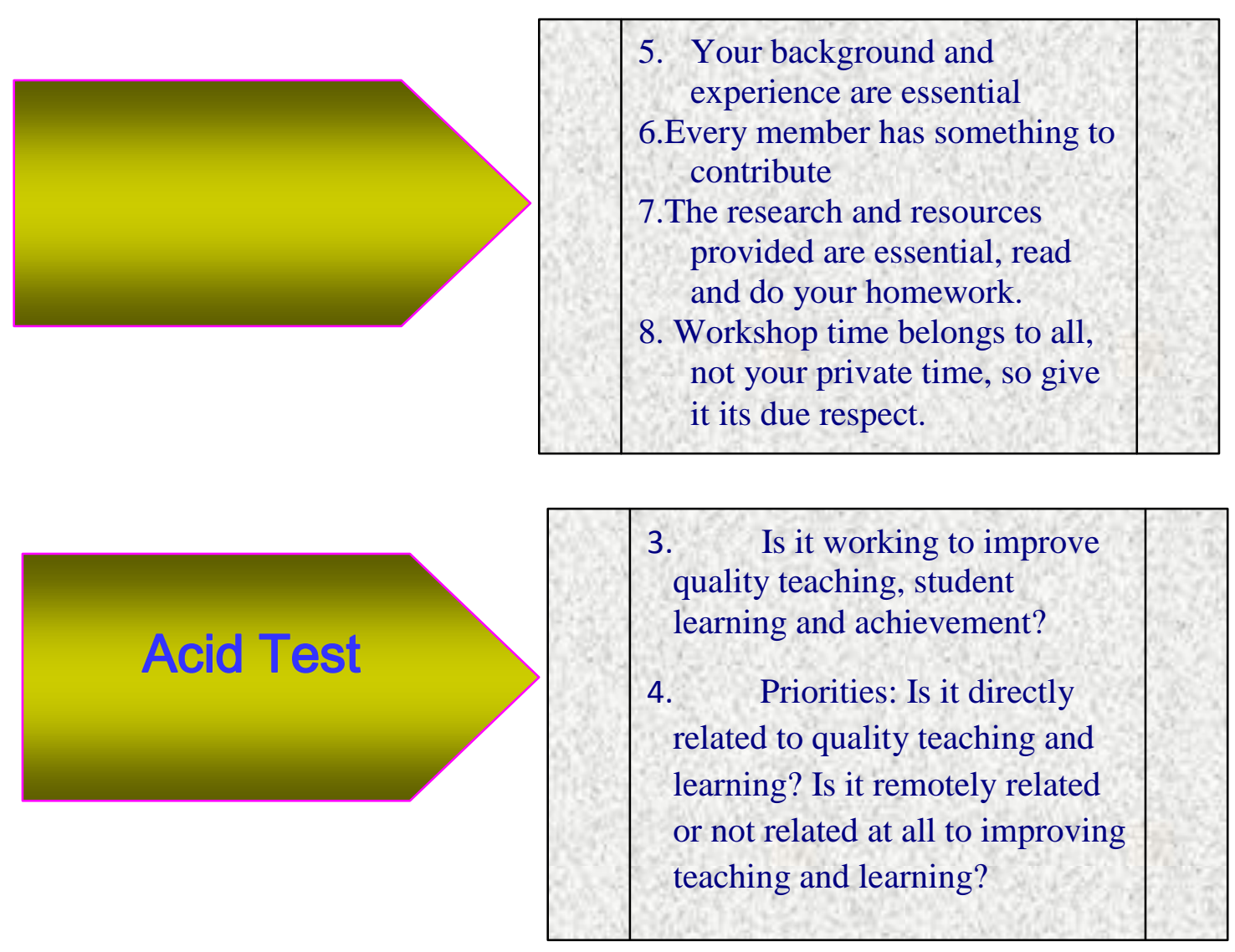

. Your background and experience are essential

Every member has something to provided are essential, read and do your homework. not your private time, so give it its due respect.
8. Report on time always

9. Cell phones: Must be silenced. 10. Avoid side bar conversations.

11. Participation-Others have a right of your active participation.

12. Come prepare and share your thoughts and experiences. 
APPENDIX H

LEARNING OBJECTIVES 


\section{Learning Objectives}

1. The learner will be able to use the resources provided in the module in understanding the relationship between instruction and transformational leadership and quality teaching and learning; and the relationship between ESCI and quality teaching and student achievement.

2. The learner will develop a knowledge base about instructional leadership that helps solving the problem of student achievement in his/her school.

3. The leaner will be able to demonstrate an understanding of the doing teacher evaluation using Danielson's evaluation tool by participating in the group discussion, role playing, and forming action plan resolution presentations on how he/she will implement ESCI in his/her school environment and culture.

4. The learner will be able to demonstrate an understanding of the relevance of the school culture by participating in the process of acculturating the Danielson teacher evaluation.

5. The learner will be able to analyze the school's problem of student underachievement, its main cause, and provide a rationale for changes to take place.

6. The learner will be able to personalize their understanding of how to use Danielson's model of instructional evaluation by presenting a two-year action plan. 
APPENDIX I

GROUP PRESENTATION GUIDELINES 


\section{Group Presentation Guidelines}

You will prepare an action plan that will be presented at the end of your 6 days training workshop. Below are specifications for the action plan:

1. Please prepare a one to two year action plan that reflects that reflects possible solutions to the problems affecting student achievement in your school. The plan should include:

i. The severity of the problem of student achievement in your school. [You can use the last 4 years of the national exam results to concretize your claim].

ii. Explain how quality teaching is related to the problem

iii. Activities that will help quality teaching and learning

iv. How to restructure your leadership schedule and routine to be responsive to the goals of solving the problem

v. Strategies for gaining the support of the important players who can facilitate school change that will address and solve this most urgent problem.

2. The action plan should not exceed four pages, in the sense that each Danielson's Domain should have no more than one page.

3. One member from your group should represent the group and present your plan in class on the last day of your training.

[NB: Just for your information, among your audience together with your cohort will be Most Rev. Isaac Amani, the Bishop of Moshi, Rev. Fr. William Ruwaich, the superintendent of Moshi, Dr. Philbert Vumilia, the President of Mwenge University, 5 professors from Mwenge University and some priests and high school teachers who asked to attend and have promised to be there. Some of them are your teachers!]

4. You will be asked some question from the audience. Please, get prepared to answer them. The presenter or any member of his/her group is expected to answer those questions. Remember to tell us why you chose the recommendations you are making in your plan. 
APPENDIX J

GROUP ROLES AND RULES 


\section{Group Roles and Rules}

Roles of the Manager:

$\diamond$ Responsible for planning and chairing the group

$\checkmark$ Remind members of the group protocols such us silencing their cell phones etc.

$\checkmark$ Facilitate the group activities or appoint a group member to do the job

$\diamond$ Ensure order and active participation of the members.

$\diamond$ Push for clarity and closure of action item

$\diamond$ Remind the members to keep focused on the agenda

$\checkmark$ Manages time or appoint a person in the group for the job

$\diamond$ Appoint the secretary and ensures the minutes/points are recorded clearly

$\checkmark$ Ensure that the group has a presenter of the group's ideas to the main cohort

$\checkmark$ Answer/clarify the questions of the members or seek answers for them

$\diamond$ Get agreement on the common problem and process before beginning or continuing with another task

$\checkmark$ Protect individuals from personal attack

$\diamond$ Encourage active participation in the discussion or role play

\section{Role of Recorder}

$\checkmark$ Maintains group memory: main idea, suggestions, solutions, inquiries.

$\diamond$ Check with group on accuracy and ask for feedback

$\checkmark$ Organize ideas logically and cross check with the group

$\checkmark$ Consult with the workshop facilitator in case more time is needed to get the work done.

\section{Role of Group Members}

$\diamond$ Keep the chair neutral

$\diamond$ Keep an eye on group memory and accuracy

$\checkmark$ Actively participate and contribute from personal and professional experiences

$\diamond$ Respect others' opinions and be respectful when correcting/expressing different opinion

$\diamond$ Listen attentively

$\checkmark$ Don't be defensive

$\diamond$ Don't take things personally

$\diamond$ Create and maintain a study environment by avoiding unnecessary interruption [Silence your cell phone, no smoking in the unauthorized areas etc.]. 
APPENDIX K

WORKSHOP LEARNING OBJECTIVES 


\section{Workshop Learning Objectives}

1. The learner will be able to use the resources provided in the module in understanding the relationship between instruction and transformational leadership and quality teaching and learning; and the relationship between ESCI and quality teaching and student achievement.

2. The learner will develop a knowledge base about instructional leadership that helps solving the problem of student achievement in his/her school.

3. The leaner will be able to demonstrate an understanding of the doing teacher evaluation using Danielson's evaluation tool by participating in the group discussion, role playing, and forming action plan resolution presentations on how he/she will implement ESCI in his/her school environment and culture.

4. The learner will be able to demonstrate an understanding of the relevance of the school culture by participating in the process of acculturating the Danielson teacher evaluation.

5. The learner will be able to analyze the school's problem of student underachievement, its main cause, and provide a rationale for changes to take place.

6. The learner will be able to personalize their understanding of how to use Danielson's model of instructional evaluation by presenting a two-year action plan. 
APPENDIX L

TALK BACK QUESTIONNAIRE 
Number:

Date:

\section{TALK BACK}

Thank you for taking the time to respond to the questions below. Please, feel free to continue your remarks on the reverse page, if necessary, in answer to the questions.

1. What stood up as the highest point of the day? (Please remember to mention the session, the topic and specifically why you thing it was the highest highlight of the day)

2. What changes are you planning to make in your leadership or school as a result what you learned this day?

3. What would you change to make the next day more effective?

4. Any other comments or recommendations? 


\section{APPENDIX M}

DANIELSON ADAPTATION PROCESS GUIDELINES 


\section{Danielson's Four Domains Adaptation Process Guidelines}

At your own time read carefully and reflectively all the materials provided for Danielson's Four Domains. Follow the following guidelines to read and do all the works associated with this work. This work is designed to be done progressively, so follow the numerical order in doing this work as follows:

11. Read though the longer version materials from Domain 1 to 4 . Then read the shorter version, the rubrics.

12. Re-read each domain at a time. This time highlight or write down any word, statement, phrase, or claim that does not seem to make sense to you or seems incompatible with your school system and culture.

13. By using stick notes, or writing on the pads given to you, suggest or add any word, statement, phrase, claim or paragraph that is not in the given domain materials, but you think will make the domain compatible to your school system and culture or will make it more effective to improving the quality of teaching and learning in your school.

14. Re-read the corrected version you have made [omitting all that you crossed out and including what you have inserted in]. Pay attention while reading if it makes sense to you, if it sounds culturally sensitive to your school culture, and if feel comfortable standing for its implementation in your school. In doing this pay attention to its meaning and flow, and see if it makes sense to you or not.

15. Write down the reasons why you think your corrections make the domains more effective in improving the quality of classroom teaching and learning.

16. Bring your final draft to your small discussion group for further discussion on the same. Be prepared to give your reasons as to why you thought the changes you made should be embraced. Be reasonable and ready to change your stand if more convincing reasons contrary to yours are given. The group secretary will write the final domain draft after all the adjustments of the group are done. This draft will have all the adjustments of the individual group members as agreed or voted for by the group. The group chair will ensure that a fair procedure is followed to arrive at conclusion on what are to be included or excluded in the final draft of the domain.

17. Each group will deal with only one domain. Since there are four groups, each group will have only one.

18. The final copy of the adapted domain will be compared with the Danielson's rubrics in which changes will be made in the rubrics to reflect the changes made in the domain. The reason for doing this is that rubrics are the abbreviation form of the four domains.

19. The final copy of the group-adapted domain materials will be presented to the main cohort. The cohort will discuss the validity of the adjustments made by the group. The cohort will have the power keep the adjustments if the cohort class is convinced that they will serve the purpose, or reject them. The class can also make further adjustments by adding or removing anything that will be agreed on as making the domain/rubrics more effective and culturally relevant for their work.

20. This will be the final copy the HMs will take back to their schools and their leadership tool of improving and influencing quality teaching and learning. 
APPENDIX N

WORKSHOP GENERAL GUIDING QUESTIONS 


\section{General Study Guide Questions}

6. What do I need to do as a Headmaster/headmistress [HM] to improve teaching and learning in my school?

7. What are the major factors that influence quality teaching and learning and how can I make them applicable in my school?

8. Is there anything else I can do under my power to help teachers improve student learning and achievement?

9. What other HMs are doing in their schools which seem to help increase academic performance that are not in my school?

10. How is my leadership style and priorities associated to the current quality of teaching and students' performance? 
APPENDIX O

COURSE OVERVIEW: THE PURPOSE OF THE WORKSHOP 


\section{Course Overview - Purpose of the Workshop, Learning Goals, and Objectives}

1. Acquire an understanding of the headmaster/headmistress [HM] work as an instructional leader, problems, frustrations and challenges associated with the job.

2. Acquire the sense of what is involved in performing teacher evaluation including classroom instructional evaluation and supervision.

3. Acquire some ways of making priorities in the principal's excise of leadership and give instruction its due priority and importance.

4. It takes expertise to create expertise (Fink \& Markholt, 2011). This course work is intended to make HM an instructional instructor and expert so as to be able to train his/her teachers aiming at making them instructional experts as well.

5. Add some competencies and confidence in the instructional leadership role and facilitating instructional improvement through supervision, evaluation, feedback and teachers' improvement through appropriate professional development programs.

6. Acquire motivation of doing teacher evaluation after knowing how to do it and what it can achieve, and commit to do it. Also acquire and express the conviction that teacher evaluation can improve teaching and learning. 


\section{APPENDIX P}

BRAINSTORMING QUESTIONS: PRIOR KNOWLEDGE AND ANTICIPATION 


\section{Brainstorming Questions: Prior knowledge \& Anticipation}

11. What do you know about improving student achievement through Instructional Evaluation and Supervision?

12. What do you want to know about your role as an instructional leader in terms of quality instructions of your teachers?

13. How student learning and achievement do connect to instructional supervision and evaluations?

14. What does the HM need to know to become an efficient instructional leader by performing formal, informed instructional supervision and evaluation in any discipline at any level?

15. If you were to choose one thing that will make your school known for, what will that be?

16. What are some of the ways in which a school leader might approach the task of establishing a school and his/her personal leadership priorities?

17. How supervision and evaluation are helpful in the decision making to initiate school change, improve teachers' instructions, student learning and achievement?

18. How is instructional supervision and evaluation connected to the key roles of HM?

19. How do I use my knowledge as HM to develop commitment to institutionalize the instructional and transformational leadership?

20. How do you exercise your leadership so as to directly improve student learning and achievement? 


\section{APPENDIX Q}

WORKSHOP EVALUATION QUESTIONNAIRE 


\section{Workshop Evaluation Questionnaires}

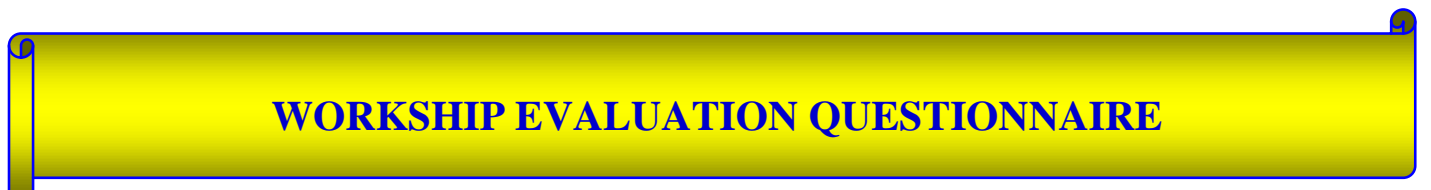

Evaluation of the Workshop, the Presenter and Competence and Confidence Indicator:

5. What did you like most in this workshop?

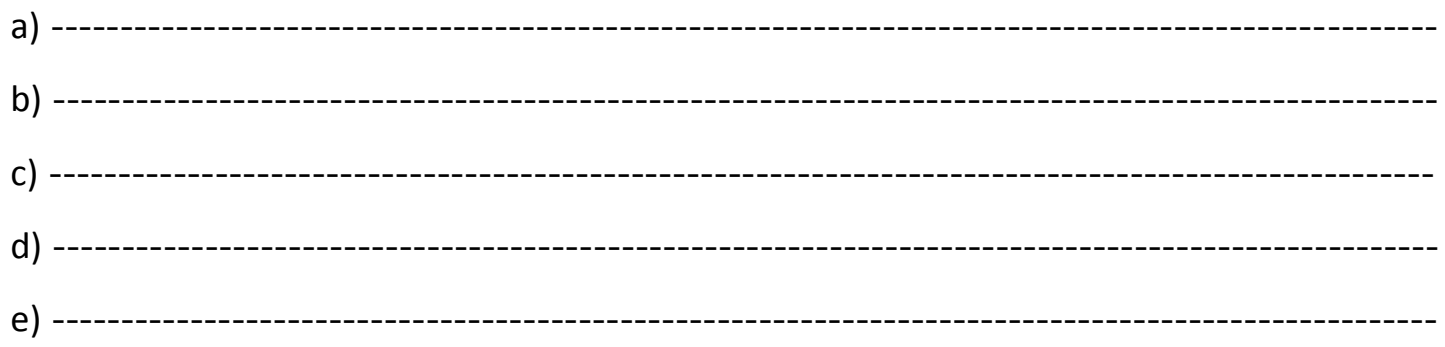

6. What did you not like in the training process?

a)

b)

c)

d)

e)

7. What would you change to make this workshop more effective for school leaders?

a)

b)

c)

d)

e)

8. If you were to attend the same workshop again, what elements would you add?

a)

b)

c)

d)

e) 
9. In the following chat, rate yourself, the presenter and the effectiveness of the workshop. Check or darken only one circle per item.

\begin{tabular}{|l|l|l|l|l|}
\hline Measure Yourself, the Presenter(s) and the Workshop & $\begin{array}{c}1= \\
\text { Poor }\end{array}$ & $\begin{array}{c}2= \\
\text { Good }\end{array}$ & $\begin{array}{c}3=\mathrm{Ve} \\
\text { ry } \\
\text { Good }\end{array}$ & $\begin{array}{c}4 \\
\text { Excell } \\
\text { ent }\end{array}$ \\
\hline My confidence of conducting ESCI before this workshop & $\bigcirc$ & $\bigcirc$ & $\bigcirc$ & $\bigcirc$ \\
\hline My confidence of conduction ESCI Now after this workshop & $\bigcirc$ & $\bigcirc$ & $\bigcirc$ & $\bigcirc$ \\
\hline $\begin{array}{l}\text { The way I feel now in doing conference with a teacher of } \\
\text { his/her instruction }\end{array}$ & $\bigcirc$ & $\bigcirc$ & $\bigcirc$ & $\bigcirc$ \\
\hline My Knowledge or skills of doing ESCI before the workshop & $\bigcirc$ & $\bigcirc$ & $\bigcirc$ & $\bigcirc$ \\
\hline My knowledge or skills of doing ESCI after the workshop & $\bigcirc$ & $\bigcirc$ & $\bigcirc$ & $\bigcirc$ \\
\hline $\begin{array}{l}\text { My level of competence in doing evaluation before the } \\
\text { workshop }\end{array}$ & $\bigcirc$ & $\bigcirc$ & $\bigcirc$ & $\bigcirc$ \\
\hline $\begin{array}{l}\text { My level of competence in doing evaluation before the } \\
\text { workshop }\end{array}$ & $\bigcirc$ & $\bigcirc$ & $\bigcirc$ & $\bigcirc$ \\
\hline The overall rate of the presenter(s) of the workshop & $\bigcirc$ & $\bigcirc$ & $\bigcirc$ & $\bigcirc$ \\
\hline $\begin{array}{l}\text { My motivation to do ESCI despite by busy schedule before } \\
\text { the workshop }\end{array}$ & $\bigcirc$ & $\bigcirc$ & $\bigcirc$ & $\bigcirc$ \\
\hline $\begin{array}{l}\text { My motivation to do ESCI despite by busy schedule after the } \\
\text { workshop }\end{array}$ & $\bigcirc$ & $\bigcirc$ & $\bigcirc$ & $\bigcirc$ \\
\hline My conviction before the workshop that ESCI can help us & $\bigcirc$ & $\bigcirc$ & $\bigcirc$ & $\bigcirc$ \\
\hline My conviction after the workshop that ESCI can help us & $\bigcirc$ & $\bigcirc$ & $\bigcirc$ & $\bigcirc$ \\
\hline $\begin{array}{l}\text { The overall rate of the content/materials learned in the } \\
\text { workshop }\end{array}$ & $\bigcirc$ & $\bigcirc$ & $\bigcirc$ & $\bigcirc$ \\
\hline The effect of this workshop in my future leadership practices & $\bigcirc$ & $\bigcirc$ & $\bigcirc$ & $\bigcirc$ \\
\hline $\begin{array}{l}\text { The rate of skills I acquired as an Instructional Leader, } \\
\text { through this workshop }\end{array}$ & $\bigcirc$ & $\bigcirc$ & $\bigcirc$ & $\bigcirc$ \\
\hline $\begin{array}{l}\text { The possibility of improving the quality of teaching and } \\
\text { learning in my school after this workshop }\end{array}$ & $\bigcirc$ & $\bigcirc$ & $\bigcirc$ & $\bigcirc$ \\
\hline $\begin{array}{l}\text { The possibility of being more effective leader to influence } \\
\text { student achievement in my school after this workshop }\end{array}$ & $\bigcirc$ & $\bigcirc$ & $\bigcirc$ & $\bigcirc$ \\
\hline $\begin{array}{l}\text { The Likelihood that I will use the skills I learned to actually } \\
\text { conduct classroom evaluation with my teachers from now on } \\
\text { is }\end{array}$ & $\bigcirc$ & $\bigcirc$ & $\bigcirc$ & $\bigcirc$ \\
\hline
\end{tabular}

10. Any other comments? 
Thank you so much for your active participation and for your commitment to the lives of the young generation of this country. You are making a difference!

Peter Siamoo (PSU, USA) 
APPENDIX R

PARTICIPANTS' EXPECTATIONS AND THEIR FULFILLMENT: ASSESSMENT 


\section{Participants' Expectations and Their Fulfillment or Lack of Thereof}

\section{What do you expect/anticipate to learn from this workshop?}

Write your response at the back of pre-evaluation sheet, then write it also on the given piece of paper and keep it safely till the end of the workshop as you will be asked if your expectations were met.

[31 schools: 5 did not attend; 3 sent Vice Principals and 2 public school principal attended thus making a total of 28 participants: 25 principals and 3 vice principals]

\begin{tabular}{|c|c|}
\hline PERSON & PRE-WORKSHOP RESPONSES \\
\hline 1 & $\begin{array}{l}\text { I would like to learn more about how to help/uplift teachers who have the } \\
\text { tendency of being late for classes, lazy in teaching. Even after several } \\
\text { friendly talks, the problem remains. } \\
\text { - I want to learn how to improve student performances despite the fact that } \\
\text { the intake might be of the average to poor students. } \\
\text { - I want to know how to give a more holistic education }\end{array}$ \\
\hline 2 & $\begin{array}{l}\text { - To improve my leadership skills as HM } \\
\text { - Techniques on how to motivate my teachers to improve teaching } \\
\text { instructions in the classrooms } \\
\text { - Techniques on making priorities in my school to enhance student } \\
\text { performance } \\
\text { - Financial management in my school } \\
\text { - The use of technology since it is the area I really feel ashamed of. }\end{array}$ \\
\hline 3 & $\begin{array}{l}\text { - Tool that will help me to supervise the school and make it more effective } \\
\text { in teaching and learning } \\
\text { - How to be firm to my teachers without being a bully } \\
\text { - How to make other source of school income than school fees. }\end{array}$ \\
\hline 4 & $\begin{array}{l}\text { How to treat my staff especially teachers more psychologically than } \\
\text { tricking them. That is how can I make them follow my lead by making } \\
\text { them bye in and own the process of reforming my school without pushing } \\
\text { them? }\end{array}$ \\
\hline 5 & $\begin{array}{l}\text { - I would like very much to learn about "budgeting." } \\
\text { - I want to know more about computer use, especially PowerPoint and Excel }\end{array}$ \\
\hline 6 & $\begin{array}{l}\text { I anticipate getting the skills and techniques that will enable me to } \\
\text { effectively do the Evaluation and Supervision of Classroom Instruction } \\
\text { [ESCI]. I must say, I do not know anything about this issue and it sounds } \\
\text { that this might help me change my mind from resignation because I feel } \\
\text { that student performance is a shame is my school and I have run out of } \\
\text { new ideas to make it work. This workshop might save my employment, } \\
\text { God help! }\end{array}$ \\
\hline 7. & - To maximize quality teaching and leaning in my institution. \\
\hline 8 & $\begin{array}{l}\text { I would like to learn how to really help my teachers to be good teachers } \\
\text { and to help my students be good students and to perform well. } \\
\text { - How to help slow learners to achieve as much. }\end{array}$ \\
\hline
\end{tabular}




\begin{tabular}{|c|c|}
\hline 9 & $\begin{array}{l}\text { - Be encouraged to do ESCI and to meet its expected challenges } \\
\text { - Be more supportive to teachers and other school staff } \\
\text { staff to set a good example and model effective teaching to my teaching } \\
\text { - Avoid blames and be supportive to students as we have a habit of blaming } \\
\text { them for their failing in examinations as being lazy, not studying enough, } \\
\text { not serious with their future etc. }\end{array}$ \\
\hline 10 & $\begin{array}{l}\text { - School leadership techniques } \\
\text { - Know more about computer in making presentations to my staff }\end{array}$ \\
\hline 11 & $\begin{array}{l}\text { - How to communicate negative feedback after teacher evaluation } \\
\text { - How to hand resistance for those teachers who don't like any change }\end{array}$ \\
\hline 12 & $\begin{array}{l}\text { - How to be more professional as in instructional leader who knows not only } \\
\text { what I am doing but also what every teacher is doing and push them to the } \\
\text { next level of performance. }\end{array}$ \\
\hline 13 & $\begin{array}{l}\text { Improve my ability to improve the grades of my students not only in the } \\
\text { classes I teach but as a leader to improve the grades of all the students in } \\
\text { my school } \\
\text { Make both teachers and student accountable for teaching and learning } \\
\text { process }\end{array}$ \\
\hline 14 & $\begin{array}{l}\text { - After going through the entire schedule of the workshop, I really want to } \\
\text { know about "Consultancy Protocol." I do not have a clue of what this is } \\
\text { and how can it help me as an educational leader }\end{array}$ \\
\hline 15 & $\begin{array}{l}\text { - I want to know more about what makes a quality teacher and how I can be } \\
\text { of help to make my teachers quality teachers. I could do this, I think I think } \\
\text { will be forever thankful because I know it will make a huge difference in } \\
\text { the student performance in my school }\end{array}$ \\
\hline 16 & - I want to know about the skills of ESCI \\
\hline 17 & $\begin{array}{l}\text { - Leadership skills for quality teaching and learning } \\
\text { - } \text { Instructional supervision and evaluation done in a supportive manner } \\
\text { - Assessment of teachers and communication of feedbacks in a non- } \\
\text { - } \text { accusatory way } \\
\end{array}$ \\
\hline 18 & $\begin{array}{l}\text { I expect to get some new information about how to be more effective as a } \\
\text { leader and all around school leadership in realizing goals and objective we } \\
\text { set at the beginning of every school year. }\end{array}$ \\
\hline 19 & $\begin{array}{l}\text { - How to make a new vision of my school that reflects our goals and } \\
\text { objective of quality teaching and higher student performances }\end{array}$ \\
\hline 20 & $\begin{array}{l}\text { - I want to know how to effectively conduct ESCI } \\
\text { - I want to see the anticipated challenges of ESCI and how to tackle those } \\
\text { challenges as the heard of the school }\end{array}$ \\
\hline 21 & $\begin{array}{l}\text { - I am a new headmistress, so any thing you have prepared for this } \\
\text { workshop will be of great for me since I even do know where to begin to } \\
\text { improve student achievement. My predecessor left because of the same } \\
\text { challenge that she could not make teachers do their job and so my school is }\end{array}$ \\
\hline
\end{tabular}




\begin{tabular}{|c|c|}
\hline & among the worst schools in the region academically. Please, help me! \\
\hline 22 & $\begin{array}{l}\text { - How to make teachers and other staff own their responsibility without } \\
\text { waiting to be pushed. } \\
\text { - How to do ESCI and make a constructive feedback to my teachers }\end{array}$ \\
\hline 23 & $\begin{array}{l}\text { - How to do ESCI and communicate feedback without making the teacher } \\
\text { feel like he/she is singled out or is not qualified enough to teach in my } \\
\text { school }\end{array}$ \\
\hline 24 & $\begin{array}{l}\text { - I want to know more about Transformation leadership. I know nothing } \\
\text { about this concept. It sounds like I need it as a leader who wants to } \\
\text { influence my teachers to be a better job }\end{array}$ \\
\hline 25 & $\begin{array}{l}\text { - How to do ESCI effectively } \\
\text { - How to make my teachers agree with it since it sounds to be a new thing in } \\
\text { the system and my teachers are very opposed to new things } \\
\text { - How can I improve student performance in my school }\end{array}$ \\
\hline 26 & $\begin{array}{l}\text { - How to use consultancy protocol in decision-making. My school is in the } \\
\text { countryside and I do have access to legal consultations. I think this might } \\
\text { help in decision-making. }\end{array}$ \\
\hline 27 & $\begin{array}{l}\text { - Just anything I can do to support my teachers and hold them accountable } \\
\text { for a better student performance }\end{array}$ \\
\hline 28 & $\begin{array}{l}\text { - Any skills and tools to improve student teaching and learning } \\
\text { - Have better National Exam results } \\
\text { - The use of PowerPoint might be fun to know and use } \\
\text { - Budgeting and financial management in the day in day out school duties as } \\
\text { a leader }\end{array}$ \\
\hline \multicolumn{2}{|c|}{$\begin{array}{l}\text { Did you learn what you anticipated/wanted in this workshop? [Please, read what you } \\
\text { anticipated to learn to be precise in answering this question]. }\end{array}$} \\
\hline 1 & $\begin{array}{l}\text { - I really learned what I anticipated, that is instructional leadership, } \\
\text { instructional evaluation and supervision are vital for quality teaching, and } \\
\text { helping teachers to set high expectations for learners' high academic } \\
\text { achievement. I got more than I expected, thank you. }\end{array}$ \\
\hline 2 & $\begin{array}{l}\text { - I was not expecting to learn what I have learned. For the short time I have } \\
\text { been here I have gained much more that I anticipated. I did not anticipate } \\
\text { what I went through. } \\
\text { - I am going back a complete changed head of the school. } \\
\text { - May I, from the bottom of my heart, convey my sincere thanks to the } \\
\text { facilitator! Well done! Keep it up. We need more of this kind frequently. }\end{array}$ \\
\hline 3 & $\begin{array}{l}\text { - The workshop enhanced what I knew and deepened it, I am thankful for it. } \\
\text { It was well done. Congratulations for a job well done. }\end{array}$ \\
\hline 4. & $\begin{array}{l}\text { - Yes, I learned what I wanted in this workshop; but still more time was } \\
\text { needed. }\end{array}$ \\
\hline 5. & - I want more handouts \\
\hline
\end{tabular}




\begin{tabular}{|c|c|}
\hline & $\begin{array}{l}\text { - I know now how to make close supervision/ follow up } \\
\text { - Excellent performance at the school } \\
\text { - To improve teaching and learning process }\end{array}$ \\
\hline 6. & $\begin{array}{l}\text { - Frankly speaking, I did not have a clear picture of what this workshop was } \\
\text { all about. Partly because I did not know much about ESCI. But now I } \\
\text { realize that what I have learned here is very necessary for me as a school } \\
\text { head in order to improve academic performance at my school, but also to } \\
\text { develop integrity and ethical conduct of both my staff and students. }\end{array}$ \\
\hline 7 & $\begin{array}{l}\text { - In this workshop, I learned a lot of skills more that I deserve. } \\
\text { I promise that, basing on all the things I learned from this workshop, I will } \\
\text { make my teachers the first priority in my daily business as the head of the } \\
\text { school. } \\
\text { - Lastly, I am now committed to improve the achievements of my students } \\
\text { through the knowledge I get from this workshop. Thanks. }\end{array}$ \\
\hline 8 & $\begin{array}{l}\text { - I have attained more knowledge than what I anticipated. Thank you so } \\
\text { much. }\end{array}$ \\
\hline 9 & $\begin{array}{l}\text { - Yes, I did get so many skills I was not familiar with before. So this } \\
\text { workshop enriched me in different areas of my work and makes me } \\
\text { comfortable in my daily school leadership activities and teaching. }\end{array}$ \\
\hline 10 & $\begin{array}{l}\text { - I am sure of one thing; I learned how to help my teachers to do better in } \\
\text { improving our students to do better. }\end{array}$ \\
\hline 11 & $\begin{array}{l}\text { Yes, I learned what I anticipated in this sense: } \\
\text { - The things which I learned from day one of this workshop to today have } \\
\text { influenced my effective working as the HM. I knew some of them, but not } \\
\text { in the sense I have learned and know them now. I am really lucky to get } \\
\text { this. } \\
\text { - I feel that I am doing back as a new person who can make both my } \\
\text { students and teachers more effective. } \\
\text { More often than not I will visit and supervise my teachers in the classroom } \\
\text { and allow them to assess themselves with the rubrics I have, and } \\
\text { immediately give them my feedback. I will always remember that my role } \\
\text { in this is to be supportive to make my teachers to reach their best potential } \\
\text { as professional teachers. } \\
\text { With that in mind, I surely agree that it was my expectations that I will } \\
\text { come out more informed and in fact it is the case. Thanks. }\end{array}$ \\
\hline 12 & $\begin{array}{l}\text { - Yes, I did. It is better even for the governmental [public] schools to get this } \\
\text { kind of seminar because they have even graver academic problems and the } \\
\text { heads of the schools and teachers could really benefit from this kind of } \\
\text { knowledge. }\end{array}$ \\
\hline 13 & $\begin{array}{l}\text { - Oh my God! What a wonderful workshop! I got more than I ever } \\
\text { imagined. The workshop literally transformed me and my school has to } \\
\text { change for sure. Thank you. }\end{array}$ \\
\hline 14 & - Yes, I learned more than I expected. \\
\hline 15 & - Yes, I did and thank you \\
\hline 16 & - The general answer is yes. \\
\hline
\end{tabular}




\begin{tabular}{|c|c|}
\hline 17 & $\begin{array}{l}\text { - Personally, I learned exactly what I really wanted to study, and yes, more } \\
\text { than what I could ask for. I was more organized and informative than I } \\
\text { could ever imagine. }\end{array}$ \\
\hline 18 & $\begin{array}{l}\text { - Yes, I learned something I always struggled to improve: the academic } \\
\text { performance in my school. }\end{array}$ \\
\hline 19 & - Yes, I have learned what I wanted in this workshop \\
\hline 20 & $\begin{array}{l}\text { - Yes, I learned what I expected as I learned the following which will be } \\
\text { more of use in my leadership: } \\
\checkmark \text { Consultation protocol [ I did not know this, it was excellent]. } \\
\checkmark \text { HM as an instructional and transformational leader } \\
\checkmark \text { The } 4 \text { domains of teacher evaluation and teaching responsibility: } \\
\circ \quad \text { Planning and Preparation } \\
\circ \text { The classroom environment } \\
\circ \quad \text { Instruction } \\
\quad \text { P Professional responsibility-good way to serve community. } \\
\text { - I also learned } \\
\circ \text { Budgeting } \\
\bigcirc \text { Financial management } \\
\circ \text { Risk management etc. }\end{array}$ \\
\hline 21 & $\begin{array}{l}\text { - Yes, I learned what I anticipated/wanted in this workshop. Moreover, I } \\
\text { also learned what I did not expect. I appreciate and acknowledge the work } \\
\text { done by the facilitator. It was well conducted and it is something I wish to } \\
\text { have regularly at least once a year. }\end{array}$ \\
\hline 22 & - Yes \\
\hline 23 & $\begin{array}{l}\text { - Yes, I really get more than what I anticipated. However, I wish we had } \\
\text { more group discussion time. I would suggest that this kind of intense } \\
\text { workshop to be done at least in two weeks. }\end{array}$ \\
\hline 24 & $\begin{array}{l}\text { - Absolutely, only it was too intense, too much to process within a short } \\
\text { time. }\end{array}$ \\
\hline 25 & - Yes, I feel really tired, but it is worth it. \\
\hline 26 & $\begin{array}{l}\text { - More than I anticipated, I feel so good because I was about to send my } \\
\text { vice! }\end{array}$ \\
\hline 27 & $\begin{array}{l}\text { - Wow! I feel to be a new person, new perspective, energized and ready to } \\
\text { launch academic reform in my school. } \\
\text { - I anticipated some doubts from my teachers, but once they know what this } \\
\text { is all about, I don't doubt that they will get on board. }\end{array}$ \\
\hline 28 & $\begin{array}{l}\text { - Yes, and beyond, only the schedule was too time and group discussions } \\
\text { were not given enough time for all to share their experiences. }\end{array}$ \\
\hline
\end{tabular}

Note: There were more than 24 responses which indicates that some participants filled more than one response forms. 


\section{APPENDIX S}

EVALUATION OF CONTENT AND PRESENTERS 


\section{Evaluation of the content and presenters}

The all the 24 participants responded that the quality of the content of the training module and of the presenter(s) either met or exceeded their expectations.

\begin{tabular}{|c|c|c|c|}
\hline The Materials, activities and presenters & 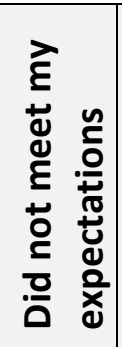 & 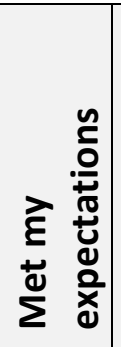 & 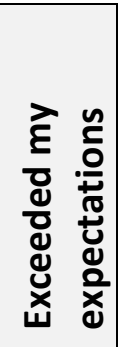 \\
\hline $\begin{array}{l}\text { The overall quality of the materials/ resources you were given } \\
\text { to read for the class work }\end{array}$ & 0 & 0 & 24 \\
\hline The overall quality of group discussion engagements & 0 & 4 & 20 \\
\hline The overall quality of Presenter(s) & 0 & 1 & 23 \\
\hline $\begin{array}{l}\text { The overall quality of the content presented by the main } \\
\text { presenter(s) }\end{array}$ & 0 & 2 & 22 \\
\hline The overall quality of the entire training & 0 & 0 & 24 \\
\hline The skills I learned about teacher evaluations & 0 & & \\
\hline $\begin{array}{l}\text { The confidence I gained as a result of participating in this } \\
\text { workshop }\end{array}$ & 0 & 2 & 22 \\
\hline The level of competence gained as a result of this training & & & \\
\hline
\end{tabular}


APPENDIX T

ADAPTED DANIELSON EVALUATION RUBRIC 


\section{Adapted Danielson Evaluation Rubric}

\begin{tabular}{|c|c|c|}
\hline & Unsatisfactory & Basic \\
\hline $\begin{array}{l}\text { Planning and } \\
\text { Preparation }\end{array}$ & $\begin{array}{l}\text { Teachers' plans reflect little understanding of the } \\
\text { content, the students, their background and available } \\
\text { resources. Instructional outcomes are either lacking or } \\
\text { inappropriate; assessment methodologies are inadequate } \\
\text { or unknown. Lesson objectives, scope, and instructional } \\
\text { strategies are not mentioned or not clear. The lesson } \\
\text { plan does not follow the current curriculum of the } \\
\text { ministry of education; and does not follow the National } \\
\text { Examination Council of Tanzania [NECTA] } \\
\text { suggestions. The standards are not reflected in the plan. } \\
\text { There is no link of the lesson with overall national } \\
\text { policy of education for self reliance. No hands on or } \\
\text { group activities. }\end{array}$ & $\begin{array}{l}\text { Teachers' plans reflect moderate understanding of the content, the } \\
\text { students, and the available resources. Some instructional outcomes } \\
\text { are suitable to the students as a group, and approaches to } \\
\text { assessment are partially aligned to the goal. There is little tie of } \\
\text { the lesson to the students real life and their diverse tribal values, } \\
\text { self reliance and some connection to other subjects or disciplines. } \\
\text { There is a partial link of the lesson to the current curriculum of the } \\
\text { ministry of education; and NECTA directives, and overall national } \\
\text { policy of education for self reliance. Group activity guidelines } \\
\text { partially reflect the understanding of the content. }\end{array}$ \\
\hline $\begin{array}{c}\text { Classroom } \\
\text { Environment }\end{array}$ & $\begin{array}{l}\text { Classroom environment is characterized by chaos and } \\
\text { conflict, with low expectations for learning, no clear } \\
\text { standards of student conduct, no class rules or they are } \\
\text { not enforced, poor use of physical space, disorganized } \\
\text { sitting order, negative interactions between individuals, } \\
\text { and disruption during class; no respect between teacher } \\
\text { and student and among students. There is littering, } \\
\text { chewing or eating, random talking and movements } \\
\text { during instruction time; disruptive or inappropriate } \\
\text { pictures or drawings in class. Not enough chairs and } \\
\text { desks for all the students. There are neither known } \\
\text { expectations nor grading standards. }\end{array}$ & $\begin{array}{l}\text { Classroom environment functions somewhat effectively, with } \\
\text { modest expectations for student learning and conduct, and } \\
\text { classroom routines and use of space that partially support student } \\
\text { leaning. Students and the teacher rarely treat one another with } \\
\text { disrespect, some disrespect among students is experienced in } \\
\text { class, and some class rules are reinforced. Instructional time is not } \\
\text { too much wasted and there is some efficiency in distributing the } \\
\text { learning materials. }\end{array}$ \\
\hline Instruction & $\begin{array}{l}\text { Instruction is characterized by poor communication, } \\
\text { low-level questions, little student engagement or } \\
\text { participation, little or no use of assessment in learning, } \\
\text { and rigid adherence to an instructional plan despite the } \\
\text { evidence that it should be revised or modified. No } \\
\text { learning activities or they are unrelated to the learning } \\
\text { outcomes. }\end{array}$ & $\begin{array}{l}\text { Only some students are engaged in learning because of only } \\
\text { partially clear communication, uneven use of discussion strategies, } \\
\text { and only some suitable instruction activities and materials. The } \\
\text { teacher displays some use of assessment in instruction and is } \\
\text { moderately flexible in adjusting instructional plan and in response } \\
\text { to students' interests and their success in learning. Some learning } \\
\text { activities are related to the outcomes. }\end{array}$ \\
\hline $\begin{array}{c}\text { Professional } \\
\text { Responsibilities }\end{array}$ & $\begin{array}{l}\text { The teacher demonstrates low ethical standards and } \\
\text { levels of professionalism, with poor record-keeping } \\
\text { systems and skills in reflection, little or no } \\
\text { communication with the colleagues, and avoidance of } \\
\text { school, community, diocese and district responsibilities } \\
\text { and participation in activities for professional growth. } \\
\text { No reputation in the community due to unacceptable } \\
\text { behavior. }\end{array}$ & $\begin{array}{l}\text { The teacher demonstrates moderate ethical standards and levels of } \\
\text { professionalism, with rudimentary record-keeping systems and } \\
\text { skills in reflection, modest communication with colleagues } \\
\text { [especially dean of studies and dean of discipline], and } \\
\text { compliance with expectations regarding participation in school, } \\
\text { diocesan and district projects and activities for professional } \\
\text { growth. }\end{array}$ \\
\hline
\end{tabular}




\begin{tabular}{|c|c|c|}
\hline & Unsatisfactory & Basic \\
\hline $\begin{array}{l}\text { Planning and } \\
\text { Preparation }\end{array}$ & $\begin{array}{l}\text { Teacher's plans reflect solid understanding of the content, } \\
\text { the students and the available resources. Instructional } \\
\text { outcomes represent important learning suitable to most } \\
\text { students. Most elements of the instructional design, } \\
\text { including the assessments, are aligned to the goals: } \\
\text { competency to national examination and preparation for } \\
\text { service to the community. Lesson's scope and its } \\
\text { relationship with other discipline are made. Most of the } \\
\text { contents are in line with the demands of national syllabus } \\
\text { and NECTA directives. Group activities mostly promote } \\
\text { the understanding of the content. }\end{array}$ & $\begin{array}{l}\text { Teacher's plans based on extensive content knowledge and } \\
\text { understanding of students, are designed to engage students in } \\
\text { significant learning. All aspects of the teacher's plans- } \\
\text { instructional outcomes, learning activities, materials, resources, } \\
\text { and assessments-are in complete alignment and are adopted as } \\
\text { needed for individual students. They also follow the directives of } \\
\text { the national syllabus and NECTA. Instructional design is in such a } \\
\text { way that all students are challenged to move to the next level and } \\
\text { all acquire significant learning which is measurable. The backup } \\
\text { plan is articulated for individual students with special needs. The } \\
\text { student learning expectations are clearly stated and they are } \\
\text { aligned with national, diocesan and school student achievement } \\
\text { standards. Group activities guidelines clearly articulate a deeper } \\
\text { understanding of the content, its connection to real life and } \\
\text { promote student creativity. }\end{array}$ \\
\hline $\begin{array}{c}\text { Classroom } \\
\text { Environment }\end{array}$ & $\begin{array}{l}\text { Classroom environment functions smoothly, with little or } \\
\text { no loss of instruction time. Expectations for student } \\
\text { learning are high, and interactions among individuals are } \\
\text { respectful. Standards for student conduct are clear, and } \\
\text { the physical environment supports learning. There is } \\
\text { class order and rules are reinforced a greater degree, with } \\
\text { no unnecessary disruption of instruction. Student } \\
\text { expectations are known and are fulfilled most of the time. }\end{array}$ & $\begin{array}{l}\text { Students themselves make a substantive contribution to the smooth } \\
\text { functioning of the classroom, with highly positive personal } \\
\text { interactions, high expectations and student pride in work, seamless } \\
\text { routines, clear standards of conducts, and a physical environment } \\
\text { conducive for high level of learning: academic posters. Students } \\
\text { take initiative to keep themselves accountable by setting higher } \\
\text { standards and initiating corrective measure among themselves. } \\
\text { Students protect instructional time. }\end{array}$ \\
\hline Instruction & $\begin{array}{l}\text { All students are engaged in learning as a result of clear } \\
\text { communication and successful use of questioning and } \\
\text { discussion techniques. Activities and assignments are of } \\
\text { high quality, and teacher and students make productive us } \\
\text { of assessment. The teacher demonstrates flexibility in } \\
\text { contributing to the success for the lesson and of each } \\
\text { student. Teaching aids and learning activities enhance } \\
\text { deeper understanding and are aligned with the outcome. }\end{array}$ & $\begin{array}{l}\text { All students are highly engaged in learning and make material } \\
\text { contributions to the success of the class trough their participation } \\
\text { in discussions, active involvement in learning activities and use of } \\
\text { assessment information in their learning. The teacher persists in } \\
\text { the search for approaches to meet the needs of every student. The } \\
\text { teacher provides extra help for the special need students. }\end{array}$ \\
\hline $\begin{array}{c}\text { Professional } \\
\text { Responsibilities }\end{array}$ & $\begin{array}{l}\text { The teacher demonstrates high ethical standards and a } \\
\text { genuine sense of professionalism by engaging in accurate } \\
\text { reflection on instruction, maintaining accurate records, } \\
\text { communication with the leadership and colleagues, } \\
\text { actively participating in school, local community, } \\
\text { diocesan and district events, and engaging in activities for } \\
\text { professional development. The teacher dresses } \\
\text { professionally in school and in the community. }\end{array}$ & $\begin{array}{l}\text { The teacher's ethical standards and sense of professionalism are } \\
\text { highly developed, showing perceptive use of reflection, effective } \\
\text { systems for record keeping and communication with-leadership } \\
\text { [dean of studies/students], taking leadership roles in both school, } \\
\text { local community like parish, diocese and district projects, and } \\
\text { extensive professional development activities. Where appropriate, } \\
\text { students contribute to the systems for record keeping and family } \\
\text { communication. }\end{array}$ \\
\hline
\end{tabular}

Note: Danielson (2007) rubrics after been acculturated to fit Moshi Catholic school culture. Every school district must use the original Danielson's rubrics and adapt to fit into their own culture. 
APPENDIX U

CONSULTANCY PROTOCOL 


\section{Consultancy Protocol}

1. Introduction (2 minutes)

- Participants briefly introduce themselves (if necessary) and facilitator will review the protocol.

2. Presentation (10 minutes)

- The presenter(s) has an opportunity to share the current plan for next steps at their school. It is important to share successes as well as growth areas related to the current instructional focus and to identify a focusing question for feedback.

\section{Clarifying Questions (3 minutes)}

- Participants have an opportunity to ask "clarifying" questions in order to get information that may have been omitted in the presentation that they feel would help them to understand the context and/or plan.

- Clarifying questions are matters of "fact."

- The facilitator should be sure to limit the questions to those that are "clarifying," judging which questions more properly belong in the warm/cool feedback section.

\section{Warm and Cool Feedback (7 minutes)}

- Participants share feedback with one another while the presenter(s) is silent. The feedback generally begins with a few minutes of warm feedback, moves on to a few minutes of cool feedback (sometimes phrased in the form of reflective questions), and then moves back and forth between warm and cool feedback.

- Warm feedback may include comments about how the work presented seems to meet the desired goals; cool feedback may include possible "disconnects," gaps, or problems. Often participants offer ideas or suggestions for strengthening the work presented.

- The facilitator may need to remind participants of the presenter's focusing question, which should be posted for all to see.

- Presenter is silent and takes notes.

\section{Reflection (5 minutes)}

- Presenter speaks to those comments/questions he or she chooses while participants are silent.

- This is not a time to defend oneself, but is instead a time for the presenter to reflect aloud on those ideas or questions that seemed particularly interesting.

- Facilitator may intervene to focus, clarify, etc.

6. Discussion and Debrief (5 minutes)

This will occur after all three schools have presented.

Adapted from National School Reform Faculty: www.nsrfharmony.org 


\section{APPENDIX V}

FORMATIVE ASSESSMENT: FILLED FORM SAMPLE 


\section{Formative assessments: Filled form sample}

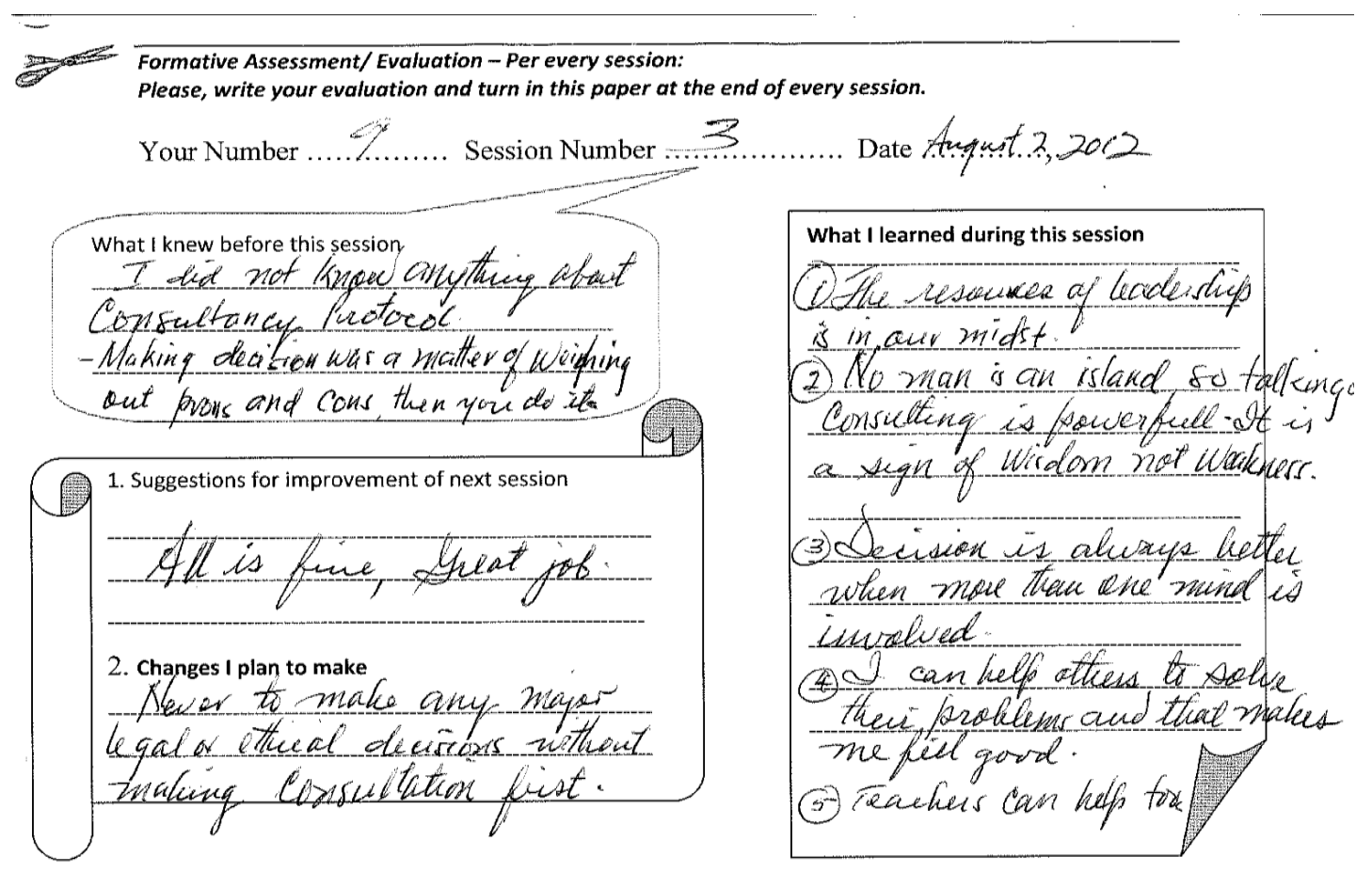

Formative Assessment/Evaluation - Per every session:

Please, write your evaluation and turn in this paper at the end of every session.

Your Number ............. Session Number ........... Date $01 / 08 / 2012$
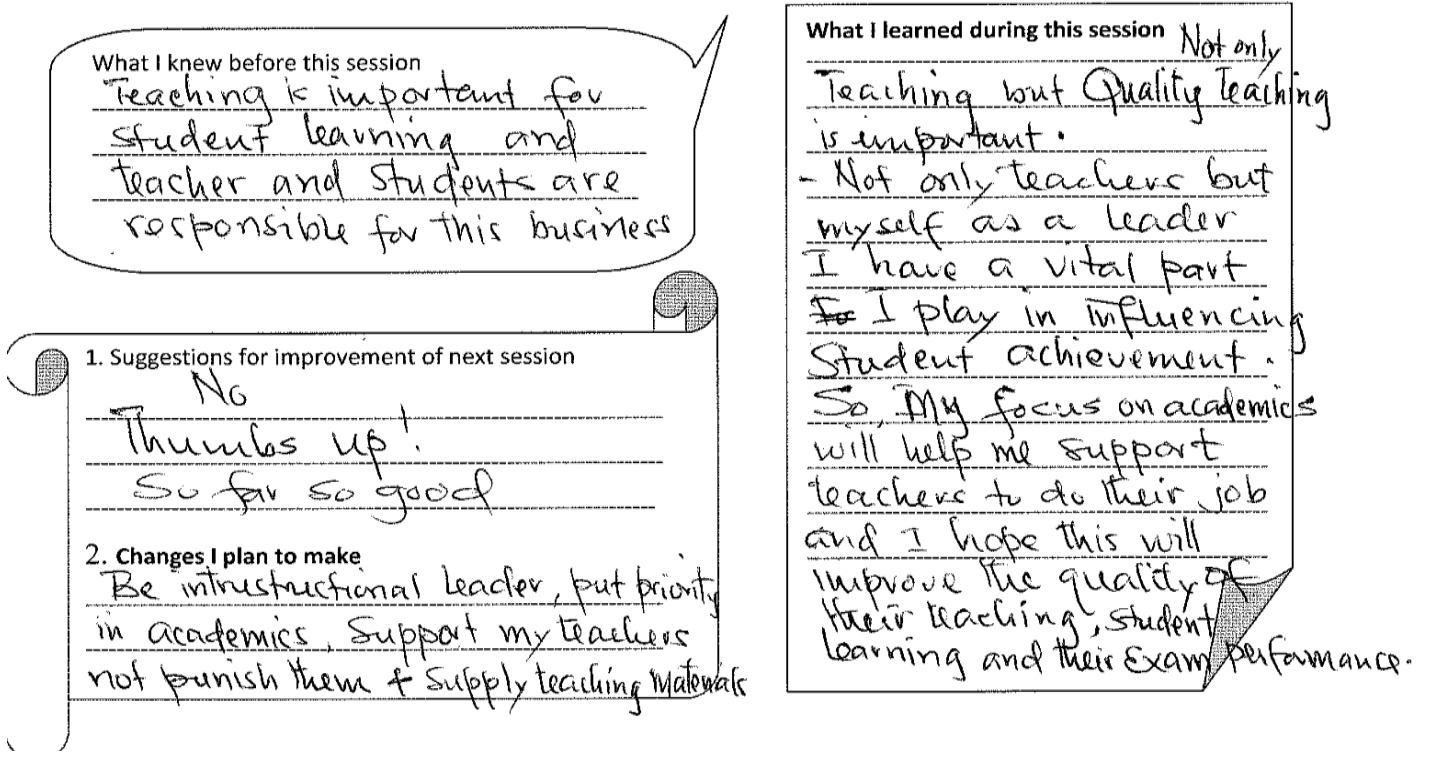


\section{APPENDIX W}

A COMPLETED SAMPLE OF THE WORKSHOP EVALUATION FORM 


\section{A completed sample of the Workshop Evalution Form}

180.17

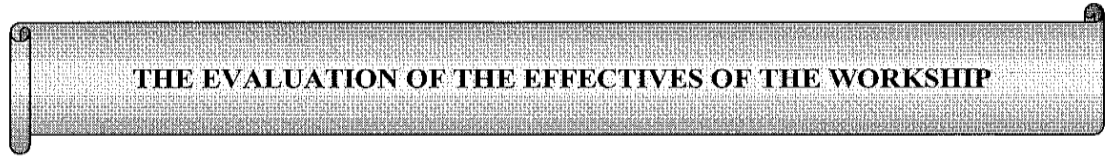

Evaluation of the Workshop, the Presenter and Competence and Confidence Indicator:

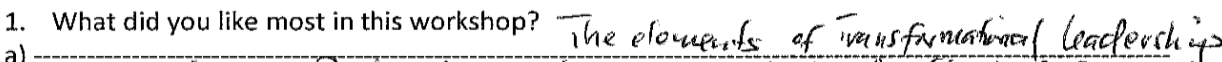

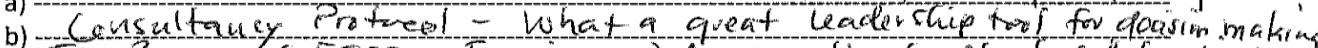

c) ILe Process of ESCI - Fuming aud comoncating feedback collabontively

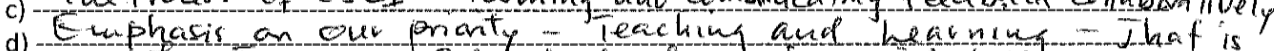

e) Why a am a selcol ceole nof an industuaf inenger.

- Organizextion of the warleshop and Densty of Matenals and expertise of Presenter

2. What did you not like in the training process?

a) Presscare of time:

b) There wes so many good tho's to tear but time

d) ores never evough

e)

3. What would you change to make this workshop more effective for school leaders?

a) I would ula Derectors of Educafion to alfend

c) aud sehool adcadpme deans becauce the

d) ars aur helpers in acadeund mither

e)

4. If you were to attend the same workshop again, what elements would you add?

a) Nono

b) Ihe matenols and teve forefertev wese great.

d) -

e)

5. Any other comments? The workebop was engoyabl Wety

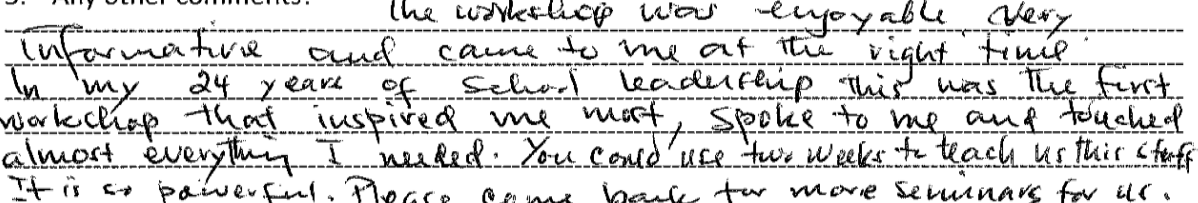

6. In the following chat, rate yourself, the presenter and the effectiveness of the workshop. Check or dark only one circle per item. 


\begin{tabular}{|c|c|c|c|c|}
\hline Measure roursel the presenter (s) and the Workshop & & (6060) & & 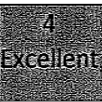 \\
\hline My confidence of conducting ESCl before this workshop & $\rightarrow$ & 0 & $\bigcirc$ & $\bigcirc$ \\
\hline My confidence of conduction ESCI Now after this workshop & 0 & & 6 & \\
\hline $\begin{array}{l}\text { The way I feel now in doing conference with a teacher of his/her } \\
\text { instruction }\end{array}$ & $\bigcirc$ & $\bigcirc$ & 8 & $\bigcirc$ \\
\hline My Knowledge or skills of doing ESCI before the workshop & 8 & & $\cap$ & \\
\hline My knowledge or skills of doing ESCl after the workshop & $\bigcirc$ & ○ & ○ & \\
\hline My level of competence in doing evaluation before the workshop & 0 & O & O & \\
\hline My level of competence in doing evaluation before the workshop & 0 & 0 & -7) & $\bigcirc$ \\
\hline The overall rate of the presenter(s) of the workshop & 0 & $\bigcirc$ & $C$ & \\
\hline $\begin{array}{l}\text { My motivation to do ESCl despite by busy schedule before the } \\
\text { workshop }\end{array}$ & 0 & - & $\bigcirc$ & $\bigcirc$ \\
\hline $\begin{array}{l}\text { My motivation to do ESCl despite by busy schedule after the } \\
\text { workshop }\end{array}$ & 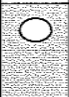 & & & \\
\hline My conviction before the workshop that ESCI can make a help us & -6) & 0 & 0 & 0 \\
\hline My conviction after the workshop that ESCI can make a help us & 0 & O & O & \\
\hline The overall rate of the content/materials learned in the workshop & 0 & 0 & $\bigcirc$ & \\
\hline The effect of this workshop in my future leadership practices & 0 & 0 & 0 & \\
\hline Skills I acquired as an Instructional Leader, through this workshop & 0 & 0 & 0 & \\
\hline $\begin{array}{l}\text { The possibility of improving the quality of teaching and learning in } \\
\text { my school after this workshop }\end{array}$ & 0 & C & 0 & $\Rightarrow$ \\
\hline $\begin{array}{l}\text { The possibility of being more effective leader to influence student } \\
\text { achievement in my school after this workshop }\end{array}$ & 0 & 0 & 0 & \\
\hline $\begin{array}{l}\text { he Likelihood that I will used the skills l learned to actually } \\
\text { conduct classroom evaluation with my teachers from now on is }\end{array}$ & 0 & & & \\
\hline
\end{tabular}

Thank you so much for your active participation and for your commitment to the lives of the young generation of this country. You are making a difference! 
APPENDIX X

FOLLOW-UP LETTER AND QUESTIONNAIRE 
Dear.

Thank you very much for your participation in the Problem-Based Learning [PBL] Module during the Spring Time at Longuo Retreat Center-Moshi, Tanzania. I appreciated the time, energy and contribution that you put in the workshop process, group discussions, presentations and action plan final presentation on the last day of your training. As you know well, the schedule was very tight, but productive! Your thoughts and suggestions gave me helpful insights that I find invaluable in modifying and refining the curriculum/module to make it more suitable for instructional leadership training future school leaders.

Additionally, I am grateful if you can give me few minutes of your time to answer the questions below. I have enclosed a self-addressed, stamped envelope for your convenience, to be mail to Fr. Peter Siamoo, c/o Fr. William Ruwaichi, P. O. Box 3041, Moshi, Tanzania. He will collect your responses in your sealed envelopes and get them to me. If you have any questions, please email me: revpsiamoo@yahoo.com or Call +1 3306397919 (This is my USA phone number.

Again, than you kindly.

Peter Siamoo

Questions:

1. Have you begun using ESCl in your school as you promised to do in the first semester of 2013?

2. What is your general experience with $\mathrm{ESCl}$ ?

3. Did your participation in the workshop encourage you to undertake some kind of change, personally or professionally, in terms of improving quality teaching and learning in your school?

4. Can you give any examples?

(To be sent out in Summer 2013). 
APPENDIX Y

INFORMED CONSENT 
Portland State University

Graduate School of Education

May 14, 2012

\section{Informed Consent Form}

\section{Please cross all the words that do not apply}

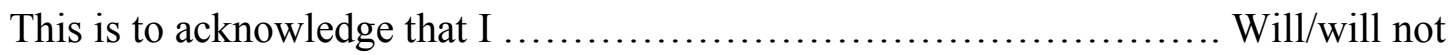

participate in the Problem-Based Learning Study in which Peter Siamoo is leading. I agree/disagree to participate in the training and field testing of his Instructional Leadership Curriculum for high school principals, and to study and adopt the teacher evaluation tool of Charlotte Danielson. I understand that this study is for academic purposes of Peter Siamoo and that the information I will share will either be anonymous or will be kept confidential. I allow/not allow him to share the information for academic reasons only. I understand that I am free to opt out at any time during the study. I also know that there is no payment or remuneration that will be given to me for participating in this study. I also agree/disagree that photo/video/audio recording can be taken while I am participating in this study. I allow/disallow my photos/video/audio record to be used for Peter Siamoo's study and he can/can't share with his writing and presentations for this particular study.

My name

Signature Date 


\section{APPENDIX Z}

PICTURES OF WORKSHOP HALL GROUP AND RETREAT HOUSE 
The pictures of the Workshop Hall Group and the Retreat House

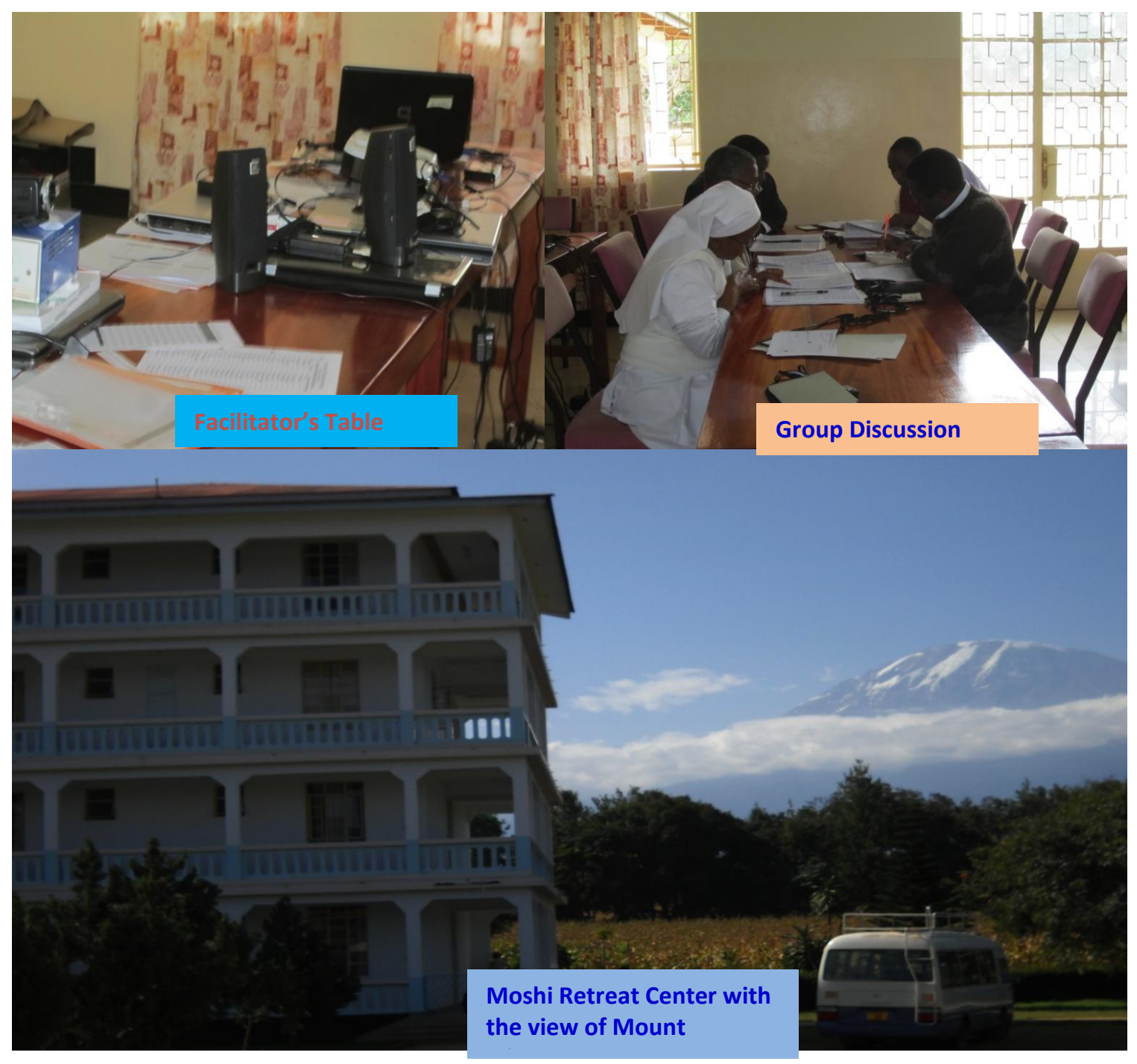

